\begin{tabular}{|c|c|}
\hline $\begin{array}{l}\text { 2. To: (Receiving Organization) } \\
\text { Distribution }\end{array}$ & $\begin{array}{l}\text { 3. From: (Originating Organization) } \\
\text { Tank Farm Restoration \& Safe Ops }\end{array}$ \\
\hline $\begin{array}{l}\text { 5. Proj./Prog./Dept./Div.: } \\
\text { Project } W-314\end{array}$ & $\begin{array}{l}\text { 6. Design Authority/Design Agent/Cog. Engr.: } \\
\text { D. E. Bowers }\end{array}$ \\
\hline $\begin{array}{l}\text { 8. Originator Remarks: USQ } \\
\text { For approval This de } \\
\text { cwhok be } \\
\text { mainten } \\
\text { Reveruid. } \\
\text { radioley }\end{array}$ & 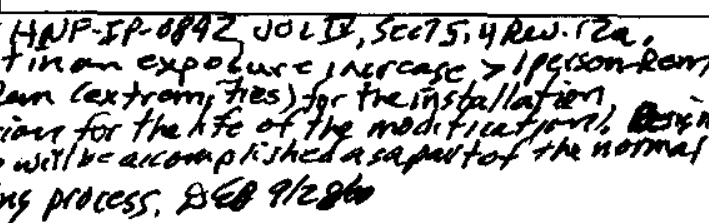 \\
\hline
\end{tabular}

11. Receiver Remarks:

4. Related EDT No.:
N/A
7. Purchase Order No.:
N/A
9. Equip./Component No.:

10. System/BIdg./Facility:

12. Major Assm. Dwg. No.:

13. Permit/Permit Application No:

14. Required Response Date:

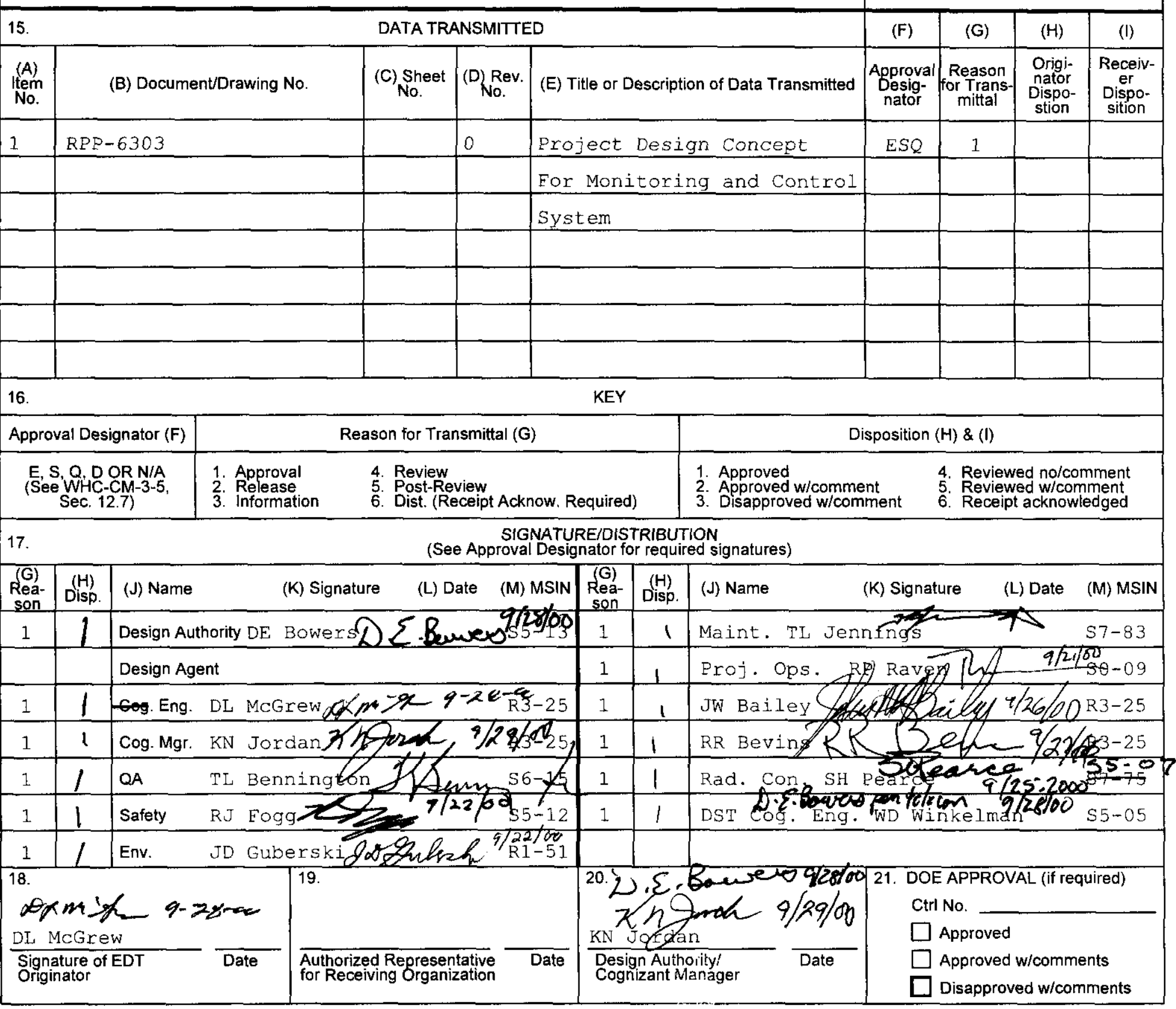

BD-7400-172-2 (10/97)

BD-7400-172-1 


\section{DISTRIBUTION SHEET}

To

Distribution

Project TitleMork Order

W-314, Tank Farm Restoration and Safe Operations

\begin{tabular}{|l|}
\hline \\
\hline J.B. Bailey \\
\hline D.E. Bowers \\
\hline T.L. Bennington \\
\hline K.N. Jordan \\
\hline J.L. Gilbert \\
\hline R.R. Bevins \\
\hline R.W. Root \\
\hline D.L. McGrew \\
\hline B.L. Syverson \\
\hline J.W. Lentsch \\
\hline R.J. Eogg \\
\hline J.D. Guberski \\
\hline Project Files \\
\hline Broject Library \\
\hline R.P. Raven \\
\hline T.L. Jennings \\
\hline C.A. Burke \\
\hline \\
\hline \\
\hline \\
\hline \\
\hline \\
\hline \\
\hline \\
\hline \\
\hline
\end{tabular}

From

TFR\&SO

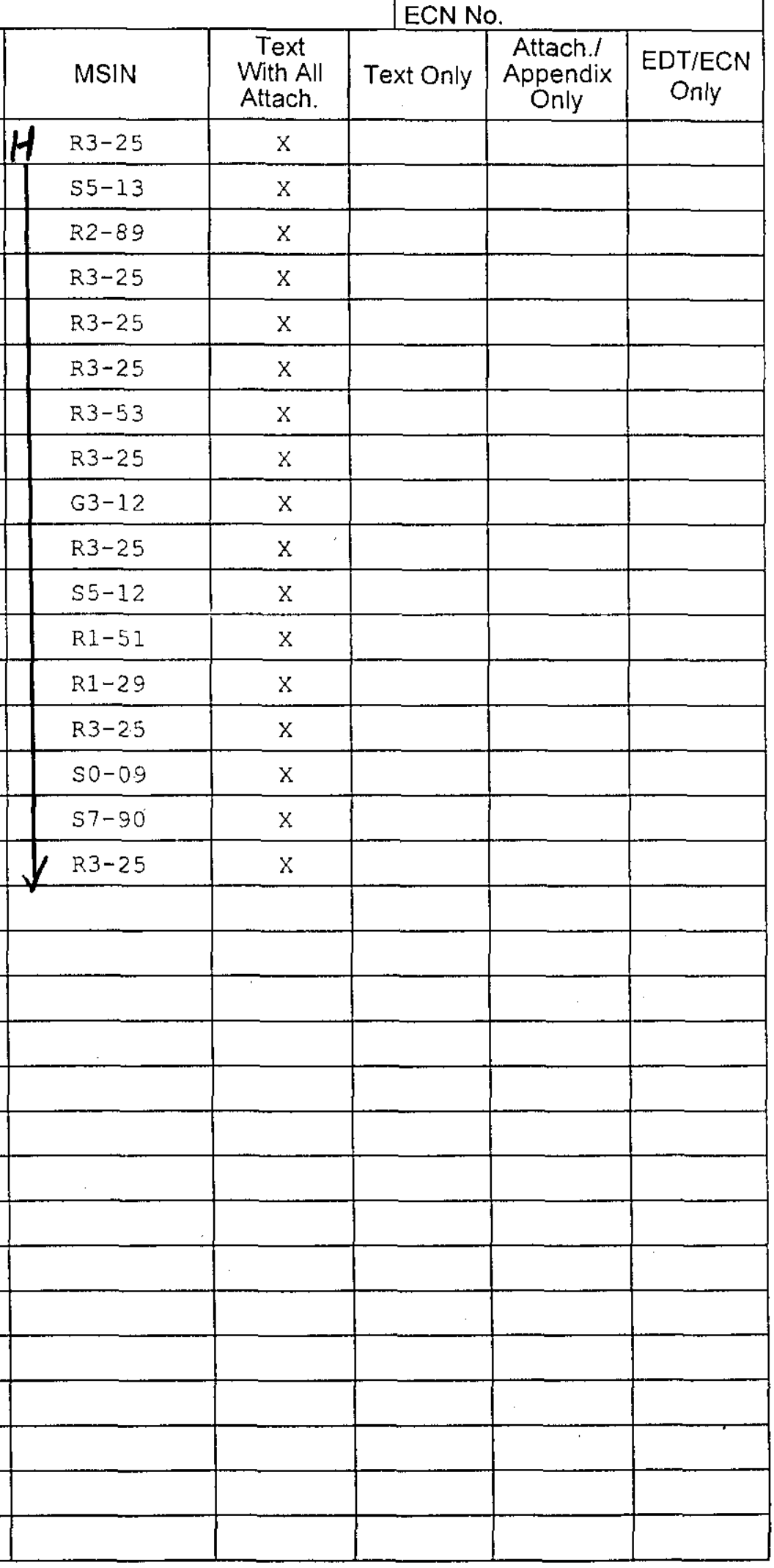

A-6000-135 (10/97)

Page 1 of 1
Date $10 / 2 / 00$

EDT No. 630781

ECN No.
Attach./

pendix Only 


\title{
Project Design Concept for Monitoring and Control Sysem
}

\author{
DL McGrew \\ $\mathrm{NHC}$ \\ Richland, WA 99352 \\ U.S. Department of Energy Contract DE-AC06-99RL14047
EDT/ECN: 630781 UC:
Cost Center: 7C900 Charge Code: 109749
B\&R Code: \\ Total Pages: 165 \\ Key Words: Project W-314, Tank Farm Restoration and Safe Operations, \\ Monitoring and Control System, Master Pump Shutdown System \\ Abstract: This Project Design Concept represents operational requirements \\ established for use in design the tank farm Monitoring and Control \\ system. These upgrades are included within the scope of Project $\mathrm{W}-314$, \\ Tank Farm Restoration and Safe Operations.
}

TRADEMARK DISCLAIMER. Reference herein to any specific commercial product, process, or service by trade name, trademark, manufacturer, or otherwise, does not necessarily constitute or imply its endorsement, recommendation, or favoring by the United States Government or any agency thereof or its contractors or subcontractors.

Printed in the United States of America. To obtain copies of this document, contact: Document Control Services, P.O. Box 950, Mailstop H6-08, Richland WA 99352, Phone (509) 372-2420; Fax (509) 376-4989.
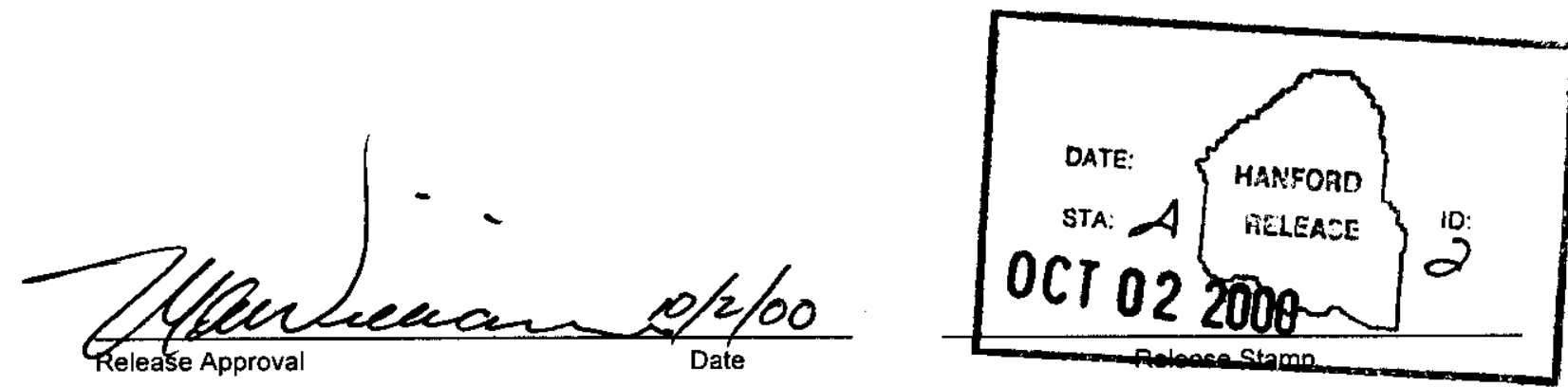

\section{Approved For Public Release}




\section{Project Design Concept}

\section{Monitoring and Control System}

Project W-314

Tank Farm Restoration and Safe Operations

Prepared by Fluor Federal Services

for CH2M HILL Hanford Group, Inc.

September 19, 2000

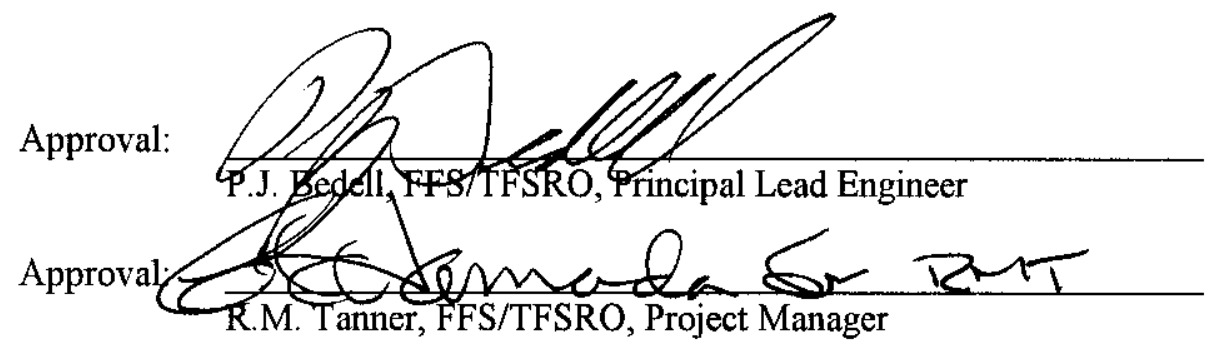

Approval:

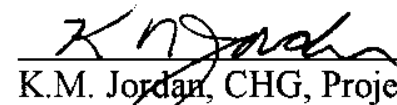

K.M. Joydan, CHG, Project Manager

Approval: D.E. Banrevo

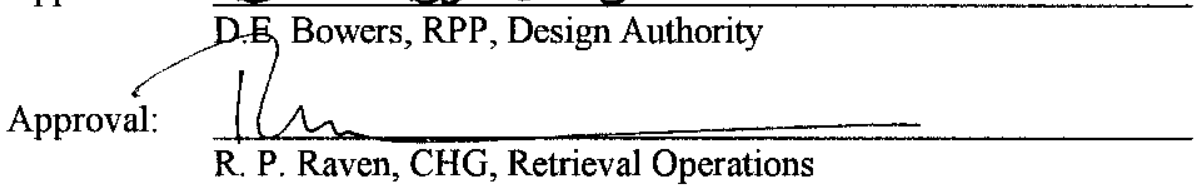

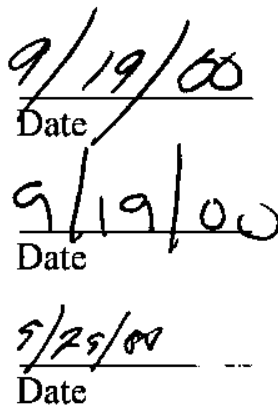

9128100

Date

$\frac{9 / 21 / 00}{\text { Date }}$ 


\section{CONTENTS}

1.0 DESCRIPTION OF PROBLEM

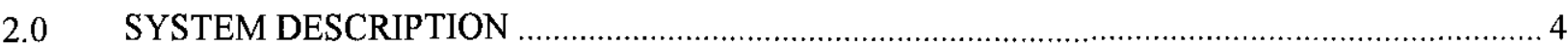

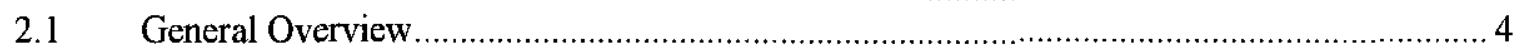

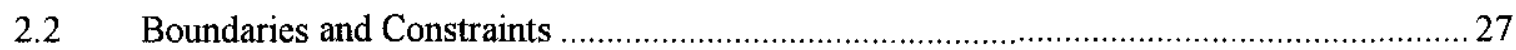

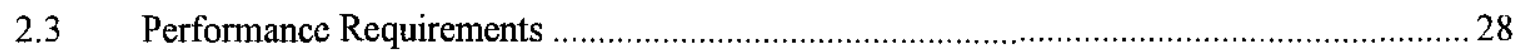

$3.0 \quad$ OPERATIONS CONCEPT DESCRIPTION

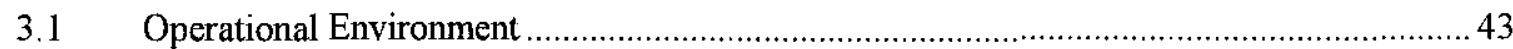

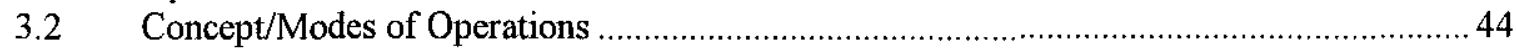

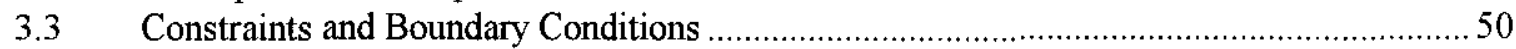

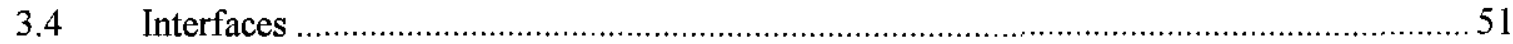

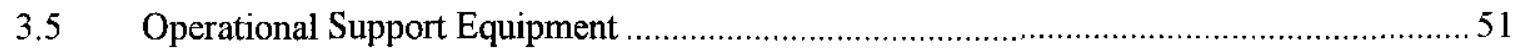

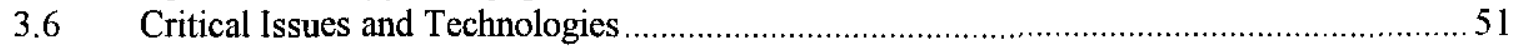

$4.0 \quad$ SUPPORT CONCEPT DESCRIPTION

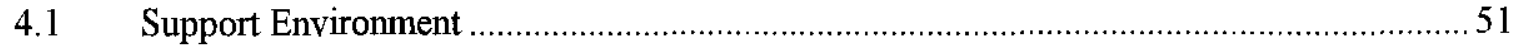

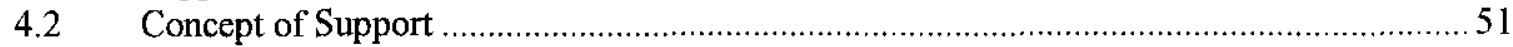

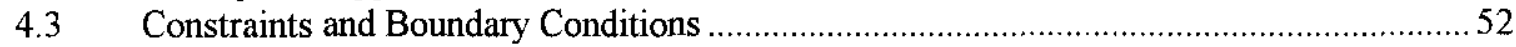

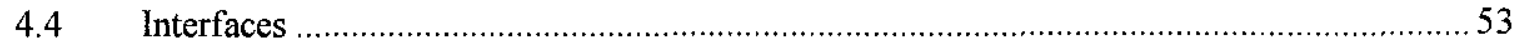

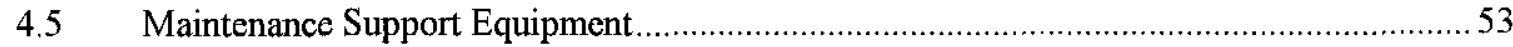

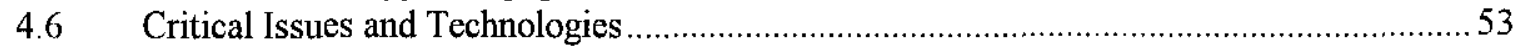

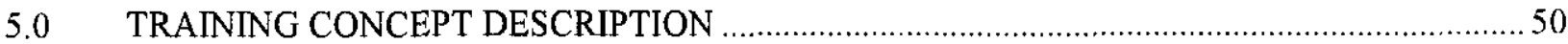

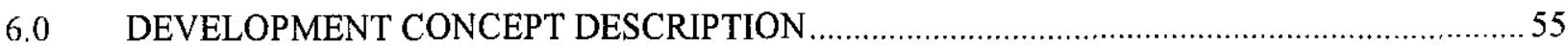

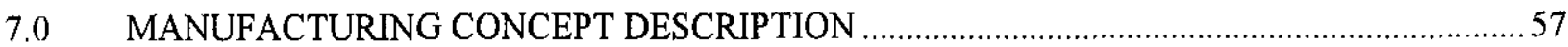

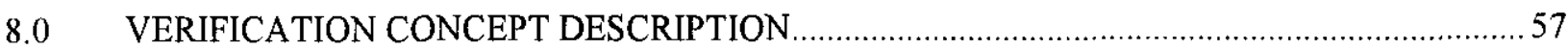

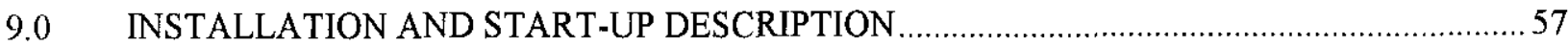

10.0 SYSTEM DECONTAMINATION AND DECOMMISSIONING (D\&D) ...............................60

\section{APPENDIX}

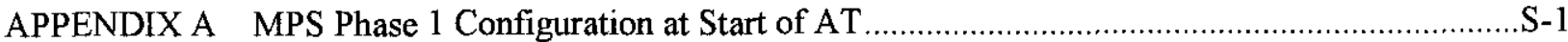

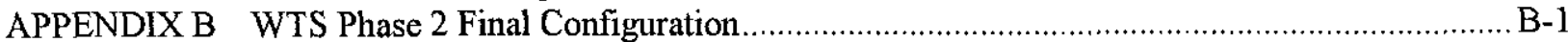

APPENDIX D Monitoring and Control System Operational Logic Diagrams ..................................... D-1

APPENDIX S Monitor and Control System Human Machine Interface …........................................ -1

\section{LIST OF FIGURES}

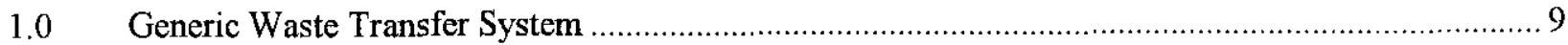

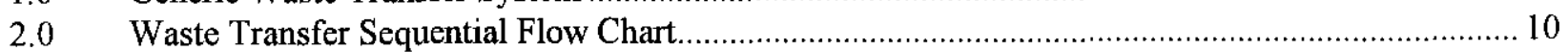

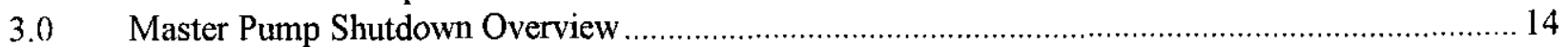


RPP-6303

Rev. 0

\section{LIST OF FIGURES CONT.}

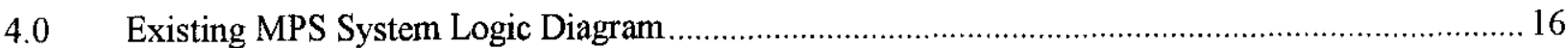

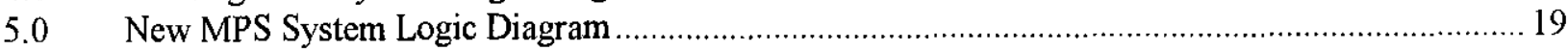

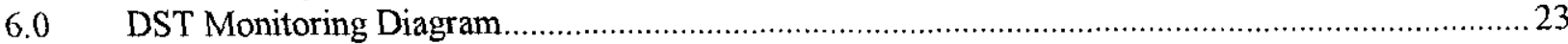

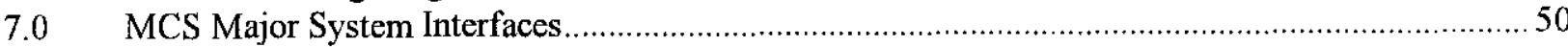




\section{ABBREVATIONS/ACRONYM LIST}

$\begin{array}{ll}\text { ATP } & \text { Acceptance Test Procedure } \\ \text { CCTV } & \text { Closed Circuit Television } \\ \text { CRT } & \text { Cathode Ray Tube } \\ \text { CSTCS } & \text { Cross-Site Transfer System Control System } \\ \text { CST } & \text { Cross-Site Transfer System } \\ \text { DST } & \text { Designated Storage Facilities } \\ \text { HLAN } & \text { Hanford Local Area Network } \\ \text { HMI } & \text { Human Machine Interface } \\ \text { HLW } & \text { High Level Waste } \\ \text { HVAC } & \text { Heating Ventilation Air-Conditioning } \\ \text { I/O } & \text { Input/Output } \\ \text { LDK } & \text { Leak Detector Relay } \\ \text { MCC } & \text { Motor Control Center } \\ \text { MCS } & \text { Monitoring and Control System } \\ \text { MPS } & \text { Master Pump Shutdown } \\ \text { MTBF } & \text { Mean Time Between Failures } \\ \text { MTS } & \text { MCS Training System MTS } \\ \text { PDC } & \text { Project Design Concept } \\ \text { PDS } & \text { Project Design Specification } \\ \text { PICD } & \text { Project Interface Control Document } \\ \text { PLC } & \text { Programmable Logic Controllers } \\ \text { PS } & \text { Pressure Switch } \\ \text { RAS } & \text { Remote Access Server } \\ \text { RPP } & \text { River Project Projects } \\ \text { RTD } & \text { Resistance Temperature Detector } \\ \text { SACS } & \text { Surveillance Analysis Computer System } \\ \text { SQL } & \text { Structured Query Language } \\ \text { TBX } & \text { Terminal Box } \\ \text { TCP/IP } & \text { Transmission Control Protocol/Internet Protocol } \\ \text { TFLAN } & \text { Tank Farm Local Area Network } \\ \text { TFO } & \text { Tank Farm Operations } \\ \text { TMACS } & \text { Tank Monitoring and Control System } \\ \text { WTA } & \text { Waste Transfer Annuciator } \\ \text { WTS } & \text { Waste Transfer System } \\ & \end{array}$




\section{PROJECT DESIGN CONCEPT MONITORING AND CONTROL SYSTEM}

\subsection{DESCRIPTION OF PROBLEM}

The new Monitoring and Control System (MCS) will allow a remedy to the following problems:

- The existing Master Pump Shutdown (MPS) System is very prone to spurious shutdowns since any process pit or transfer line leak detection event in any of the Hanford Tank Farms will cause operating transfer pumps to shut down. A spurious shutdown is one caused by a leak detection event not associated with a waste transfer. Spurious shutdowns interrupt River Protection Projects (RPP) operations, leading to increased operating costs, potential delays, and adds risk to the government in meeting the privatized waste feed delivery activities.

- The existing MPS System does not allow isolating parts of the MPS System not associated with a particular waste transfer except by temporary wiring modifications.

- $\quad$ The existing MPS System does not indicate at any central location which specific leak detection element/system has initiated an alarm. The leak source indication is located in the tank farm. The identification of the alarming leak detector has to be made in the field.

- The existing MPS System documentation is difficult to follow due to the relay ladder logic being dispersed among a large number of drawings not directly related to the MPS System.

\subsection{SYSTEM DESCRIPTION}

\subsection{General Overview}

The MCS will provide the following capabilities:

- Spurious alarms will be reduced by the replacement of existing leak detection systems and MPS relays with new remotely testable leak detection systems for those waste transfer systems that are to be used throughout the RPP mission. The overall system reliability shall have, at the minimum, a $90 \%$ chance of completing a seven day (168 hr) transfer.

- All operational functions identified as safety class shall be automatic reducing operational manpower requirements.

- At a minimum, the modified MPS System will allow leak detection systems located in tank farms not associated with a particular waste transfer to be bypassed. For example, if a leak occurs in Tank Farm A while a waste transfer between two tanks in Tank Farm B is occurring; the Tank Farm A leak will not shutdown the Tank Farm B transfer.

- $\quad$ Each individual input to the MCS shall be statused, with appropriate inputs alarmed and identified to Operators at the Human Machine Interfaces (HMI) locations. 
- A single set of documentation will be prepared dedicated to the MCS to provide an easier retrieval of information associated with the MCS.

- A common operator interface throughout the tank farms.

- Allows viewing of data via secure web pages over Hanford Local Area Network (HLAN).

\subsubsection{Waste Transfer Process Overview}

Figure 1 illustrates a generic waste transfer system.

A waste transfer is the batch process of moving liquid radioactive waste between designated storage facilities (i.e., DSTs) and processing facilities (242-A Evaporator, future High Level Waste/Low Level Waste (HLW/LLW) vitrification plants, 204-AR, etc.) as shown in Appendix B. The following steps as shown in Figure 2, Sheet 1, "Waste Transfer Sequential Flow Chart", equate to a waste transfer process. Some of the steps may not be applicable to any specific transfer since the process represented is generic.

\section{WASTE TRANSFER PROCESS}

\section{Step Description}

1. Pre-Flush the Transfer Route towards the transfer pump. (e.g., running hot water through the transfer lines, adding reagents to waste, etc.)

2. Pre-Flush the Transfer Route towards the route destination.

3. Transfer Waste through the Transfer Route.

4. Post-Flush the Transfer Route towards the transfer pump.

5. Drain Transfer Line towards the transfer pump.

6. Post-Flush the Transfer Route towards the route destination.

7. Drain Transfer Line towards the route destination.

8. If a Transfer Pump Shutdown occurred, then fix problem and then start over; Otherwise, proceed to next transfer.

9. Post-Transfer Valve Line-up.

Step $1,2,3,4,5,6,7$, and 8 above can each be described as a generic transfer process which, in turn, consists of the sub-steps listed below. Sub-steps for step 9 are unique and also listed below as $9.1,9.2$, etc. Again, some steps may not be applicable due to the process represented being generic.

The MCS primarily performs steps $.6, .27, .27 \mathbf{a}, .27 \mathbf{b}$, and .30 described below and also assists in performing steps $.1, .7, .11, .12, .13, .14 \mathrm{~b}, .15, .16, .17, .19, .20, .21, .21 \mathrm{a}$, $.22 \mathrm{a}, .26, .28, .29,9.3 \mathrm{a}, 9.3 \mathrm{~b}, 9.3 \mathrm{c}, 9.4$, and 9.5. All other operations are assumed to be done manually by Tank Farm Operations (TFO) or performed by the Tank Monitoring and Control System (TMACS). The MCS will assist in the management of a waste transfer process by a combination of automatic inputs (i.e., leak detection signals, etc.) and manual inputs (i.e., the verification that a step has been completed that has no automatic input). 
Figure 2, Sheets 2 and 3, "Waste Transfer Sequential Flow Chart", and the following is a list of the steps necessary to perform each generic transfer process with the steps shown in bold illustrating those steps that are included in Project W314 scope:

\section{GENERIC TRANSFER PROCESS}

\section{Step Description}

$.1 \quad$ Select source and destination of transfer route.

.2 Check that transfer volume will not overfill the destination tank.

.3 Check source and destination tank waste compatibility.

.4 Check waste temperature difference between source and destination tanks.

.5 Check source and destination equipment systems are operational.

.6 Select transfer route and input to MCS.

.7 Select passive elements (such as lines, pits, tanks, etc.) for the transfer route and input to MCS. Passive elements are those elements that are physically connected to the transfer route but do not normally come into contact with any of the waste being transferred. These elements are selected based on the safety criteria in place at the time of the transfer.

.8 Set piping jumpers for those pits in the transfer route that has not been modified by project W314.

.9 Position manifold valves for those pits in the transfer route that have been modified by project W314 with manifolds.

9a Position cross-site transfer valves utilizing cross-site control system.

.10 Set up transfer pump(s) ancillary systems such as lube oil, seal glands, purges, etc.

.11 Remotely Verify transfer route valve positions (line-up) equipped with position sensors that are connected to the Programmable Logic Controllers (PLCs). In the case of cross-site transfers, obtain valve position information from the Cross-Site Transfer System Control System (CSTCS).

.12 Manually verify transfer route valve positions (line-up) for those valves not equipped with valve position sensors.

.13 Field Operator, Independent Verifier and Supervisor manually verifies all transfer route valve positions (line-up) .

$.14 \mathrm{a}$ Verify flush water backflow preventer operation.

.14b Verify Service Water Pressure Detection System operation.

.15 Remotely Verify MCS PLC operation.

16 Remotely Verify MCS interlock relay operation including the MCS to- Cross-site Transfer System Interlock relays.

.17 Remotely Verify existing MPS relay input operation including the Cross-site Transfer System -to- MCS Interposing relays.

.18 Verify that transfer line heat tracing systems are operational.

.19 Remotely Verify that Leak Detection Systems installed by W314 are operational.

.20 Manually verify Leak Detection Systems that are not connected to any MPS System are operational.

.21 Manually verify that non-MCS testable Leak Detection Systems, 
which are connected to MCS via the existing MPS relays, are operational.

.21 If a cross-site transfer, manually verify that the Cross-site Transfer System non-MPS System testable Leak Detection Systems are operational.

.22 Manually verify that all pit cover blocks in the transfer route are installed.

.22a Supervisor approves the Waste Transfer.

.23 Close transfer pump circuit breakers.

.24 Manually start transfer pump(s) and pump waste from source to destination through the selected transfer route.

.25 Monitor material balance and compare to limits.

.26 Monitor tank pressures, temperatures, levels, corrosion/waste chemistry, tank leak detection, flammable gas concentration, and gaseous effluent discharge and compare to limits.

.27 Monitor for leaks in pits and transfer line encasements and automatically shut down the transfer pump(s) and the Cross-site Transfer booster pumps if a leak is detected for those leak detectors connected to the MCS. Leaks on both active and selected passive transfer line encasements are monitored where active implies those transfer lines that contain waste and passive implies those transfer lines that are empty.

.27a If applicable, Monitor the Cross-site Transfer System shutdown function initiated by the Cross-site Transfer control system and shut down the transfer pump(s) if a shutdown is detected.

$.27 \mathrm{~b}$ Monitor transfer pump status and confirm that the pump(s) has shut off.

.28 Manually monitor for leaks for those leak detection devices and interconnected level systems not connected to the MCS.

.29 Monitor for back flow in connected flush lines during waste transfer and shutdown automatically the transfer pump(s) if back flow is detected.

.30 Monitor for incorrect transfer valve position and automatically shutdown the transfer pump if any valve position changes to an incorrect position during a waste transfer.

.31 Manually stop transfer pump if any limit, waste misrouting or tank leak is detected. Limit also includes required waste volume transferred or a normal completion of the transfer.

.32 Open transfer pump circuit breakers.

9.0 Post-Transfer Valve Lineup.

9.1 Position the transfer valves for post-transfer valve line-up.

9.2 Shut down transfer pump(s) ancillary systems such as lube oil, seal glands, purges, etc.

9.3a Remotely verify transfer route valve positions (line-up) equipped with position sensors that are connected to the PLCs.

9.3b Manually verify transfer route valve positions (line-up) for those valves not equipped with valve position sensors.

9.3c If a cross-site transfer, manually verify transfer route valve positions (line-up) for the Cross-site Pipeline whose valve position sensors are not connected to the MCS.

9.4 Field Operator, Independent Verifier and Supervisor manually 
verifies all transfer route valve positions (line-up).

9.5 Reset the MCS route selection, which disconnects all MCS inputs and outputs from this route.

Figure 2, Sheets $2 \& 3$, "Waste Transfer Sequential Flow Chart", illustrates a typical sequence in which the above steps may be performed.

\subsubsection{Waste Storage Process Overview}

The waste storage process consists of keeping the DST parameters within the authorized limits. This includes, monitoring waste parameters, comparing the monitored parameters to limits, and responding to the events that cause the authorized limits to be exceeded.

\subsubsection{Waste Storage Parameters}

The following waste storage parameters shall be monitored by the MCS:

a) Vapor Space Pressure

b) Selected parameters as detailed in RPP-6066, Rev, 0, "Heating Ventilation Air-Conditioning (HVAC) Project Design Concept (PDC)". 


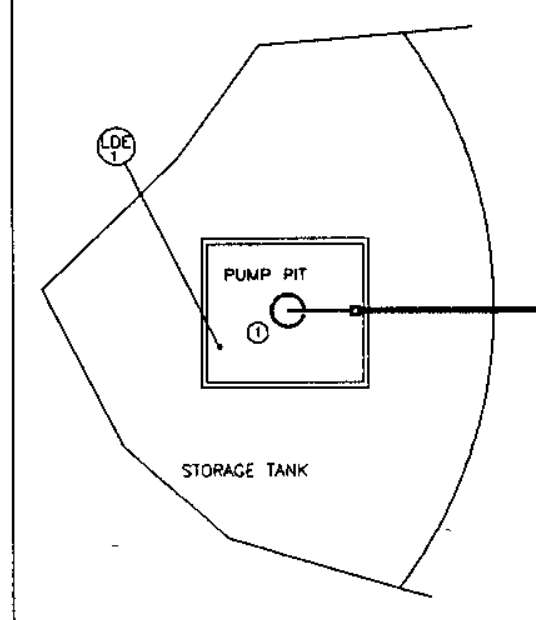

IIEMS

(1) TRANSFER PUMP

(2) VALVE MaNifOLD

(3) JUMPER

(4) HOSE CONNECTION

(E) FLOW MONITTR

(10) PIT LEAK OETECTOR

(20) ENCASEMENT LeAK DEtector

(25) VALVE POSTION SENSOR

(PS) BACK RLOW PRESSURE SWTCH

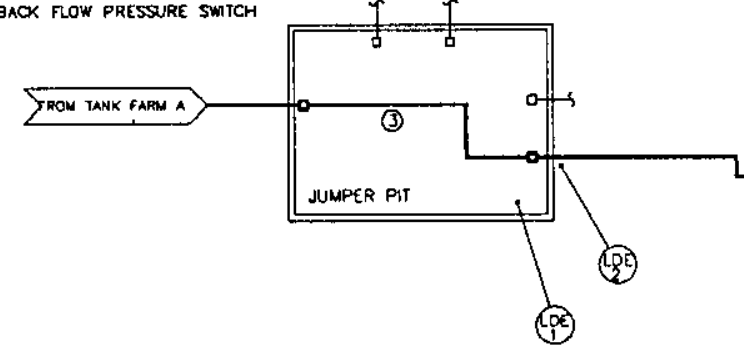

TANK FARM B

(25)

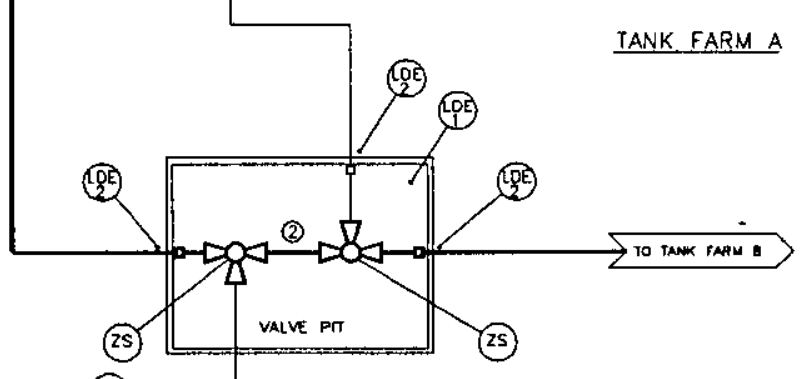

(P)<smiles>CCCC</smiles><smiles>O=C1CCCC1</smiles>

Rev. 0

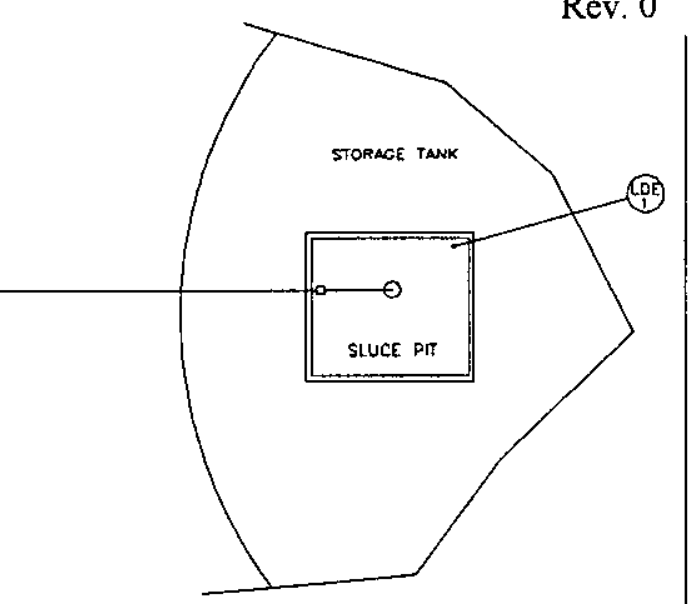


RPP-6303

Rev. 0
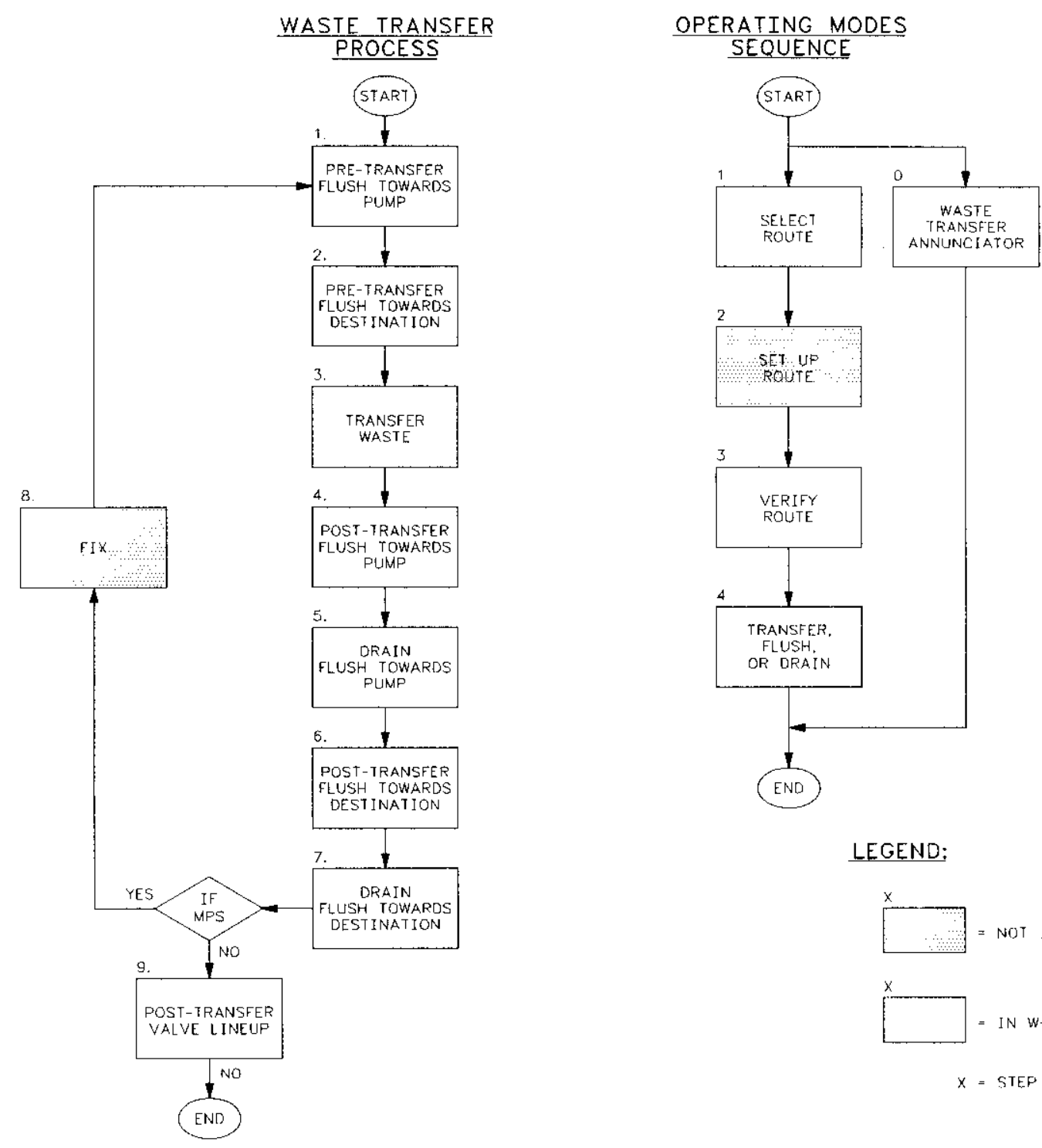

ACAD FILE BLOCK1A.DWC

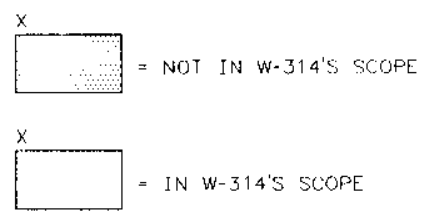

WASTE TRANSFER SEQUENTIAL FLOW CHART FIG. 2. $\mathrm{SH} .1$ 
RPP-6303

Rev. 0

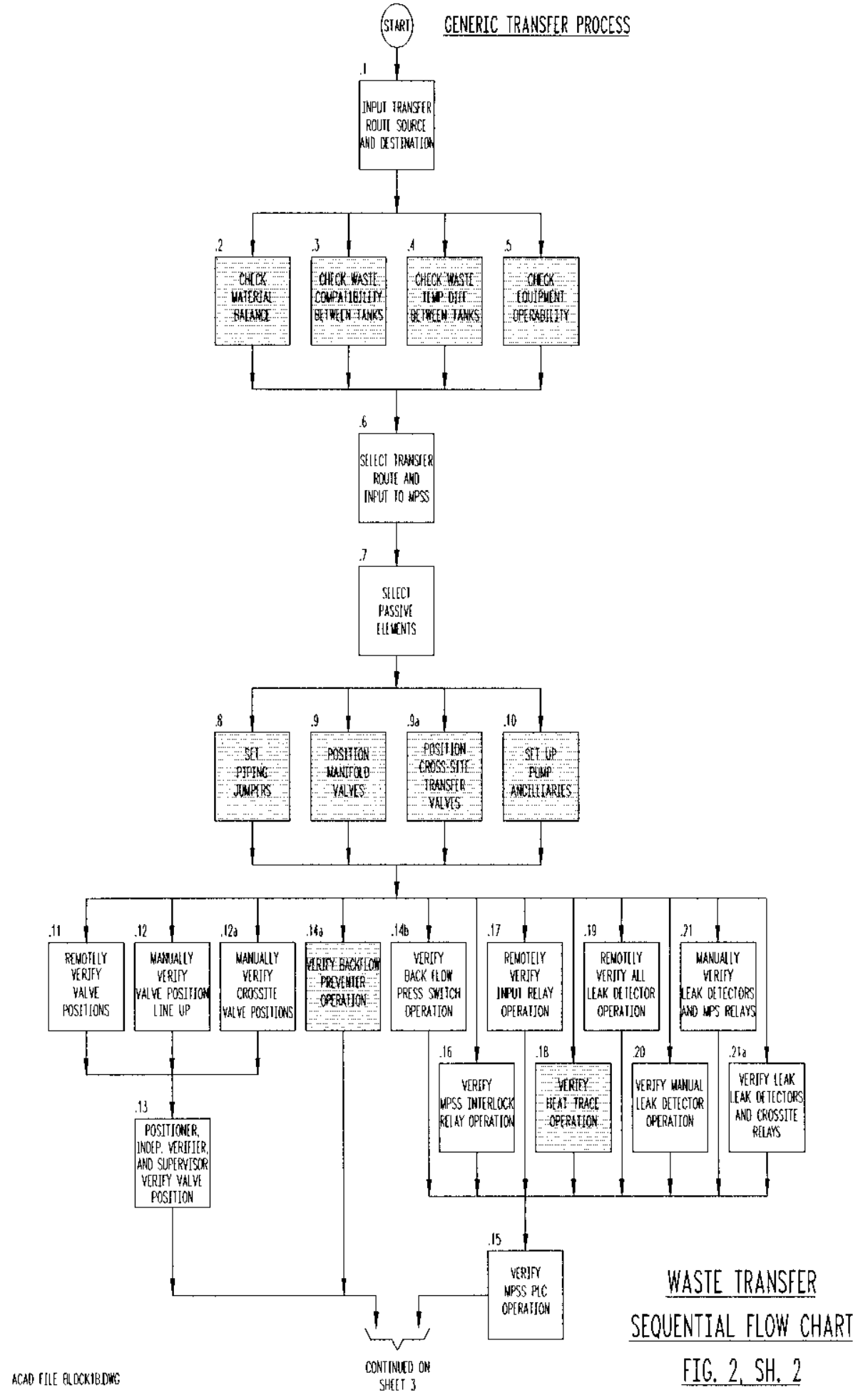


RPP-6303

Rev. 0
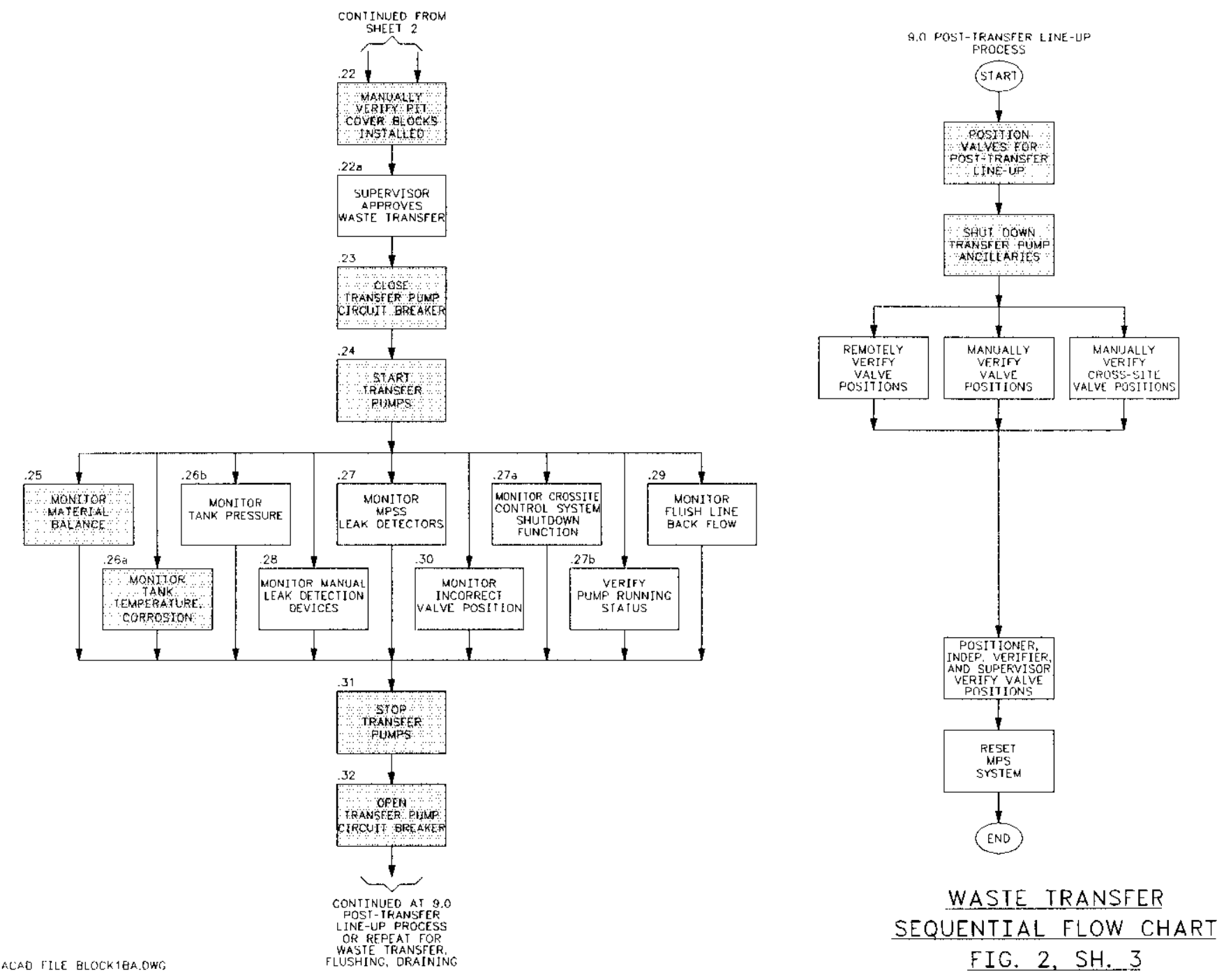


\subsubsection{Waste Storage Parameter Authorized Limits}

The authorized limits for the waste storage parameters shall be in accordance with the current revisions of the RPP FSAR, TSRs, and OSD's.

\subsubsection{Responses to Exceeding Waste Storage Authorized Limits}

The following responses shall be used by the MCS to control storage parameters:
a) Interlocking Tank Waste Mixers
b) Adjusting DST Ventilation Flow Rate
c) Interlocking Waste Transfers
d) Switching Primary Ventilation Filter Banks

\subsubsection{Monitoring and Control System (MCS) Overview}

The following definitions and Figure 3, "Monitoring and Control System Overview", provide a description of the MCS. The new pit leak detection systems, encasement leak detection systems, and valve position sensors are discussed in the "Project Design Concept for the Transfer Piping", HNF-SD-W314-TI-007. The DST Primary Ventilation Systems are discussed in the "Project Design Concept for the Primary Ventilation Exhaust System, "RPP-6066". 


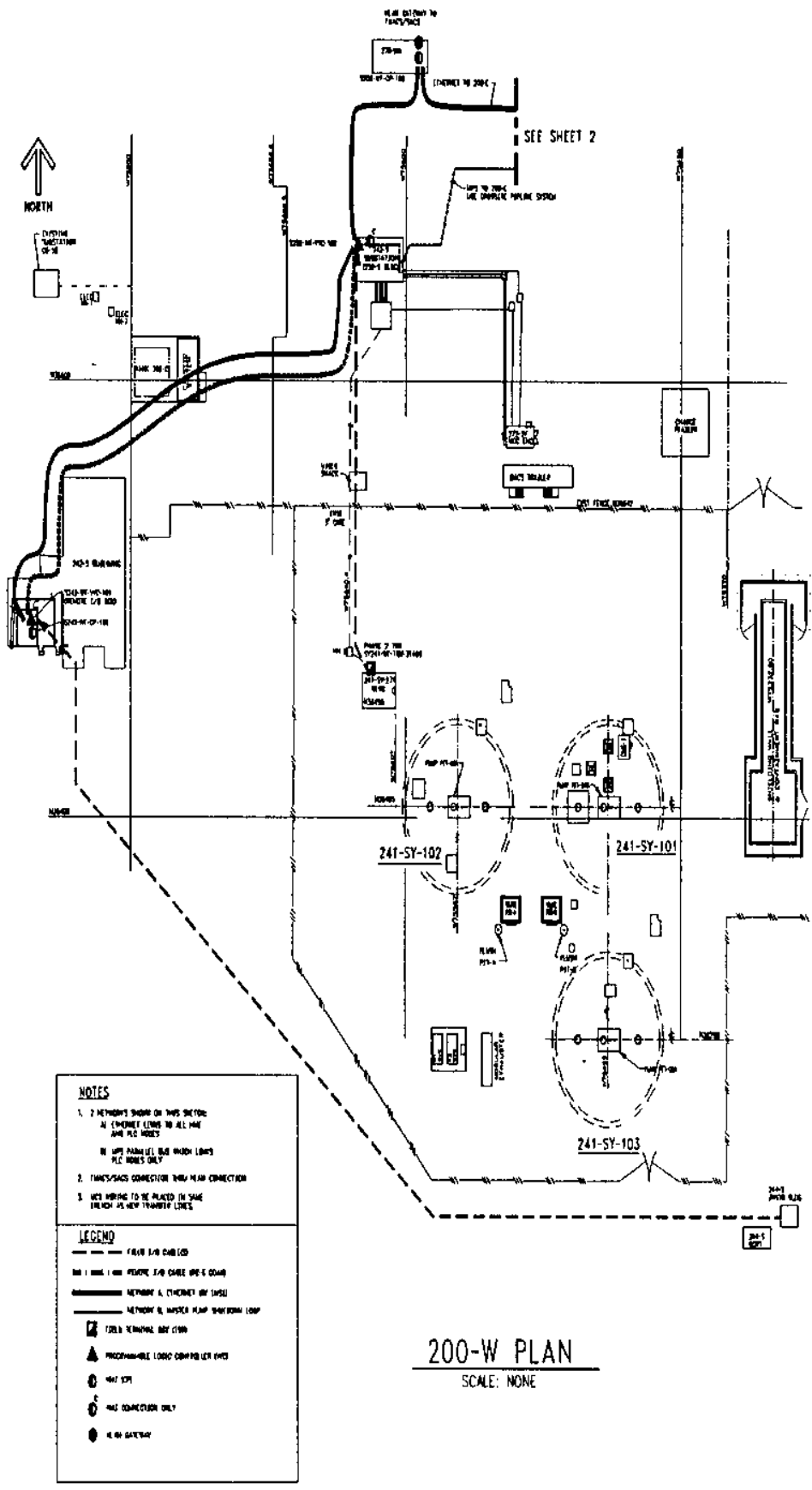

Figure 3, "MASTER PUMP SHUTDOWN OVERVIEW, SH 1 
RPP-6303

Rev. 0

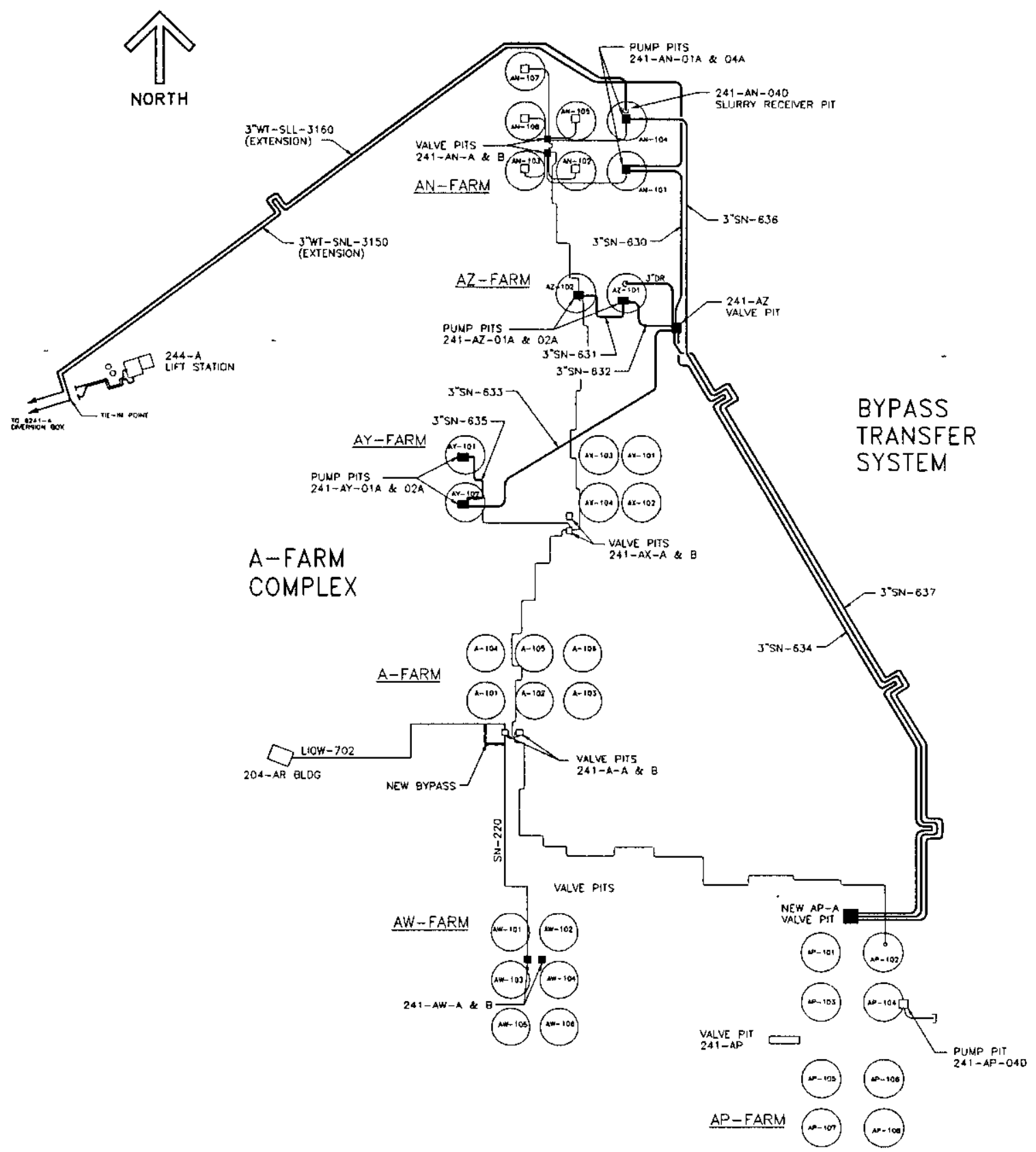

carfile: 200ewis.dwg

Figure 3, "MASTER PUMP SHUTDOWN OVERVIEW, SH 2 


\subsubsection{Existing MPS System}

The existing leak detection systems and other existing MPS devices perform Figure 4, "Existing MPS Logic Diagram" step .27 listed in Section 2.1.1. The leak detection systems monitor for leaks in transfer pits and pipe encasements and monitors itself for malfunctions. Upon detection of a leak in any pit or encasement line, or leak detection system malfunction; the leak detection system outputs a signal to the Existing MPS System. The Existing MPS System consists of a set of relays that interconnect leak detectors in a tank farm and and then interconnect those relays between tank farms. The Existing MPS System monitors signal inputs from any connected leak detection system and controls all waste transfer pumps. Upon receiving an input from a leak detection system, the Existing MPS System shuts down "all" transfer pumps. See Figure 4, "Existing MPS Logic Diagram" for illustration.

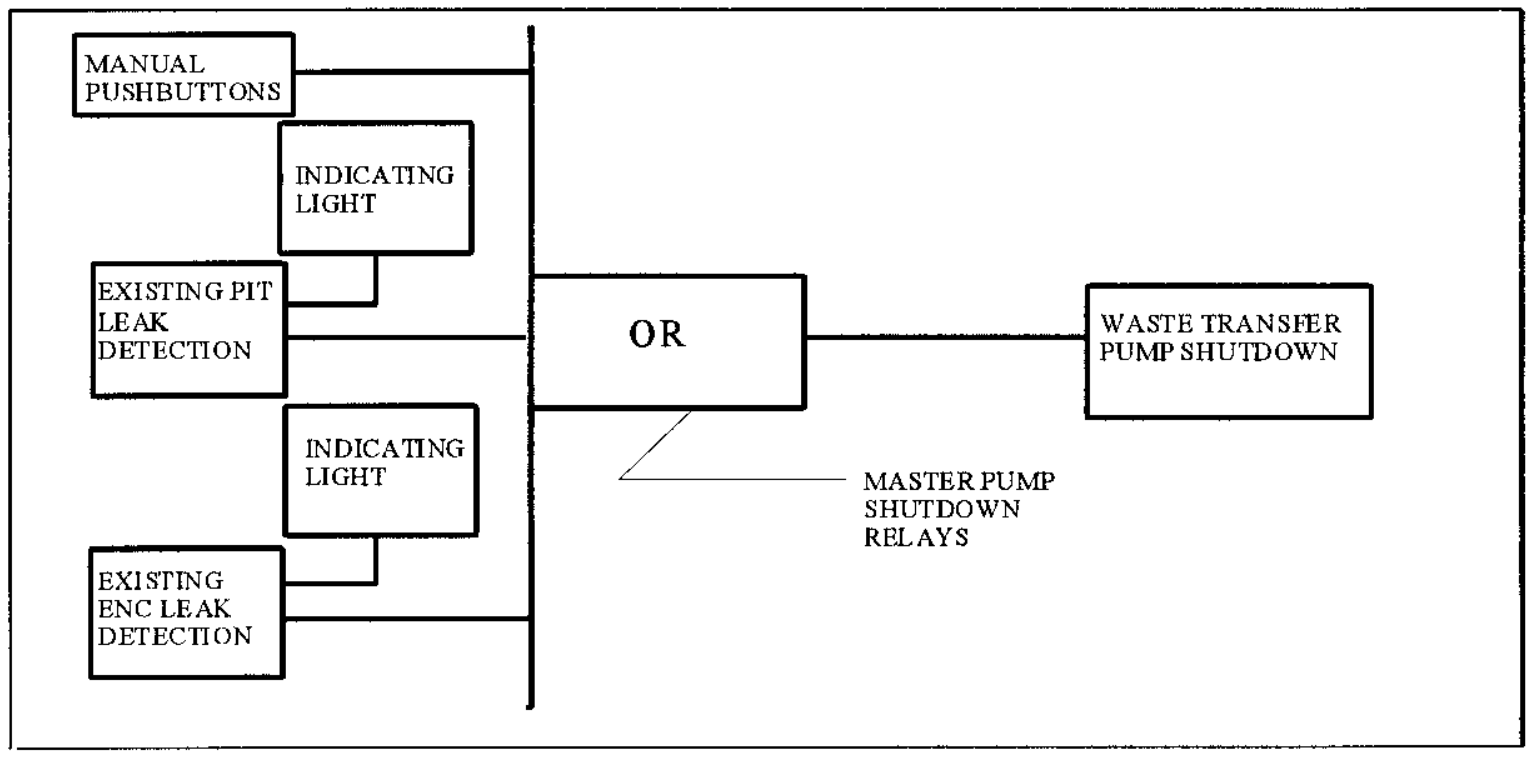

Figure 4, "EXISTING MPS LOGIC DIAGRAM" 


\subsubsection{Phase 1 Monitoring and Control System (MCS)}

An overview of the Phase 1 MCS is shown in Figure 5, "MCS Logic Diagram". This diagram shows generic leak detector inputs, existing MPS Relay Inputs, valve position sensor inputs and manual MPS pull switch inputs at each PLC location. The PLC initiates a transfer pump shutdown which is represented by an interlock relay output. The actual inputs and outputs can be found in the "Drawing B-221, MPS, Phase 1 Configuration at Start of Acceptance Testing", in Appendix A. The operation of these generic inputs and outputs is defined in the following bulleted paragraphs.

\section{- $\quad$ Programmable Logic Controller (PLC)}

The PLCs shown on Figure 5 are represented by logic symbols. In Phase 1, the PLCs replace the existing MPS relays that interconnect the tank farms. The PLCs also process the inputs and outputs as described below.

\section{- $\quad$ Existing MPS Relay Inputs $\left(\mathrm{K}_{\mathrm{in}}\right)$}

During the initial phases of the MCS implementation, parts of the existing MPS System shall remain in service. These parts or a subsystems shall be referred to the following as "Existing". The existing master pump shutdown relay inputs are shown as $\mathrm{K}_{\text {in }}$ on Figure 5. The existing MPS electromagnetic relays receive signals from existing leak detectors, area radiation detectors, flush water valve limit switches, flush water pressure switches, manual pushbuttons and other devices and outputs a single input to the PLCs. Several of these existing relays will input to the MPS System via a PLC at any one of the Instrument Buildings.

- Valve Position Sensor Input (ZS)

Each valve position sensor installed by Project $\mathrm{W}-314$ will be monitored and, if the valve is in an incorrect position, a transfer pump shutdown will be initiated.

- $\quad$ Leak Detector (LDK)

Each leak detector installed by Project W-314 will be monitored and, if a leak is detected or if the leak detection system malfunction is detected, a transfer pump shutdown will be initiated.

- $\quad$ Service Water Pressure Detectors (PS)

Each Service Water Pressure Detector installed by Projects W-314, W-211 or W-521 will be monitored. If a flush line high pressure is detected, signifying a flush line back flow, a master pump shutdown will be initiated. 
Each manually operated master pump shutdown switch installed by Project W-314 will be monitored and, if operated, a transfer pump shutdown will be initiated.

- Route Selector Switch (SSn, where $n=1,2,3,4,5,6$ or $\mathrm{C}$ )

Each MCS input and output installed by Project W-314 and the cross site input and output switches will be able to be associated with six different waste transfer routes by toggling a particular route selector switch.

- Transfer Pump Interlock Relay $\left(\mathrm{K}_{\text {out }}\right)$

Each Transfer Pump interlocked to the MCS by project W314 will be equipped with redundant interlock relays which, when de-energized, opens the transfer pump's motor control circuit causing the pump to shut down. 


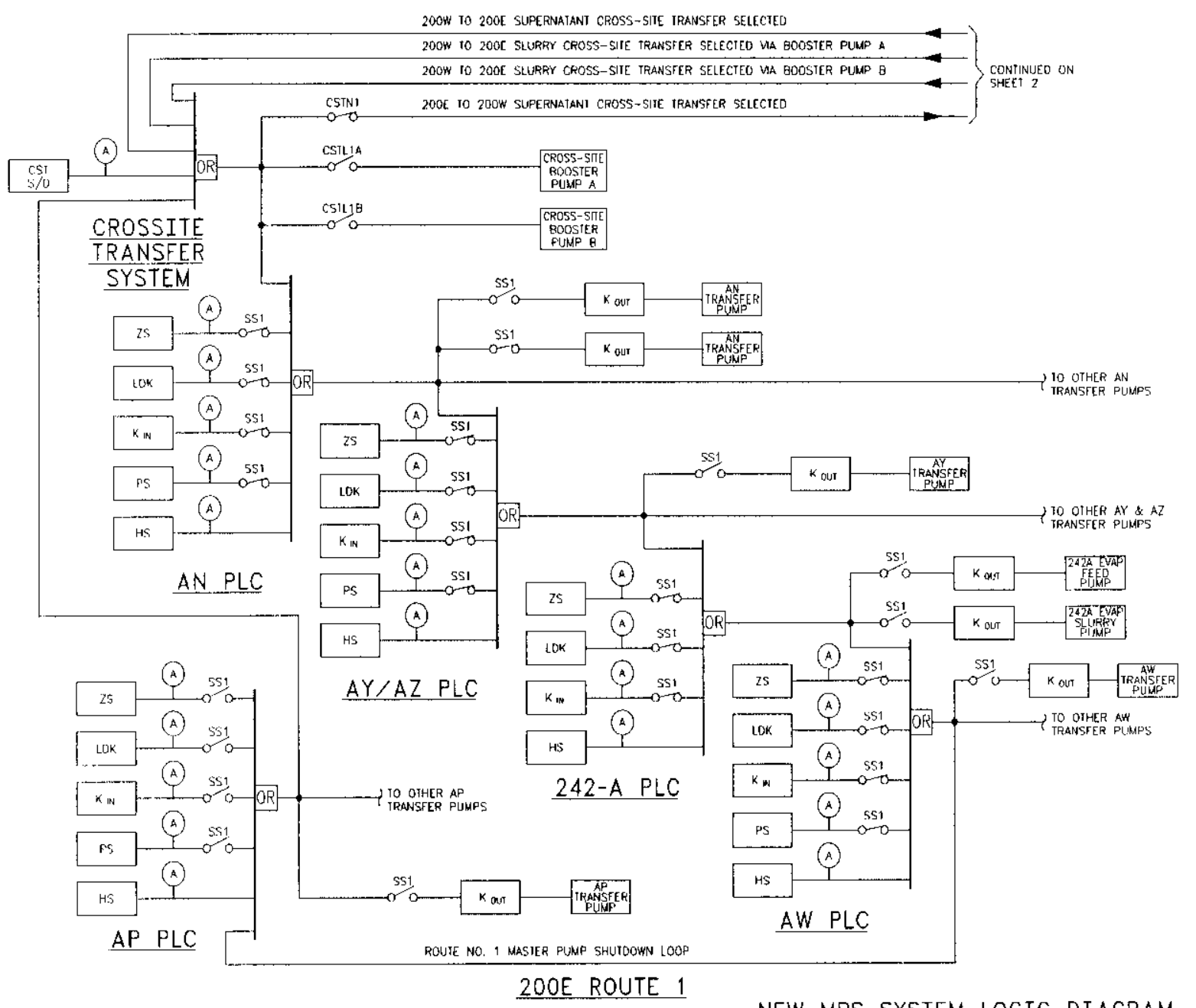


RPP-6303

Rev. 0

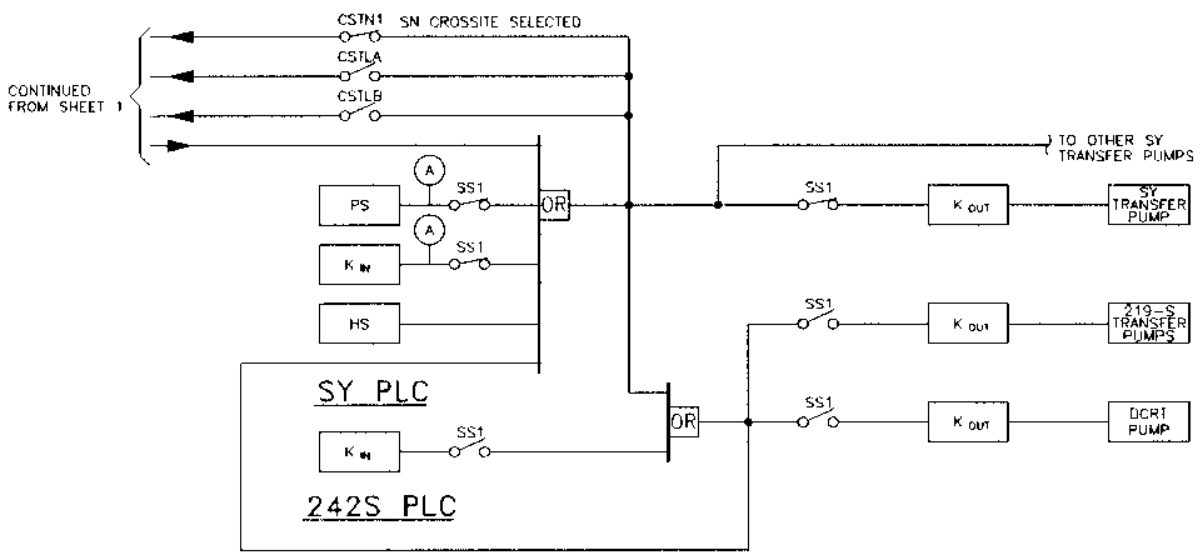

LEGEND:

(a) = HMI ALAFM

$K_{N}=$ EXISING MPS RELAY INPUT

25 = TRANSFER VALVE PUSIIION SENSOR INPUT

LLIK = LEAK DETECTOR INFUT

HS = MANUAL MPS

AS = SERVICE WATER PRESSLIRE OETECTOR INPIJT

K OUT = TFANSFER PLIND INIERLOCK RELAY OUTPITT

200W ROUTE 1

\begin{tabular}{cc}
\hline CST \\
S/O
\end{tabular}

NOTES:

1. THIS LOGIC UIACRAM SHOWS A TYPLCAL ROUTE MPS SHUTOOWN LOUP.
THERE ARE SIX OF THESE CONTROL SYSTEMS FOR SIX ROLTES.

2. EXAMPLE SHOWS IHAT ROUIE I CONSISTS UF ROUTE INITATING IN SY FARM AND ENDING IN AW FARM,
A GOOSTER PIJMP IN THE AN FARM,

NEW MPS SYSTEM LOGIC DIAGRAM FIG. 5 . SHEET 2 
The purpose of Figure 5 is to illustrate the functional operation of the MCS for one transfer route. Note that there are six transfer routes in which the MCS may be operating concurrently and which operate identically. The MCS is summarized in the following operational sequence:

1. Initially, prior to starting a waste transfer, the Operator selects all of the MCS PLC inputs (by one of two methods explained in Section 2.3.2.5) that will cause a transfer pump shutdown and all of the MCS outputs that control transfer pumps used for a particular route. It is done, for instance, for Route No. 1 by the Operator toggling the SS1 switches. If Route No. 2 was chosen for use, SS2 switches will be toggled. Likewise, SS3 switches will be toggled for Route No. 3; SS4 switches will be toggled for Route No. 4; SS5 switches will be toggled for Route No. 5; SS6 switches will be toggled for Route No. 6. Note that every PLC input and output will have selector switch SS for each transfer route that can be operated simultaneously. If one of four possible cross site transfers, is selected by the Operator as part of the route, sclector switch CSTN-EW, CSTN-WE, CSTL-A, or CSTL-B, also needs toggling. The four possible cross-site transfers are:

- CSTN-EW = Supernatant transfer from 200 East to 200 West

- CSTN-WE = Supernatant from 200 West to 200 East

- CSTL-A = Slurry Transfer via Booster Pump A

- CSTL-B = Slurry Transfer via Booster Pump B

The Operator toggles the selector switches; CSTN1 through CSTN6 or CSTL1 through CSTL6, SS1 through SS6; at any HMI. The SS switch positions reside in the PLCs and are retained in the PLC memory no matter if the HMIs and Tank Farm Local Area Network (TFLAN) are shut down.

2. A MPS command is initiated if either a leak is detected, an existing MPS relay input is de-energized, an incorrect valve position is sensed, a flush line back flow is sensed, an Operator pulls a MPS pull-switch, OR the PLC receives a MPS command from another PLC.

3. An alarm is activated immediately when a MPS command is initiated to identify the source of the command activation.

4. After the MPS command is initiated, the PLC de-energizes all Interlock relay outputs connected by SS1 which stop transfer pump operation. It also transmits a MPS command to other PLCs which, in tum, deenergize all their Interlock relay outputs connected by SS1. In this way all transfer pump operation associated with Route No. 1 is stopped. 
5. Assuming that the MPS command is initiated in 200 East and that the cross-site transfer line is connected by a toggled switch, CSTN1-WE, CSTL1-A or CSTL1-B to Route No. 1, a MPS command is transmitted cross site to 200 West where the 200 West PLC de-energizes all interlock relays connected by SS 1 shutting down all waste transfer pumps in Route No. 1 service. The reverse is true if the MPS command is initiated in 200 West.

The MCS will be programmed such that the transfer pump shutdown function of any specific leak detection system, incorrect valve position, or existing MPS relay input may be bypassed by not connecting the input to any transfer route. The bypassing of these shutdown functions is done due to the following:

- If the particular shutdown function is not associated with a particular waste transfer route.

- $\quad$ During a transfer, the MPS command may be bypassed by an operator located at a HMI allowing the waste transfer to continue operation. The bypass is required when it is determined that the MCS shutdown function is impaired causing an unwarranted transfer pump shutdown and when the impaired MPS function is replaced with operator surveillance.

\subsubsection{Phase 2, Monitoring and Control System (MCS)}

An overview of the Phase 2 MCS is Figure 5, "MCS Logic Diagram" modified as described in the following as well as Figure 6, "DST Monitoring Diagram".

In Phase 2, the MCS Logic Diagram (Figure 5) remains the same except the existing MPS Input Relays (Kin) are deleted. The leak detectors, hand switches, Service Water Pressure sensors connecting as inputs into the existing MPS Systems are individually monitored thereby eliminating their need for existing MPS input relays. Most of the existing MPS inputs are replaced as well. See HNF-SD-W314-TI-007 for details. 
RPP-6303

Rev. 0

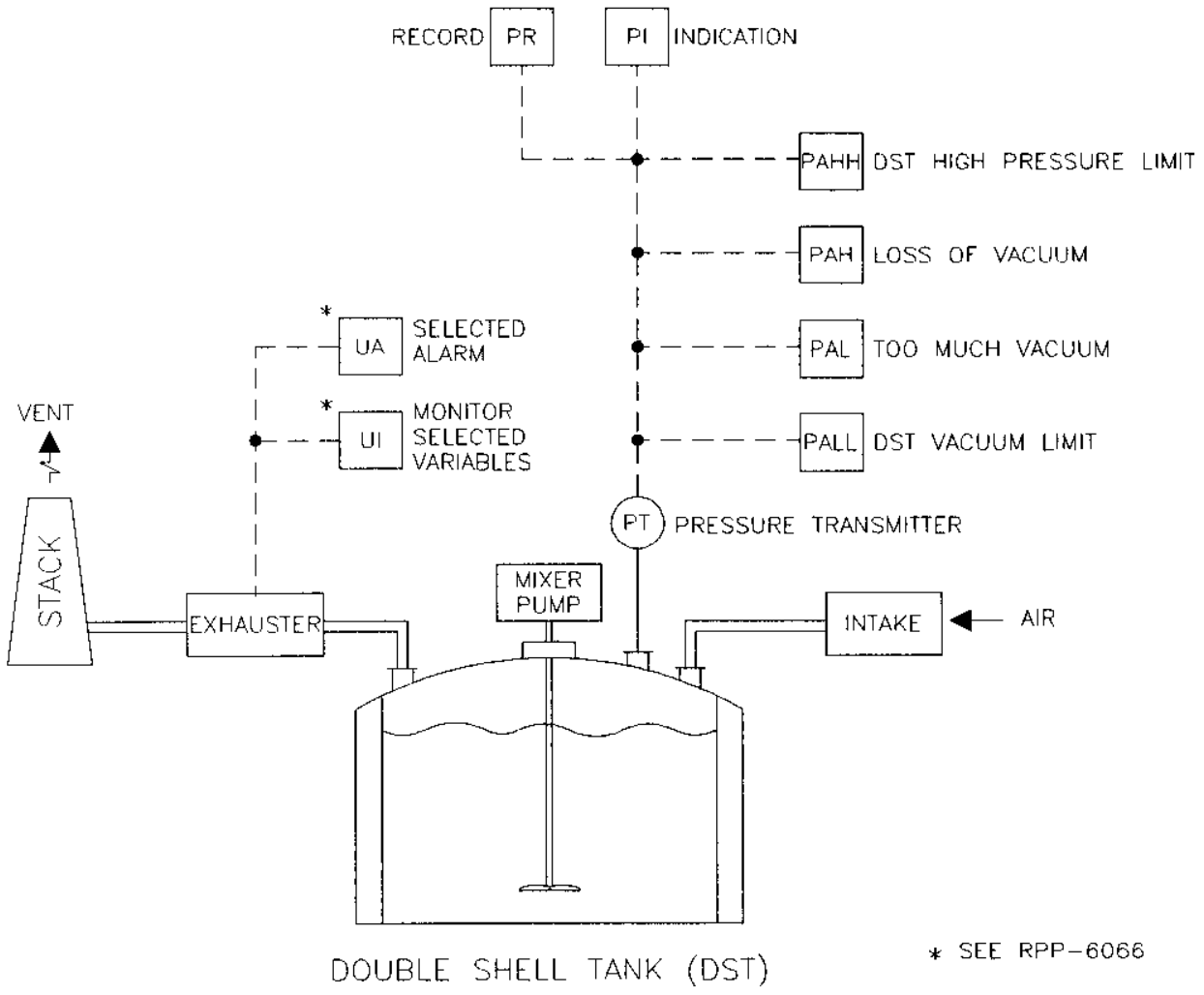

DST MONITORING

ACAD FILE FIG6DST.DWG

FIGURE 6 
- In Phase 2, the MPS System was re-designated as the MCS. In addition, vapor pressure is monitored for all Hanford DSTs. See Figure 6 for illustration of the functionality that is required. Any DST Vapor Pressure may be indicated and trended at any MCS HMI. Vapor Pressure Alarms to alert operations that tank vacuum is not being maintained correctly and that the DST Vapor Pressure limits have been exceeded shall be provided at all MCS HMIs.

- In Phase 2, selected DST Primary Ventilation parameters shall be monitored and alarmed at any of the MCS HMIs. The details of this monitoring are provided in RPP-6066.

- $\quad$ For Phase 2, the actual inputs and outputs can be found in "WTS Phase 2 Final Configuration" in Appendix B.

\subsubsection{MCS Component Definitions}

The following describes the components of the MCS.

- $\quad$ Existing Master Pump Shutdown Relay Inputs

The existing MPS electromagnetic relays receive signals from existing leak detectors and other devices (i.e., manual pushbuttons) and output a single input to the PLCs (defined in the Section 2.1.3.1). Several of these existing relays will input to the MCS at any one of the Instrument Buildings.

\section{- Tank Monitor and Control System (TMACS) Gateway}

An existing central surveillance station is located at the $2750 \mathrm{E}$ building. The TMACS is a computerized data acquisition system and provides the input to the Tank Farms Surveillance Analysis Computer System (SACS), an information management system. The gateway is the HLAN-toTFLAN connection that allows data communication between the two systems to occur. It consists of the necessary hardware and software (protocol) that make the two systems, HLAN and TFLAN, messages compatible. Existing HLAN then transmits the messages between the gateway and TMACS or SACS. It is planned to locate the gateway in the 241-AZ-271 control room.

\section{- Tank Farm Local Area Network (TFLAN)}

TFLAN is the name given to a new W-314 installed Ethernet network that during Phase 1 communicates waste transfer route selection and MPS System status \& alarm signals in digital serial format between all PLCs and HMIs. The PLCs and HMIs communicate with each other using a dedicated high-speed communications line to share all available field 
signal and MPS System data.

\section{- Web Enabled Data Server}

An industrial Structured Query Language (SQL) Database, such as Citect Plant2 SQL shall be constructed to hold historic MCS control, monitoring and other related data. The data is to be populated from the MCS at regular intervals. The gateway shall be located in 241-AZ-271 and will provide the TFLAN to HLAN connection for data updates.

Web pages shall be provided via the HLAN. This allows a user from an HLAN connected PC, to view data (alphanumeric and/or graphical). Viewing shall be permitted with valid security login/password.

- $\quad$ Master Pump Shutdown (MPS) Loop

The MPS Loop is a 24 volt DC PLC-TO-PLC parallel bus network that communicates a transfer pump shutdown signal between PLCs for each simultaneous waste transfer. The data communicated are strictly binary and represents a shutdown command for each simultaneously operating waste transfer route. The MPS Loop allows waste transfers to continue if TFLAN or an HMI fails since the PLCs independently monitor leak detectors, etc. and issues transfer pump shutdown commands.

\section{- $\quad$ Existing Cross-site Transfer System (CTS)}

The existing CTS performs the shutdown of the cross-site booster pump if the CTS detects either a 200 East or 200 West MPS signal. The CTS also shuts down the cross-site booster pump if a cross-site pipeline leak, pit leak, valve position failure, or valve leak is detected. When a CTS initiated shutdown is detected by the MCS, the MPS loop is, then, initiated. The CTS communication system is used to communicate general service 200 East-to-200 West and 200 West-to-200 East MPS loop signals. Existing CTS conduit is used for Safety Class MPS loop signals.

- $\quad$ Programmable Logic Controller (PLC)

The PLC is a digital computer that receives output signals from field devices, communicates with other devices using digital protocols, and produces control output signals based on inputs and user configurable programming and stored algorithms. The PLC uses inputs and programmable functions such as logical operations, averaging, totalizing, timing, and mathematical operations to control PLC outputs. The PLC implements the control portion of the MCS.

The PLC is capable of translating analog voltage signals originating from current loops (4-20 mA), thermocouples, resistance temperature detectors (RTDs), etc. and discrete signals originating from relays and on/off voltage devices into digital information suitable for electronic storage and transmission. 
Communication with the HMI is done by TFLAN using a TCP/IP protocol for sending signal information to the HMI on demand. Communication between PLCs is done with a Master Pump Shutdown Loop network, which is separate from TFLAN and which is dedicated to communicating only transfer pump shutdown commands.

\section{- $\quad \mathrm{I} / \mathrm{O}$ Box}

The I/O box is a device, which functions to extend the PLC input and output capability. The I/O box contains hardware necessary to convert analog and discrete input and output signals to digital information. The digital information is transmitted over a single cable to the PLC for processing. Unlike the PLC it is not programmable, and its communications capability is limited to transmitting the digital information to the PLC over a proprietary communications network.

- Human Machine Interface (HMI)

The HMI is an industrial quality personal digital computer workstation with a CRT display, keypad/mouse, a hard disk drive for non-volatile memory, and a user configurable HMI software package. The HMI receives data from the PLC and manual inputs through the keyboard, performs calculations on and/or stores the data, and communicates the data on demand to TMACS using the existing Hanford Local Area Network (HLAN). The HMI displays alarms and signal data (or for any data that are available on the TFLAN network) on its CRT display in an operator friendly fashion. The HMI is typically installed in a tank farm instrument building with a PLC.

\section{- Tank Vapor Space Pressure Transmitters}

The tank vapor space pressure transmitters are instruments that convert DST vapor space pressure to electronic current signals. The current signals are typically 4 to $20 \mathrm{MA}$ dc. Next, the electronic signals are converted to digital information by the MCS PLCs. The digital information is then displayed in engineering units on the MCS HMIs. The PLCs also compare the digital information to the DST pressure authorized limits, and, if exceeded, initiates alarms and control actions.

There are two transmitters per DST. One transmitter measures the vapor space pressure over a very narrow range. This transmitter provides a record that DST is always operating at a small vacuum, thereby, precluding any leakage of airborne contamination to the atmosphere. The other transmitter measures the vapor space pressure over a wide range, and provides a record that the DST structural limits have not been exceeded. A single transmitter shall be considered to perform both functions. 


\section{- $\quad$ Field Terminal Boxes}

The field terminal boxes (TBX) are electrical boxes, which gather individual cables connected to leak detectors and valve position switches and converts them into multi-pair cables that connect to PLCs. They are used to reduce conduit runs and associated trenching.

\subsection{Boundaries \& Constraints}

The following boundaries $\&$ constraints are the rules-of-thumb concepts used to develop the project.

2.2.1 The existing MPS System consists of leak detection systems connected in series to interposing electromagnetic relays which are connected in parallel to Transfer pumps motor control centers (MCCs). The MCS shall use existing relays located in instrument buildings and operating centers that reflect existing master pump shutdown command (input) signals. The MCS shall also switch (output) interlock relays located in the instrument buildings and operating centers to accomplish an automatic shutdown interlock with each of the waste transfer pumps.

2.2.2 Only those leak detection systems replaced by project W-314 will be individually connected to the MCS. This includes all new leak detection systems in the AY, AZ, AW, AP, AN, and SY tank farms. Leak detection as designated in Appendix A for Phase 1 and in Appendix B for Phase 2 will be replaced by the project.

2.2.3 A HMI will be installed at each location listed below (3 HMIs will be installed in the 241-AZ-271 Control Building). The HMI shall provide a graphical user interface.

\begin{tabular}{|l|l|}
\hline \multicolumn{1}{|c|}{ HMI LOCATION } & \multicolumn{1}{c|}{ DESCRIPTION } \\
\hline BUILDING 241-AZ-271 & W-030 CONTROL BUILDING \\
\hline BUILDING 241-AN-271 & TANK FARM AN INSTRUMENT BUILDING \\
\hline BUILDING 241-AW-271 & TANK FARM AW INSTRUMENT BUILDING \\
\hline BUILDING 241-AP-271 & TANK FARM AP INSTRUMENT BUILDING \\
\hline BUILDING 272-AW & 200 EAST OPERATING CENTER SATELLITE \\
\hline BUILDING 242-A & 200 EAST EVAPORATOR OPERATING CENTER \\
\hline BUILDING 242-S & 200 WEST EVAPORATOR OPERATING CENTER SATELLITE \\
\hline BUILDING 278-WA & 200 WEST OPERATING CENTER \\
\hline BUILDING 2704HV & SHIFT OFFICE \\
\hline
\end{tabular}


2.2.4 Immediate identification of the source of a master pump shutdown command signal will be available in the form of an alarm at any HMI and will be available to be communicated per Section 2.1.3 as data to the TMACS via HLAN.

2.2.5 Cross-Site Transfer (CST) System controls the cross-site transfer pumps and interfaces with the MCS via relays which convert $24 \mathrm{v}$ dc general service MPS shutdown loop signals to $120 \mathrm{v}$ ac signals compatible with the CST System. Analog switches interface directly with CST pumps for Safety Class MPS loop signals. The HMI for the CST shall be directly compatible with the MCS.

2.2.6 All necessary leak detection and MPS push-button signals interfacing the 200 West MPS System will be available on the HMI located in the 242-S Building.

2.2.7 A communications network, named the MPS Loop, communicates master pump shutdown command signals between all of the PLCs at the following locations shall be provided:

$$
\begin{aligned}
& \text { PLC location } \\
& \text { 241-AN-271 } \\
& \text { 241-AW-271 } \\
& \text { 241-AZ-271 } \\
& \text { 241-AP-271 } \\
& \text { 252-S Building } \\
& \text { 242-A Evaporator } \\
& \text { 242-S Evaporator }
\end{aligned}
$$

2.2.8 Each PLC location will have the capability to have a portable HMI connected to it if a permanent HMI is not associated with it. One portable HMI shall be provided and its functionality tested as part of Project W-314 Phase one scope.

2.2.9 Part of the MCS shall be designed as failsafe. If the power supply to the MCS, MPS shutdown loop, Leak Detector, interlock relay, existing MPS relay input or MCS PLC fails, the transfer pumps for the particular route affected shall be shut down. If the HMI or HMI/PLC communication network (TFLAN) fails, the transfer pumps shall continue to run providing there are no MPS commands. If the TFLAN fails, the MCS HMIs shall alarm to notify the HMI Operators.

2.2.10 All new back flow detecting pressure switches installed by Project W-211 and W521 shall be directly connected to the MPS System. Each pressure switch will be identified on MPS HMls and alarm when high pressure is detected. Existing back flow pressure switches connected to existing MPS relays will be connected to the new MPS System via the relays.

\subsubsection{The CST control system allows only one CST at a time.}

\subsection{Performance Requirements}

All Operators shall be required to log on and off of the MCS. The log on process shall include all Operators inputting a password into the MCS. The MCS shall allow an Operator to perform only those operations that the Operator is authorized to perform, 
where the password is the basis of the authorization. The MCS shall provide multiple access levels such as Read Only, Operator, Shift Supervisor, Technician and Systems Administrator as defined in the following:

- Technician Level: Access to read all displays but no ability to change parameters other than those negotiated in site specific labor contracts.

- Operator Level: Access to read all displays, adjust the process parameters associated with any waste transfer route, and select a predetermined route.

- Supervisor Level: Access to create and select predetermined transfer routes, read all displays, adjust all process parameters associated with the waste transfer operations, inhibit alarms, invoke a MCS element bypass, and release approval of administrative hold points within his area of responsibility.

- Engineer Level: Access to create transfer routes, read all displays, and reconfigure PLC logic, MCS hardware and HMI displays.

- $\quad$ Super User Level: Full access to all MCS operator, hardware and software functions. Performs the Systems Administrator functions.

The MCS is involved with steps $.1, .6, .7,, .11, .12, .12 \mathrm{a}, .13, .14 \mathrm{~b}, .15, .16, .17, .19, .20$, $.21, .21 \mathrm{a}, .22 \mathrm{a}, .26, .27, .27 \mathrm{a}, .27 \mathrm{~b}, .29, .30,9.3 \mathrm{a}, 9.3 \mathrm{~b}, 9.3 \mathrm{c}, 9.4$, and 9.5 of a waste transfer as described in section 2.1.1. The MCS will include each of these steps in the modes of operation described in Section 3.0. The Operator shall be able to select any operating mode from a list of operating modes being displayed at any HMI location.

Manning Levels for operation of the MCS shall be normally one operator for each waste transfer route. Multiple operators shall be able to select different transfer routes with each operator manning a different $\mathrm{HMI}$.

The operator mans a HMI and must complete in the proper sequence the route selection, route set up, and equipment functional verifications prior to making the waste transfer or flushing out the lines. See Figure 2 for illustration. The MCS shall be able to insure that a proper sequence of operations occurs. The sequence shall be selectable by the Operator. At the end of each operating step, the MCS shall log Operator specified data that document the completion of that operating step.

Each HMI shall operate independently from other HMIs unless otherwise required in the following.

An alarm message indicating a pump shutdown of any transfer and the source of the alarm shall be displayed at all HMIs in all modes of operation.

In addition to the above, an additional mode of operation shall be required. This is the MCS Annunciator (WTA) mode of operation. In this mode, Operators shall be able to identify the source of transfer pump shutdown commands, waste transfer pump running status, and the transfer routes in use and the DST storage parameters. This mode is normally used all through the waste transfer process, therefore, a step number is not applicable. 
The following are performance requirements that shall apply to the MCS performing the steps shown above:

\subsubsection{Step .1 Input transfer route source and destination}

The purpose of this step is to select the appropriate source and destination for the transfer route. When input into the MCS, it initializes the route selection Step .6. Identification names and numbers for each unique waste transfer route shall be assigned by the MCS.

2.3.2 Step .6 \& .7 Select transfer route including passive elements and input selection into MCS.

The purpose of this step from the viewpoint of the MCS is to select the appropriate MCS inputs and outputs for a particular waste transfer route and its associated flush routes. The minimum number of flush routes that can be associated with a particular waste transfer shall be four. These are the pre-transfer flush towards the pump, the pre-transfer flush towards the destination, the posttransfer flush towards the pump, and the post-transfer flush towards the destination. The inputs to the MCS include, but are not limited to, leak detectors, valve position sensors, flow meters, transfer lines, source/destination locations, and MPS pushbuttons. The outputs of the MCS are connected to waste transfer pumps.

2.3.2.1 The maximum number of simultaneous waste transfer route allowed shall be six. Identification names and numbers for each unique waste transfer route shall be assigned by the MCS during Step .1 execution.

2.3.2.2 When two or more waste transfer routes are set up, the MCS shall check the equipment selected for each route for interference's prior to any new waste transfer taking place. An equipment interference is established when equipment is selected for a new route that has already been selected for another route. In the case of pits and tanks an equipment interference is of no consequence. In the case of lines, valves and pumps, an equipment interference is not allowable. The associated pre-transfer and post-transfer flush route equipment selections shall also be checked for interference's to insure that the route can be flushed before or after the waste transfer. A local message shall be displayed on the local HMI when the same transfer element is identified for use by two or more waste transfer routes.

2.3.2.3 HMI Databases for associating MCS inputs and outputs to selected transfer routes and waste transfer mechanical segments such as tanks, pits, pumps, transfer lines, and jumpers are provided in Appendix B, Drawing B-221-P2, "Waste Transfer System (WTS) Phase 2 Final Configuration". Programs with appropriate configuration control shall allow the adding to, deleting from and changing of the records of all transfer route and mechanical segment databases. 
2.3.2.4 Canceling or de-selecting a transfer route from the MCS shall not occur when the transfer route's assigned transfer pump's motor controls are energized. The transfer pump's motor controls are de-energized by opening the pump's circuit breaker.

2.3.2.5 Operational Requirements - shall be capable of selecting a transfer route. There shall be two methods with which the operators at the MCS HMIs can select MCS inputs and outputs for a particular waste transfer operation. They are:

- $\quad$ An Operator at the HMI shall be able to select a route from a list of predetermined transfer routes. Once the route selection is made, the MCS automatically selects and identifies all associated MCS inputs and outputs for that particular route. It also deselects all MCS inputs and outputs not associated with the selected route. This method is the most preferable of the two methods since it minimizes operator input to the HMI.

- A shift supervisor or cog engineer located at a HMI shall be able to create a predetermined transfer route by selecting mechanical segments of a transfer route such as tanks, pumps, pits, transfer lines and jumpers. The MCS inputs and outputs associated with each selected mechanical segment are then automatically selected.

2.3.2.6 The MCS shall be able to display graphically, on the HMIs, the selected transfer routes in the MCS Annunciator mode of operation.

2.3.2.7 Due to construction work or maintenance activities, waste transfer equipment elements are often taken out of service temporarily. When this occurs, the "Out of Service" status for the applicable equipment elements shall be entered manually into the MCS via a HMI. The access level for the HMI operator performing the manual entry of the waste transfer equipment element "Out of Service/In Service" status shall be "Supervisor" which shall be authenticated by the MCS log in process. When the equipment elements are placed back into service, the "In Service" status is assigned to the applicable elements by also manually entering the new status into a MCS HMI. The "Out of Service/In Service" state entry shall be accomplished by manually entering the new state, the time and date of entry, and the name of the Supervisor doing the entry into a MCS HMI.

A local message shall be displayed on the HMI being used for route selection identifying the transfer elements that are in the "Out of Service" state and shall indicate that the transfer element(s) are unable to be used in the route.

When an equipment element state is designated "Out of Service", the MCS shall prevent the equipment element from being selected for use in a transfer route and shall inhibit its alarm and route shutdown functions until its state is changed manually back to "In Service". After an 
equipment element is selected (assigned) for use in a route, the MCS shall prevent its state from being "Out of Service". (Note that the Bypass function performs a similar function during the Verification and the Transfer modes of operation.)

2.3.2.8 The HMI Operator shall determine the need for additional passive elements required to satisfy the Authorization Basis. Passive elements are those mechanical segments or MCS input/output elements whose associated primary confinement does not normally come in contact with the waste during a transfer. Passive element selections shall be performed by an Engineer or Supervisor Access level to the MCS.

\subsubsection{Step .11 Remotely verify transfer route valve positions (line-up).}

2.3.3.1 For those transfer valves that have position monitors connected to the MCS, the MCS HMI graphics for each valve shall be color coded per Appendix $S$.

2.3.3.2 Operational Requirements - shall be able to display graphically valve position. A flashing valve symbol shall indicate that a valve is in an incorrect position. A report of all valve verifications shall be displayed (and/or printed) at the HMI, and/or be available to external systems such as TMACS. The HMI shall display a local message indicating that all transfer valves in the selected transfer route are positioned correctly. Logic diagram in Figure 17, Appendix D, "Valve Position Verification Mode Logic", shows functional requirements for this step.

2.3.4 Step .12, 12a, \& .13 Manually verify transfer route valve positions (line-up) with separate verifications by the valve field Operator, an independent verifier and the Supervisor.

2.3.4.1 Operational Requirements - shall be able to display graphically valve positions for those transfer valves not connected to the MCS where the valve positions displayed are the last position manually entered into the MCS HMI. Once all the valve positions are verified by the valve field Operator, an independent verifier and the Supervisor, the valve position shall be displayed in a verified state. Manual valve position verification shall be accomplished by entering the valve position, the time and the date of verification and the name of the verifiers into the MCS. The HMI shall also display a local message indicating that all transfer valves in the selected transfer route are positioned correctly. A report of all valve verifications shall be displayed (and/or printed) at the local HMI, and/or be available to external systems such as TMACS.

2.3.4.2 The MCS HMI graphics for each valve shall be color coded per Appendix $\mathrm{S}$.

2.3.4.3 The HMI shall display a local message indicating that all transfer valves in the selected transfer route are positioned correctly. Logic diagram in Figure 17, Appendix D, "Valve Position Verification Mode Logic", shows 
functional requirements for this step.

2.3.4.4 The MCS shall authenticate the valve field Operator, an independent verifier and the Supervisor verifiers by the initial login process performed during system initialization.

2.3.4.5 The MCS shall update a route's valve position status to verified only when the MCS receives input that the route valve position status has been verified in the following order: (1) the valve field Operator, (2) an independent verifier and (3) a Supervisor.

\subsubsection{Step .15 Remotely Verify MCS PLC operational.}

2.3.5.1 Operational Requirements - shall be able to verify the PLC software logic with a combination of the following tests after leak detector, valve position, existing MPS relay and pump interlock relays are verified. For each transfer route the MCS shall output a functional test command to each leak detection system, valve position sensor, or existing MPS relay input and shall monitor and display on the HMI the status of the transfer pump MCC interlock relays to determine whether or not the functional test was successful. The success or failure of each functional test shall be displayed by a local message presented on the HMI. A report of all MCS PLC System verifications shall be displayed (and/or printed) at the local HMI, and/or be available to external systems such as TMACS.

Prior to the completion of a route's verification process, a pump interlock relay shall not be allowed to energize unless the pump's MCC is not energized.

2.3.5.2 The HMI shall display a message indicating that all MCS PLCs in the selected transfer route are verified as operational. Logic diagram in Figure 18, Appendix D, "Route No. 1 PLC Operation Verification Mode Logic", shows functional requirements for this step.

\subsubsection{Step .16 Remotely Verify MCS Transfer Pump Interlock Relay Operation.}

2.3.6.1 Operational Requirements - shall be able to output a master pump shutdown command to the appropriate transfer pump MCC interlock relays and shall monitor and display on the HMI the status of the MCC interlock relays to determine whether or not the functional test was successful. The HMI shall display a local message indicating that all MCS interlock relays in the selected transfer route are verified as operational. A report of all transfer pump MCC interlock relay verifications shall be displayed (and/or printed) at the local HMI, and/or be available to external systems such as TMACS.

Prior to the completion of a route's verification process, a pump interlock relay shall not be allowed to energize unless the pump's MCC is not energized. 
2.3.6.2 Logic diagram in Figure 16, Appendix D, "Route No. 1 Transfer Pump Interlock Operation Verification Mode Logic", shows functional requirements for this step.

2.3.7 Step .14b \&.17 Remotely Verify existing MPS System relay input and back flow pressure switch operation.

2.3.7.1 Operational Requirements - shall be able to output a functional test command to an existing MPS relay input or back flow pressure switch and shall display the result of the test as an alarm for function confirmation. An existing MPS relay or back flow pressure switch functional test shall not shut down a waste transfer. The HMI shall display a local message indicating that all existing MPS relay inputs or back flow pressure switch in the selected transfer route are verified as operational. A report of all existing MPS relay input and back flow pressure switch verification shall be displayed (and/or printed) at the local HMI, and/or be available to external systems such as TMACS.

2.3.7.2 Logic diagram in Figure 14, Appendix D, "Route No. 1 Relay Input Operation Verification Mode Logic", shows functional requirements for this step.

2.3.7.3 If an existing leak detector or back flow pressure switch, which is connected as an input to an existing MPS relay, fails a verification test; the verification failure shall be indicated via a HMI to the Operator(s) responsible for other selected transfer routes that are currently utilizing that existing leak detector or back flow pressure switch as a MCS input.

2.3.7.4 The functional test of the back flow pressure switch circuit is identical to the existing MPS relay's test. To functionally exercise the pressure switch, the transfer and flush lines shall be pressurized to check for line leaks and pressure switch function.

\subsubsection{Step .19}

Remotely Verify MCS Leak Detection System operation (this includes leak detectors associated with the flush route).

2.3.8.1 Operational Requirements - shall be able to output a functional test command to the leak detection system for each transfer route and shall display the result of the test as an alarm for function confirmation. A leak detection functional test shall not shut down a waste transfer. The HMI shall display a local message indicating that all leak detection systems in the selected transfer route are verified as operational. A report of all leak detector verifications shall be displayed (and/or printed) at the local $\mathrm{HMl}$, and/or be available to external systems such as TMACS.

2.3.8.2 Logic diagram in Figure 15, Appendix D, "Route No. 1 Leak Detector Operation Verification Mode Logic", shows functional requirements for this step. 
2.3.8.3 If a leak detector fails a verification test; the verification failure shall be indicated via a HMI to the Operator(s) responsible for other selected transfer routes that are currently utilizing that leak detector as a MCS input. The change in verification status of the leak detector shall shut down or prevent the starting of all transfers for which leak detector has been selected.

2.3.9 Step .20 Manually verify leak detection systems that are not connected to either the MCS or existing MPS System (this includes leak detectors associated with the flush route).

2.3.9.1 Operational Requirements - shall be able to graphically display Leak detector status (leak or no-leak) for each transfer route for those leak detection systems not connected to the MCS where the leak detector status displayed are the last states manually entered into the MCS HMI. Once the Leak detection systems are verified, the Leak detector status shall be displayed on the HMIs to indicate a verified state. Verification shall be accomplished by field testing the leak detector; and then manually entering the leak detector's last state, the time and date of verification, and the name of the verifier into an MCS HMI. The HMI shall display a local message indicating that all leak detection systems in the selected transfer route are verified as operational. A report of all leak detector verifications shall be displayed (and/or printed) at the local HMI, and/or be available to external systems such as TMACS.

2.3.9.2 The MCS HMI graphics for each leak detector shall be color coded per Appendix S.

2.3.9.3 Logic diagram in Figure 15, Appendix D, "Route No.1 Leak Detector Operation Verification Mode Logic", shows functional requirements for a remotely verified leak detector which is similar to this step. The difference is that the leak and malfunction functional tests are manual as are their corresponding alarm inputs into the MCS.

2.3.10 Step $.21 \& .21 \mathrm{a} \quad$ Manually Verify that existing MPS System Leak Detection Systems, which are connected to MCS via the existing (roll up) MPS relays, are operational.

2.3.10.1 Operational Requirements - shall be able to graphically display Leak detector status (leak or no-leak) for each transfer route for those leak detection systems connected to the existing MPS System relay where the leak detector status displayed are the last states manually entered into the MCS HMI. Once the Leak detection systems are verified, the Leak detector status shall be displayed on the HMIs to indicate a verified state. Verification shall be accomplished either by field testing the leak detector in combination with the existing MPS System relay input operation per Section 2.3.7 or by reviewing the Tank Farm PM/S to determine if the leak detection system has been verified within a specific time period defined by the date of the transfer and the 
date of the PM/S verification; and then manually entering the leak detector's last state, the time and date of verification, and the name of the verifier into an MCS HMI. The HMI shall display a local message indicating that all leak detection systems in the selected transfer route are verified as operational. A report of all leak detector verifications shall be displayed (and/or printed) at the local HMI, and/or be available to external systems such as TMACS.

2.3.10.1.1 When it is determined by review of a PM/S record that the nonMPS System testable Leak Detection System does not require a functional test, it shall be verified by manually entering into an MPS System HMI:

- The time and date of PM/S verification.

- The name of the verifier.

- "Verification by $\mathrm{PM} / \mathrm{S}$ record".

Note that the MCS shall allow only "Supervisor" access for performing an existing MPS System Leak Detection System verification by $\mathrm{PM} / \mathrm{S}$ record.

2.3.10.2 The MCS HMI graphics for each leak detector shall be color coded per Appendix S.

2.3.10.3 Logic diagram in Figure 20, Appendix D, "Route No. I Manual Leak Detector Verification Mode Logic", shows functional requirements for this step when the verification method is by functional test.

\subsubsection{Step .22a}

2.3.11.1

2.3.11.2

2.3.12 Step .26
Supervisor approves the Waste Transfer.

Operational Requirements - shall be able to manually enter a Supervisor's approval into the MCS HMI once all the required systems are verified. Approval shall be accomplished by manually entering the time and date of approval, and the name of the supervisor into an MCS HMI. The HMI shall display a local message indicating that the selected transfer route is approved as operational.

The Supervisor's name shall be authenticated by the login process.

Monitor tank pressures and gaseous effluent discharge and compare to limits.

Operational Requirements for this step, all DSTs shall be monitored for:

a) Tank Pressure 
b) Tank Gaseous Effluent Discharge (GED)

For each parameter monitored, there shall be:

- A value displayed in engineering units on a MCS HMI screen.

- A comparison made with limits defined by the authorization basis or operating specifications that when exceeded, will display as an identifiable alarm on MCS HMI screen.

- An interlock provided to shutdown an appropriate waste transfer if an authorized limit is exceeded.

- An interlock provided to shutdown other equipment not in W-314's scope.

Note that $b$. is defined in the DST Primary Ventilation PDC, RPP-6066.

For DST pressure, two measurement ranges, wide and narrow, shall be monitored. The narrow range measurement shall be capable of providing the information that DST vacuum has been maintained. The narrow range measurement shall be such that DST ventilation may be used for airflow balancing between tanks for those tank farms, which have only one Primary Ventilation System. The wide range measurement shall be used to compare with the DST structural limits.

Monitor for selected MCS inputs and automatically shutdown the transfer pump if an input, e.g., leak, is detected.

Step .27a Monitor, if selected, CST System inputs and automatically shutdown the transfer pump if a CST input is detected.

Step .27b Monitor transfer pump running status to verify pump shut down.

Step .29 Monitor for back flow in connected flush lines during waste transfers.

Monitor for selected MCS inputs for six simultaneous waste transfers.

2.3.13.2 Operational Requirements -

During this step for each simultaneous transfer, there shall:

- be a manual indicating pushbutton located on each HMI screen that initiates a manual shutdown.

- $\quad$ be an indication of a pulled button at each of the pullbuttons. The pull buttons are switches that when pulled by an operator cause a route or all farm transfers to shut 
down.

- be the ability to alarm and identify which MCS input (leak detectors, manual pullbutton, existing relay inputs, Cross-site Transfer System, back flow pressure switches, etc.) caused a transfer pump shutdown.

- $\quad$ be the ability to interlock the appropriate transfer pump and Cross-site booster pump so as to be able to shut them down if a selected MCS input is detected.

- be the ability to not shutdown other transfer or booster pumps not associated or selected for the route being shutdown if simultaneous waste transfers are taking place.

- the ability to identify any MCS input that is selected as a component of a waste transfer route that has been bypassed.

- be the ability to identify any MCS input that is in an alarm state.

- always be an enabling of this operational step whenever the motor control circuit(s) of the transfer route's waste transfer pump(s) are energized.

- $\quad$ provide a means for an Operator to verify that all transfer pumps have shut off by either monitoring the transfer pump running status at an HMI or by obtaining the pump running status manually and then manually inputting pump-running status into the MCS via a HMI. be the ability to operate concurrently with other steps of operation during a waste transfer.

2.3.13.2.1 During a transfer only a HMI operator with a "Supervisor" access level, authenticated by the system login process, shall be allowed to bypass a MCS element. An element shall be bypassed by manually entering into an MCS HMI:

- The time and date of bypass.

- The name of the supervisor.

2.3.13.3Logic diagrams located in Figure 1, Appendix D, "Generic Existing MPS Relay Input Logic"; Figure 2, Appendix D, "Generic Leak Detector Operation Logic"; Figure 5, Appendix D, "Cross Site MPS Logic"; Figure 6, Appendix D, "Route No. 1 MPS Logic"; Figure 7, Appendix D, "Route No. 2 MPS Logic"; Figure 8, Appendix D, "Route No. 3 MPS Logic"; Figure 9, Appendix D, "Route No. 4 MPS Logic"; Figure 10, Appendix D, "Route No. 5 MPS Logic"; Figure 11, Appendix D, "Route No. 6 MPS Logic"; Figure 12, Appendix D, "All Route Manual MPS Logic"; and Figure 13, Appendix D, "Generic Pump Interlock Logic"; show additional functional requirements for this step. manually shutdown the appropriate transfer pump if any 
valve position changes to an incorrect position during a waste transfer.

2.3 .14 .1

2.3.14.2

Monitor for incorrect transfer valve position for six simultaneous waste transfers.

Operational Requirements -

This step and for each simultaneous transfer, the MCS shall:

- $\quad$ provide an alarm which identifies which incorrectly positioned valve caused a transfer pump shutdown.

- be the ability to interlock the appropriate transfer pump so as to be able to shut it down if a leak is detected.

- be the ability to not shutdown other transfer pumps not associated with the valve position change if simultaneous waste transfers are taking place.

- always be operational whenever the motor control circuit(s) of the waste transfer pump(s) are energized.

- have the ability to operate concurrently with other modes of operation during a waste transfer.

- $\quad$ provide a means of manually inputting into MCS via a HMI the position of those valves not connected to the MCS System.

2.3.14.3 Logic diagrams for three way valves located in Figures 3, Appendix D, "Generic Three Way Valve Position Logic", show additional functional requirements for this step of operation.

2.3.14.4 Logic diagrams for two way valves located in Figures 4, Appendix D, "Generic Two Way Valve Position Logic", show additional functional requirements for this step.

2.3.14.5 Valve position entry into the MCS for those valves not connected to the MCS shall be accomplished by manually entering the transfer valve's last position, the time and date of entry, and the name of the Operator doing the entry into an MCS HMI.

2.3.15 Step 9.3a

Step 9.3b

Step 9.3c

Step 9.4
Remotely Verify for the route the post-transfer valve positions (line-up) equipped with position sensors that are connected to the MCS Programmable Logic Controllers (PLCs).

Manually Verify for the route the post-transfer valve positions (line-up) for those valves not equipped with valve position sensors.

If a cross-site transfer, Manually Verify for the route the post-transfer valve positions (line-up) for the Cross-site Pipeline whose valve position sensors are not connected to the new MCS.

Field Operator, Independent Verifier and Supervisor 
Step 9.5

2.3.15.1

2.3 .15 .2

2.3.15.5

2.3.16 Step $\mathbf{n} / \mathbf{a}$

2.3.16.2

2.3.16.3 manually verifies all for the route the post-transfer route valve positions (line-up).

Reset the MCS route selection, which disconnects all MCS inputs and outputs from this route.

Reset each of six simultaneous waste transfer routes independently.

Operational Requirements -

- Reset shall always be prevented whenever the motor control circuit(s) of the transfer route's waste transfer pump(s) are energized.

- $\quad$ Reset shall be initiated by the operator via the HMI.

Logic diagrams located in Figures 19, Appendix D, "Transfer Pump MCC Circuit Breaker Interlock" shows additional functional requirements for this step.

An Administrative approval shall be required prior to releasing the route equipment for use for other transfers. The HMI operator performing the Transfer Route Reset function shall have a supervisor's access level.

The MCS HMI graphics for each valve shall be color coded per Appendix S.

The MCS shall authenticate the valve field Operator, an independent verifier and the Supervisor as verifiers by the initial login process performed during system initialization.

The MCS shall update a route's valve position status to verified only when the MCS receives input that the route valve position status has been verified in the following order: (1) the valve field Operator, (2) an independent verifier and (3) a Supervisor.

MCS Annunciator

All MCS alarms shall be displayed in a set of MCS HMI graphical screens that simplify the presentation of approximately 200 alarms. The alarms shall be grouped on the HMI screens as described in Appendix S.

All waste transfer routes selected in Step 6, section 2.3.2, shall be displayed on the MCS Annunciator set of MCS HMI graphical screens.

The running status of all waste transfer pumps selected for operation in Step 6, Section 2.3.2, shall be displayed on the MCS Annunciator set of MCS HMI graphical screens. 
The dynamic analog data associated with all waste transfer routes selected in Step 6, Section 2.3.2, shall be displayed on the MCS Annunciator set of MCS HMI graphical screens. This includes tank vapor space pressures.

2.3.16.5 All MCS alarms shall be identified on the MCS Annunciator set of MCS HMI graphical screens as to whether or not they are associated with a transfer route utilizing an alarm prioritizing scheme. First priority alarms shall be MCS alarms associated with any selected transfer route. All other alarms shall be second priority.

2.3.16.6 All MCS alarms shall be handled at each MCS HMI as follows:

\begin{tabular}{|c|c|c|c|}
\hline EVENT & HMI ALARM & $\begin{array}{c}\text { TANK FARM } \\
\text { AUDIBLE } \\
\text { ALARM }\end{array}$ & $\begin{array}{c}\text { LOCAL VISIBLE } \\
\text { ALARM }\end{array}$ \\
\hline $\begin{array}{c}\text { MCS Event Initiates } \\
\text { an Enabled Alarm }\end{array}$ & Flashing Symbol & On & Flashing \\
\hline $\begin{array}{c}\text { MCS Event Initiates a } \\
\text { Disabled Alarm }\end{array}$ & Off & Off & Flashing \\
\hline $\begin{array}{c}\text { Operator } \\
\text { Acknowledges Alarm } \\
\text { Tank Farm HMI }\end{array}$ & Steady On & Off & Flashing \\
\hline $\begin{array}{c}\text { MCS Alarm Recovery } \\
\text { Prior to Acknowledge }\end{array}$ & Flashing Symbol & On & Flashing \\
\hline $\begin{array}{c}\text { MCS Alarm Recovery } \\
\text { After Acknowledge }\end{array}$ & Off & Off & Off \\
\hline $\begin{array}{c}\text { Test Button On } \\
\text { Tank Farm HMI } \\
\text { responsible for alarm } \\
\text { acknowledgment }\end{array}$ & n/a & n/a & Flashing \\
\hline $\begin{array}{c}\text { Test Button Off } \\
\text { FCS Alarm @ Tank }\end{array}$ & Flashing Symbol & On & Off \\
\hline
\end{tabular}

I) Where HMI Alarm is an alarm symbol displayed on the HMI screen and audible beeps originating from HMI.

2) Where Tank Farm Audible Alarm is a horn or similar device located on the tank farm instrument building. The audible alarm actuates when a route shutdown alarm occurs in that particular 
farm. It is silenced by an operator clicking on the "silence horn" for that particular farm.

3) Where Local Visible Alarm is a light or similar device located at or near the location of the device initiating the alarm (usually located inside a tank farm).

2.3.16.7 An alarm for each transfer pump shall be provided indicating that the pump's circuit breaker is closed when the pump has not been selected for service in any transfer route. The transfer pump shall be interlocked to prevent operation when the above condition exists.

2.3.16.8 Alarm condition shall produce red flashing alarm indication on the HMI displays along with audible beeps originating from the HMI.

2.3.16.9 Alarm history shall be displayed on the HMIs in organized groups and prioritized.

2.3.16.10 The MCS shall be able to print alarm messages in the sequence as they occur with time and date on MCS printers located at all operations centers.

2.3.16.11 The MCS shall be able to log alarms to computer disk in the sequence as they occur with time and date.

2.3.16.12 The MCS shall be able to log the operator acknowledgment of each alarm to computer disk and print a message recording the alarm acknowledgment.

2.3.16.13 A HMI alarm summary display shall be able to show the alarm function status (enabled or disabled) for all alarms.

2.3.16.14 Enabled and disabled states of alarms shall be accomplished by the MCS software program or manually at a shift supervisor or systems administrator security level only.

2.3.16.15 The MCS shall log the enabling and disabling alarms with the user designator time and date of action.

2.3.16.16 All MCS alarms shall have re-alarm time delay capability and all analog alarms shall have dead band capability.

2.3.16.17 All MCS alarms and parameters shall be available to TMACS and other authorized users via HLAN connections. The HMI shall be capable of Remote Access Server (RAS) functionality.

2.3.16.18 Process lines on the MCS HMI displays shall be color-coded as specified in Appendix $\mathrm{S}$. 
2.3.16.19 Pump operation indication on the MCS HMI displays shall be color-coded as specified in Appendix S.

2.3.16.20 By clicking an alarm on the HMI, an Operator shall be automatically taken from the active alarm summary list screen to the graphic screen displaying the alarm.

\subsection{OPERATIONS CONCEPT DESCRIPTION}

3.1 Operational Environment

Figure 3 allocates the MCS components to operational environments. The following describes each of those environments.

\subsubsection{Instrument Buildings}

All the Instrument buildings that house MCS components are located just outside of the fenced-in areas of the tank farms in an uncontaminated area. The operational environment of the existing Instrument buildings are air conditioned closed buildings exposed to dust and humidity.

\subsubsection{Tank Farm}

The Tank Farm area is located inside the fenced-in areas of the tank farms in a controlled area. All MCS components located in this environment are subject to the ambient conditions at Hanford.

\subsubsection{Tank Farm MCC}

The Tank Farm MCCs are located inside unoccupied instrument and electrical buildings some of which; (AY, AZ, \& SY Tank Farms) are located in the fencedin areas of the tank farms in a controlled area. The buildings are air-conditioned for electrical equipment, not for people. There is switching of large horsepower 480 volt ac motors at these locations.

\subsubsection{HV Building and Operating Centers}

The 2704HV, 272-AW, 278-WA and 242-A buildings and operating centers are air-conditioned office buildings designed for full time human occupancy.

\subsubsection{Outside the fenced-in Areas}

All MCS components located outside the fenced-in Areas but not inside a building are subject to the ambient conditions at Hanford.

\subsection{Concept of Operations/Modes of Operations}

An example of typical HMI screens are presented in Appendix S. Also in Appendix S there is a list of screen descriptions presented in alphabetical order that describe the HMI screens purpose and operation. A "W314: HMI Menu/Screen Structure" Diagram graphically 
depicts how to navigate between the HMI screens and how the screens are inter-related. Appendix $S$ and the following provide the MCS HMI operating concept for the MCS. The HMI shall be optimally designed throughout the definitive design process to accomplish the intent of the functions below. In a short summary, the Operator/Supervisor/Technician/System Administrator must:

1. Log-on to MCS with the MENUPAGE screen.

2. Select from the Main Menu screen TOP02 the mode of operation. The different modes of operation are described below.

3. In the selected mode of operation, navigate through the screens to complete the required steps shown in figure 2 .

4. Complete Modes 1, 2, 3, and 4 in sequence.

5. Select another mode of operation or exit the HMI.

In Appendix S, a description of the typical HMI screens as well as a legend is presented.

The MCS Annunciator (WTA), which is Mode 0 described below, is the normal mode of operation for the MCS. This mode may be accessed from any other mode of operation or the Main Menu. If desired, the last HMI screen from which the WTA mode was accessed may be accessed from the WTA mode. This, in effect, would return the Operator back to his/her original point of interest after an event, such as an alarm, has occurred.

The MCS shall have a double confirmation command sequence for inputting operator control functions.

The MCS performance requirements as presented in Section 2.3 are related to the HMI screens and operating modes in the following.

\subsubsection{Mode 0 MCS Annunciator}

Any tank farm operator at any MCS HMI may observe the real-time status of the MCS. All MCS HMIs monitor all six simultaneous waste transfers utilizing the WTA set of screens located in Appendix S. The dynamic MCS parameters that are shown on graphic screens are the following:

3.2.1.1 Alarm status of all leak detectors associated with the MCS including:

- $\quad$ leak detectors directly connected to MCS PLCs.

- leak detectors connected to existing MPS System relays (which are, in turn, connected to the PLCs) where the leak detector status is manually entered into a MCS HMI after the relay has initiated a transfer route shutdown. leak detectors not connected to MCS and monitored manually in the field with its status being manually entered into a MCS HMI after every change of event.

3.2.1.2 Status of all valve positions or valve position in determinant (failure) alarms associated with the MCS including: 
- $\quad$ transfer and flush valves whose position sensors are directly connected to MCS PLCs.

- transfer, drain and flush valves whose position sensors are not connected to the MCS and are monitored manually in the field with its status being manually entered into a MCS HMI after every valve position change.

\subsubsection{3}

3.2.1.4
Alarm status of all existing MPS relays and back flow pressure switches directly connected as inputs to the MCS PLCs.

Alarm status of all existing manual pull buttons and HMI toggle switches that cause either an area or route specific pump shutdown and which are direct inputs to the MCS PLCs.

Transfer or flush pump running status as well as pump shutdown alarm status for all pumps connected as outputs to the MCS System PLCs.

Transfer or flush pump circuit breaker position status and circuit breaker closed alarm status when the pump is not selected for a transfer route for all pumps connected as outputs to the MCS PLCs.

Element selection status of all mechanical segments (such as tanks, pits, lines), pumps, valves, leak detectors, and existing MPS relays for six transfer routes.

Element functional verification status of all pump interlock relays, valve positions, leak detectors, and existing MPS relays for six transfer routes.

Alarm status of incorrect valve positions for all valves selected for one of six transfer routes.

Element bypass status of all pump interlock relays, valve positions, leak detectors, and existing MPS relays for six transfer routes.

The set of WTA graphic screens depicting the MCS are structured geographically by top, areas, tank farms, pits, and tanks. The HMI operator navigates from the upper screen down to the lower screens by selecting an element in the preceding upper screen. The order of descent from upper screen to lower screen is defined as follows: top, areas, tank farms, pits, and tanks. Each screen has a command button that will return the Operator to the top screen to start over.

Alarms shall be handled in accordance with Section 2.3.16. Alarms are generally in the lower screens which contain the most 
detailed information. The Operator is assisted in navigating to these screen by alarming the element in the upper level screens which contains the alarm. If an alarm is on a Pit screen, for instance, the Pit symbol will alarm on the tank farm screen and the tank farm symbol will alarm on the area screen and etc. The alarm is acknowledged at the Pit screen or at the lowest level screen on which it shows.

\subsubsection{Mode $1 \quad$ Select Transfer Route.}

One tank farm operator at any MCS HMI may select a source tank and destination tank for each simultaneous waste transfer. Transfers that pump from more than one tank are not allowed. Transfers that pump to more than one tank are also not allowed. Tanks for different transfer routes, however, may be the same. Two transfers may use the same tank as a source or destination. Based on this input the MCS presents a list of predetermined waste transfer routes to the Operator on the HMI. The Operator selects the route from the list and assigns it to one of six waste transfers depending on which one is available. In turn, the MCS selects all MCS inputs and outputs for the route utilizing the predetermined route selection as a basis. The Operator accomplishes the route selection by utilizing the TMS set of screens.

If no predetermined route has been created for the route source and destination originally selected, a new predetermined route must be created. Only a HMI Operators with the appropriate access are allowed to create new routes. Predetermined routes are created offline at any MCS HMIs by two methods, selection by mechanical segments and modifying an existing predetermined route.

The selection by mechanical segments method includes the use of graphic screens that are similar to the WTA set of screens where mechanical segments, such as tanks, pits, transfer lines, pumps and valves, are selected by the HMI operator and all MCS elements, such as leak detectors, valve positions sensors, existing MPS relays, and pump interlock relays, associated with the selected mechanical are selected automatically. The CBS set of graphic screens is used to accomplish the selection.

Once a predetermined route is created, operating personnel with appropriate MCS access level can retrieve, store, modify or delete the route. The modifications are accomplished to a predetermined route either by selection or de-selection of mechanical segments of the route. The modified route is then stored as a new predetermined route. The TMS, CBS, and CBE set of screens are used to accomplish the predetermined route modifications.

The predetermined route creation and all predetermined route modifications shall require independent verification.

Mode 1, Select Route, is used to perform steps 1 and 6 of a generic waste transfer as listed in Section 2.1.1. 


\subsubsection{Mode $2 \quad$ Set up Transfer Route}

Setting up a transfer route may in the future include the remote positioning of valves or starting of lube oil pumps and etc. Currently these activities are done manually; and are not in Project W-314's scope. An operating mode is provided to allow other projects, like W-211, to modify the MCS configuration.

\subsubsection{Mode $3 \quad$ Verify Transfer Route}

One tank farm operator at any MCS HMI verifies the functional operation of the MCS equipment for each particular transfer route. Mode 1, Select Transfer Route, is required to be completed prior to starting this mode. The Operator selects one of the six transfer routes on the main menu screen, TOP02. The Route Verification Summary screen is then selected. The Route Verification Summary screen presents another menu for selecting a particular MCS equipment class verification screen and also displays whether or not all the equipment in that class has been verified. After the Operator selects an equipment class verification screen, the Operator selects a single item from a list of equipment presented on that screen. The list only contains the equipment for that class that have been selected for the transfer route selected in the main menu TOP02. The Operator then initiates the functional test for the item of equipment either through remote controls or through a field test performed manually depending on the class of equipment. If the functional test is performed successfully and acknowledged by the HMI operator within a specified time period, the item of equipment is then indicated by the MCS as verified. The Operator then selects another item from the equipment list and repeats the same process until all items of equipment of that class are verified. The Operator then selects a different class of equipment and verifies all the equipment in that class and repeats this process until all equipment of all the following classes for a selected transfer route are verified. Once the above is completed, the shift supervisors administrative approval is required to complete the route verification mode of operation.

The following are the different classes of equipment that are verified:

\subsubsection{Project W-314 Leak Detectors}

Project W-314 Leak Detectors are directly connected to the MCS PLCs. Both leak detection and leak detection relay malfunction are verified per the logic diagram, "Route No. 1 Leak Detector Operation Verification Mode Logic", Fig. 15, Appendix D, utilizing the SFV set of screens. This verification mode is used to perform step .19 of a generic waste transfer as listed in Section 2.1.1.

\subsubsection{Existing MPS System Leak Detectors}

Existing MPS System Leak Detectors are connected to the existing MPS System relays which are directly connected to the MCS PLCs. Both leak detection and leak detection relay 
malfunction, if applicable, are verified per the logic diagram, "Route No. 1 Existing Leak Detector Operation Verification Mode Logic", Fig. 20, Appendix D, utilizing the SFV set of screens. This verification mode is used to perform step .21 of a generic waste transfer as listed in Section 2.1.1.

Manual Leak Detectors are not connected to the existing MPS System relays or the MCS PLCs. Both leak detection and leak detection relay malfunction, if applicable, are verified utilizing the MLD set of screens. This verification mode is used to perform step .20 of a generic waste transfer as listed in Section 2.1.1.

3.2.4.4 Existing MPS System Relays \& Cross-site Transfer System Interposing Relays

Existing MPS System Relays, Cross-site Transfer System Interposing Relays and back flow pressure switches are connected to the MCS PLCs. The relay and pressure switch inputs are verified per the logic diagram, "Route No. 1 Relay Input Operation Verification Mode Logic", Fig. 14, Appendix D, utilizing the SFV set of screens. This verification mode is used to perform step . $14 \mathrm{~b}$ and .17 of a generic waste transfer as listed in Section 2.1.1.

Transfer Pump Interlock Relays and Cross-site Transfer System Interlock Relays are connected as outputs from the MCS PLCs. The relay output is verified per the logic diagram, "Route No. 1 Transfer Pump Interlock Operation Verification Mode Logic", Fig. 16, Appendix D, utilizing the SFV set of screens. This verification mode is used to perform step .16 of a generic waste transfer as listed in Section 2.1.1.

Project W-314 Valve Position Sensors are connected to the MCS PLCs. The valve positions are verified per the logic diagram, "Valve Position Verification Mode Logic", Fig. 17, Appendix D, utilizing the VPV set of screens. This verification mode is used to perform step . 10 of a generic waste transfer as listed in Section 2.1.1.

3.2.4.7 Manual Valve Positions

Manual Valve Positions are for transfer valves not connected to 
the MCS PLCs. The valve positions are verified utilizing the MPV set of screens. This verification mode is used to perform step .11 of a generic waste transfer as listed in Section 2.1.1.

\section{MCS PLCs}

MCS inputs and outputs are used to verify the MPS PLCs. The MCS PLCs are verified per the logic diagram, "Route No. 1 PLC Operation Verification Mode Logic", Fig. 18, Appendix D, utilizing screens that are TBD. This verification mode is used to perform step: . 15 of a generic waste transfer as listed in Section 2.1.1. and requires that the equipment providing the PLC input and outputs are previously verified.

\subsubsection{Mode $1 \quad$ Monitor Transfer/Flush}

Any tank farm operator at any MCS HMI can monitor the realtime status of the MCS utilizing the WTA mode of operation (Mode 0 ) described above. This operation is used to perform steps $.27, .29$ and .30 of a generic waste transfer as listed in Section 2.1.1. In addition to monitoring the automatic master pump shutdowns, the Operator may be required to manually shutdown one of six routes if any of the following events occur.

Manual Leak Detection

When a field Operator stationed at a leak detector that is not connected to the MCS alerts a control room Operator located at the 241-AZ-271 building that there is a leak, the control room Operator will shutdown that route by pulling a route specific pull switch located near the MCS HMI. Otherwise, if the alerted Operator is located at any of the MCS HMIs, the Operator, utilizing the WTA HMI screens, will shutdown the specific transfer route that the leak detector is associated with. After the shutdown, the control room operator will enter the leak detector state change into the HMI to communicate and document the cause of the route shutdown.

\section{Incorrect Valve Position Detection}

When a field Operator reports that a valve, which is not connected to the MCS, is in an incorrect position during a transfer, the control room Operator will shutdown that route in the same manner described in the preceding Section 3.2.5.1.

\subsubsection{Misrouting Detection}

When a HMI Operator determines that there is a waste transfer misrouting, the control room Operator may shutdown that route in the same manner described in the preceding Section 3.2.5.1 
above. This operation is used to perform step .28 of a generic waste transfer as listed in Section 2.1.1.

After completing a transfer or flush, the final step of the waste transfer process, step .33, is resetting the Waste Transfer route which de-selects all inputs and outputs associated with that route allowing the route to be reconfigured for a different transfer or flush. An Operator at any HMI accomplishes this utilizing HMI screens.

\subsection{Constraints and Boundary Condition}

3.3.1 The MCS HMI shall be able to be operated by color blind operators.

3.3.2 Project W-314 HMIs shall integrate seamlessly with Projects W-211 and W-521 HMIs. HMI screen symbology, legends and color coding shall be identical for each project to enable the same operators to operate each projects HMI.

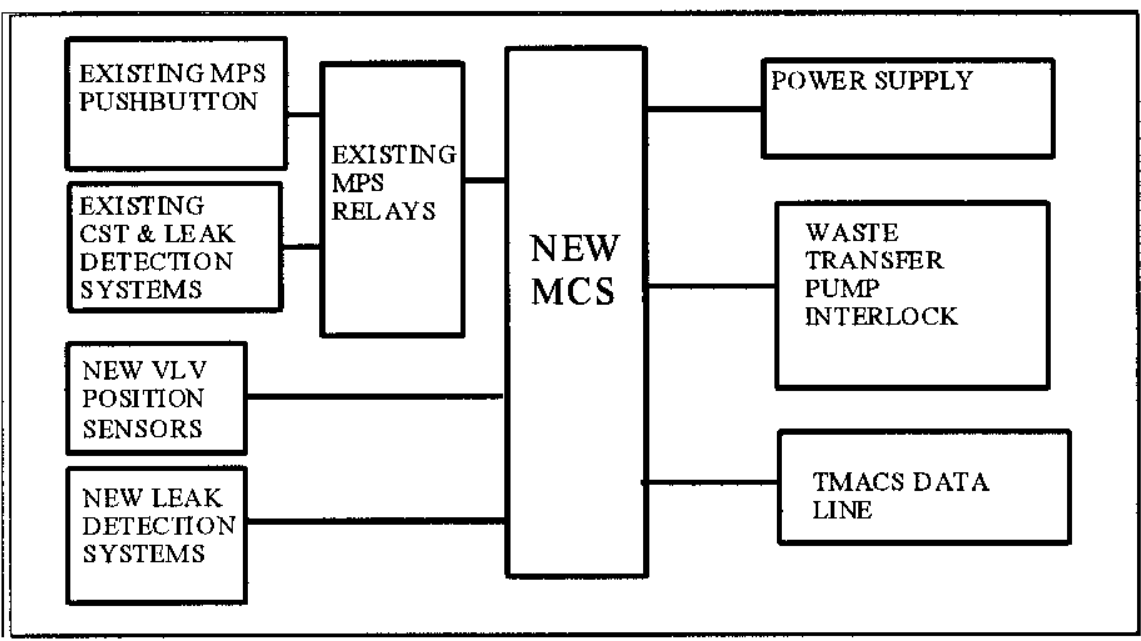

Figure 7 "MCS MAJOR SYSTEM INTERFACES"

Figure 7 illustrates the major system interfaces to the MCS System. The Project W-314 "Project Interface Control Document (PICD) for Project W-314", describes in detail the MCS System interfaces.

3.3.3 All MCS functions identified, as safety class shall require no operator actions or interventions. The function shall be fully automatic requiring no operator input.

$3.4 \quad$ Interfaces

\subsection{Operational Support Equipment}

The operational support equipment is listed in the following:

3.5.1 Workstation furniture to support HMI compatible with existing furniture located 
in the Instrument buildings and shift offices.

3.5.1 Mouse, 21" video display minimum, keyboard to support Operator manipulation of the HMIs.

3.5.3 Voice communication between all HMls through the use of the existing onsite telephone system.

3.5.4 The TFLAN communication media shall be capable of supporting closed circuit television (CCTV) signals and voice transmission signals.

\subsection{Critical Issues \& Technologies}

3.6.1 The results of a Human Factors Engineering Evaluation and Verification Study will have an impact on the project design concept.

\subsection{SUPPORT CONCEPT DESCRIPTION}

\subsection{Support Environment}

The support environment is existing onsite maintenance and procurement organizations which currently serves the Hanford Tank Farms. Existing Hanford shops, labs, warehouses are to be utilized to support the MCS. No new maintenance buildings are planned.

\subsection{Concept of Support}

\subsubsection{Electrical Maintenance}

Electrical maintenance is to be performed by qualified electricians and/or instrument technicians. Their responsibilities include MCS wiring. Wiring materials are readily available from commercial suppliers in bulk quantities.

\subsubsection{Electronics Maintenance}

MCS electronics are to be modular and plug-in to facilitate repairs by replacing failed parts with uninstalled plug-in spares that are stored onsite.

Electronic Maintenance is to be performed by certified onsite Instrument/computer technicians. If the maintenance requires an effort greater than parts replacement, the maintenance is to be performed by the offsite MCS supplier. A HMI shall be provided to give notification of PLC status via TFLAN.

\subsubsection{Software Testing and Maintenance}

A MCS System operator training system (described in Section 5.3) and test bed will assist programmers in the updating of MCS software, maintaining software configuration validation, and the diagnosing and remediation of software bugs. The test bed portion shall allow a user to:

- Implement HMI changes per Software Quality Assurance Plan (SQAP) 


\author{
procedures. \\ - Implement PLC logic program changes per SQAP. \\ - Implement database and $\mathrm{O} / \mathrm{S}$ changes per SQAP. \\ - Perform testing and other verification and validation activities. \\ - Perform reporting of all activities including testing and maintenance \\ w/audit log showing usage.
}

The test bed shall be able to generate input signals to simulate any and all input points on the MCS, and it shall be able to monitor and record all output signals generated. The test bed shall be programmable via database. The test bed can also receive manual input signals from the training system instructor station. All MCS programming shall be developed and tested offline so as to not affect tank farm operations by utilizing the test bed.

Software maintenance is to be performed by qualified Systems Administrators and/or System Integrators.

\title{
4.2.4 MCS Network Maintenance
}

MCS network maintenance which includes the TFLAN network and the TMACS interface is to be performed by onsite telecommunications technicians. Spare cable materials are to be stored onsite.

\subsection{Constraints and Boundary Conditions}

4.3.1 There are onsite Union agreements that allocate maintenance work among the trade unions.

\subsubsection{Concept of Maintenance}

4.3.2.1 Alarm rates of the MCS shall have an alarm rate time to satisfy the human factors requirements for a human-machine interface.

4.3.2.2 Response Times of the MCS shall be less than or equal to the human factor requirements for a human-machine interface.

4.3.2.3 Not Used.

4.3.2.4 Mean-Time-to-Repair of the MCS shall be less than or equal to 4 hours.

4.3.2.5 The MCS shall perform self diagnostics and shall prevent any waste transfers from occurring if an equipment malfunction is detected. The initiating self diagnostics are manufacturer specific and depend on the design of the electronic components of the MCS. As a minimum, however, each digital or analog output module shall produce a specific output signal, that is configurable, when a system failure is detected by the output module. The output signal shall be configurable as high, low, hold last value, or a specific value within the range of the output signal. 
$4.4 \quad$ Interfaces

Not applicable.

4.5 Maintenance Support Equipment

The maintenance support equipment, facilities, and resources except for the following new diagnostic equipment:

4.5.1 MCS Operator Trainer provides an offline example of all the components of the MCS. This will provide rapid initial training for maintenance workers.

4.6 Critical Issues \& Technologies

Not applicable.

\subsection{TRAINING CONCEPT DESCRIPTION}

The training concept for the MCS is the following:

5.1 New Tank Farm operating procedures shall be prepared to cover new equipment. The specific list of new procedures shall be prepared when the design is defined enough to do so. Procedure writing personnel may access the test bed described in 4.2 .3 for access to all system functions.

5.2 Existing Tank Farm operating procedures shall be modified to cover changes to the existing MPS System. The specific list of procedure modifications shall be prepared when the design is defined enough to do so.

5.3 Provide on-the-job training utilizing an MCS Training System (MTS) as described below and close personal supervision during the initial introduction of a new operator to the MCS.

\subsubsection{MTS General Requirements}

5.3.1.1 The MTS shall be off line, independent and duplicative of the MCS.

5.3.1.2 The MTS shall be portable. The MTS's environment shall be indoors.

5.3.1.3 The MTS shall consists of multiple Human-Machine Interface (HMI) desk-top PC's: operator stations and at least one instructor station. PLCs and I/O, reflecting the current MCS design, will be mounted in Nema 12 enclosures. The HMIs and the PLCs are networked together via a separate Ethernet hub. (not TFLAN)

5.3.1.4 The MTS operator stations shall provide the same human 
machine interface as an actual MCS operator station as described in Section 3.0. The MTS PLCs shall run identical logic as described in Section 3.0.

5.3 .1 .5

Generic $\mathrm{I} / \mathrm{O}$ with controlling CPU, mirroring the $\mathrm{I} / \mathrm{O}$ of the $\mathrm{MCS}$, collectively referred to as SIMCART, are cable connected to the PLC equipment.

5.3 .1 .6

The Instructor's station shall have the capability of running training scenarios from a database that will simulate each of the field inputs to the MCS and monitor each of the MCS outputs, for a given scenario. Responses may be recorded to assist training.

5.3.1.7 In addition to all of the operations functionality provided by the MCS hardware and software, the MTS shall provide a sample of each MCS field device for maintenance personnel training and software development purposes. These field devices shall include a single leak detector system with a relay panel and sensors and two MCS interlock relays. The leak detector sensors shall be mounted in a container to which water can be added for simulating a leak.

\subsubsection{MTS PLC Requirements}

There are duplicate MTS PLCs of the MCS mounted in multiple NEMA 12 enclosures with window in the door to display the I/O module status LED's. Each PLC will have appropriate equipment manufacturer and model numbers including I/O racks and modules. Each PLC will have an Ethernet communications module, which will allow the controller cards to talk directly to the HMIs. The PLCs shall also be wired to SIMCART (Section 5.3.1.5) and directly to each other through the I/O modules in order to simulate the field hard-wired shutdown PLC-PLC link. A PLC panel will also house the auxiliary devices such as the Manual Shutdown Switches, the Ethernet hub and the 24VDC power supply.

\subsubsection{MTS HMI Requirements}

There are multiple MTS HMIs: including operator stations and an instructor station. The operator station HMIs will be display clients and the instructor station will be a full license I/O server. The MTS instructor station communicates with the I/O server, which in turn communicates with the SIMCART for direct monitoring and control of the MCS via, input stimulation. The operator display clients exert monitoring and control of the MCS via the I/O server. The operator display clients will have the same screens and functionality as the MCS HMIs.

\subsubsection{MTS Simulation Requirements}

The operator HMIs will be used to select routes via the three methods of selecting a transfer: selecting a predetermined route, create the transfer by segment and create the transfer by PLC I/O element. Once this is done the instructor will be 
able to simulate various field conditions by initiating databases that run to control the SIMCART per training scenarios. The instructor station will act as the field in reference to the MCS. In this way, an instructor shall be able to control or manipulate each individual input to the MCS per a scenario. For manual operations, which are the majority of operations, the instructor shall act as the field operator by positioning valves, performing verifications, etc. Simulation will also include the automatic stopping of the appropriate transfer pump when leaks are detected or other shutdown conditions occur.

\subsubsection{MTS Integration Requirements}

The MTS HMIs and the MTS PLCs are networked together on an Ethernet LAN as separate nodes. This requires the setup of the Ethernet hub with the hardware address for each of the nodes. Once this is done, it will allow the instructor station HMI acting as the database server to directly monitor and control the PLCs via the SIMCART. The MTS HMIs will then be able to access the MTS PLC data via the LAN.

\section{$5.4 \quad$ MTS CD-ROM Based Trainer}

A CD based version of the MTS shall be provided. The CD-ROM shall contain the HMI screens of the MCS. A CD based simulation engine will serve I/O data similar to the SIMCART in Section 5.3.1.5. Users may take a "tour" of the MCS (nonsimulation mode) or run a transfer simulation. The scenarios will be limited due to size and model contraints but shall allow non-day to day users to familiarize themselves with the overall MCS.

\subsection{DEVELOPMENT CONCEPT DESCRIPTION}

The following describes the two phases of Project W-314 and the capabilities and configuration the new MPS System will have at the end of each phase.

\subsection{Phase 1 Description}

At the end of phase 1, the MCS will be able to perform in accordance with the following:

- Existing leak detection devices remain in operation providing local indication of a leak and provide inputs to the MCS via existing "ganged" relays.

- $\quad$ Each new leak detection system installed by W-314 will provide a separate and identifiable input to the MCS.

- $\quad$ Each new leak detection system and the existing MPS relay inputs are indicated as alarms on the MCS tank farm HMI.

- $\quad$ Each new individual leak detection system and the existing MPS relay inputs may be enabled or disabled (In Service or Out of Service states) at the MCS tank farm HMIs prior to or "Bypassed" during a waste transfer.

Each input to the MCS will be selectable for six simultaneous waste transfers. Note this allows all MCS inputs for a tank farm that are not participating in a 
particular waste transfer to be disconnected from that waste transfer.

- $\quad$ Each MCS input from one tank farm shall provide input to other tank farms by means of the TFLAN communications network. Through this method, each new individual leak detection system and existing MPS relay inputs are each indicated as alarms on all the tank farm HMIs.

- Transfer pump shutdown signals for each separate transfer (six total) are transmitted from PLC-to-PLC. This allows a waste transfer to continue if a MCS HMI or the TFLAN fails during a transfer.

- Outputs from the MCS at each Tank Farm open the individual MCC contactor for each of the Tank Farms transfer pumps. Providing that only one of the shutdown signals for the six simultaneous routes is initiated, this event stops all waste transfer pumps that are connected to that particular waste transfer shutdown signal. The connection between the MCS outputs and each of the shutdown signals is done through the route selection process.

- $\quad$ Each existing MPS relay input, leak detector input, and output to MCC are remotely verified from the HMIs. This reduces the number of farm entries required to perform a waste transfer.

- The new MCS will have a communications link with TMACS. This link will allow TMACS to have access to any and all data available from the MCS .

6.2 Phase 2 Description

During Phase 2, additional new leak detection systems, DST vapor space pressure and tank ventilation systems will be installed, replacing existing systems. Each of these new systems will be added to the MCS as individual inputs. At the end of Phase 2, the capability for the selection of transfer routes will be the same as in Phase 1 with additional flexibility because of the additional individual inputs.

Existing MPS relay inputs not replaced by W-314 will continue to be inputted into the MPS as a single Existing MPS "ganged" input. Those existing MPS relays that are not used will be disconnected and demolished. Any tank monitoring systems and tank ventilation systems that are not replaced by W-314 will not be connected to the MCS installed by W-314.

\subsection{MANUFACTURING CONCEPT DESCRIPTION}

MCS equipment is readily available from commercial suppliers. No special manufacturing processes are required. However, the SIMCART is proprietary technology available only from Fluor Federal Services, Richland, WA.

\subsection{VERIFICATION CONCEPT DESCRIPTION}

The verification of the MCS is accomplished at various stages during Phase 1 of the project. The following sequence describes the verification that will take place: 
Phase 1 Design:

1) The HMI screens and PLC logic will be tested as part of the Operator Trainer. This testing will include verifying that the required shutdown signals are initiated for all possible inputs.

2) A MCS System Human Factors Engineering Evaluation shall be performed. Any changes that are required will be implemented prior to the end of design.

Phase 1 Construction:

1) Prior to installation in the field, all the PLCs/HMIs will be connected together to ensure they are integrated correctly and the appropriate information is displayed on the HMIs. A sampling of shutdown signals will be initiated to verify the system works correctly. This test is considered as the MCS Mock-up and will also be considered as the Acceptance Test Procedure (ATP) for the PLCs, PLC I/O, HMIs, PLC-to-HMI communication and HMI-toHMI communication. SIMCART technology using test databases (as opposed to training databases see Section 5.3.1.5) will be used to run test cases on the overall mockeup.

2) Prior to any connection of a HMI or PLC to the HMI network, an ATP for the HMI-toHMI network shall be performed. This will test all TFLAN components at an early point during construction.

3) Perform an ATP at the completion of construction at each DST and MCS PLC/HMI location. This ATP will include testing all the: PLC field terminals including cordset wiring to external device wiring; external devices such as leak detectors, valve position switches and manual shutdown pull buttons; and any existing MCS functions associated with the newly installed external devices .

4) Perform an OTP at the completion of construction at all the MCS PLC/HMI locations after HMIs, plug-in PLC cards, cordsets and system interconnections are installed. This OTP will test the whole MPS System together.

\subsection{INSTALLATION AND START-UP DESCRIPTION}

9.1 Installation and Start-up Environment

9.1.1 Permits shall be required for all excavations.

9.1.2 Tank farms shall be available for operation at all times during construction.

9.1.3 Tank farm accessibility to Operations shall be maintained at all times during construction.

9.1.4 Drawing configuration control shall be maintained in accordance with RPP-PRO224, Rev 0, "Document Control Program Standards".

$9.2 \quad$ Installation and Start-up Sequence

The following activities and their approximate sequence provide the logic of the MCS 
installation and start-up.

\subsubsection{Pre-construction Sequence}

1) MCS hardware and software procurement for Operator Trainer.

2) Utilizing the Operator Trainer as a platform, develop the HMI and control system for the MCS.

3) Onsite MCS Operator Trainer system test for configuration and Project Design Specification (PDS) verification.

4) MCS Phase 1 Construction specification and drawings are issued for construction.

\subsubsection{Phase 1 Construction Sequence}

1) MCS hardware and software procurement.

2) Set up MCS operator training system and train operators.

3) Phase 1 MCS onsite Mock-up Acceptance Test after material delivery.

4) Install all HMI and PLC enclosures.

5) Install conduit and wire connecting PLCs to existing relays, alarm horn, manual MPS pull switches, and 120 volt power. Those tank farm PLCs that do not receive inputs from devices located in modified Pits will only have the farm/area Existing MPS relay signal inputs. There will be no other inputs to connect to those PLCs until W-314 Phase 2 construction starts in that area or farm.

6) Install MCS field hardware (I/O boxes, terminal boxes, leak detectors, etc. including wiring) at those locations requiring valve pit modification needed to support new/upgraded waste transfer capability.

New valve pit instrumentation will be connected to the terminal box as it is installed.

7) From each MCS PLC enclosure new conduits and wire will be field installed to a terminal box which is located near the modified valve pit.

8) Add new MCS relay outputs such that each transfer pump can be individually controlled and functionally test transfer pump interlocks. Interlocks will be temporarily jumpered during the MCS construction period allowing only the existing MPS System to operate for transfers that occur during this period.

9) Tie the multiple MCS PLCs together using the PLC-to-PLC shutdown loop. 
10) Install TFLAN with TMACS communication interfaces interconnecting the HMIs, PLCs, \& TMACS .

11) Break existing MPS tank farm/area relay wiring and connect inputs to the MCS. This two wire connection will cover all existing leak detectors connected serially in the farm.

12) Demolish and dispose of the above ground abandoned existing MPS relays, conduit, wire and leak detectors panels.

13) Field verify Project W-314 drawings.

14) Modify Project W-314 drawings to As-Built status.

9.2.3 Phase 2 Construction Sequence for each tank farm/area:

1) Phase 2 Construction specification and drawings for each tank farm/area are issued for construction.

2) All terminal boxes and interconnecting conduits and cables to the PLCs are installed. Phase 2 program configurations are entered into the PLCs and HMIs. Terminal box wiring and all new external devices are functionally tested and Phase 2 MCS configuration is verified. Note that at this point in the sequence, unconnected Existing MPS inputs are placed in the "Out of Service" state.

3) Each existing leak detector in W-314's scope is replaced and connected to a terminal box as waste storage, route verification, waste transfer and Primary Ventilation instrumentation in a tank farm are also replaced and/or connected. Note that at this point in the sequence, the new connected MCS inputs are placed in the "In Service" state.

4) As the individual inputs to the existing MPS roll up relay in Phase 1 are cut over to the MCS in step 3) they are connected to the new PLC system and functionally tested. The majority of MPS inputs are now individually addressable from any HMI.

5) At Phase 2 completion the MCS configuration is functionally tested.

6) Demolish the existing MPS System.

\subsection{SYSTEM DECONTAMINATION AND DECOMMISSIONING (D\&D)}

It is not planned or anticipated that the MCS will become contaminated since the components reside outside the waste tanks and transfer pits. The MCS is not supposed to come into contact with the waste. Therefore, no special D\&D is required and only normal disposal practices for electronic equipment are anticipated. 
RPP-6303

Rev. 0

\section{APPENDIX A}

DRAWING B-221,

MASTER PUMP SHUTDDOWN PHASE 1

CONFIGURATION AT START OF ACCEPTANCE TESTING 
RPP-6303

Rev. 0

\section{APPENDIX A \\ MASTER PUMP SHUTDOWN \\ PHASE 1 CONFIGURATION AT START OF ACCEPTANCE TESTING}

\section{INTRODUCTION}

The following figures illustrate the planned MPS System Configuration at the start of W-314 Phase 1 Acceptance Testing. They were derived from a CHG Drawing B-221, Rev. A, such that the drawing would fit within the PDC document. The drawing showed the breakdown of scope between Projects W-314, W-211, W-521 and the existing facility differing by colors. The following figures are presented in black and white since colors are not required to illustrate design concept. The legend is on Sheet A-3. 


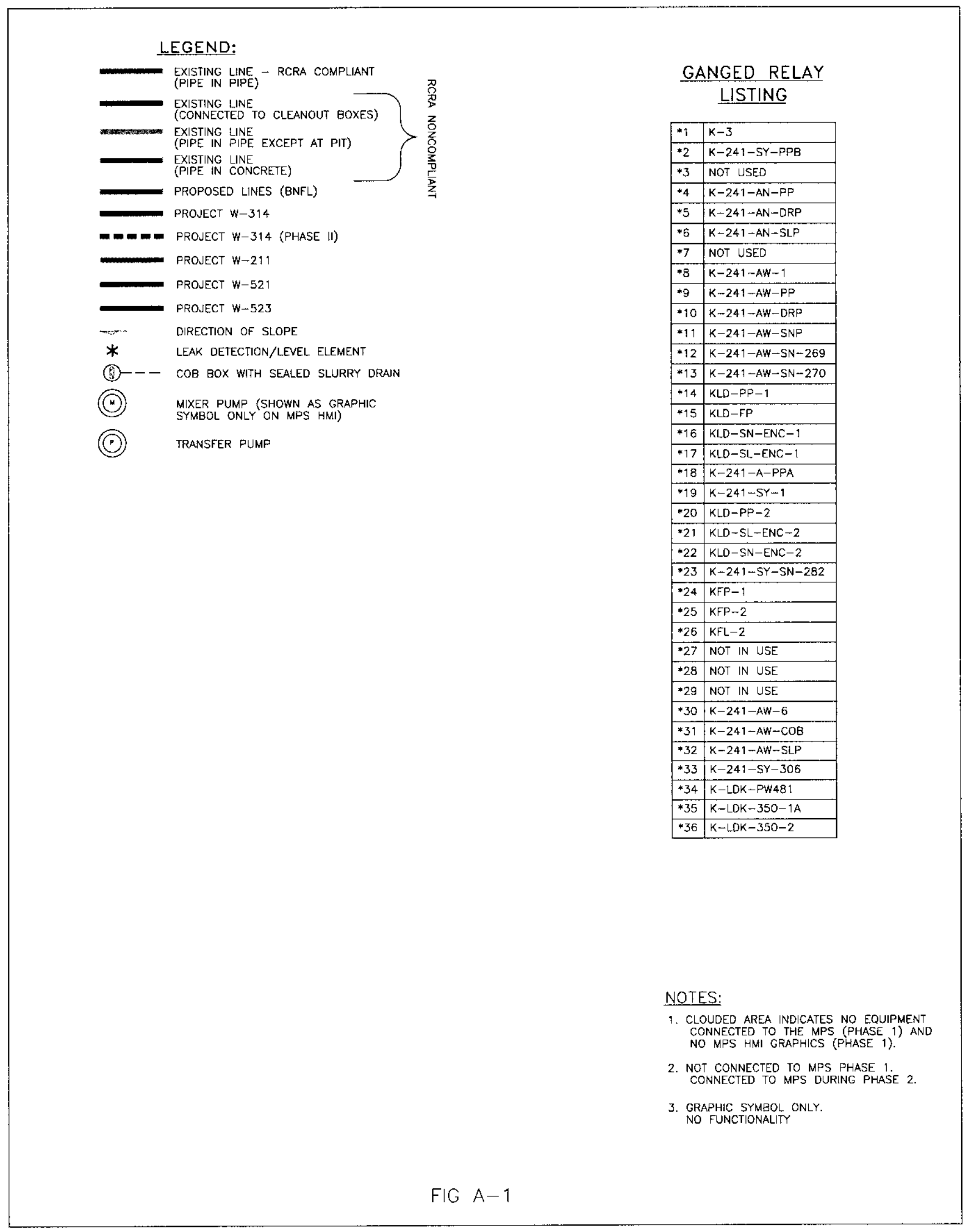




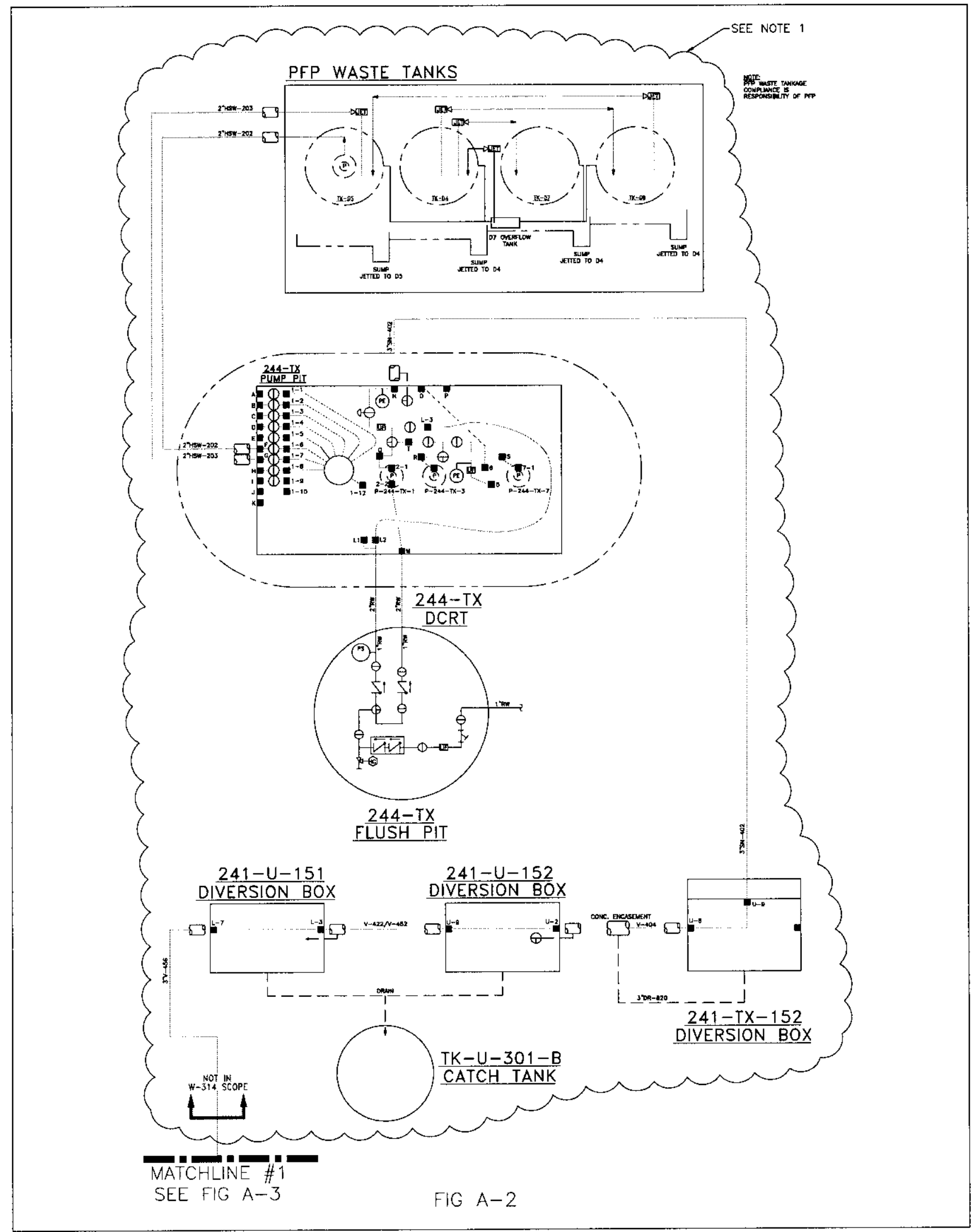


MATCHLINE \#1

SEE $F \mid G \quad A-2$

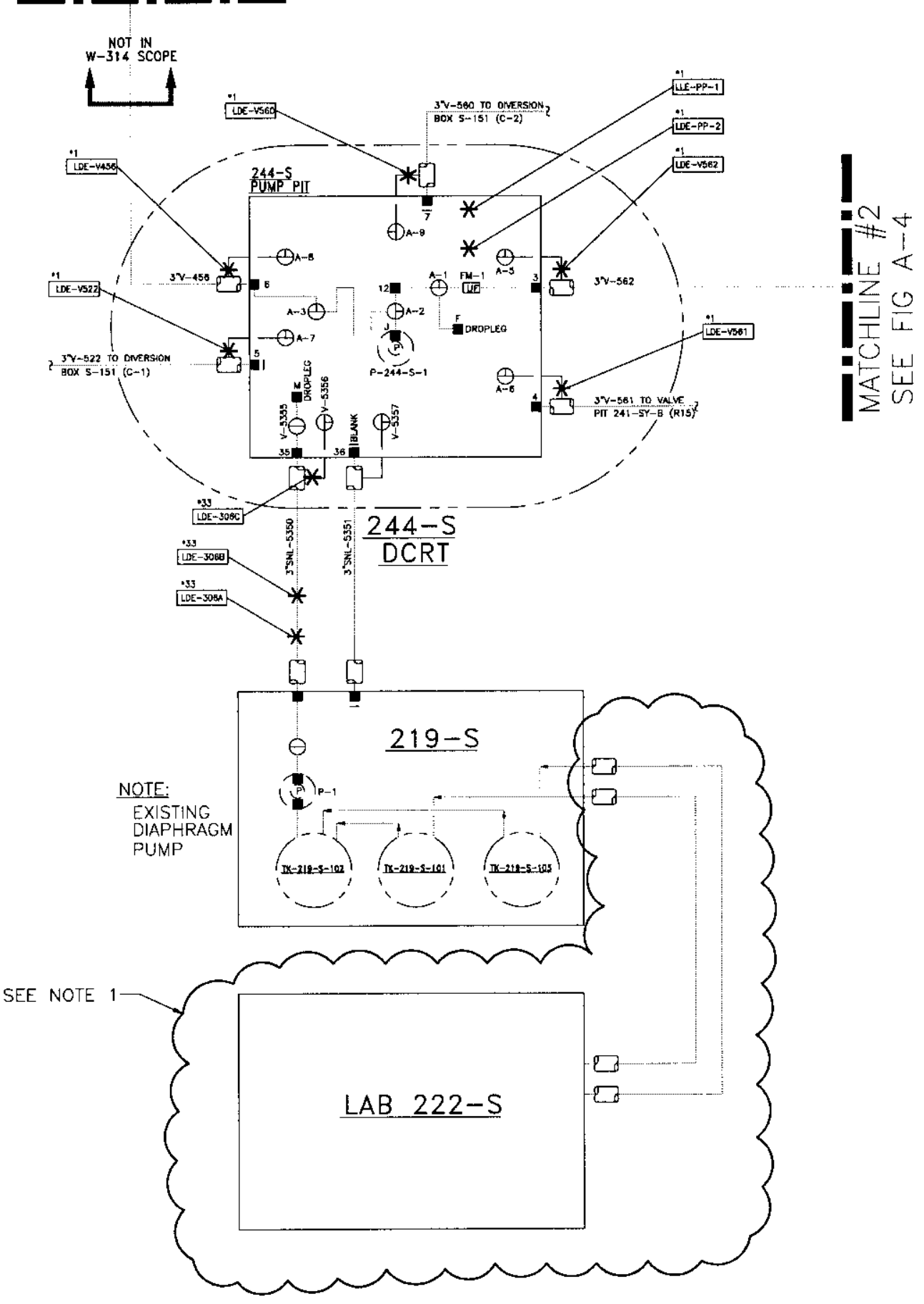

FIG $A-3$ 


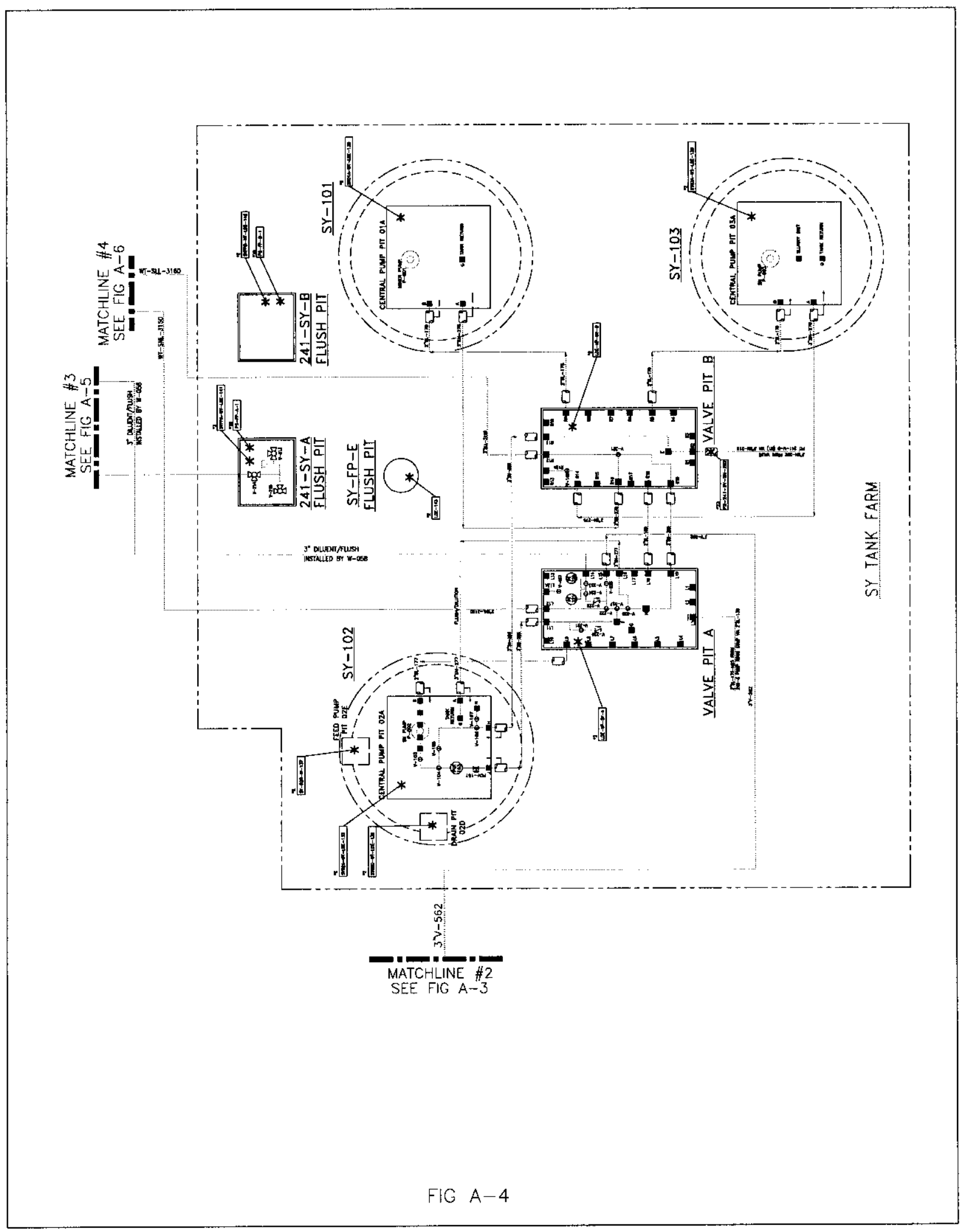




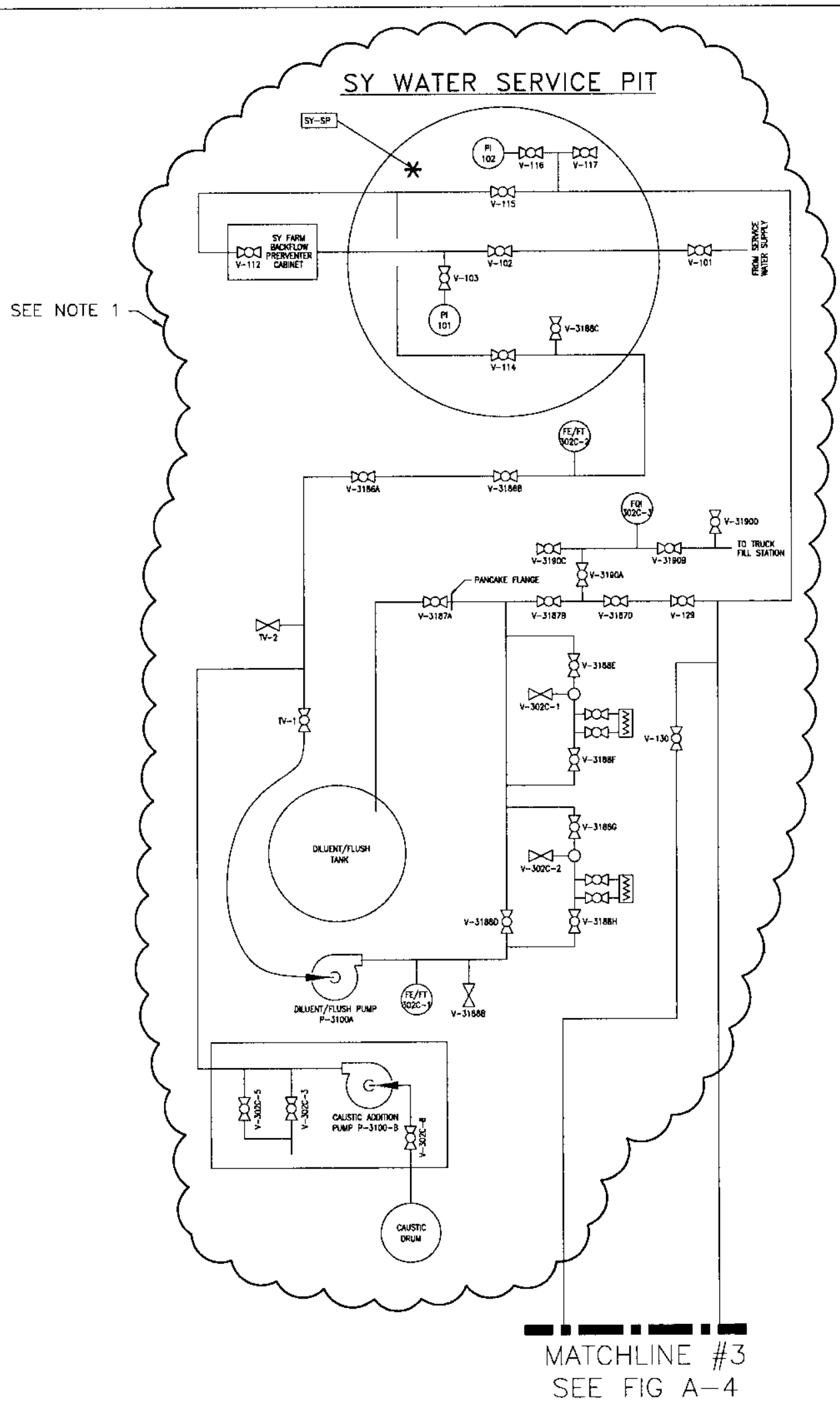

FIG $A-5$ 


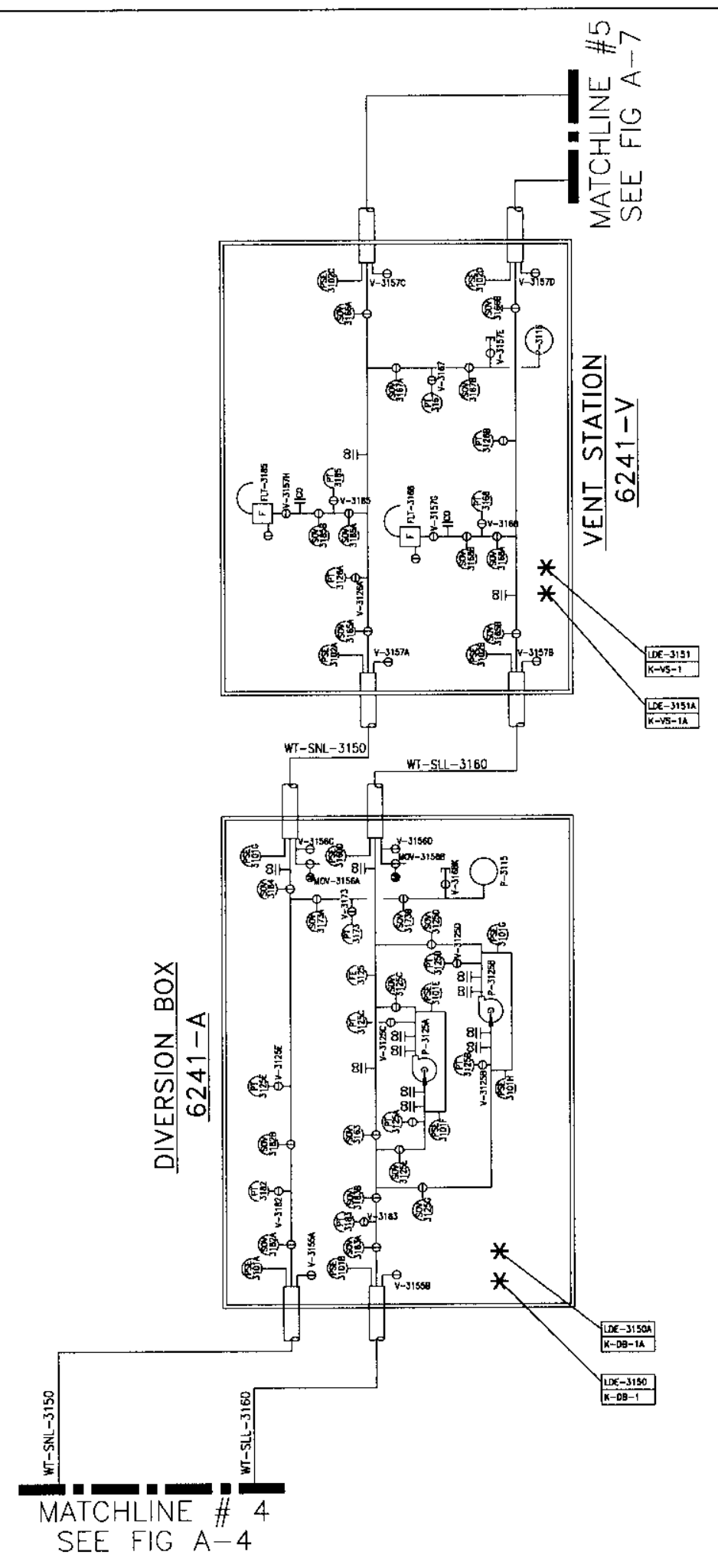

FIG A-6 


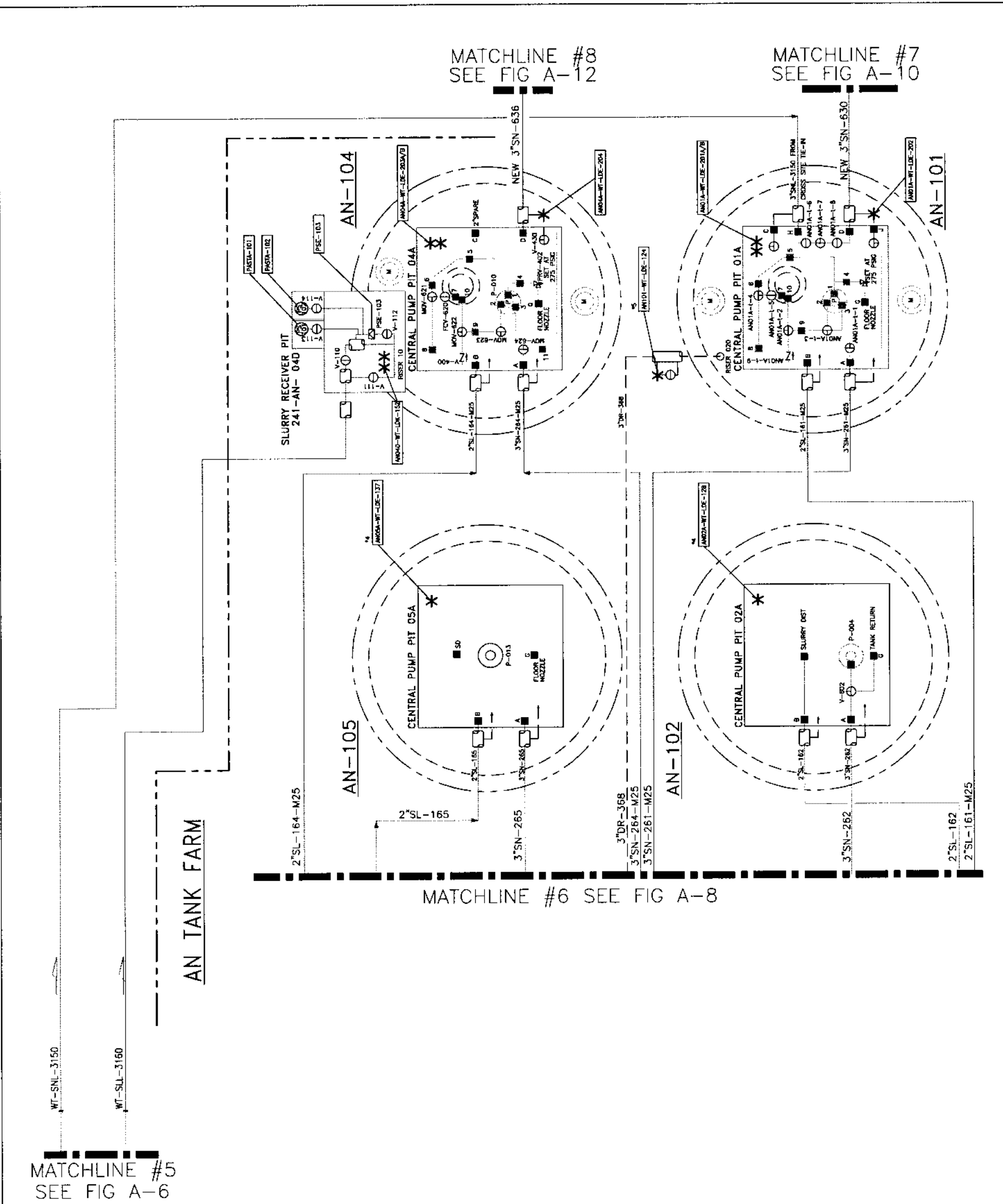

FIG $\mathrm{A}-7$ 


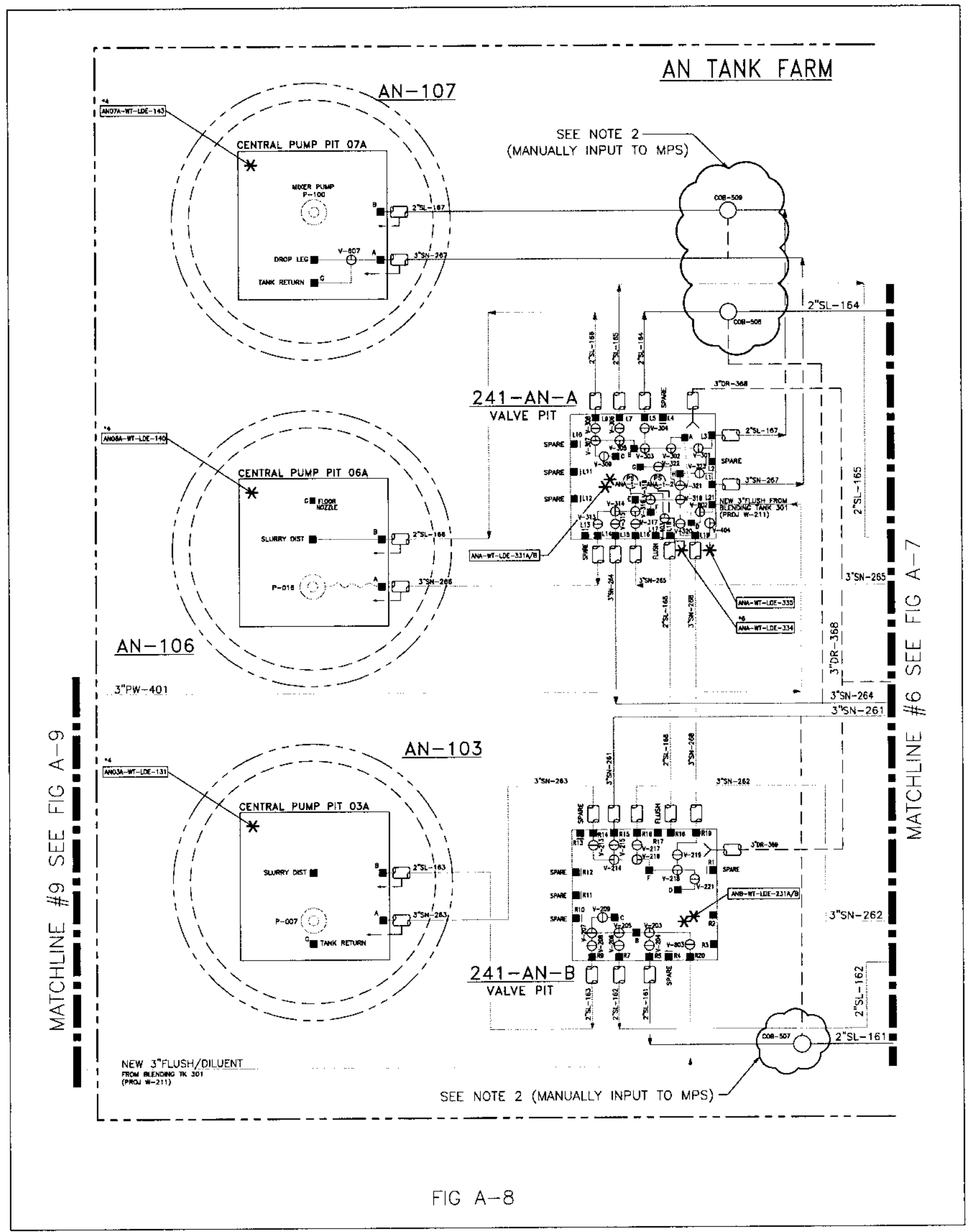


RPP-6303

Rev. 0

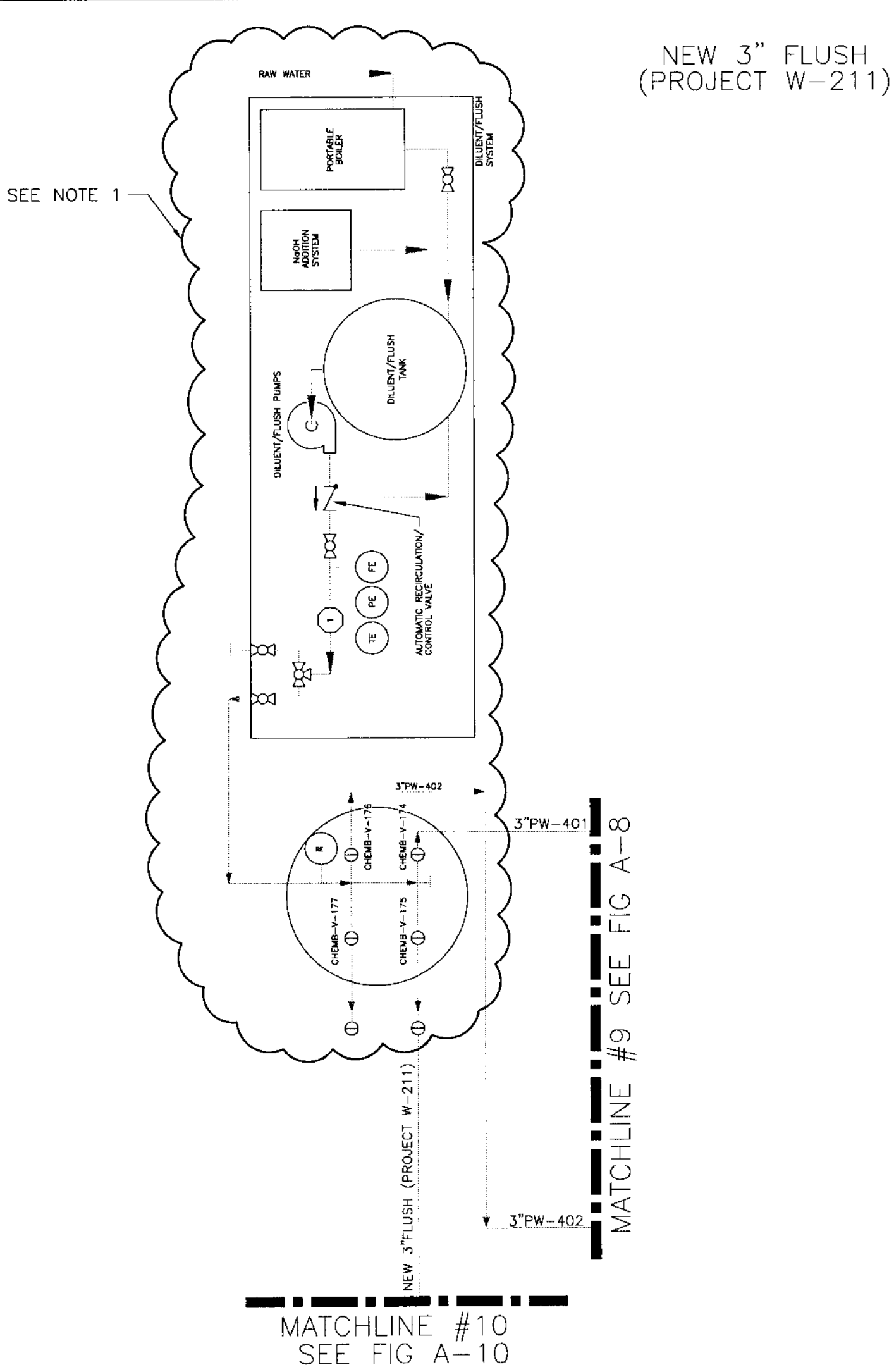

FIG $A-9$ 


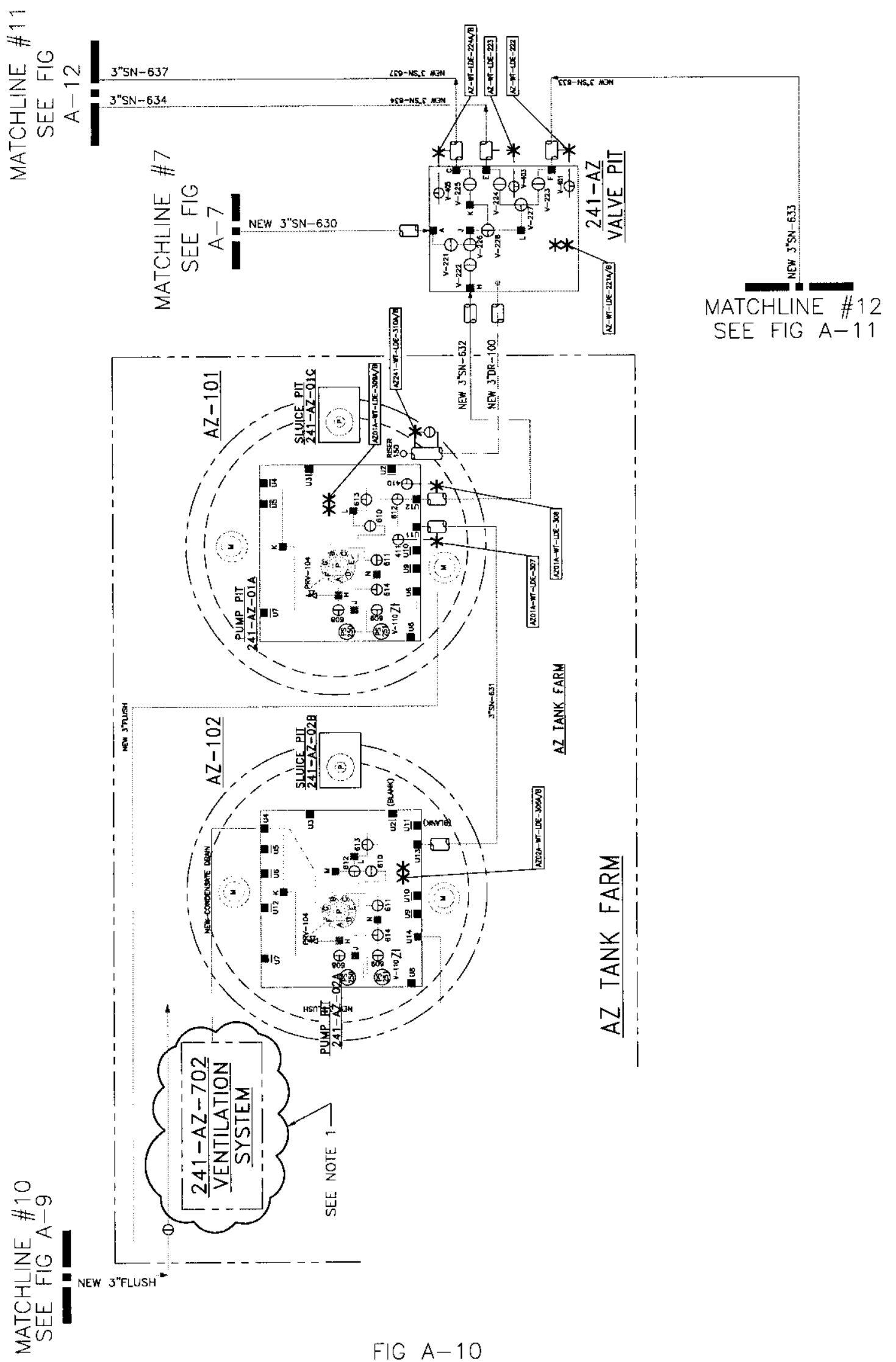




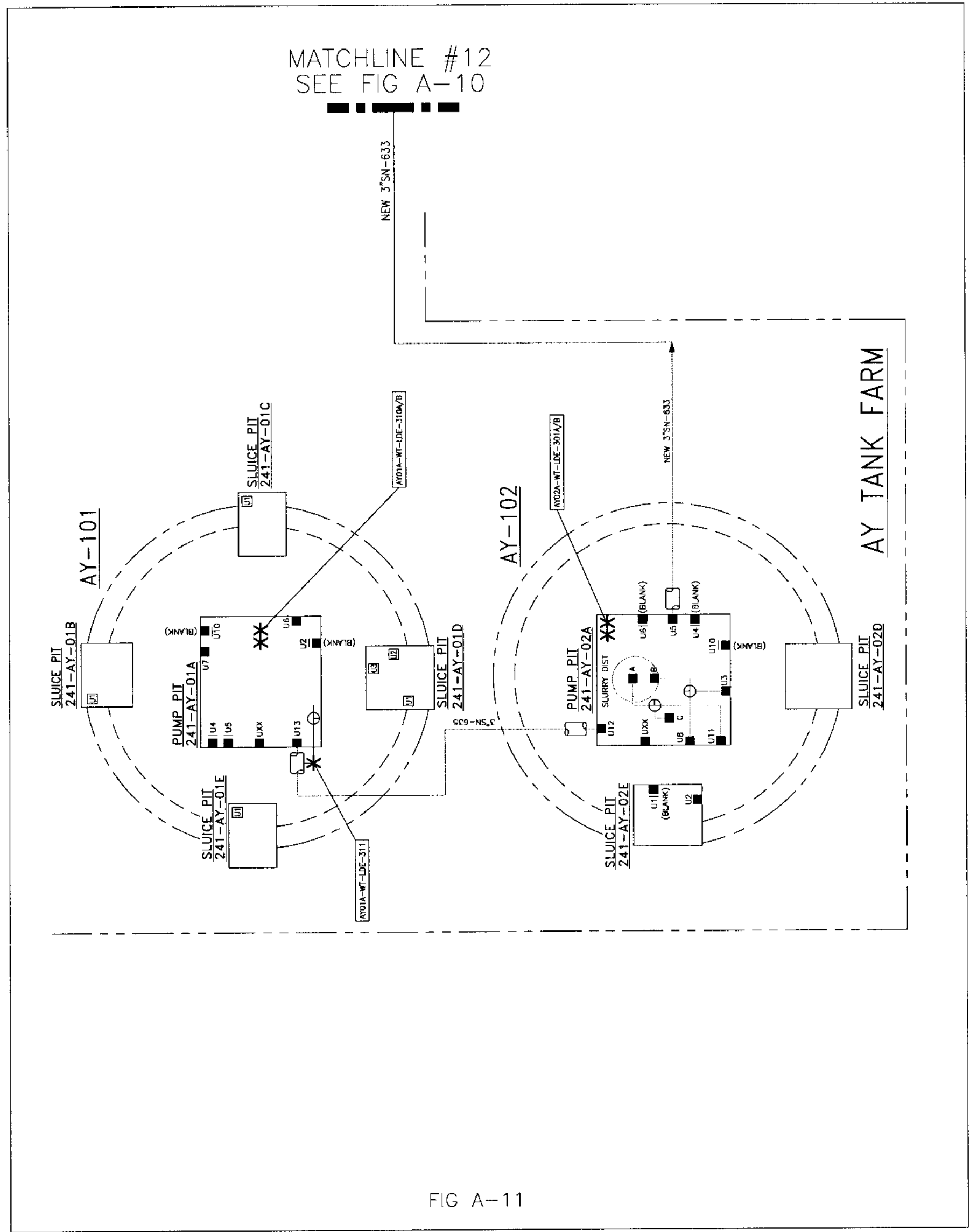




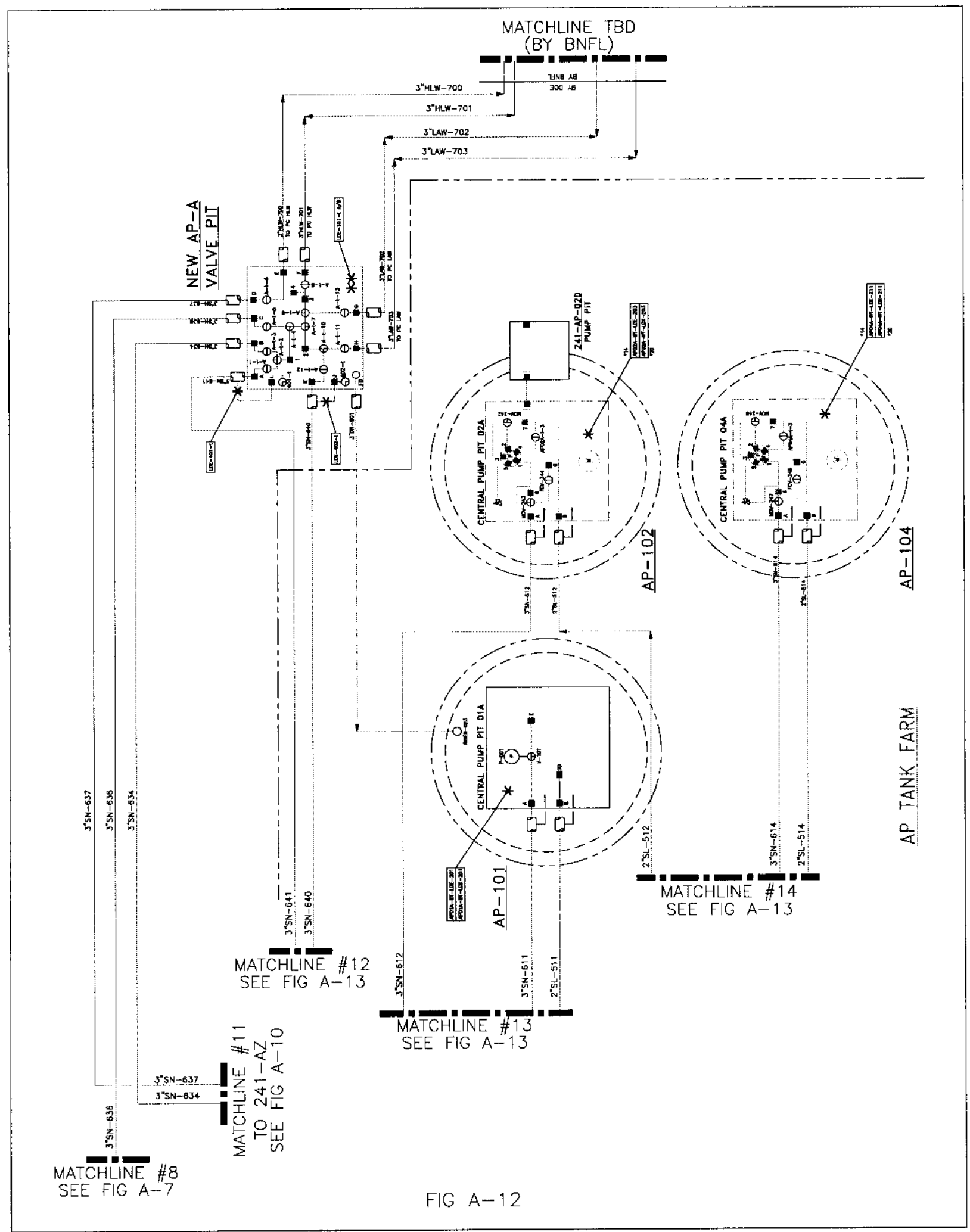




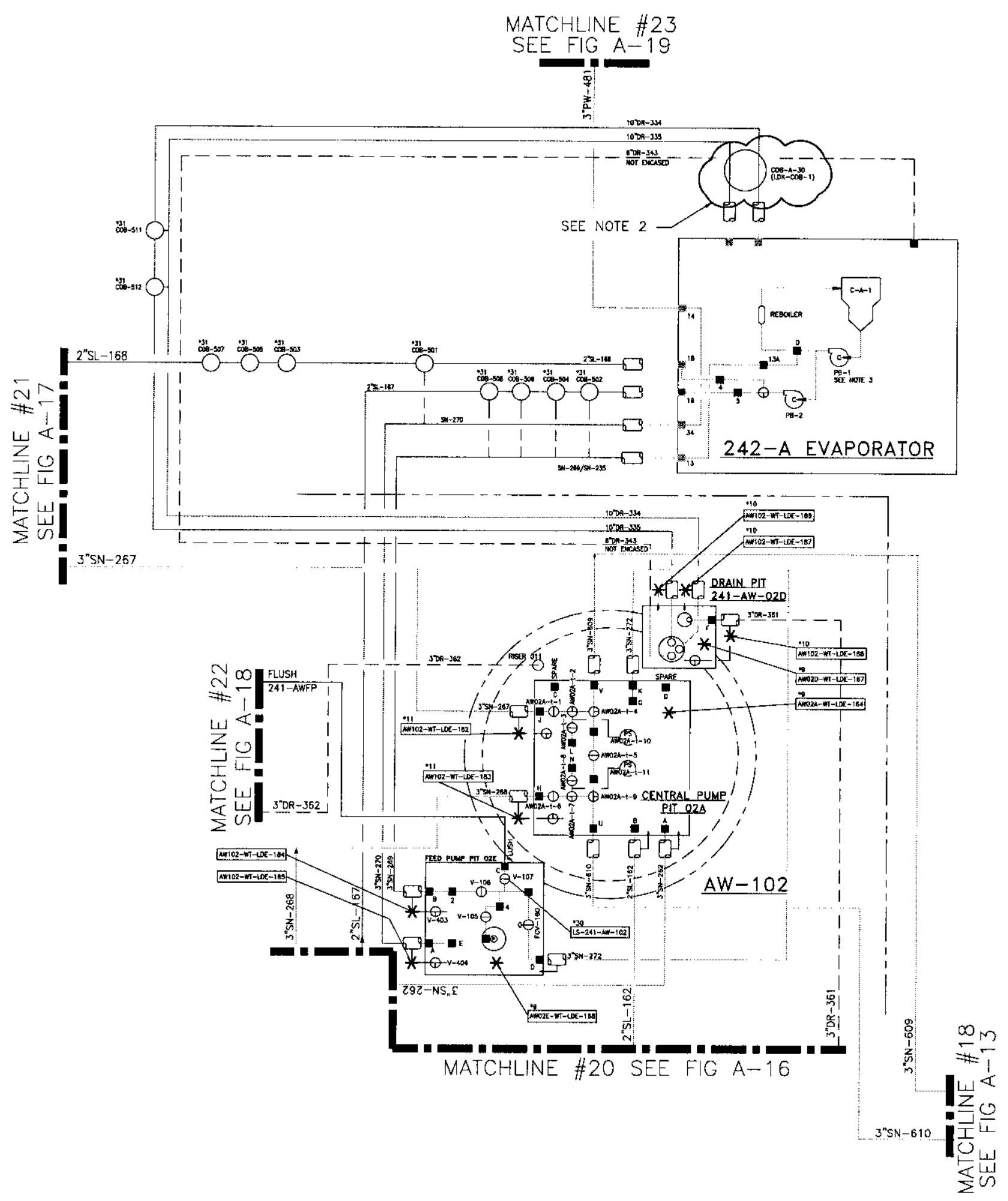

FIG $A-15$ 


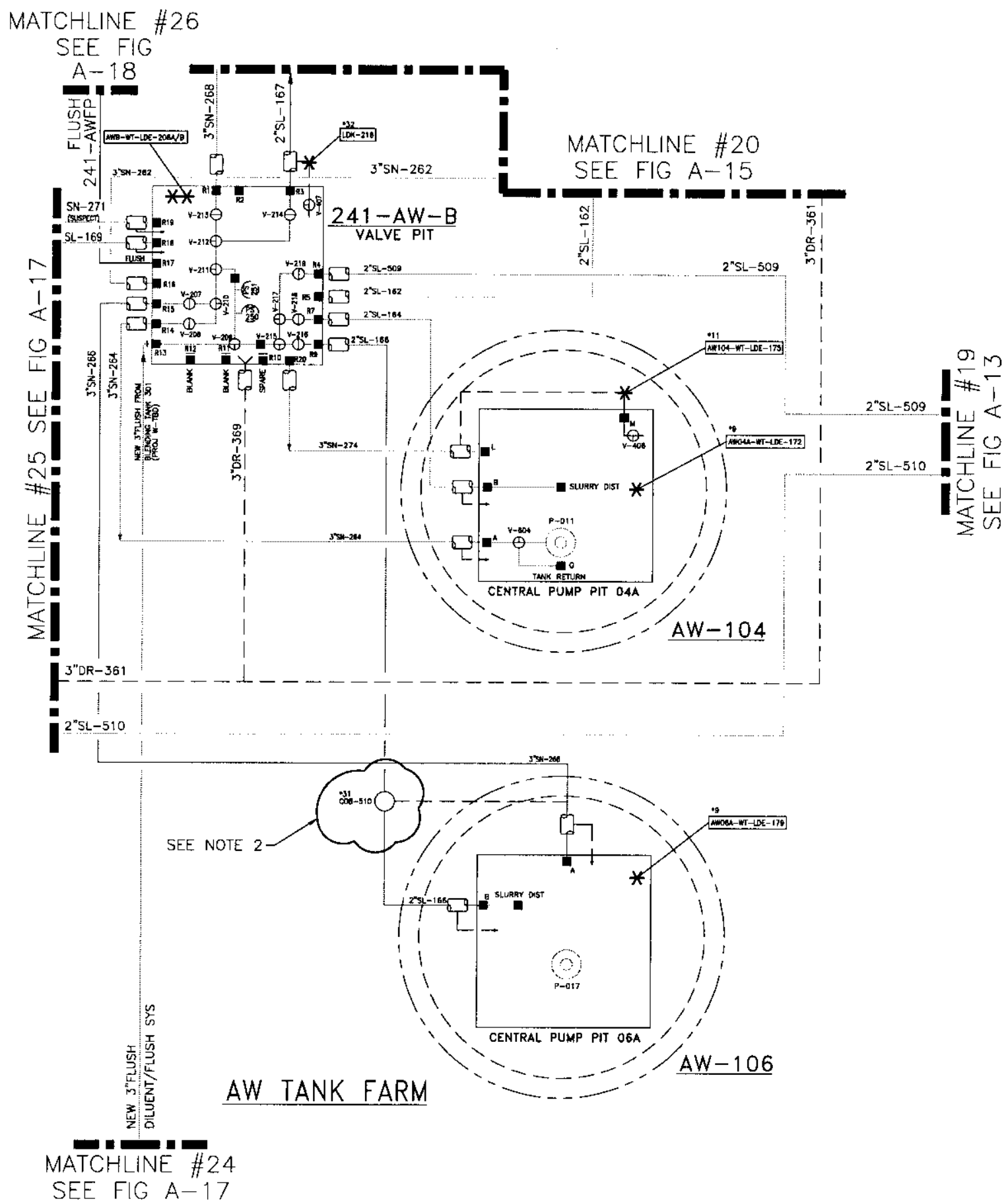

FIG A-16 


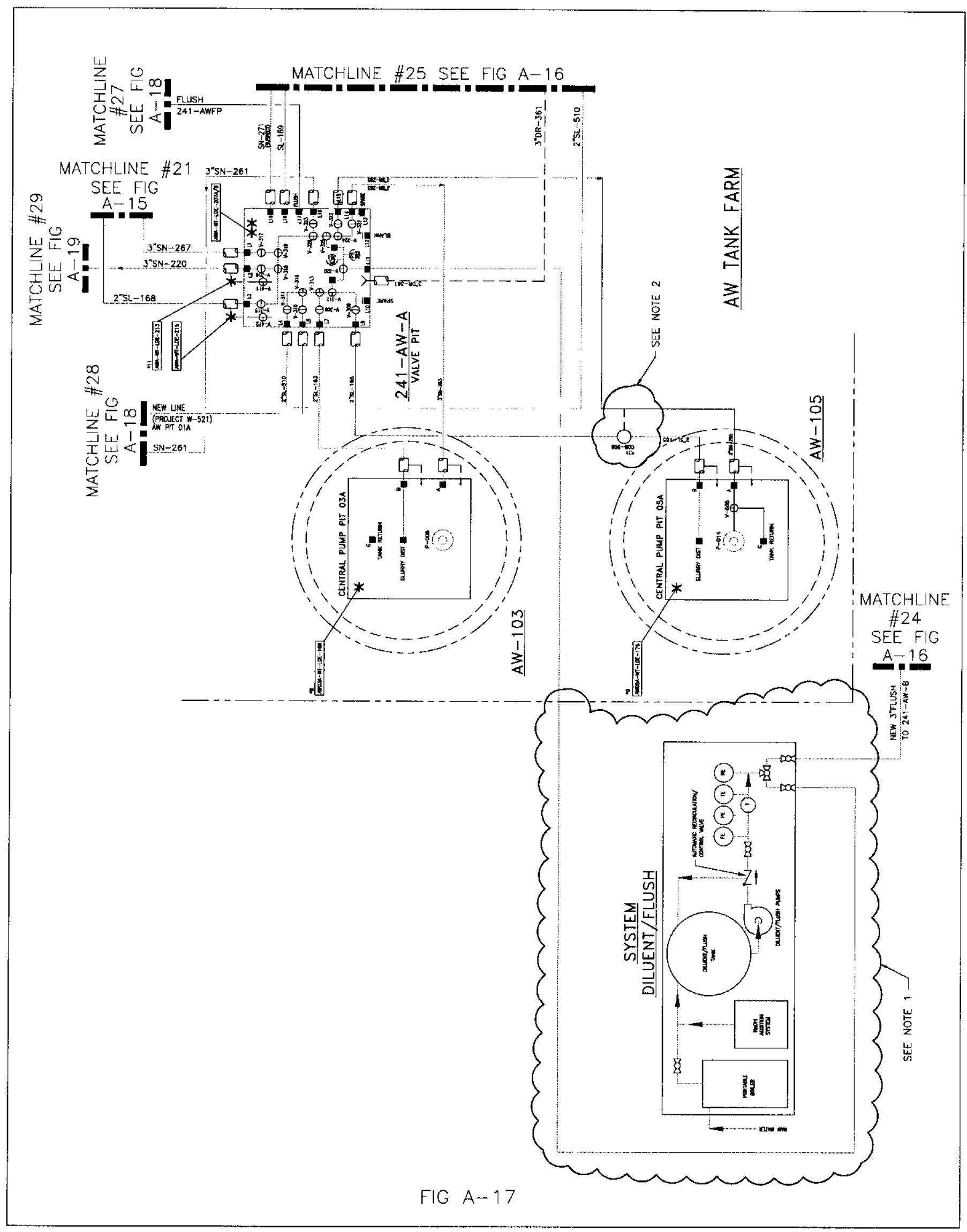




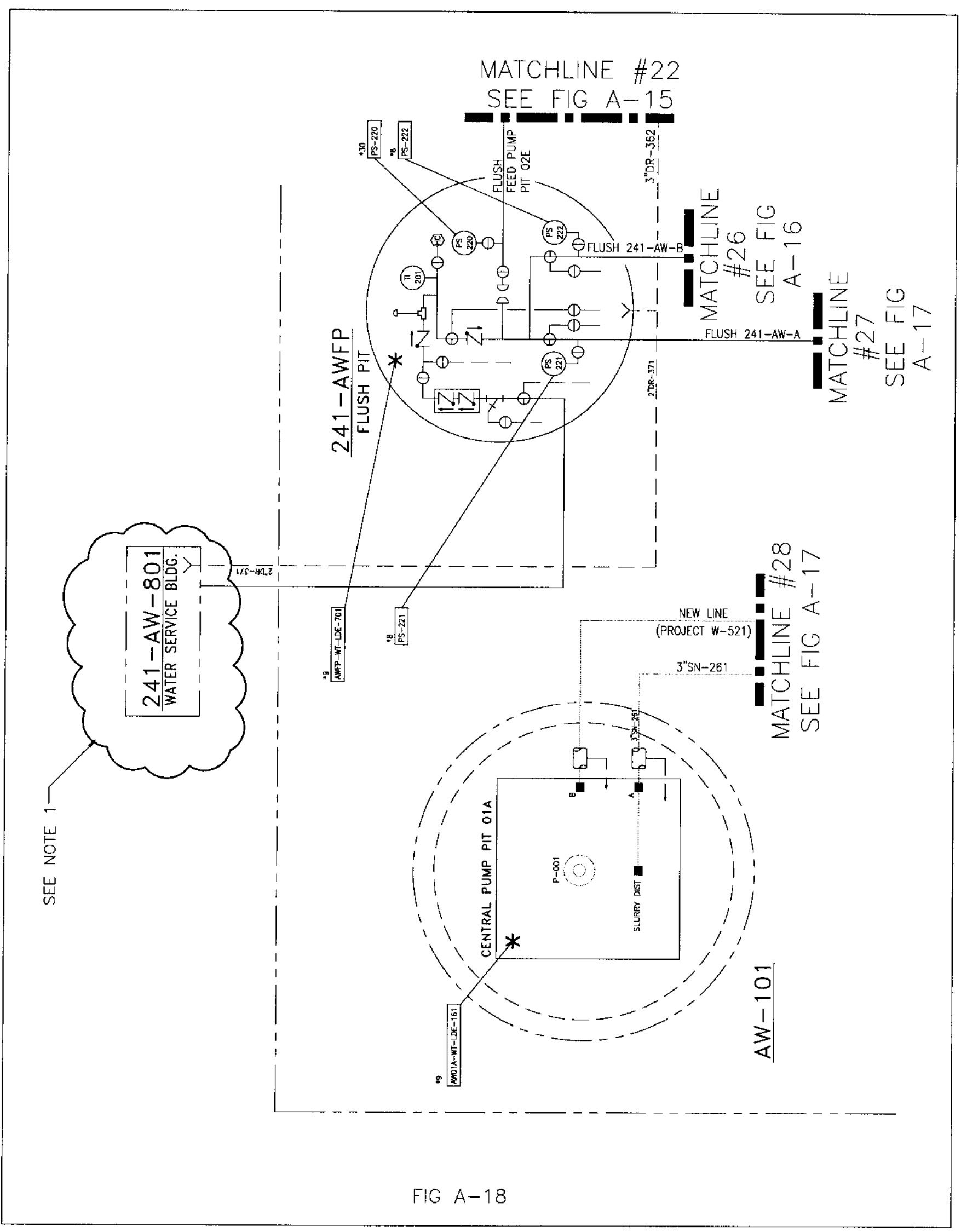




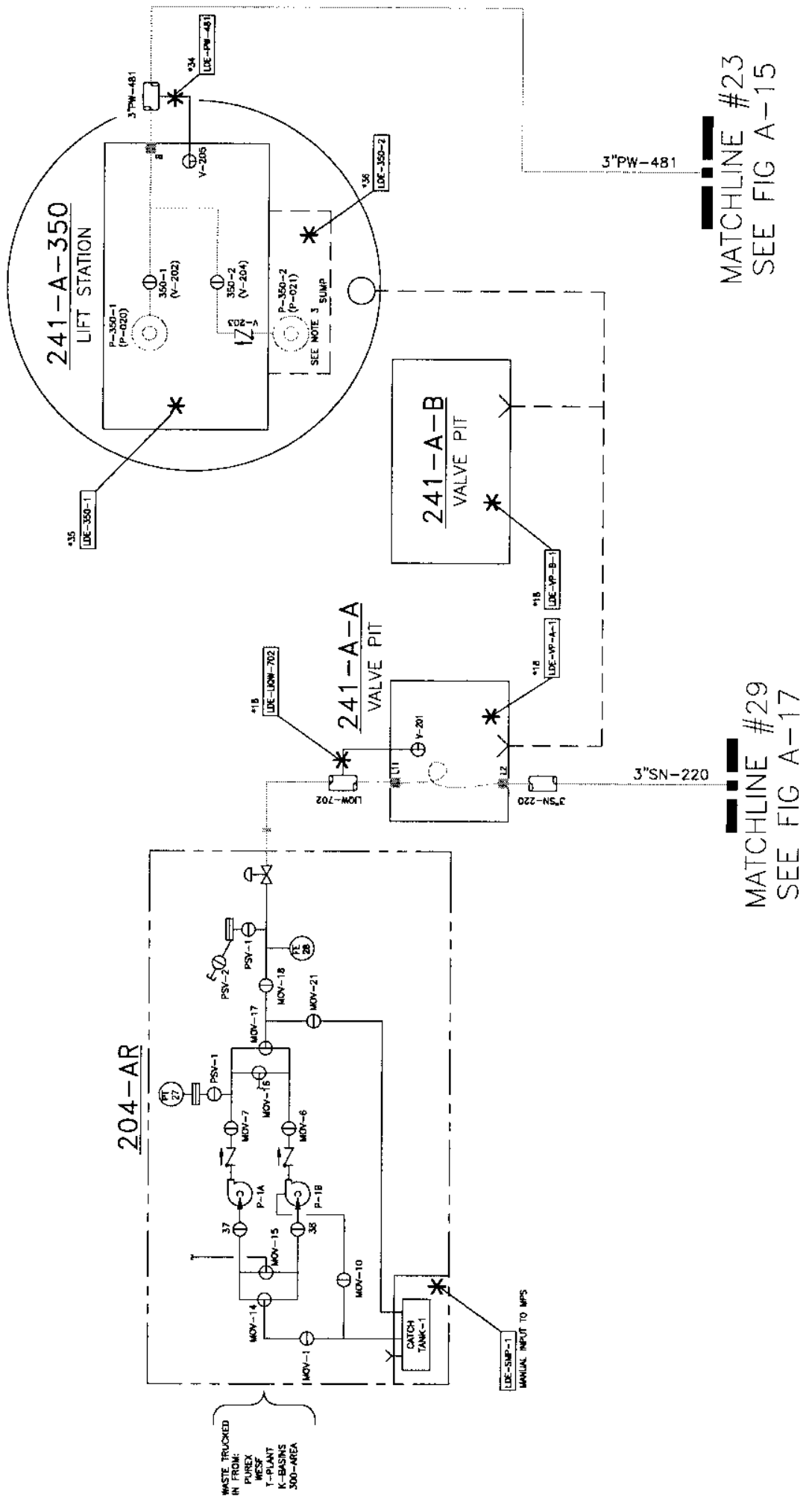

FIG $A-19$ 


\title{
APPENDIX B
}

\author{
DRAWING B-221-P2,
}

\section{WASTE TRANSFER SYSTEM PHASE 2}

FINAL CONFIGURATION 
RPP-6303

Rev. 0

\title{
APPENDIX B
}

\author{
DRAWING B-221-P2,
}

WASTE TRANSFER SYSTEM PHASE 2

FINAL CONFIGURATION

B-2 


\section{LEGEND:}

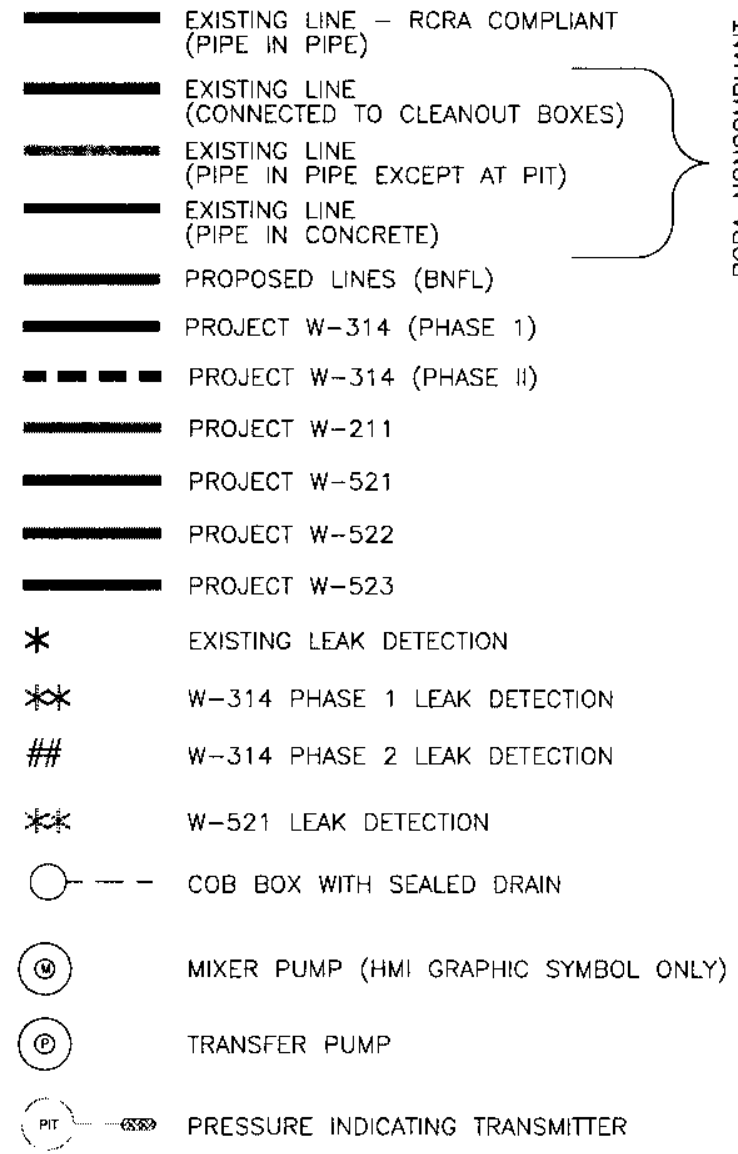

GENERAL NOTES:

1. CLOUDED AREA INDICATES NO EQUIPMENT CONNECTED TO THE MPS AND NO MPS HMI GRAPHICS.

2. GRAPHICS TO BE DONE BY $W-211$.

3. GRAPHICS TO BE DONE BY W-521.

4. TCP/IP CONNECTION TO MCS.

5. NOT IN SCOPE.

6. INTERLOCK TO MCS

7. TENTATIVE TIE-IN LOCATION - FINAL LOCATION UNDER NEGOTIATION.

8. DELETION FROM WTS UNOER NEGOTIATION WITH W-521.

9. ALL MECHANICAL, NO INSTRUMENTS CONNECTED TO MPS.

$F I G \quad B-1$ 


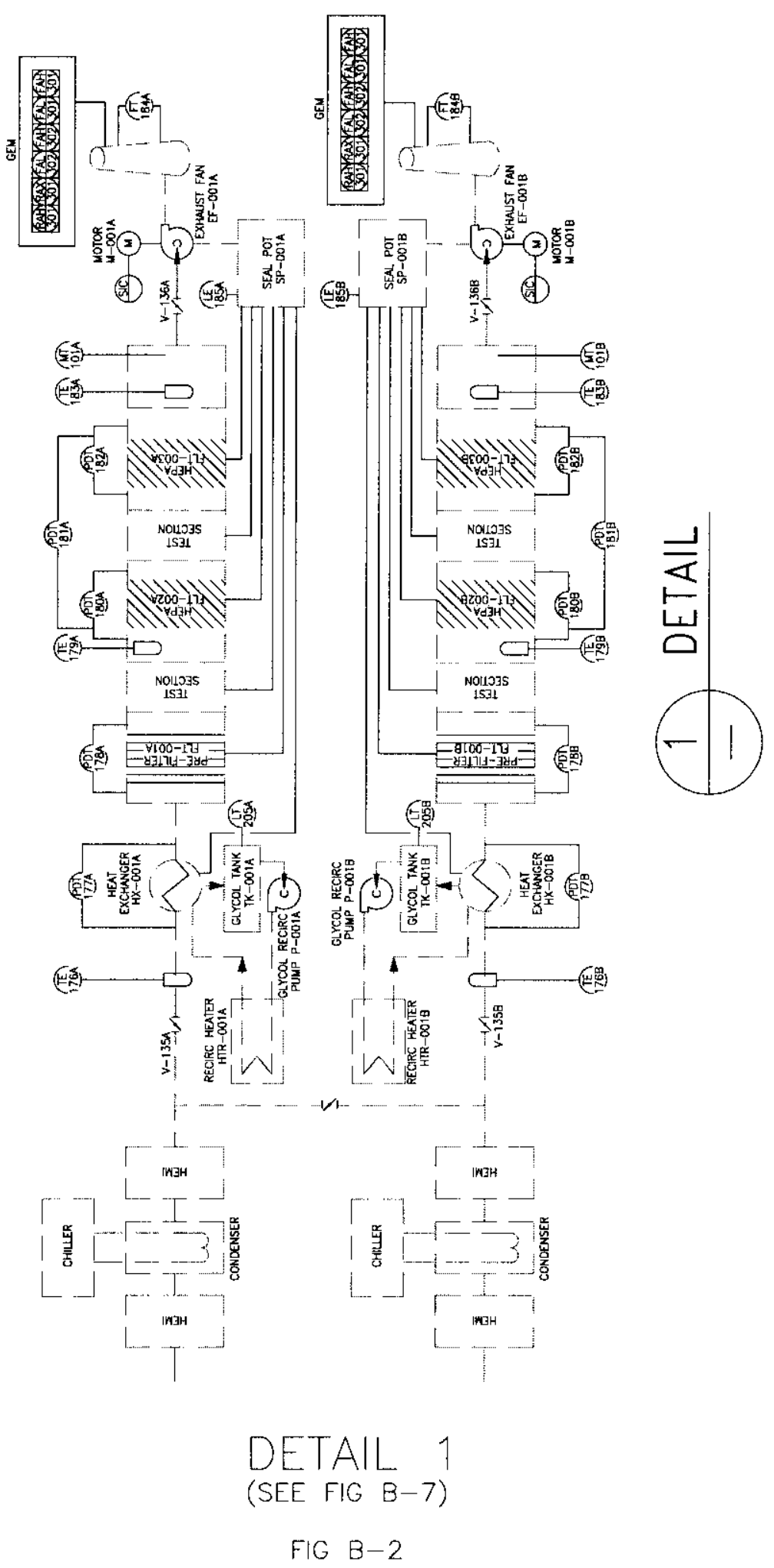




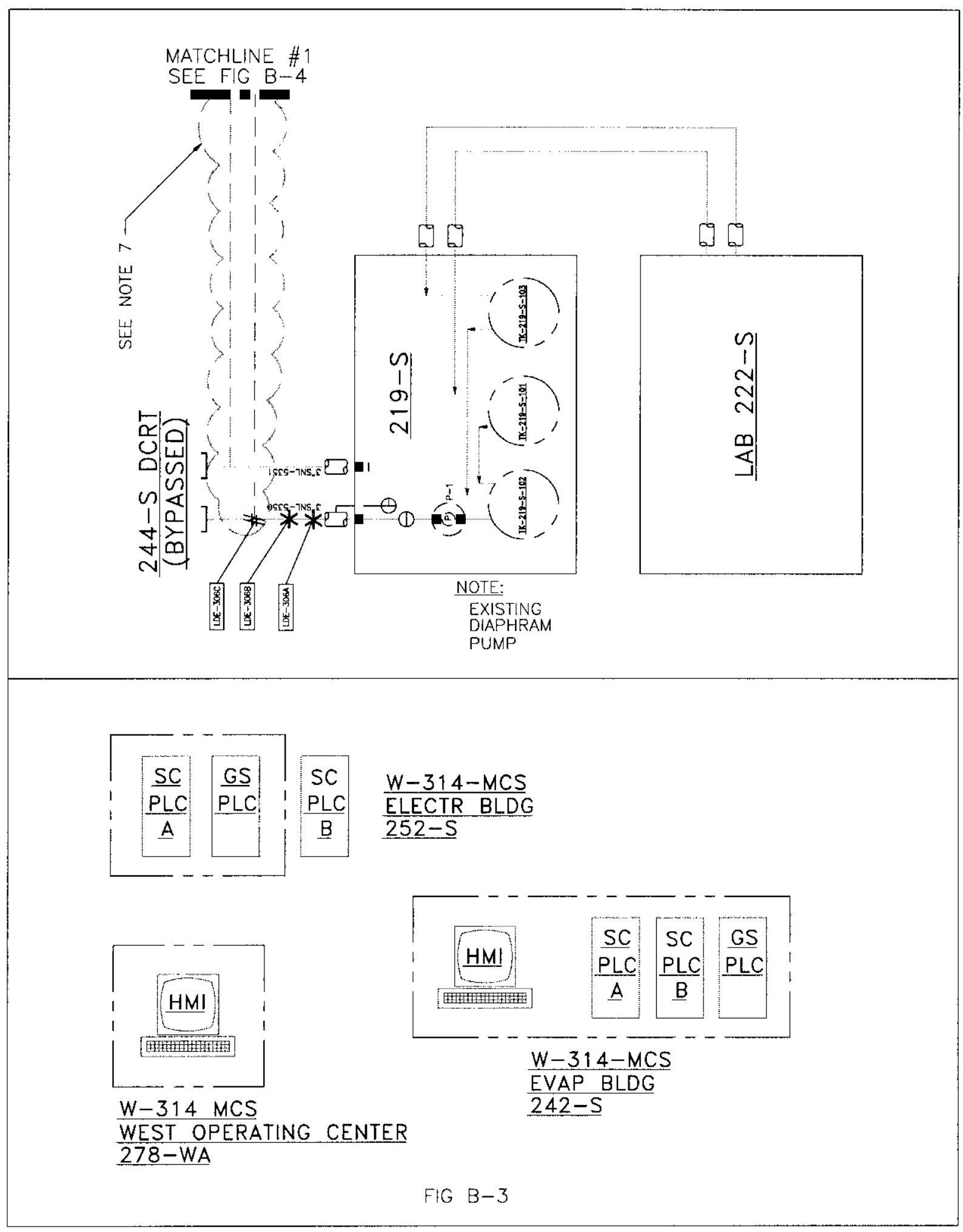




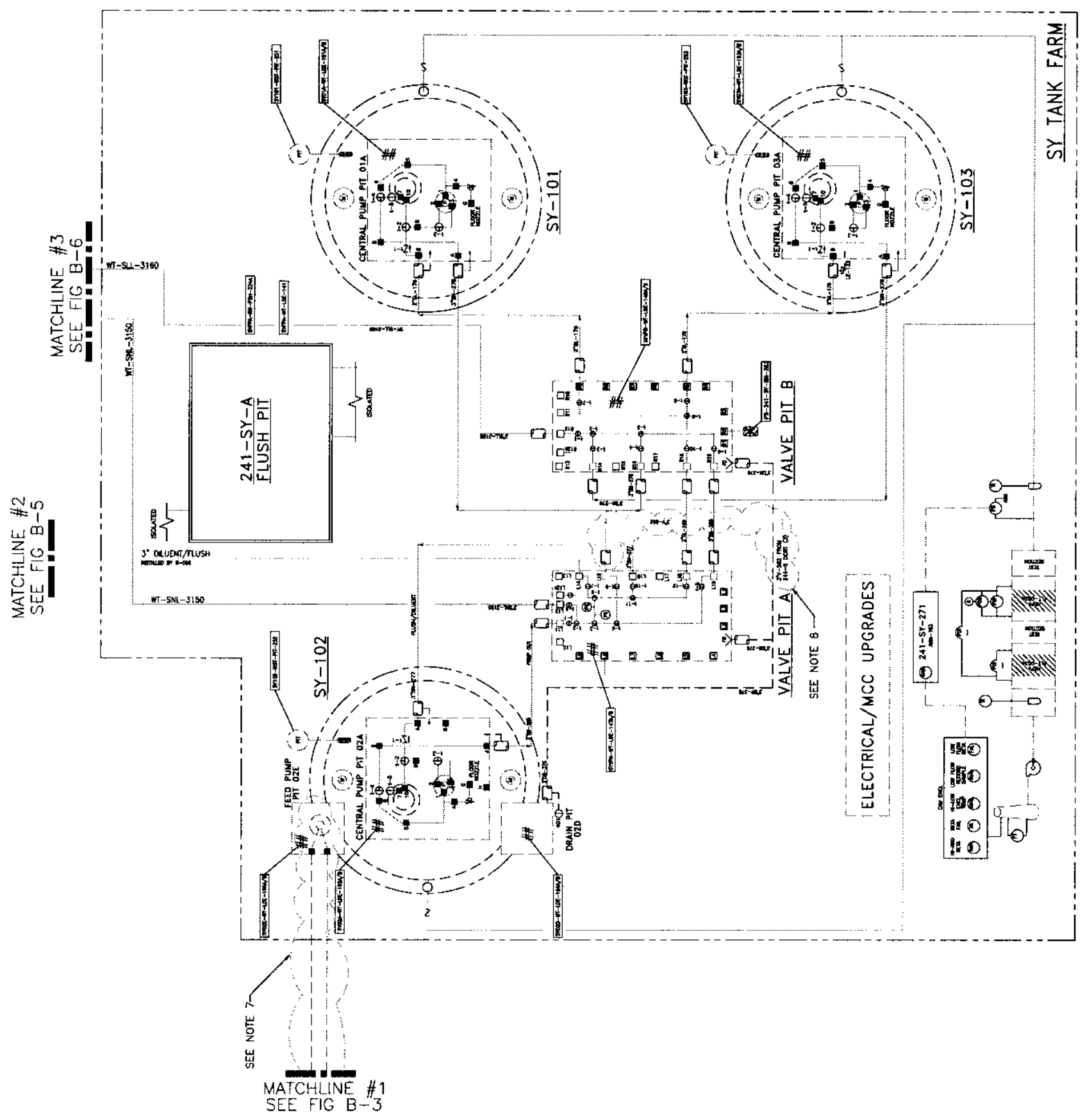

FIG B-4 


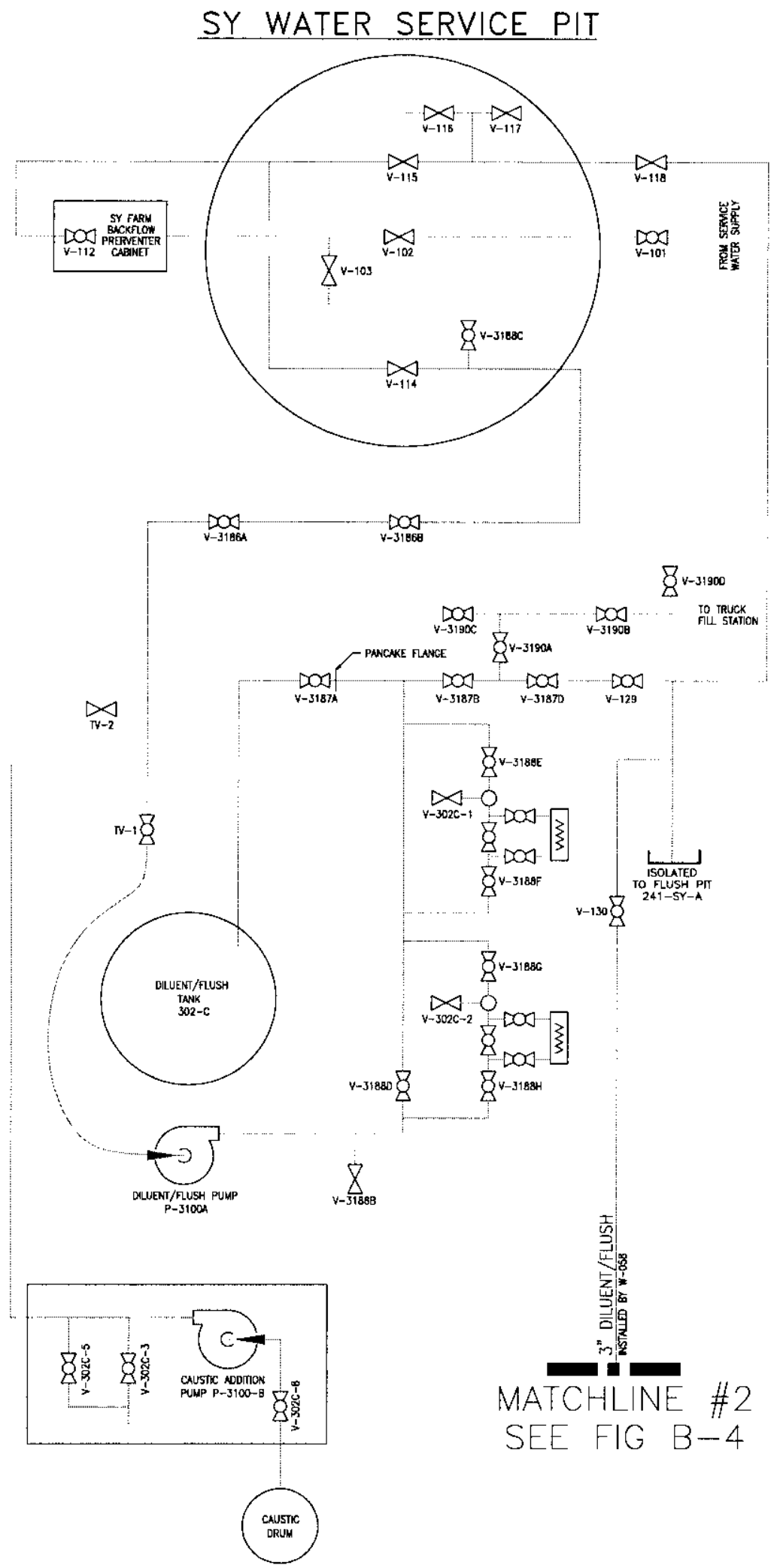

FIG B-5 


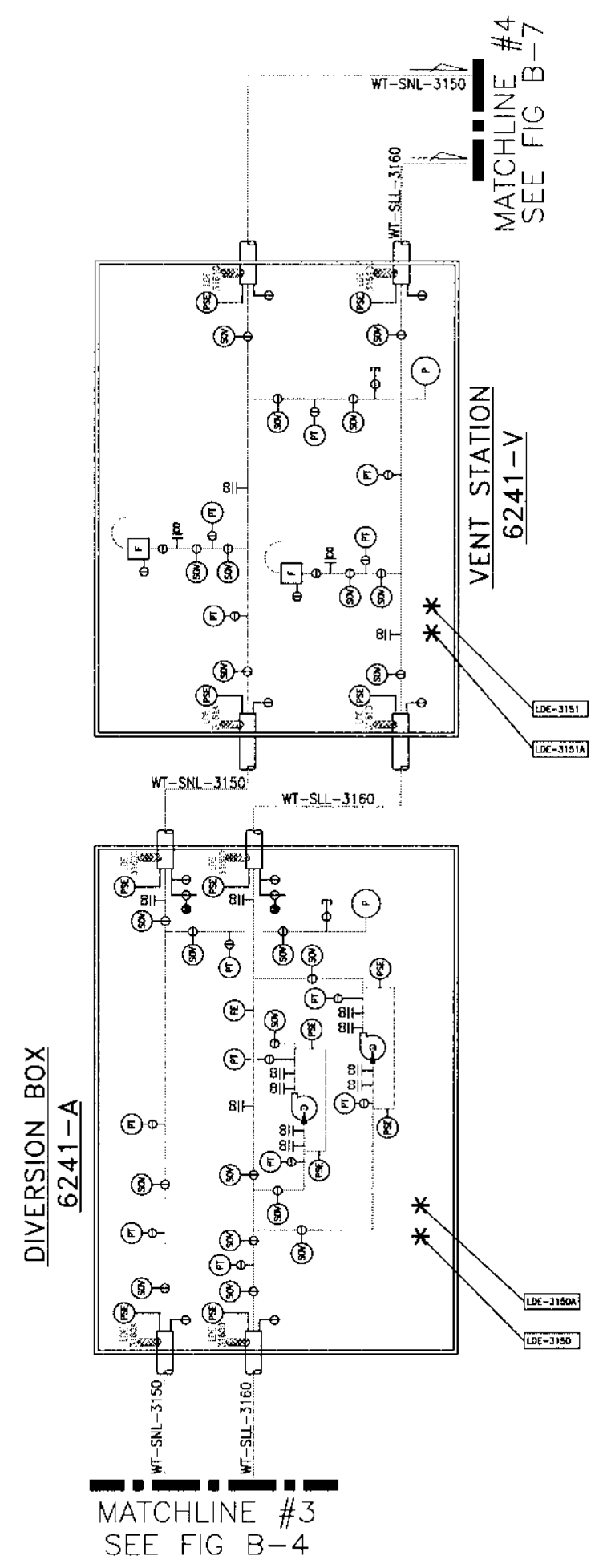

FIG B-6 


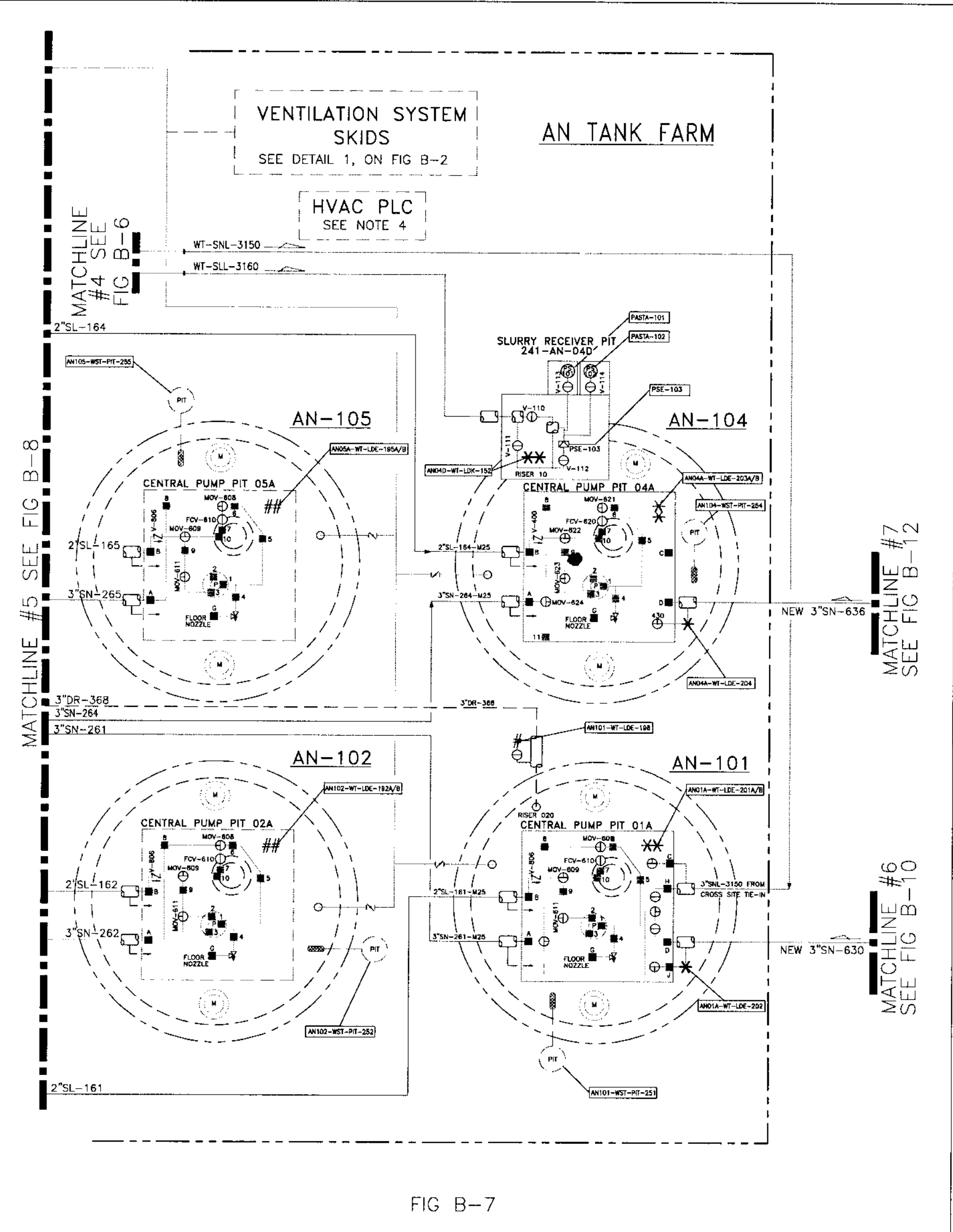


RPP-6303

Rev. 0

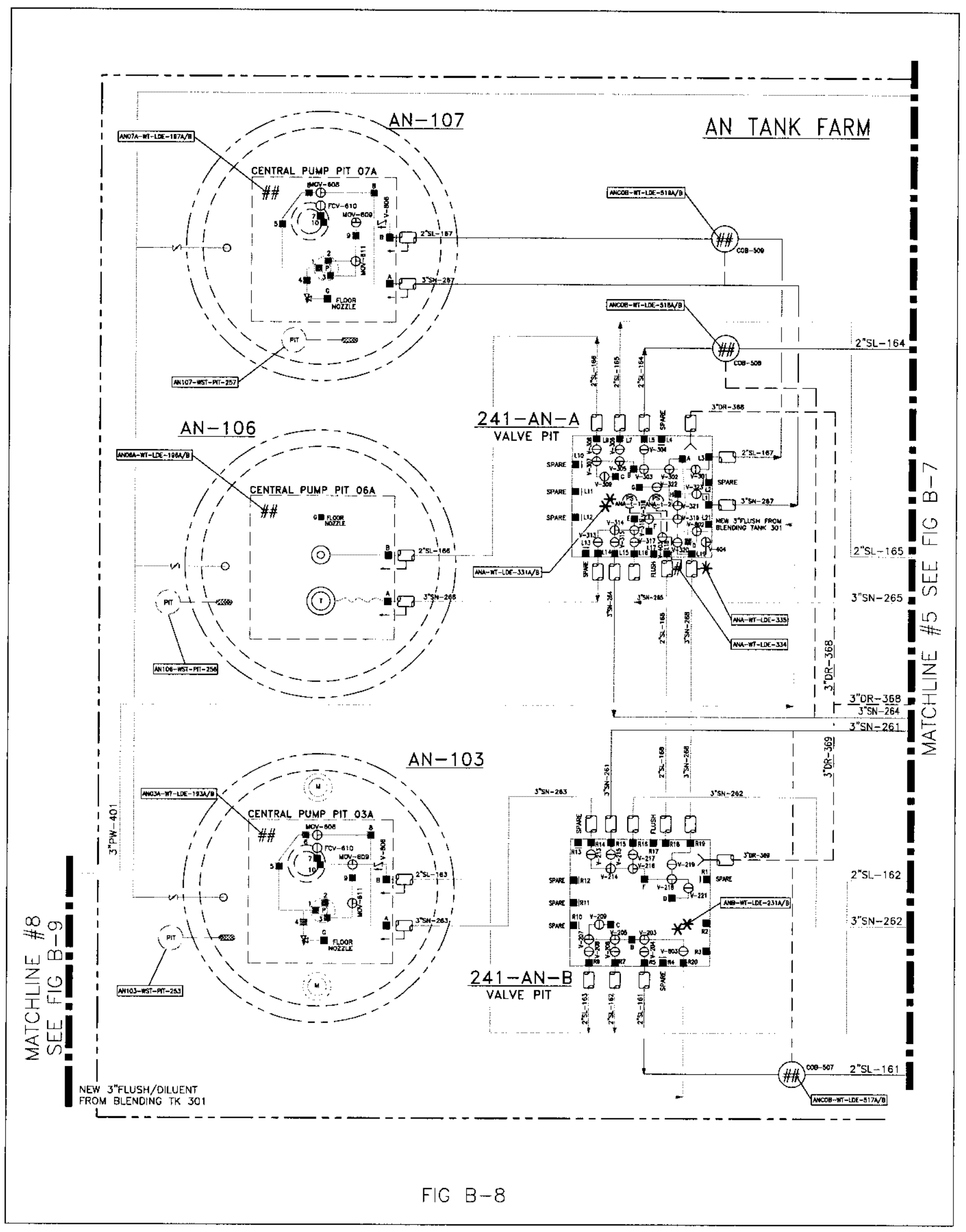



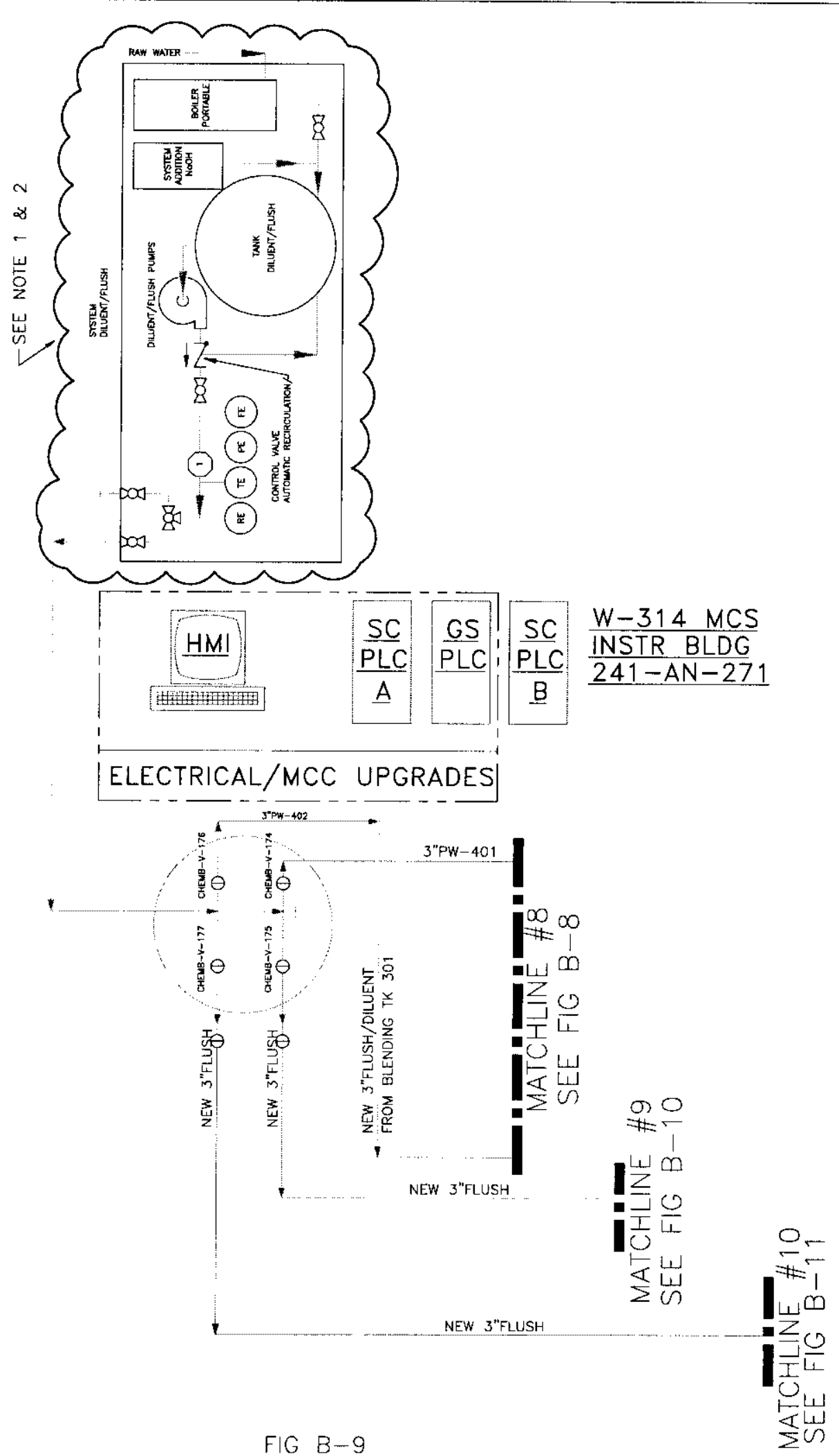


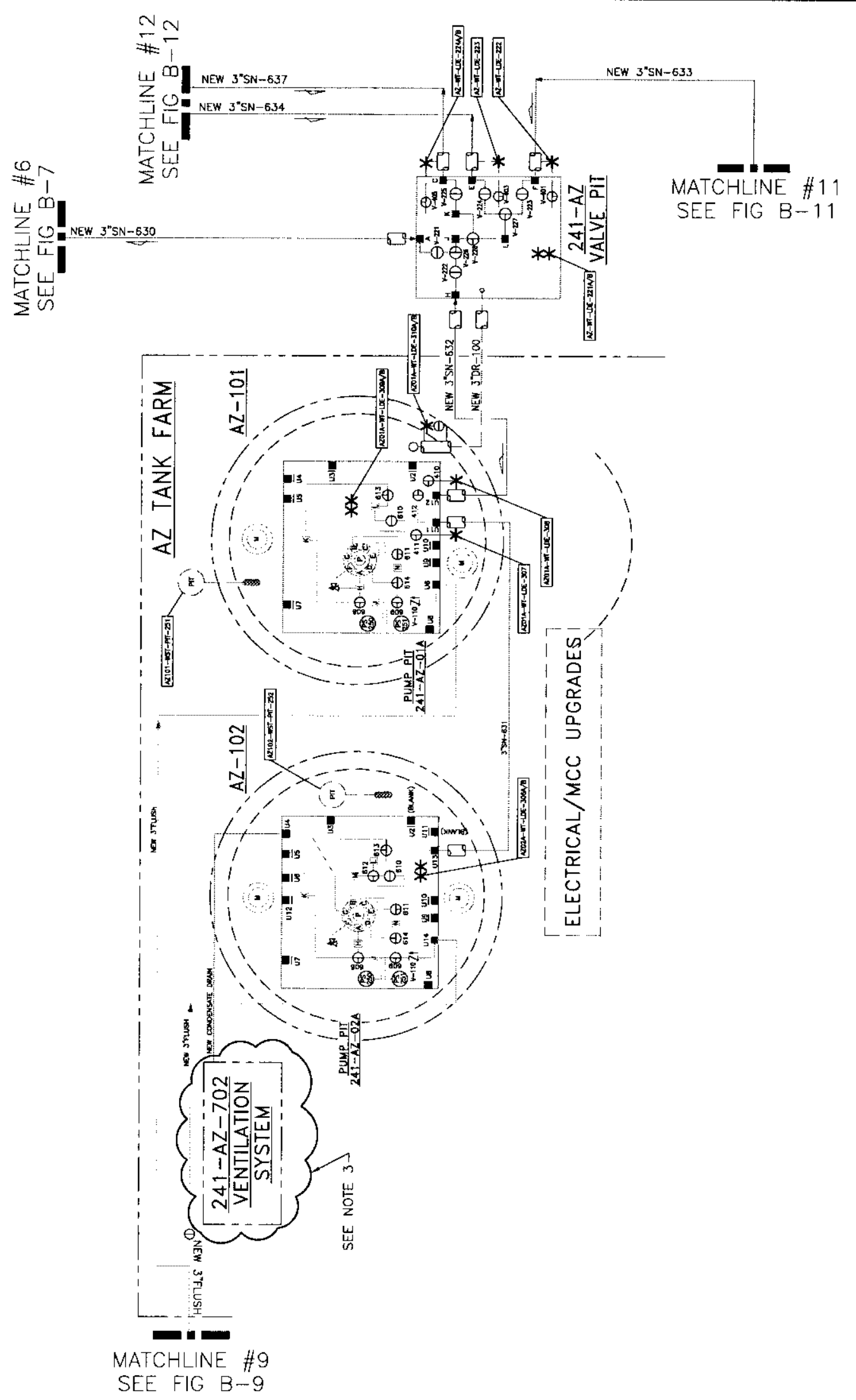

$F \mid G \quad B-10$ 


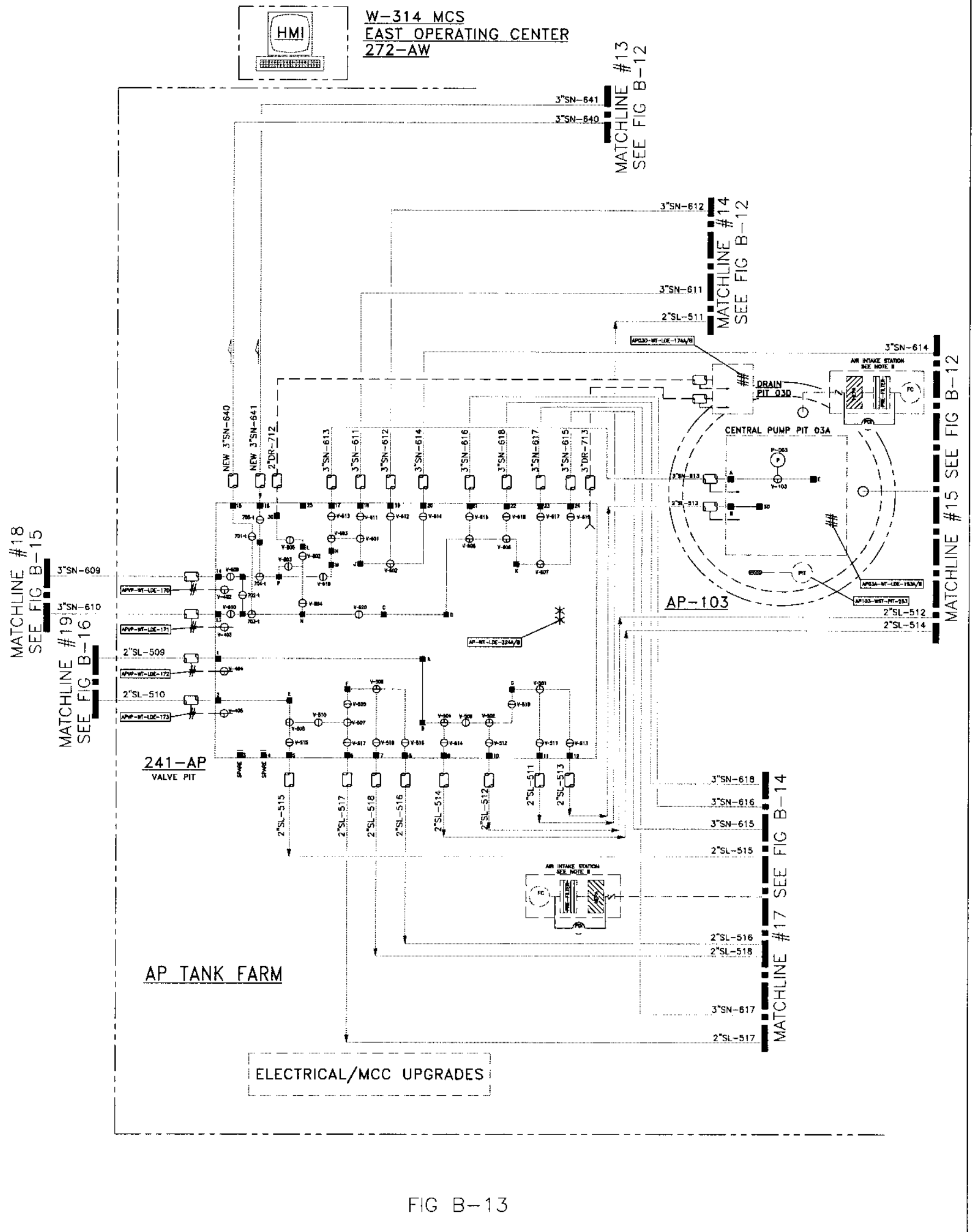




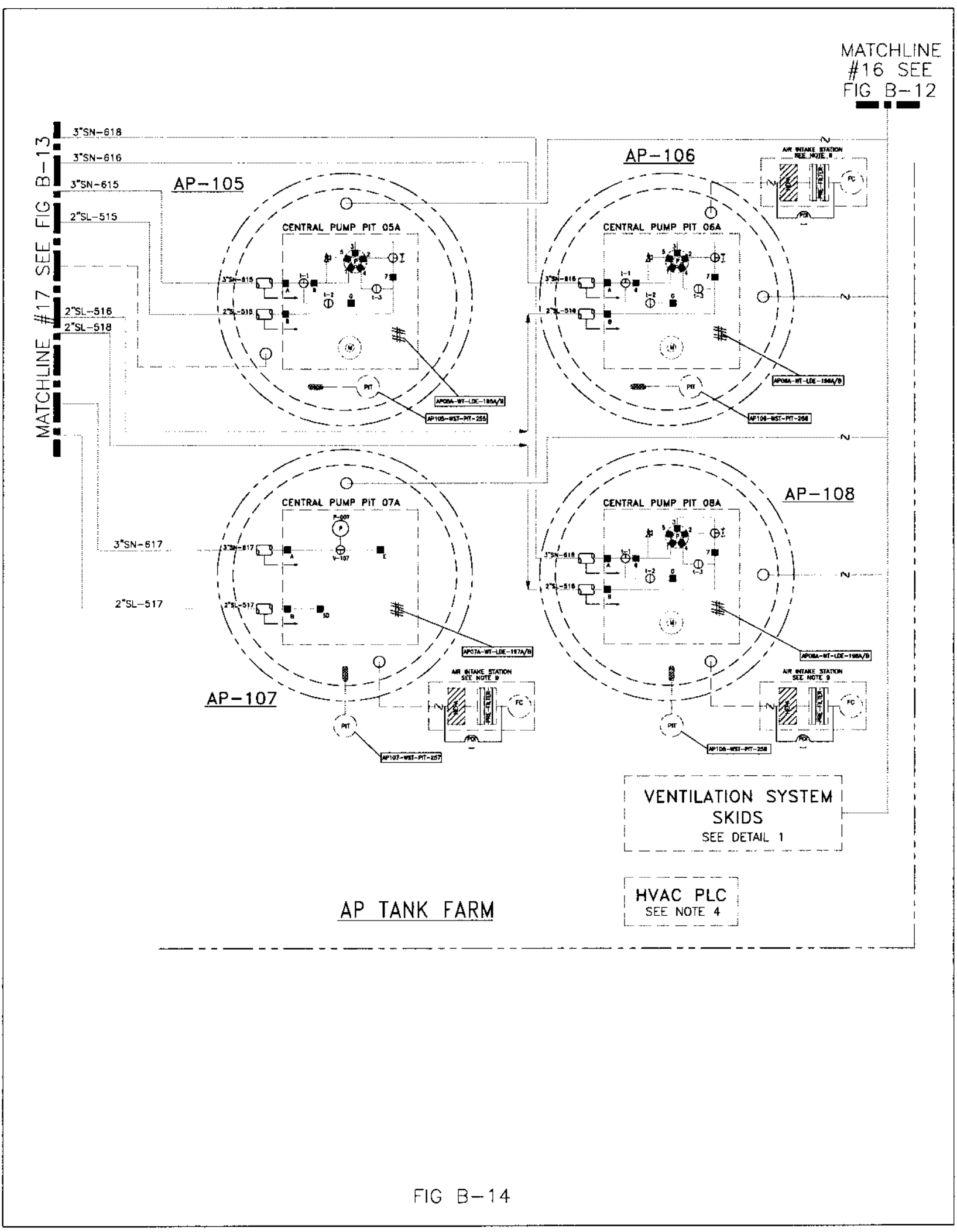




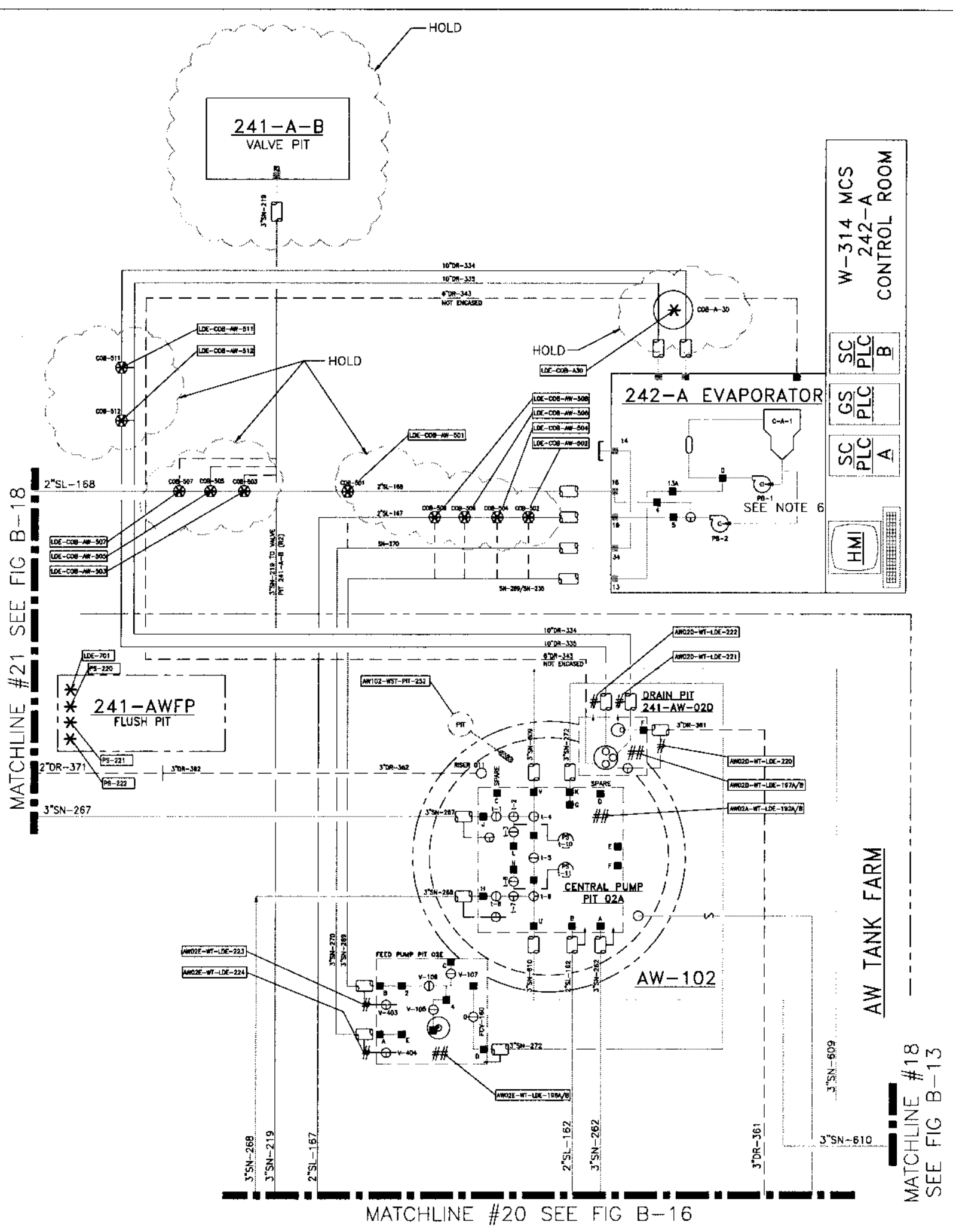

$F \mid G \quad B-15$ 


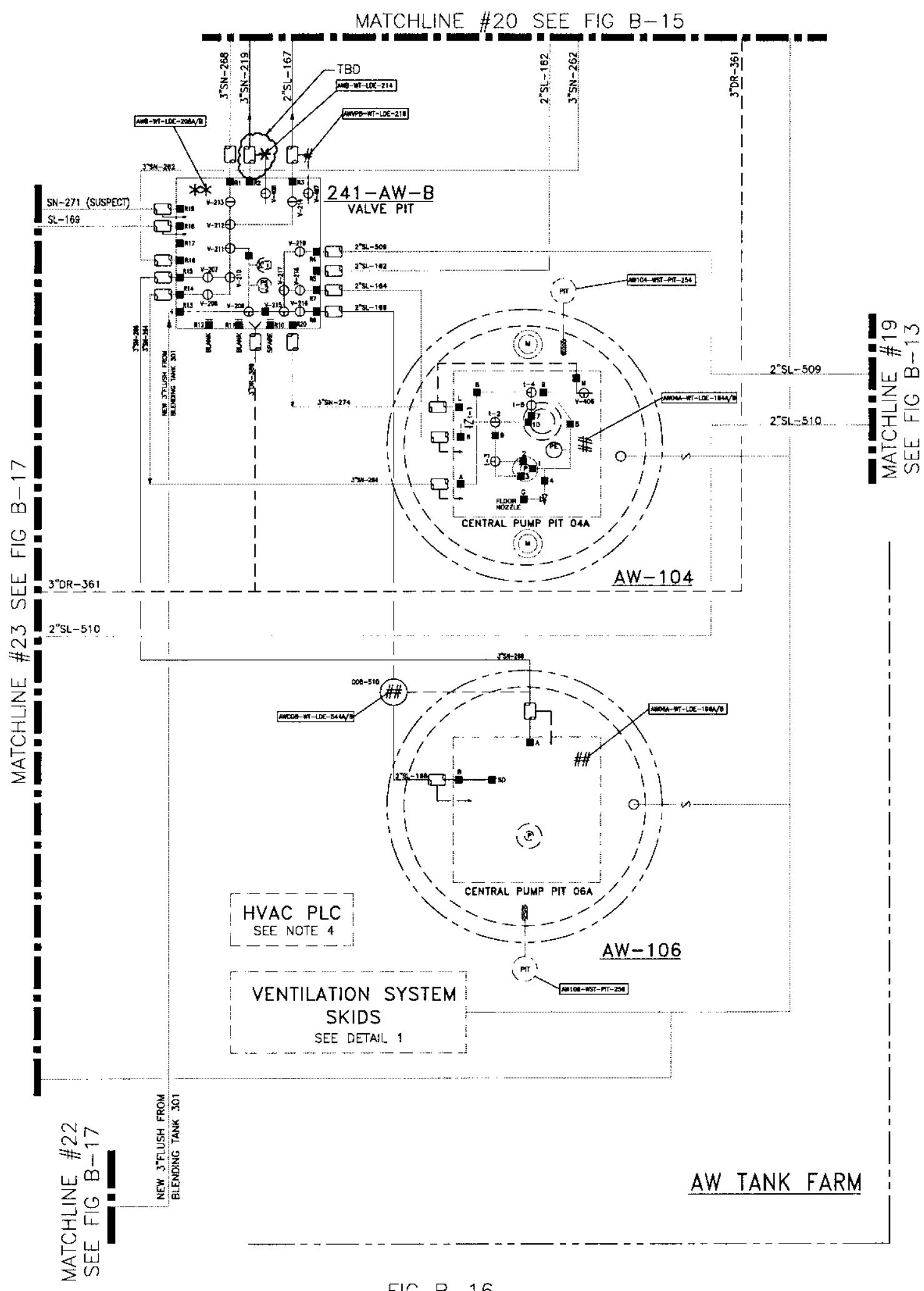

FIG $B-16$ 


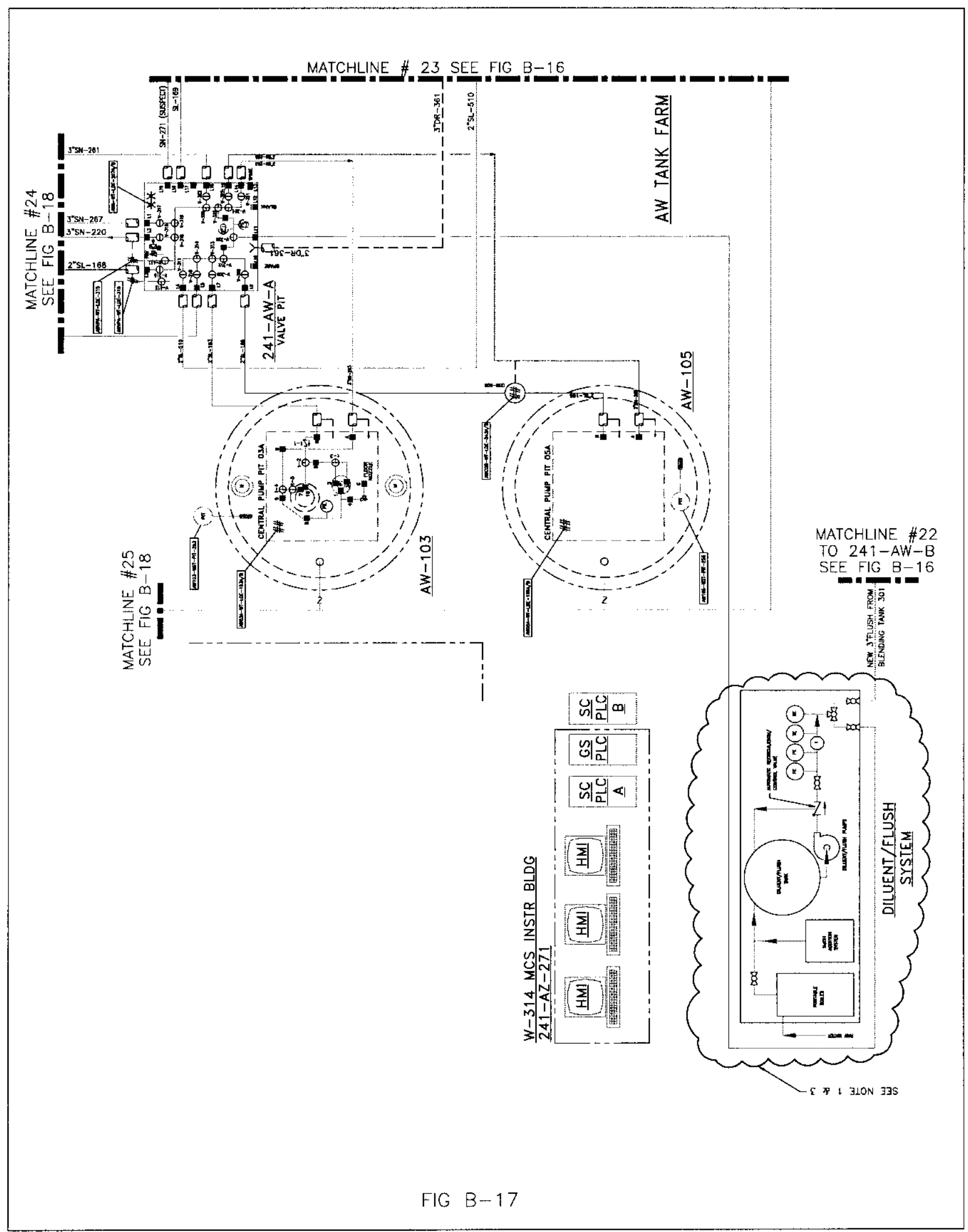


W-314 MCS INSTR BLDG $241-\mathrm{AW}-271$

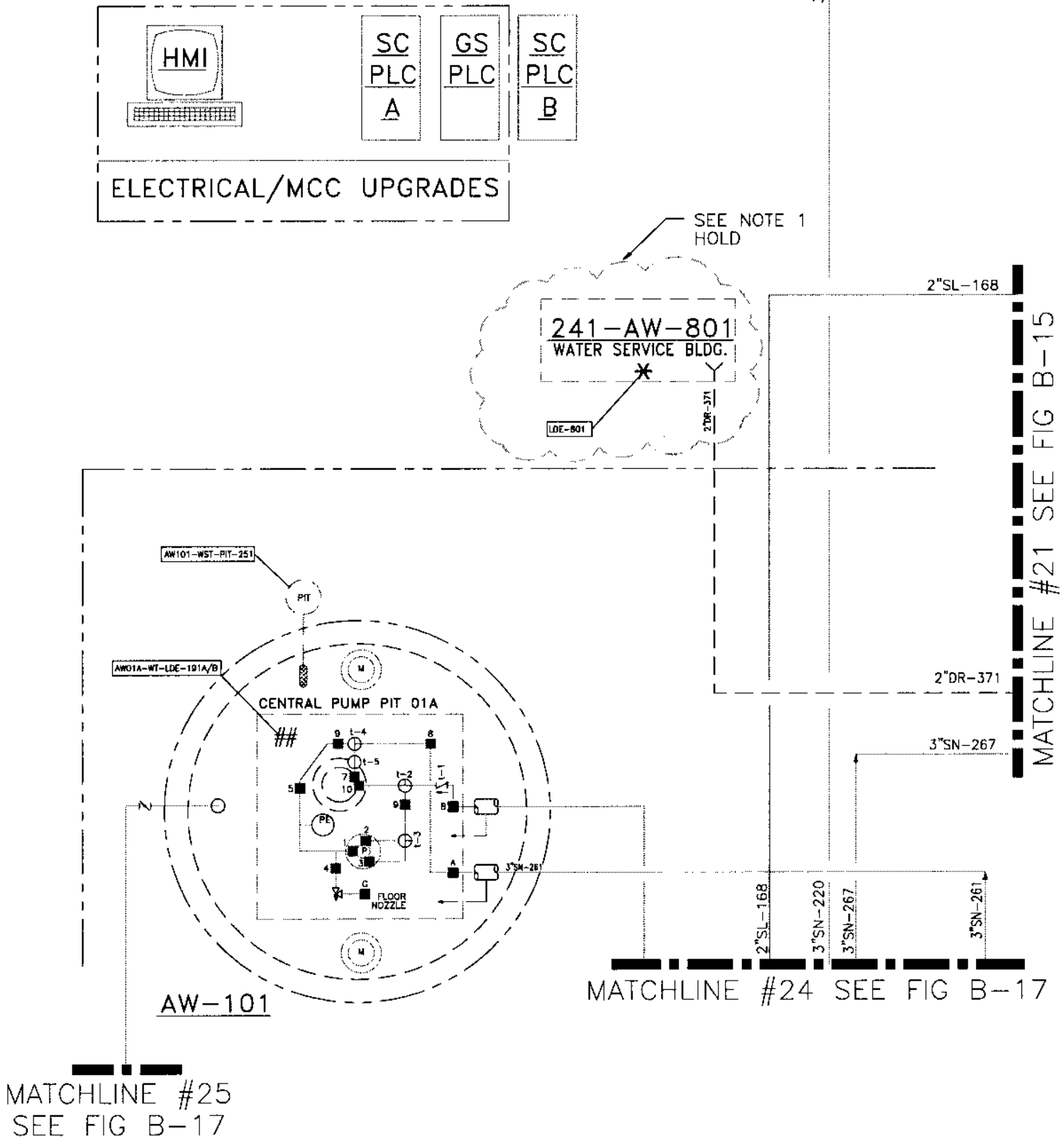

MATCHLINE \#26

SEE FIG B-19

in

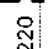

ํํ

is

$\mathrm{F} I \mathrm{G} \quad \mathrm{B}-18$ 

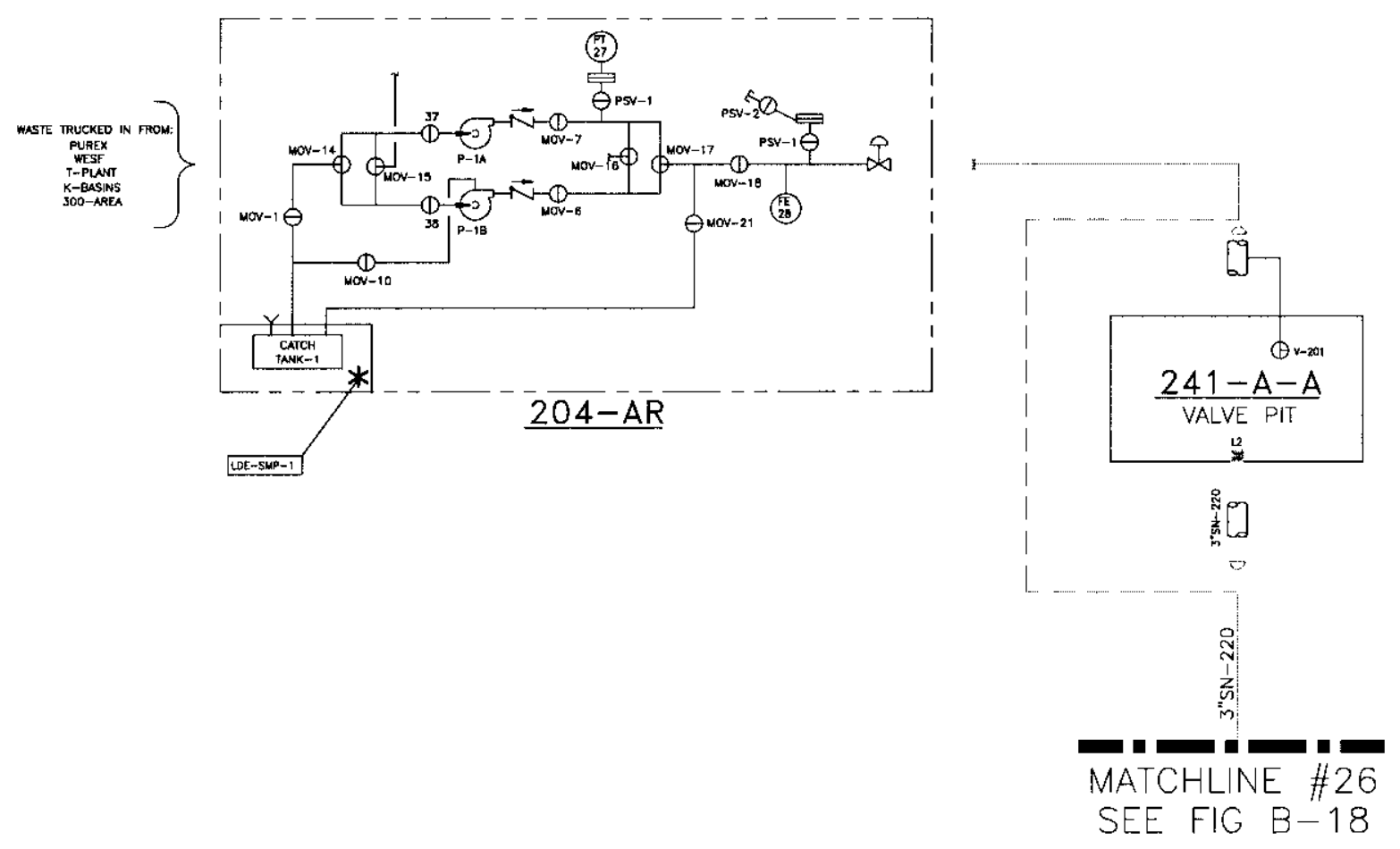

FIG $\quad B-19$ 
RPP-6303

Rev. 0

\section{APPENDIX D}

Monitoring and Control System

Operational Logic Diagrams

D-1 
RPP-6303

Rev. 0

\section{APPENDIX D \\ MONITORING AND CONTROL SYSTEM OPERATIONAL LOGIC DIAGRAMS}

\section{INTRODUCTION}

The following logic diagrams were prepared utilizing the nomenclature in ANSI/ISA -S5.2-1976(R1992), "Binary Logic Diagrams for Process Operations". A summary legend of symbols is presented in the following and is identical to the standard.

The logic diagrams present only the operational philosophy of the MCS. It is not the control system logic necessary to implement the MCS. The absence or not of input signals causing a logic action is not addressed. See section 3.3 of ANSI/ISA-S5.2 for further explanation.

The generic diagrams are software modules that are attached to the MPS loop. The specific equipment numbers of devices to be connected to the shutdown loops are presented in Appendix B.

Word descriptions are provided for each logic diagram to assist in the understanding of the operational concepts. 


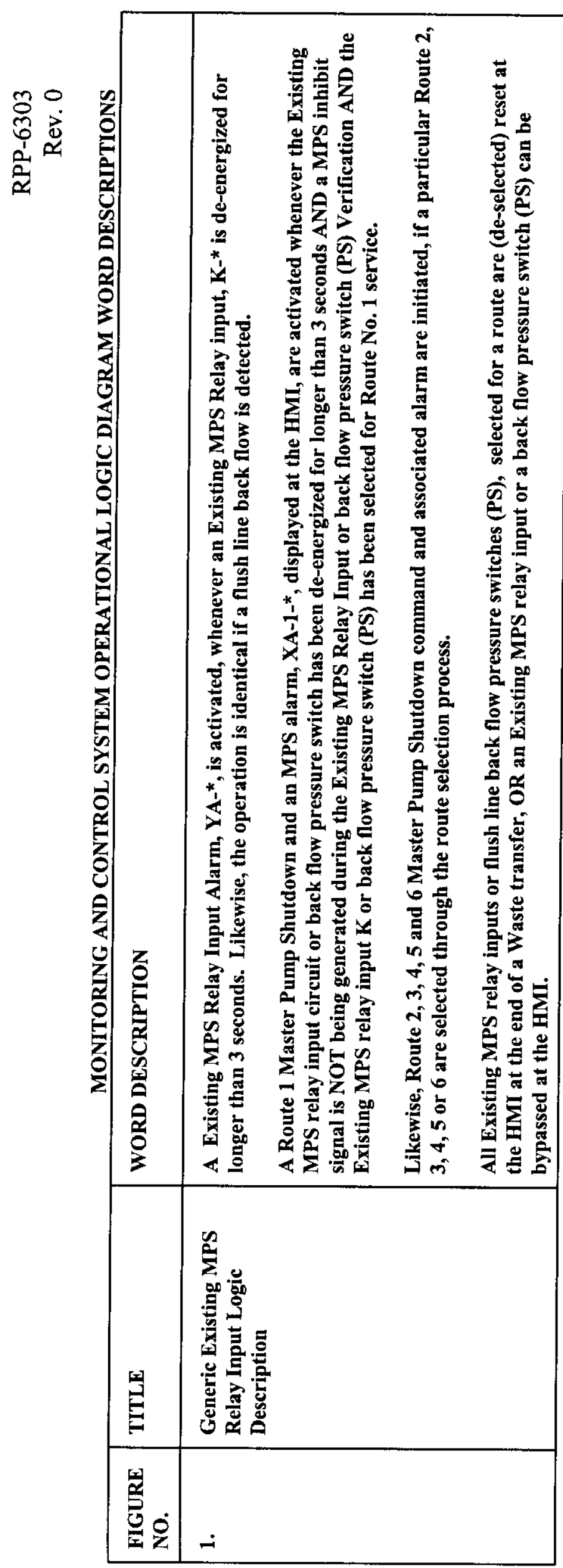




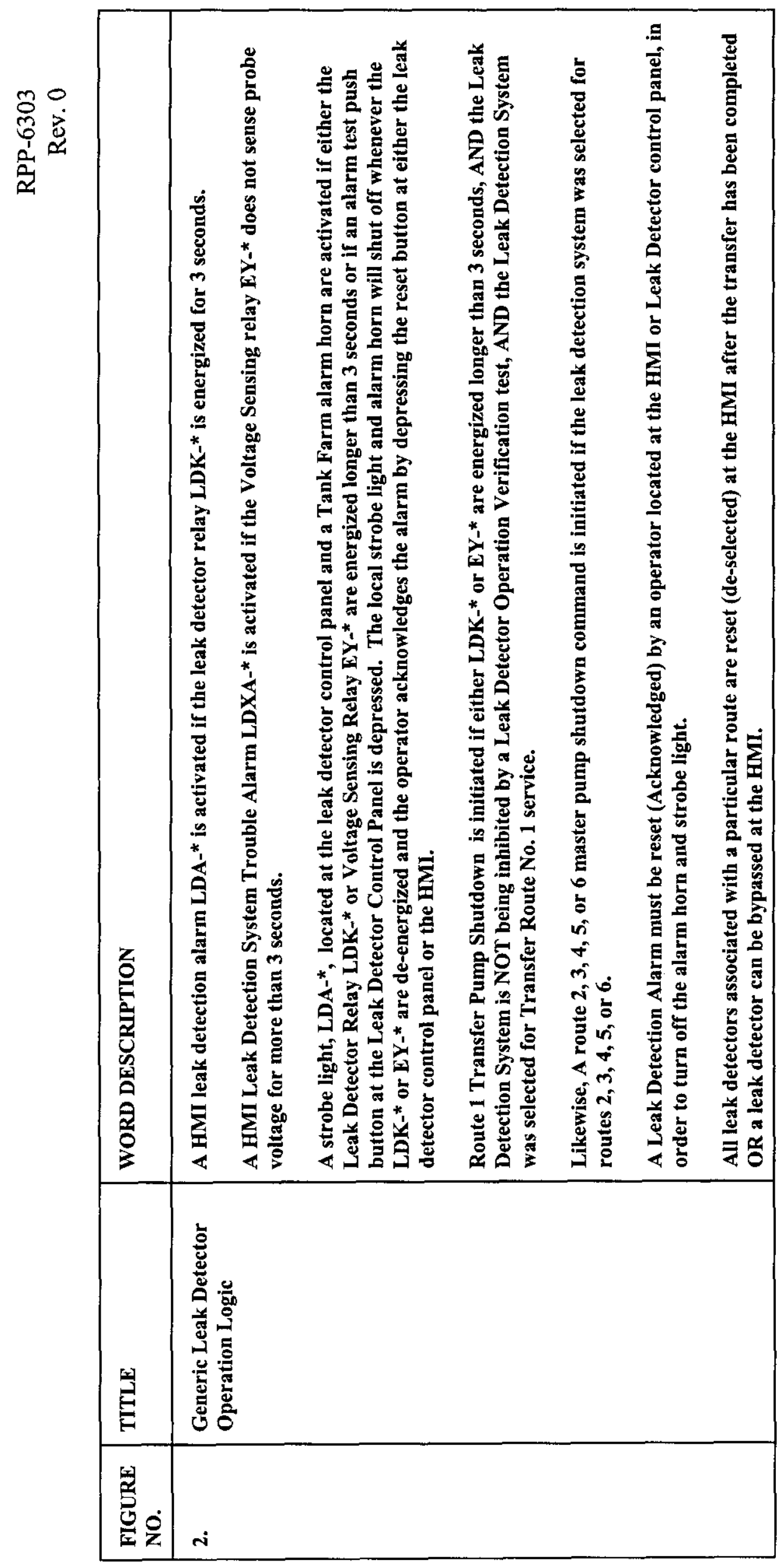




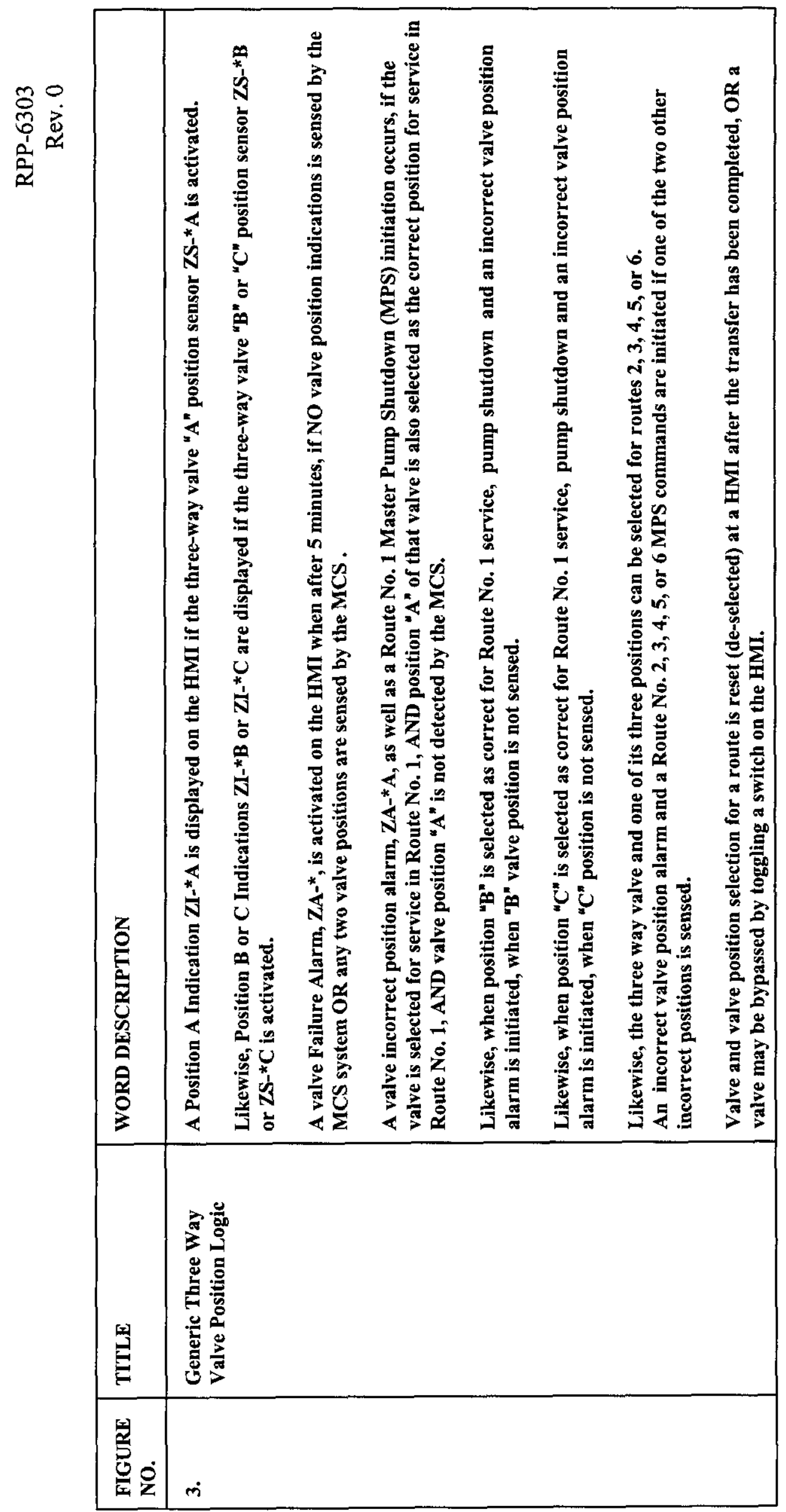




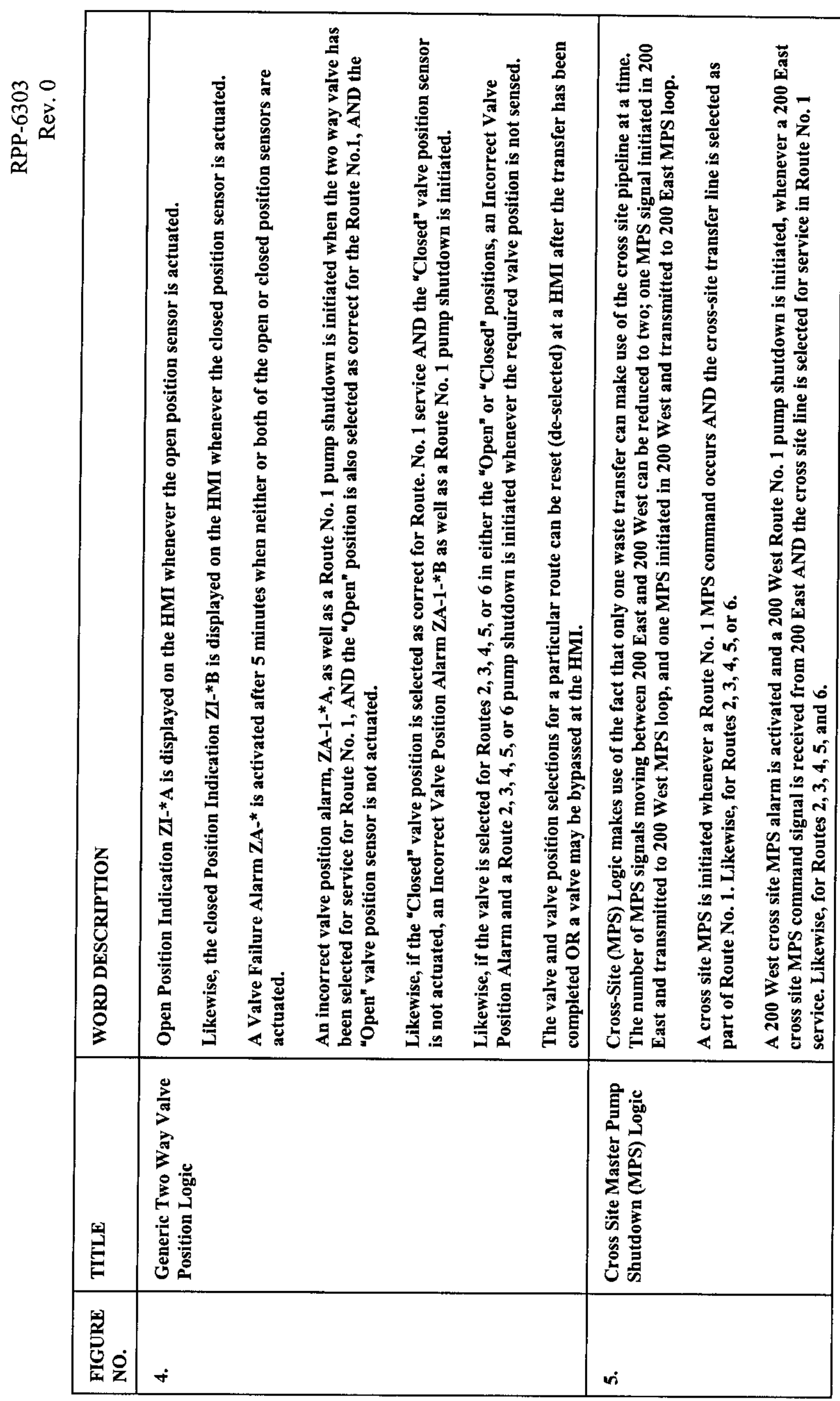




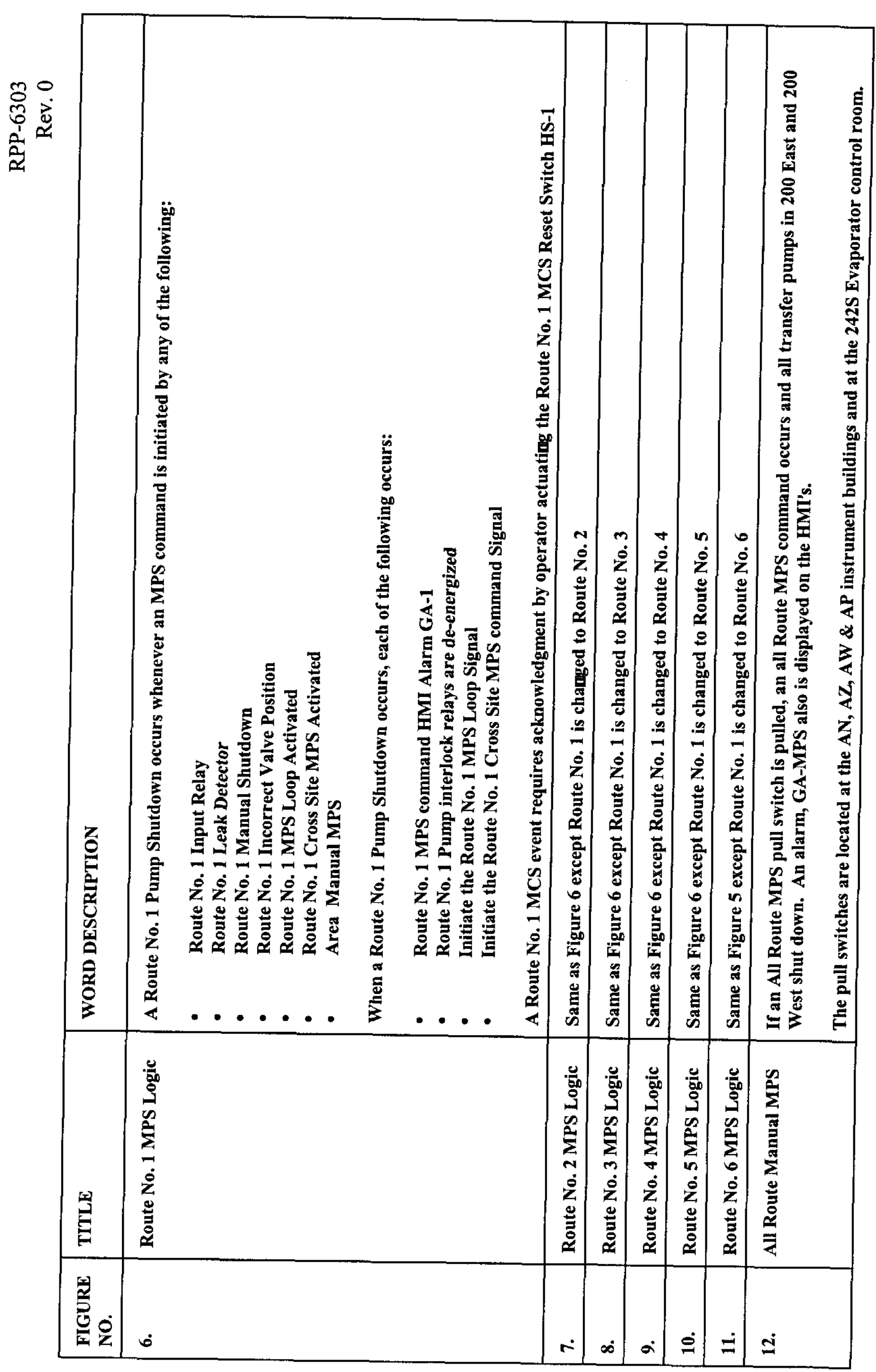

İ 


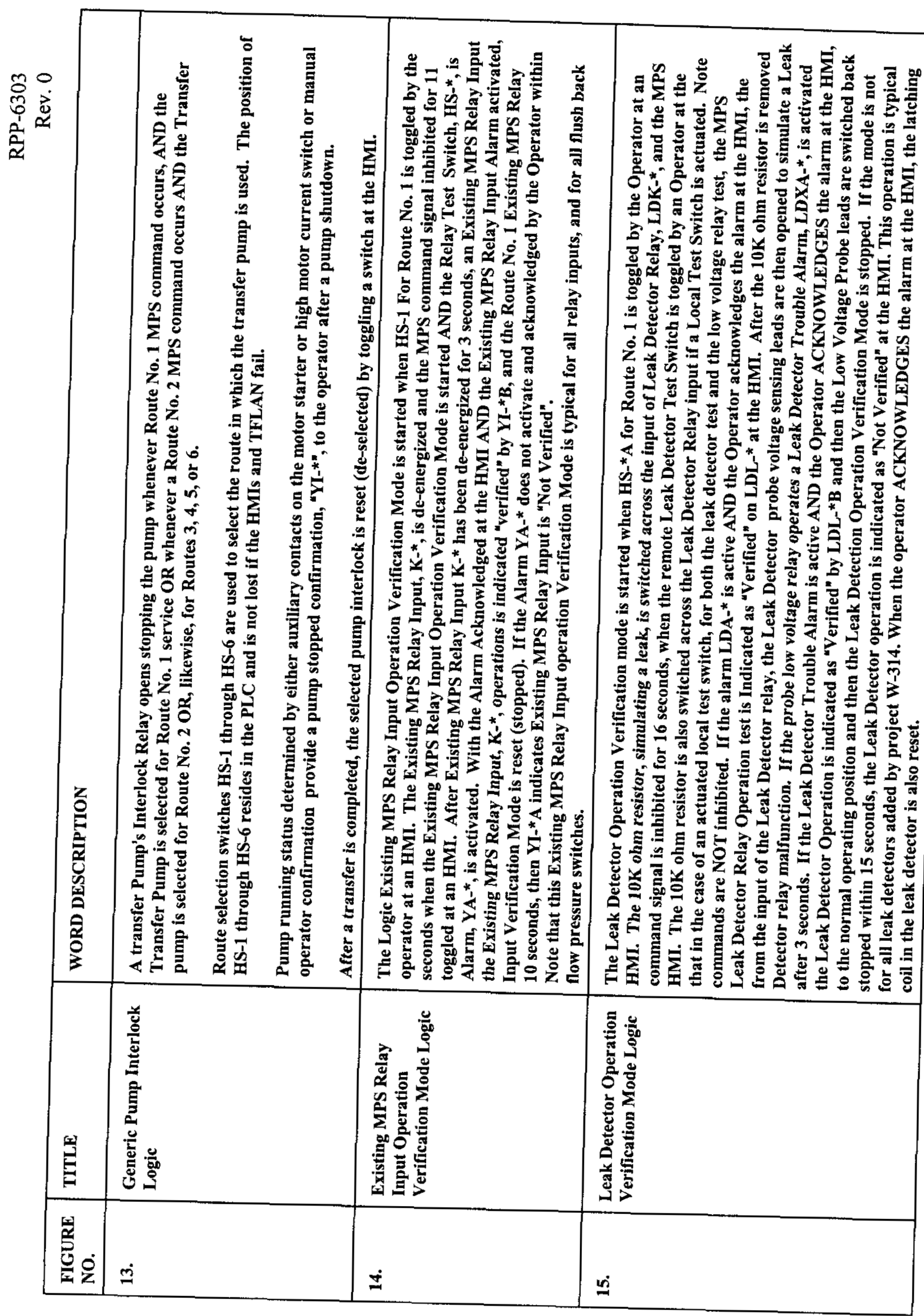




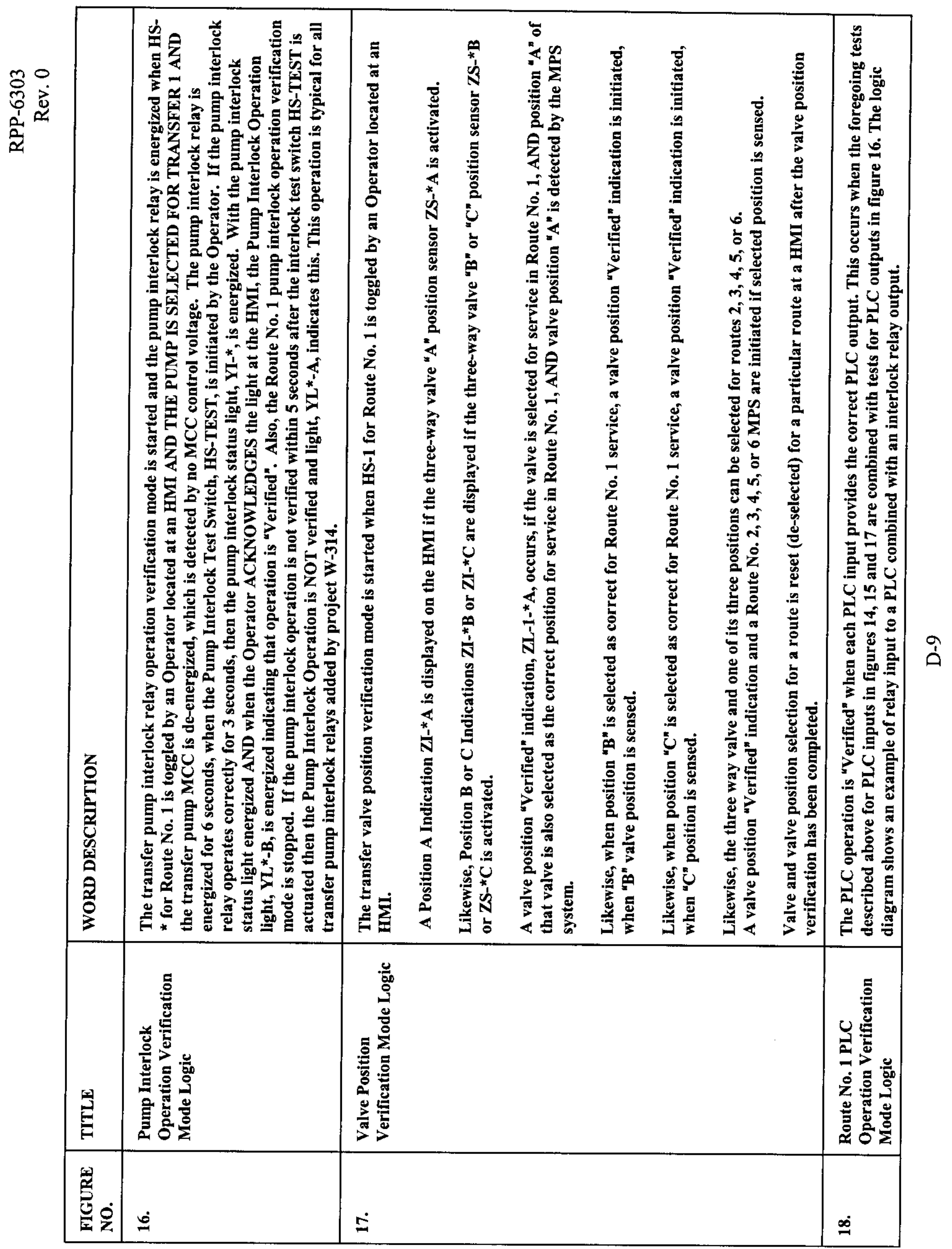




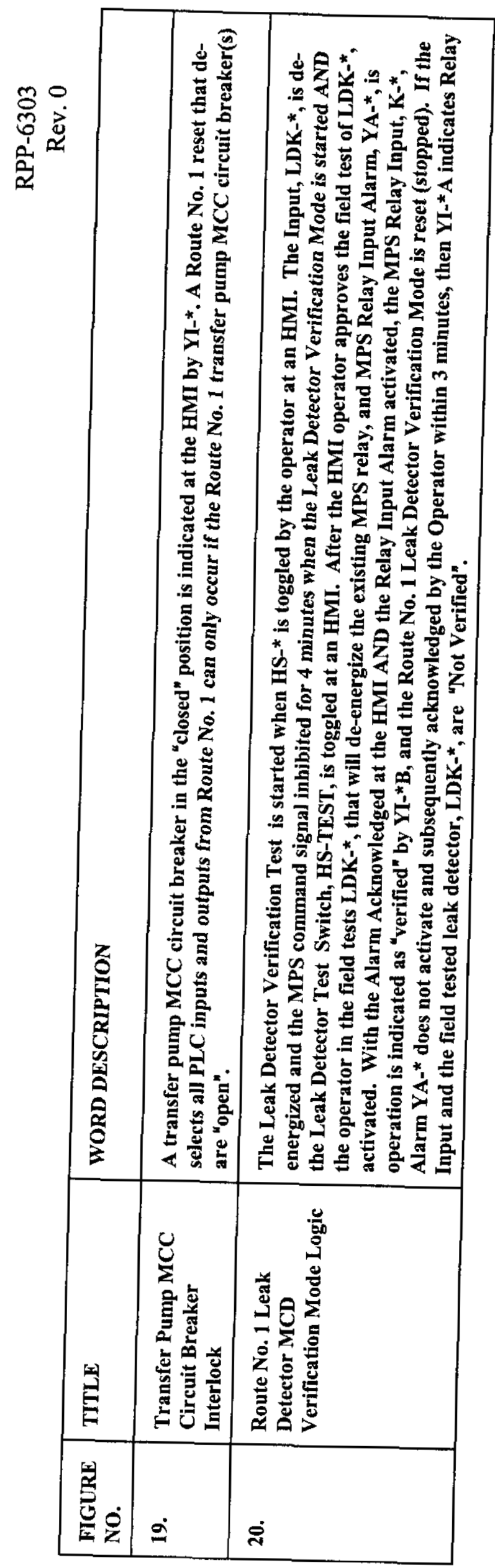

울 


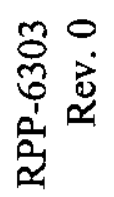

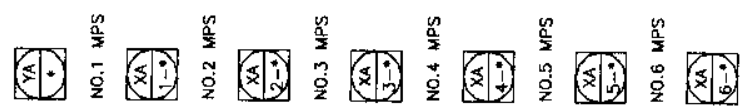
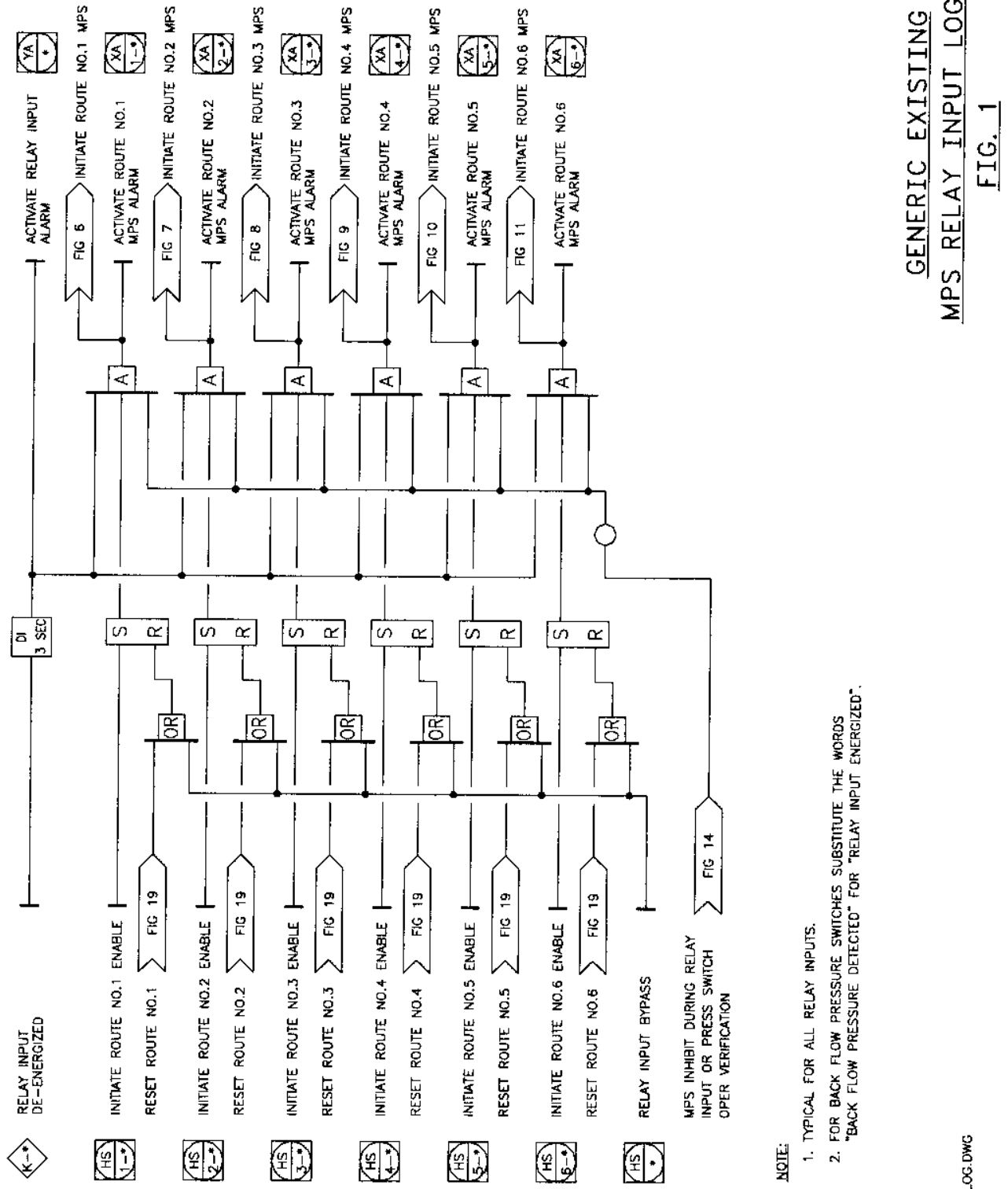


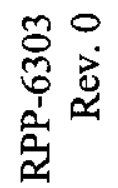

透果

国:
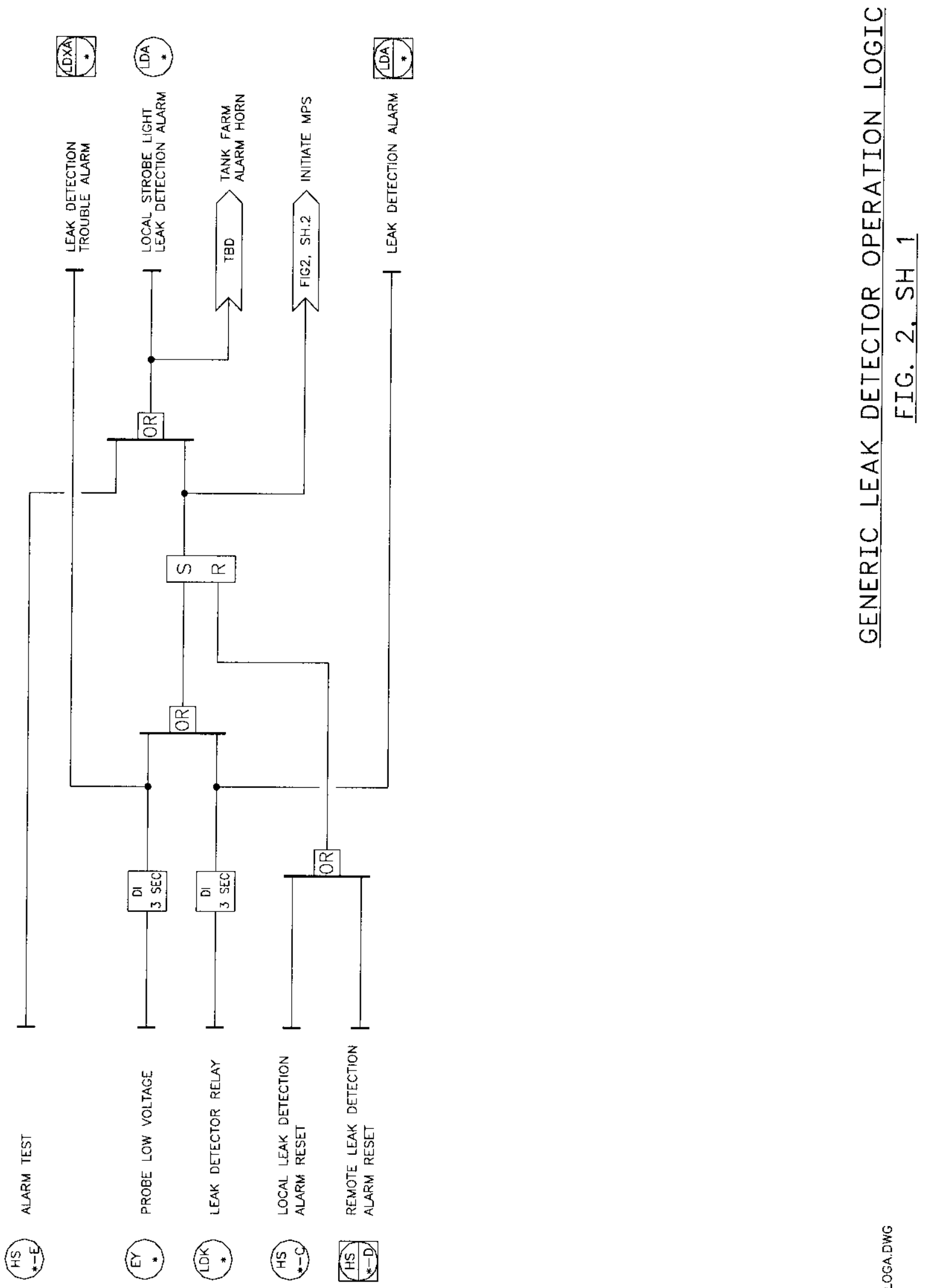

$\frac{1}{a}$ 


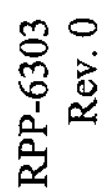

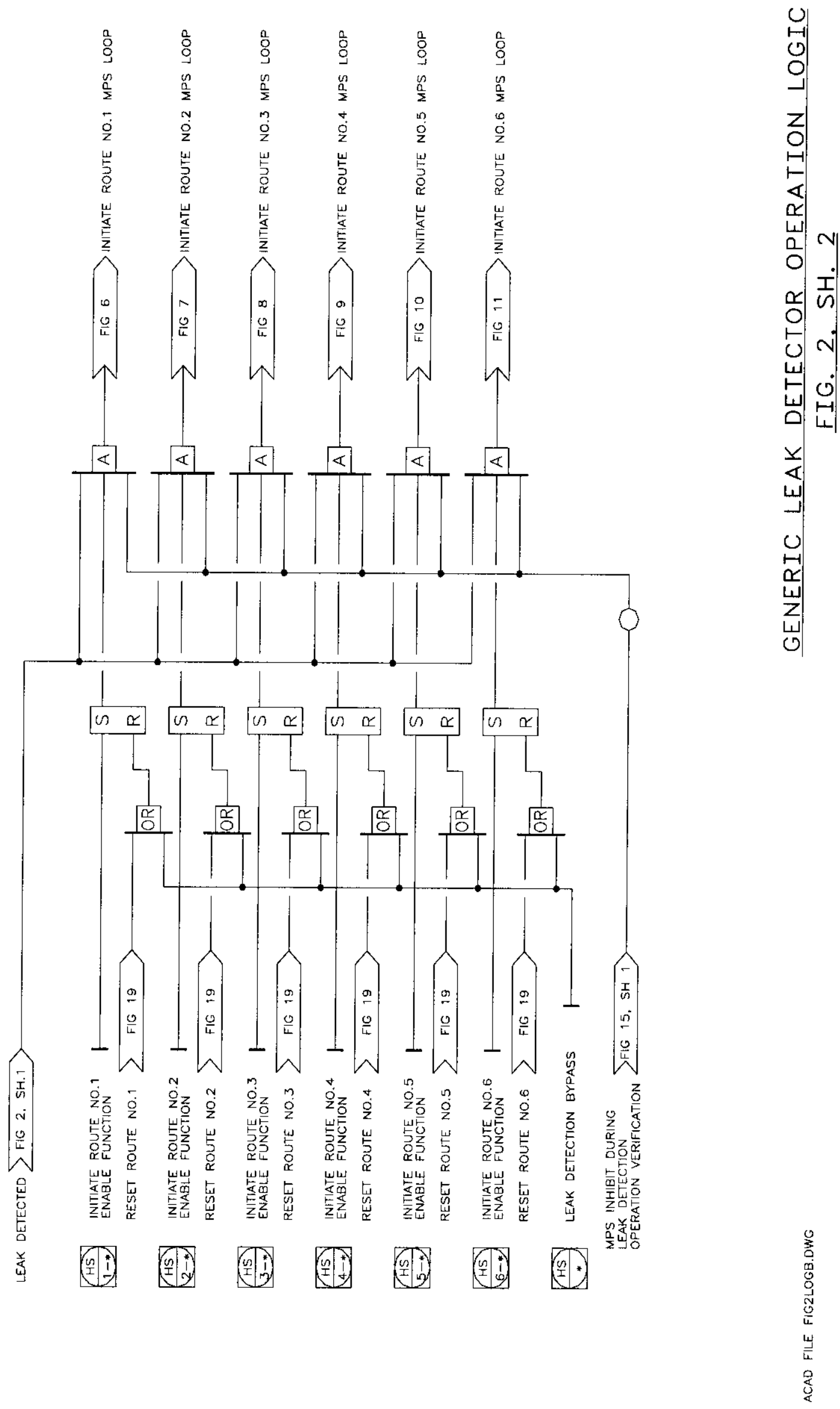




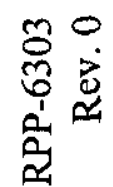
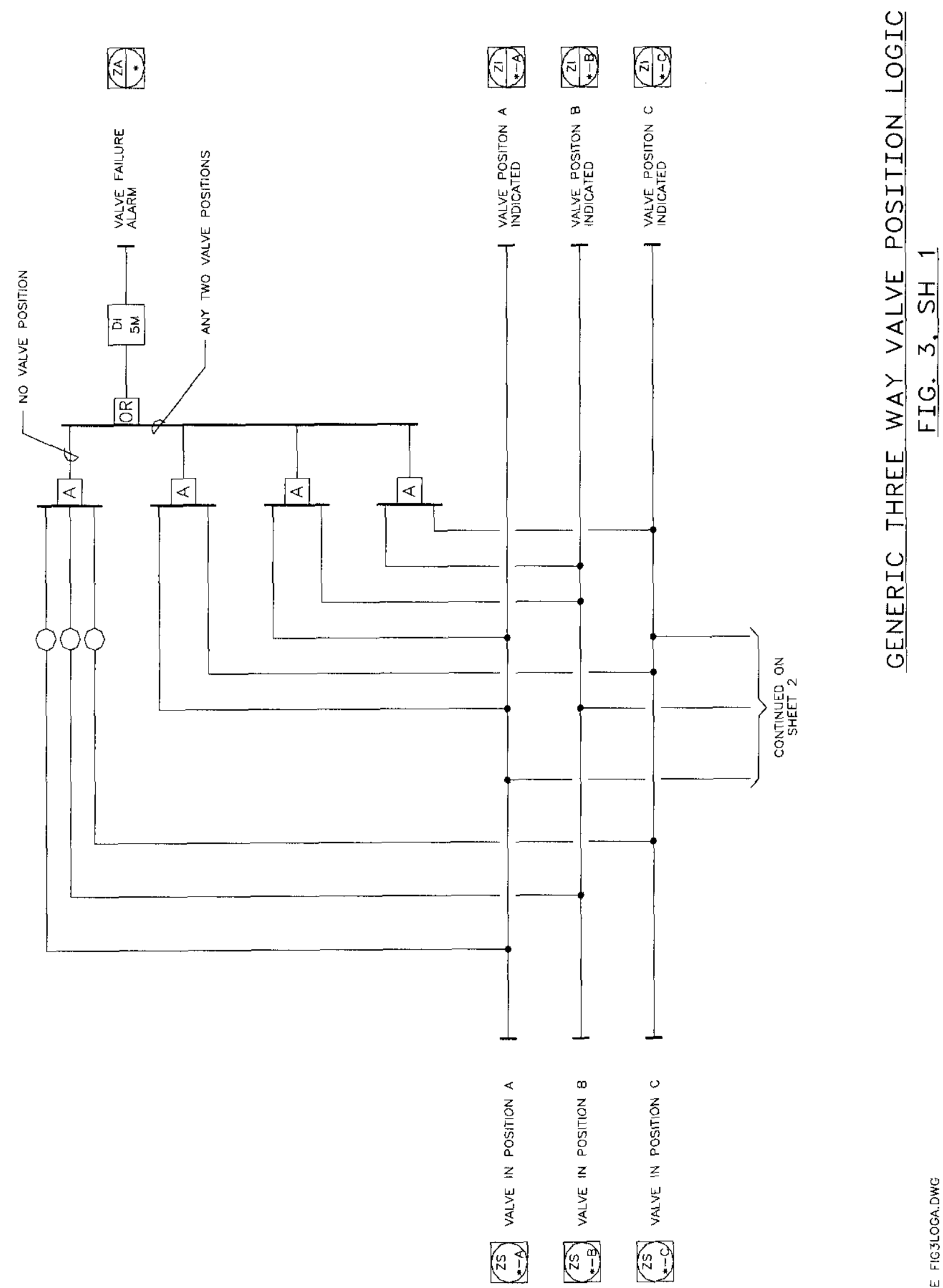

ป 


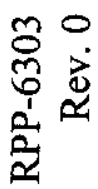

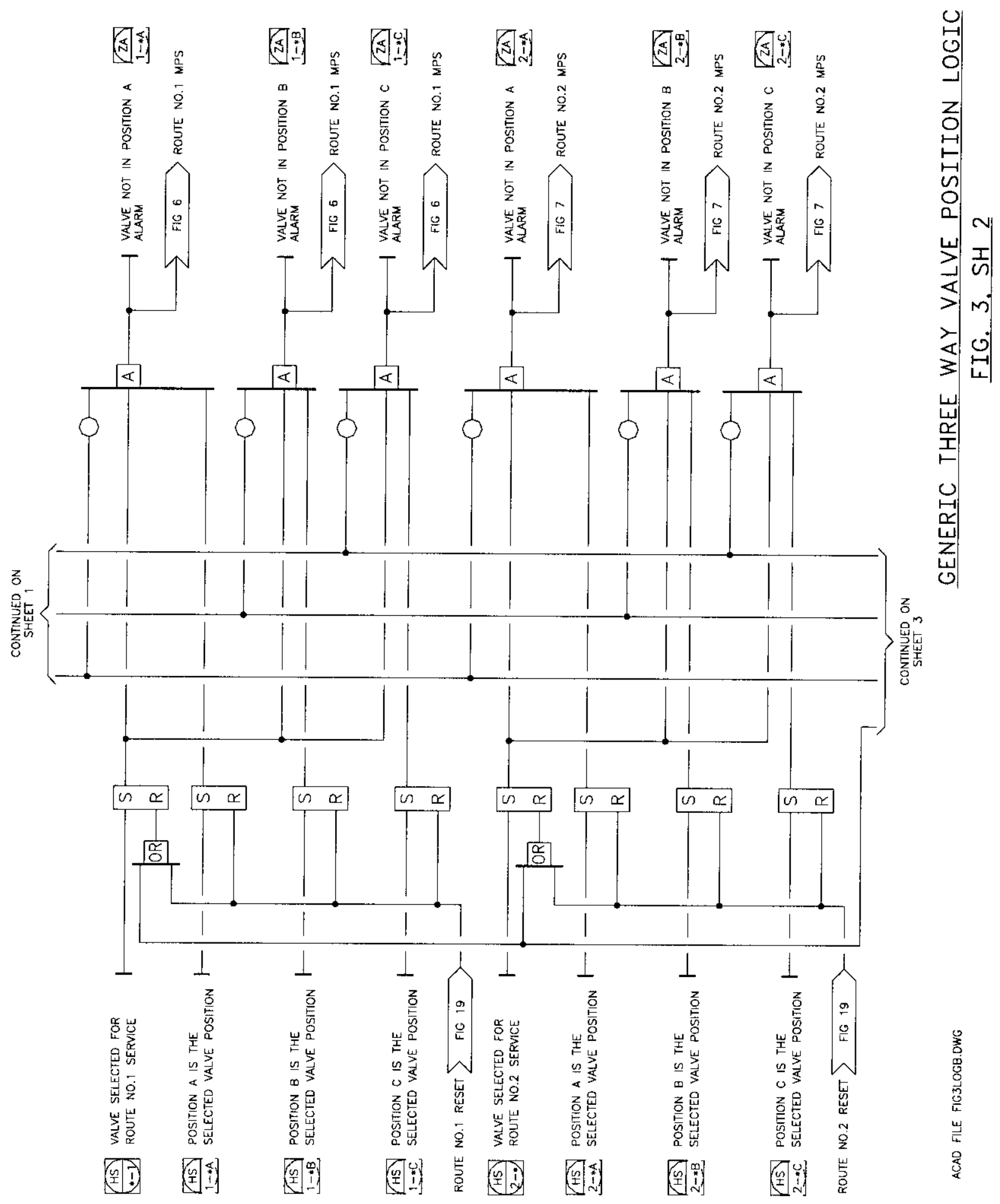




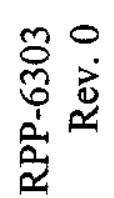

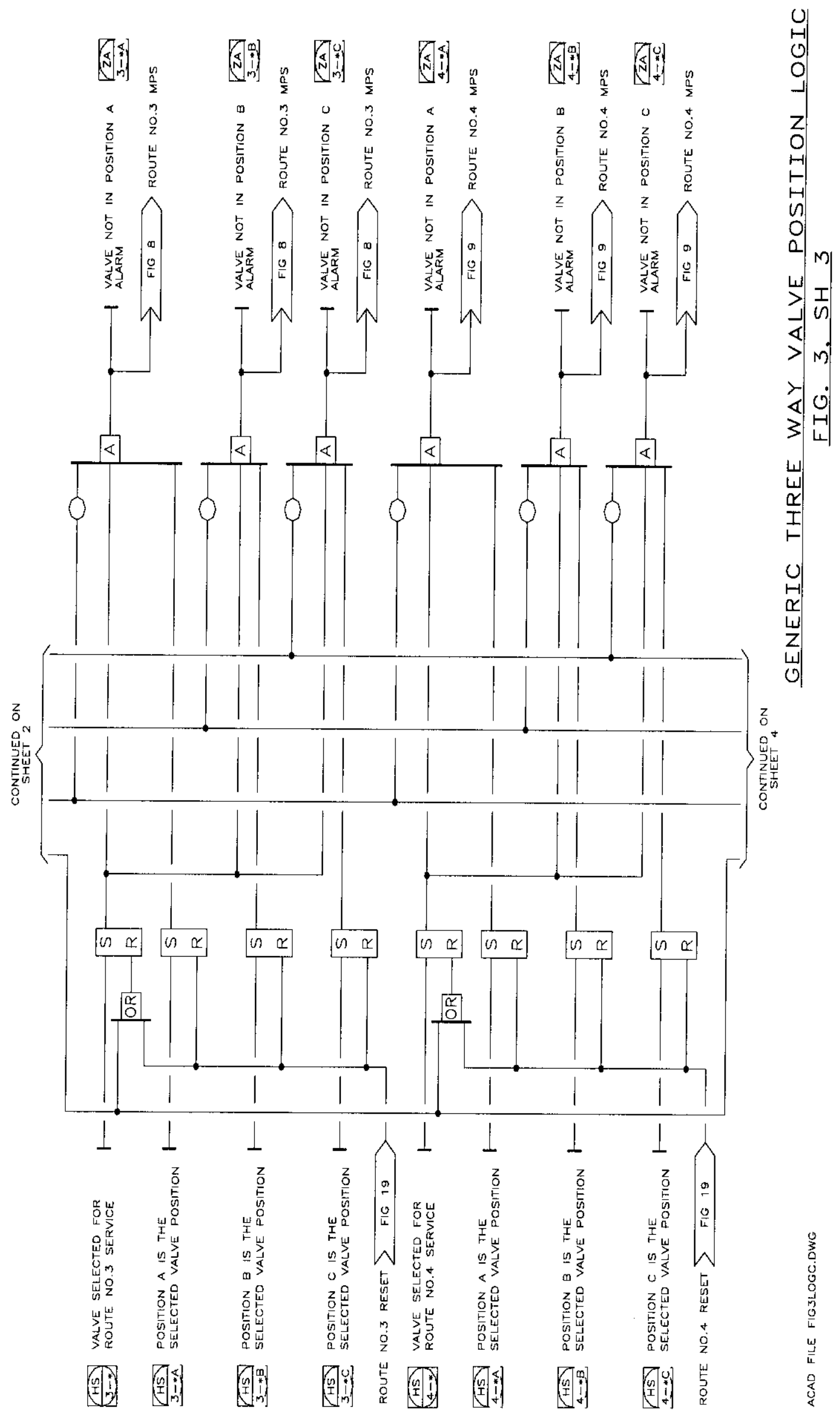




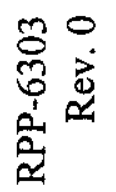

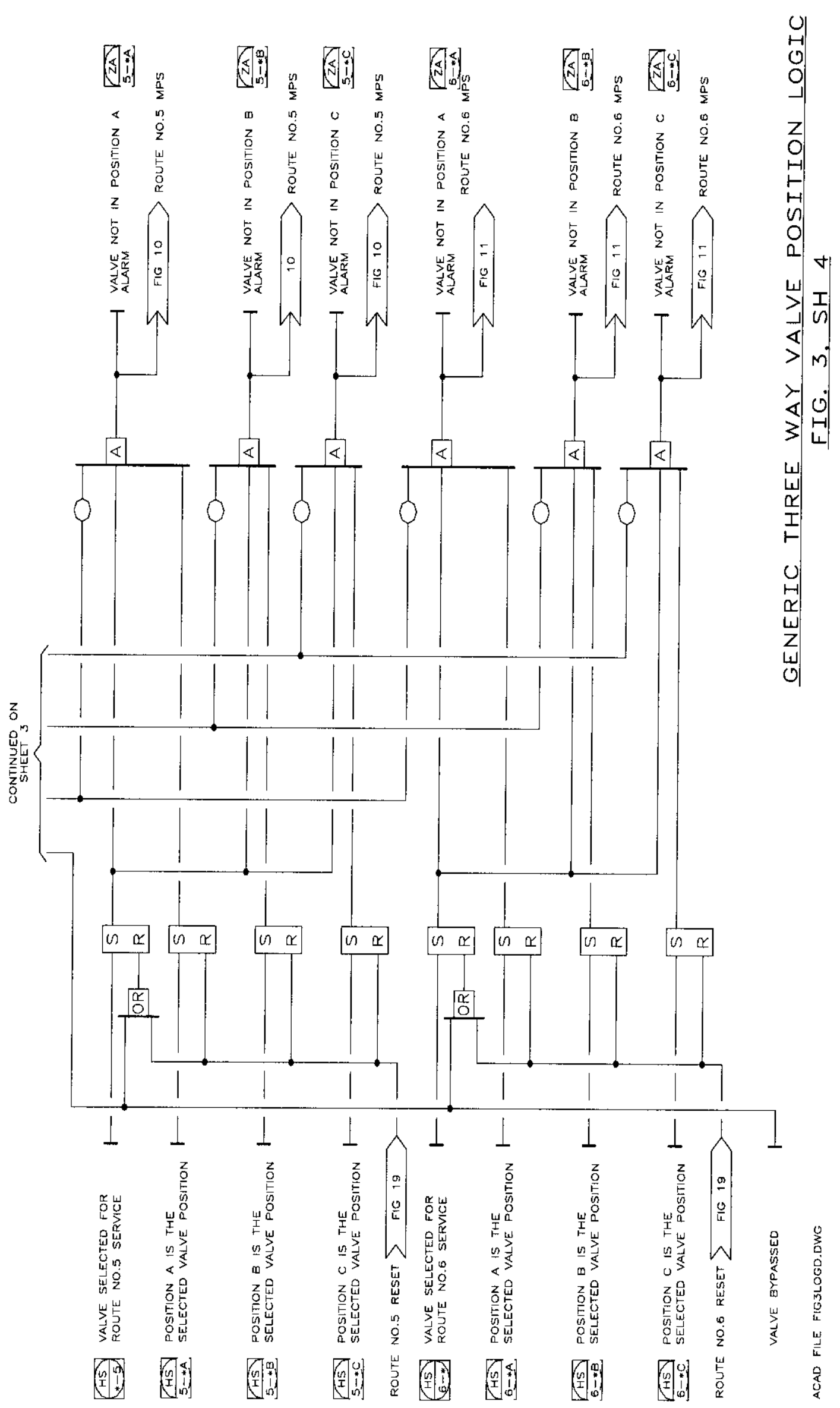




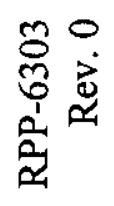

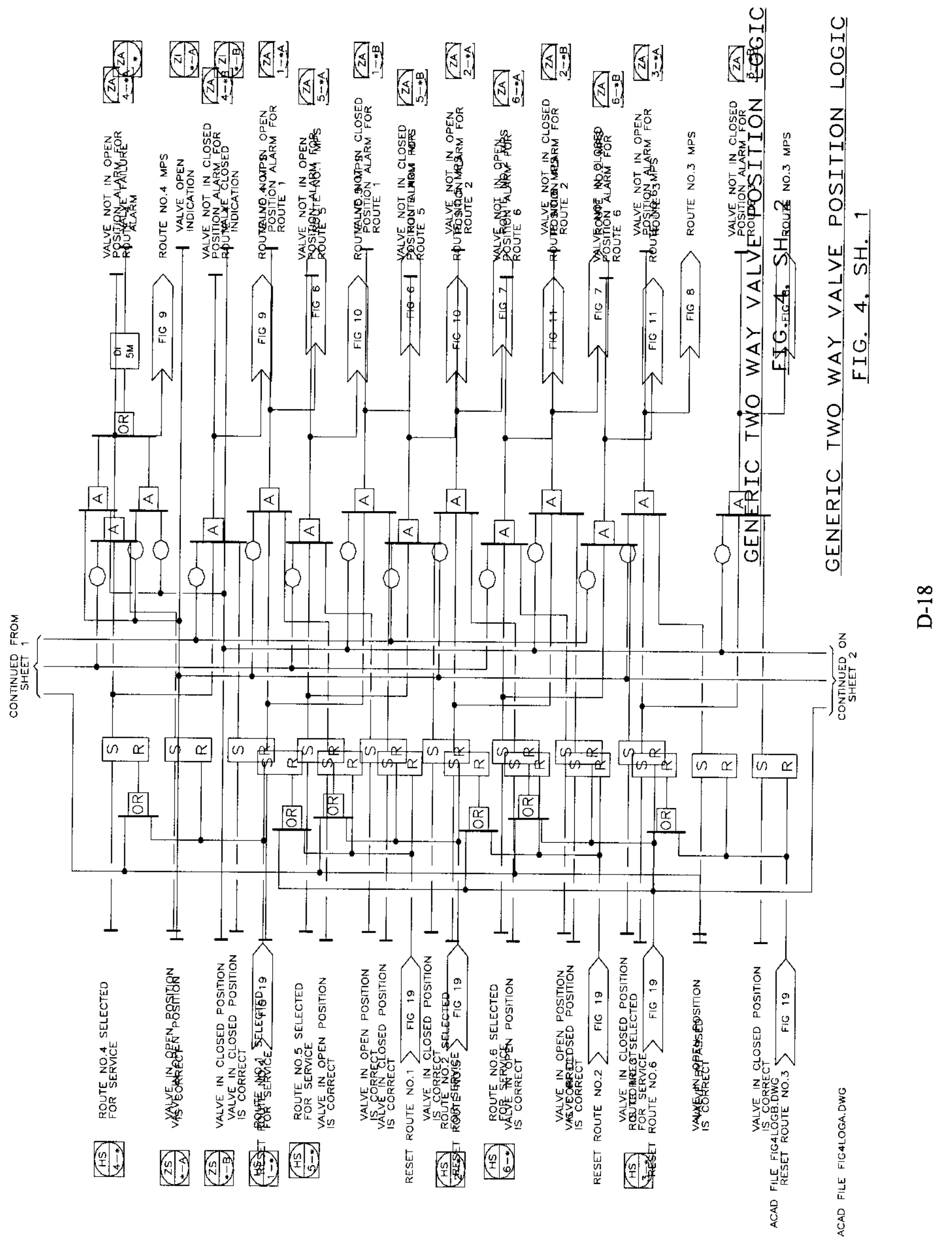




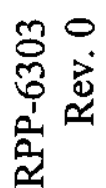

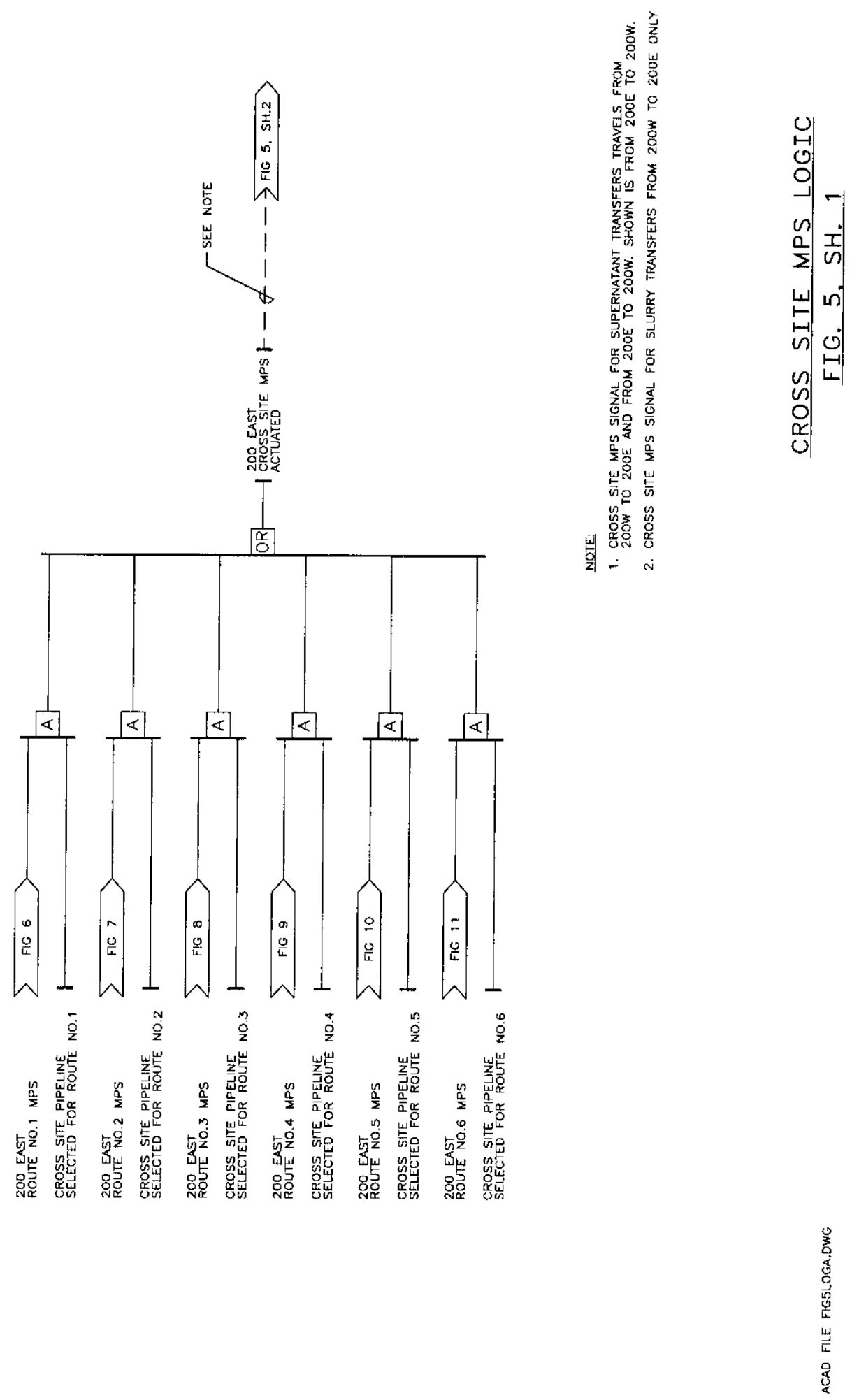

$\frac{a}{a}$ 


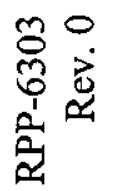
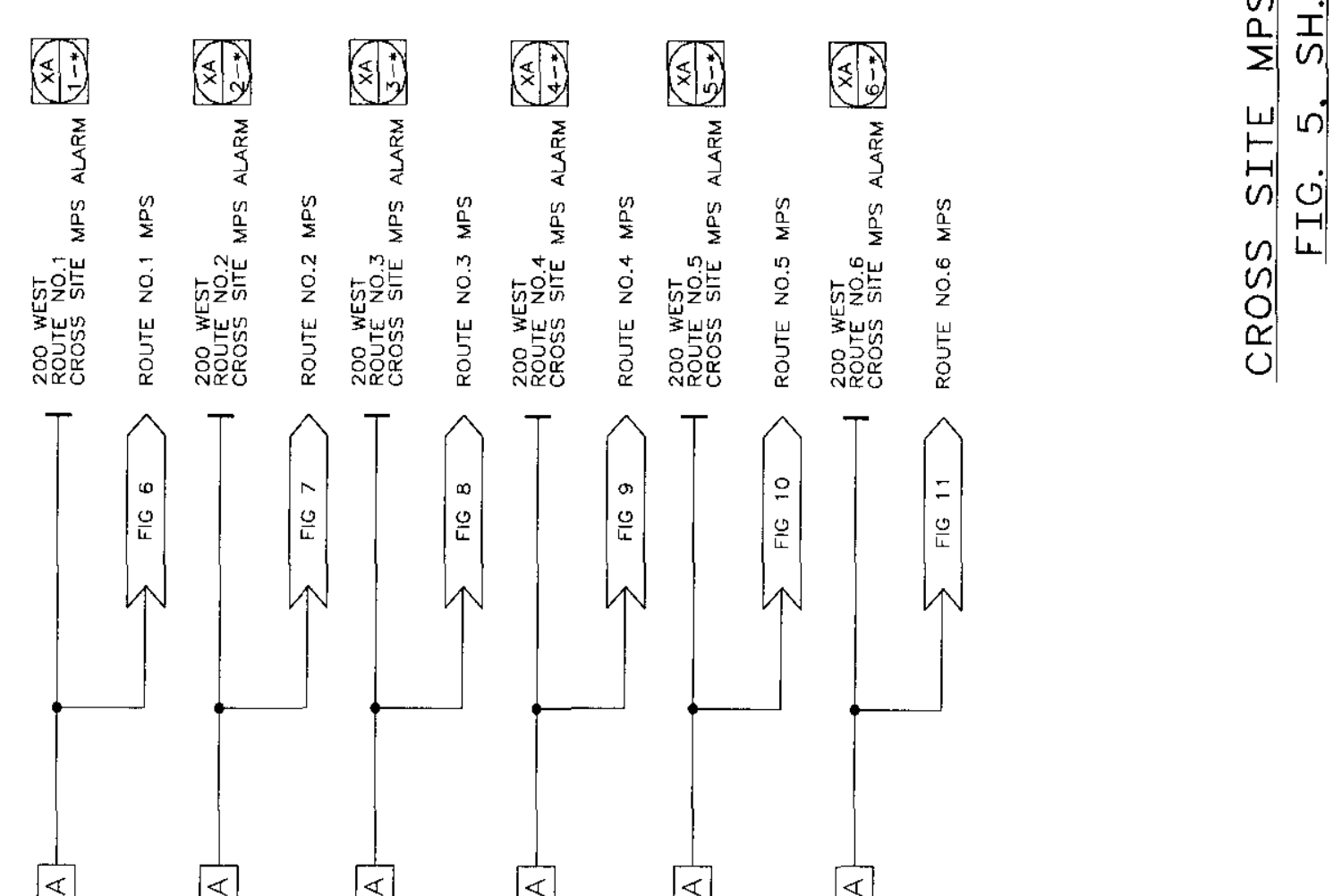

ஸे

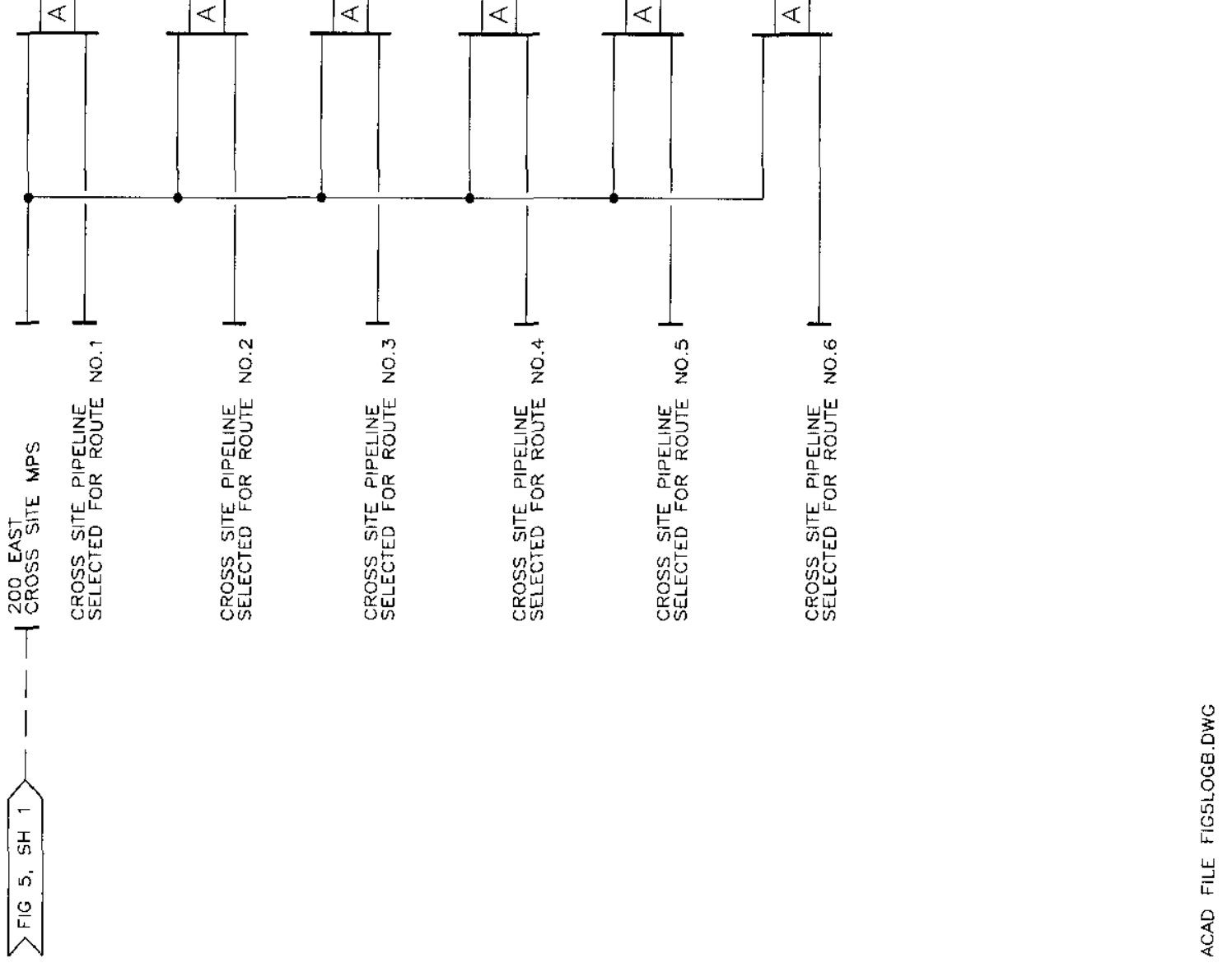




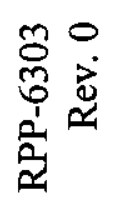

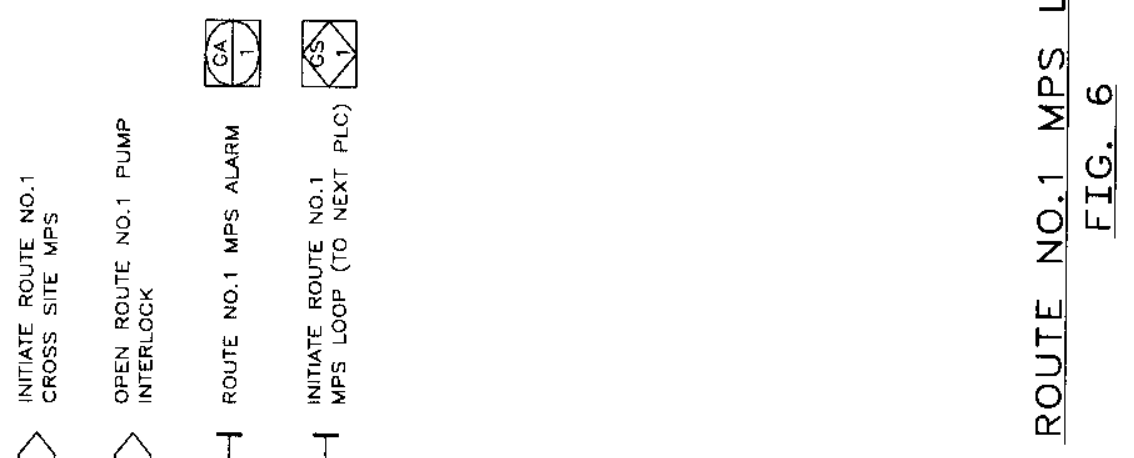

舜
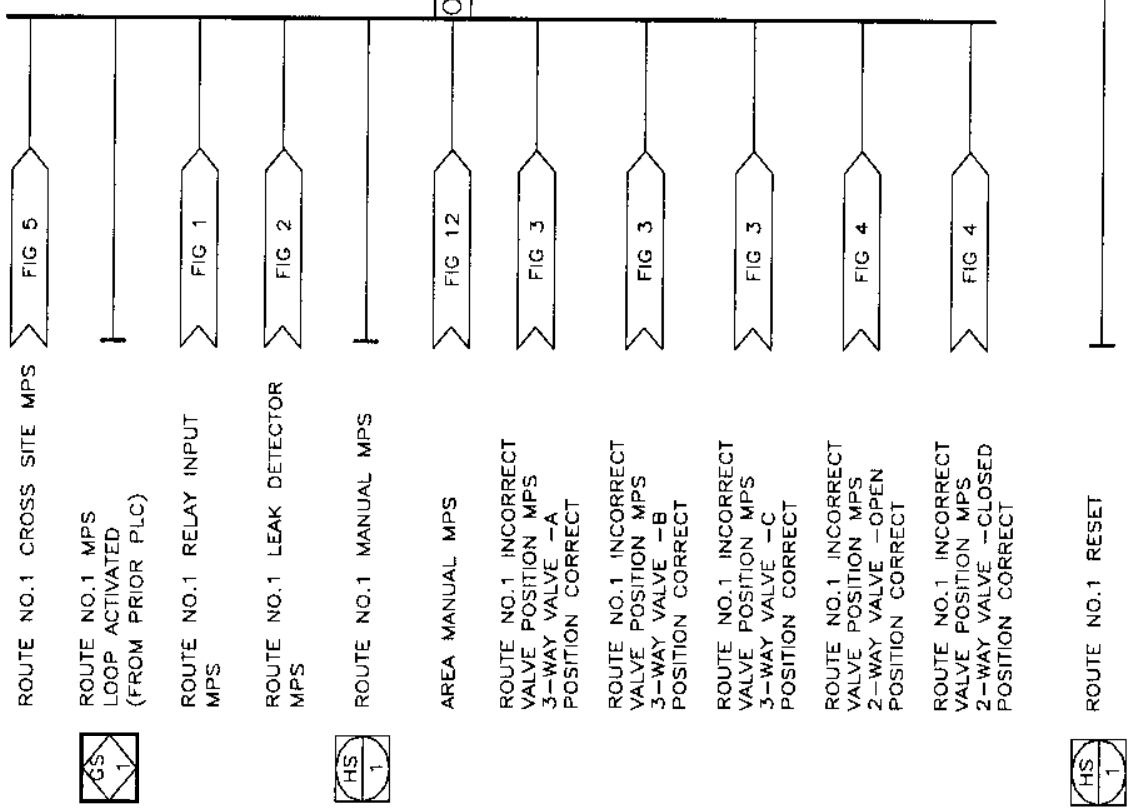


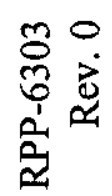
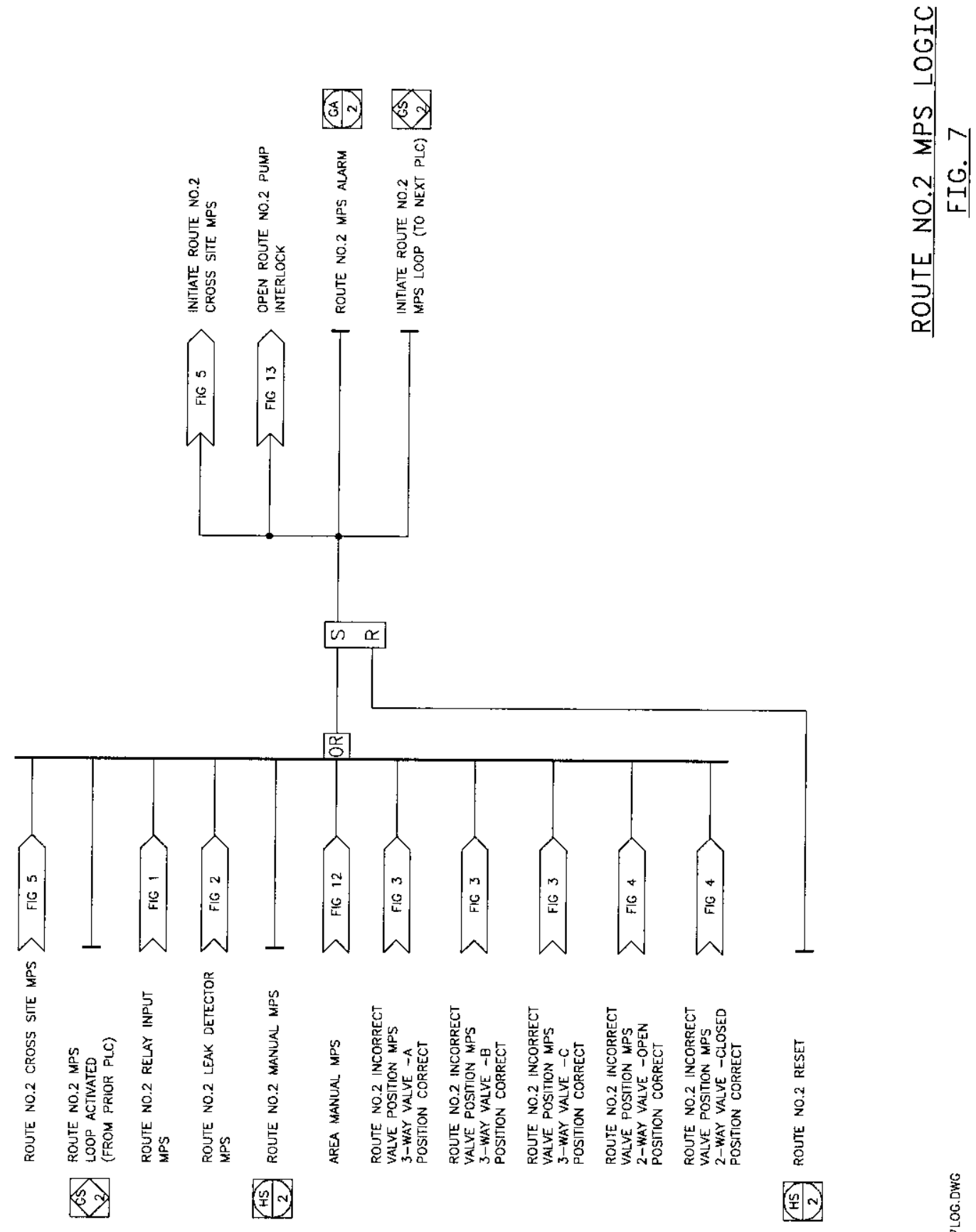


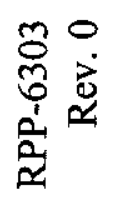
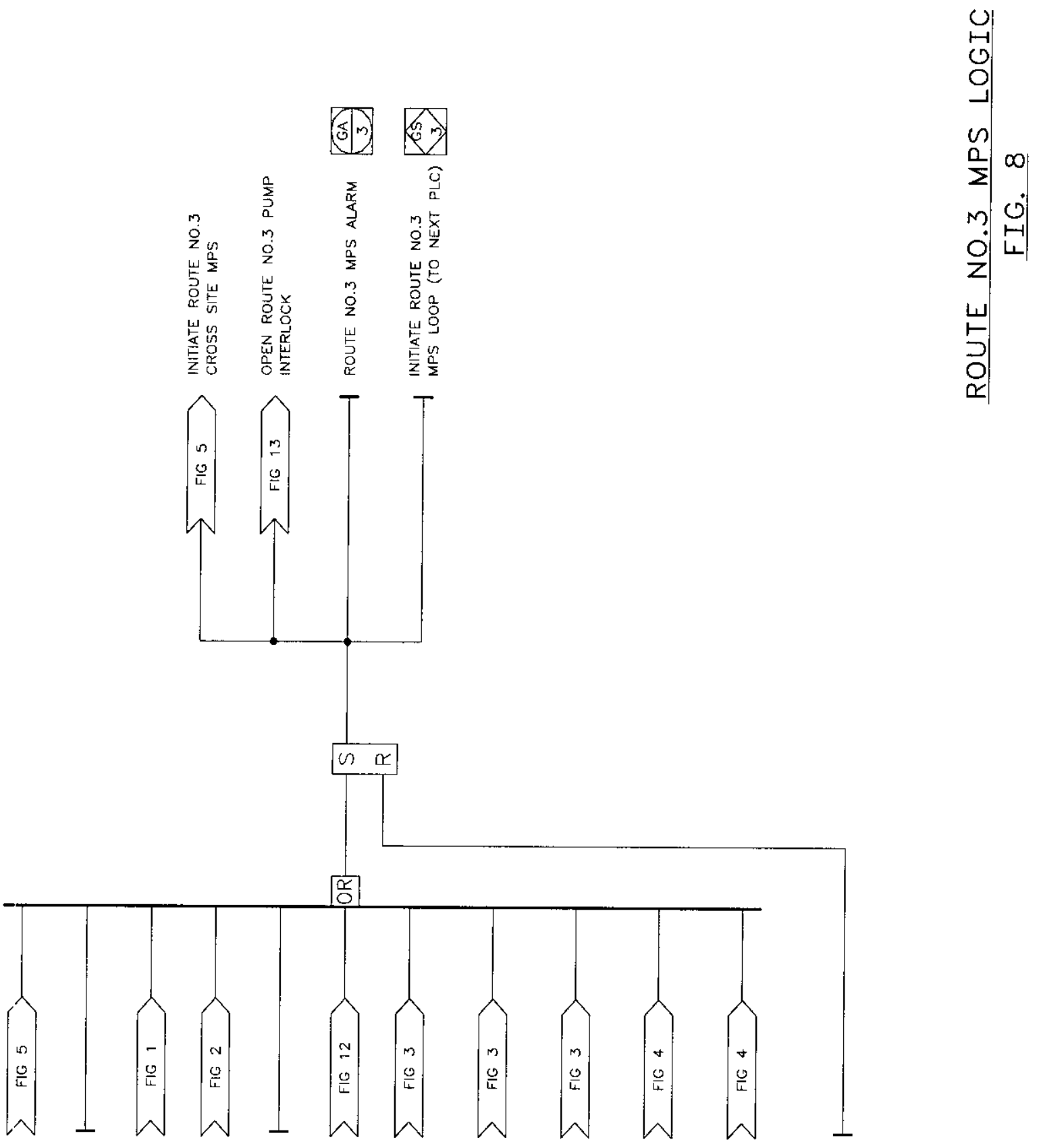

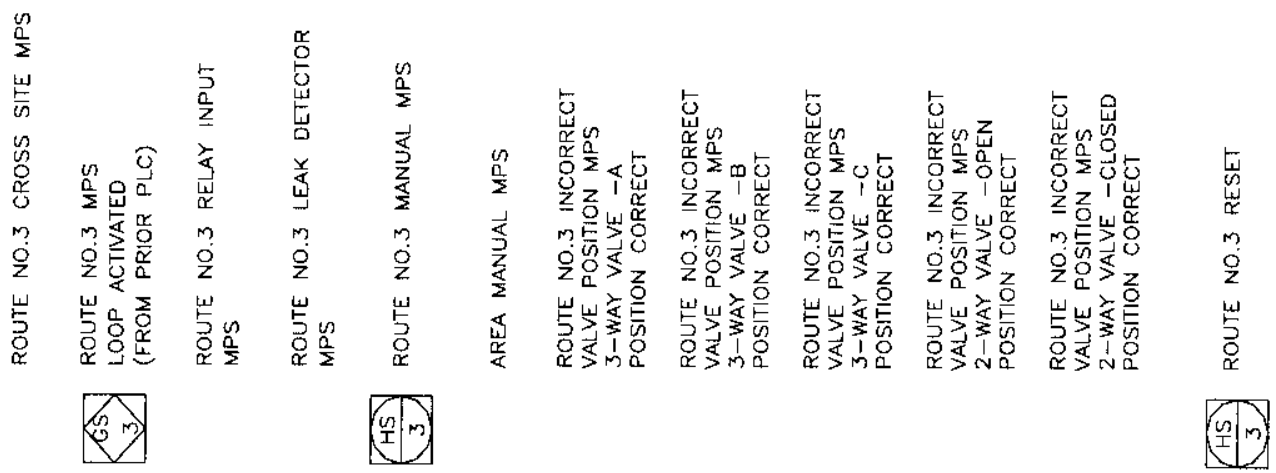




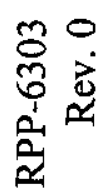

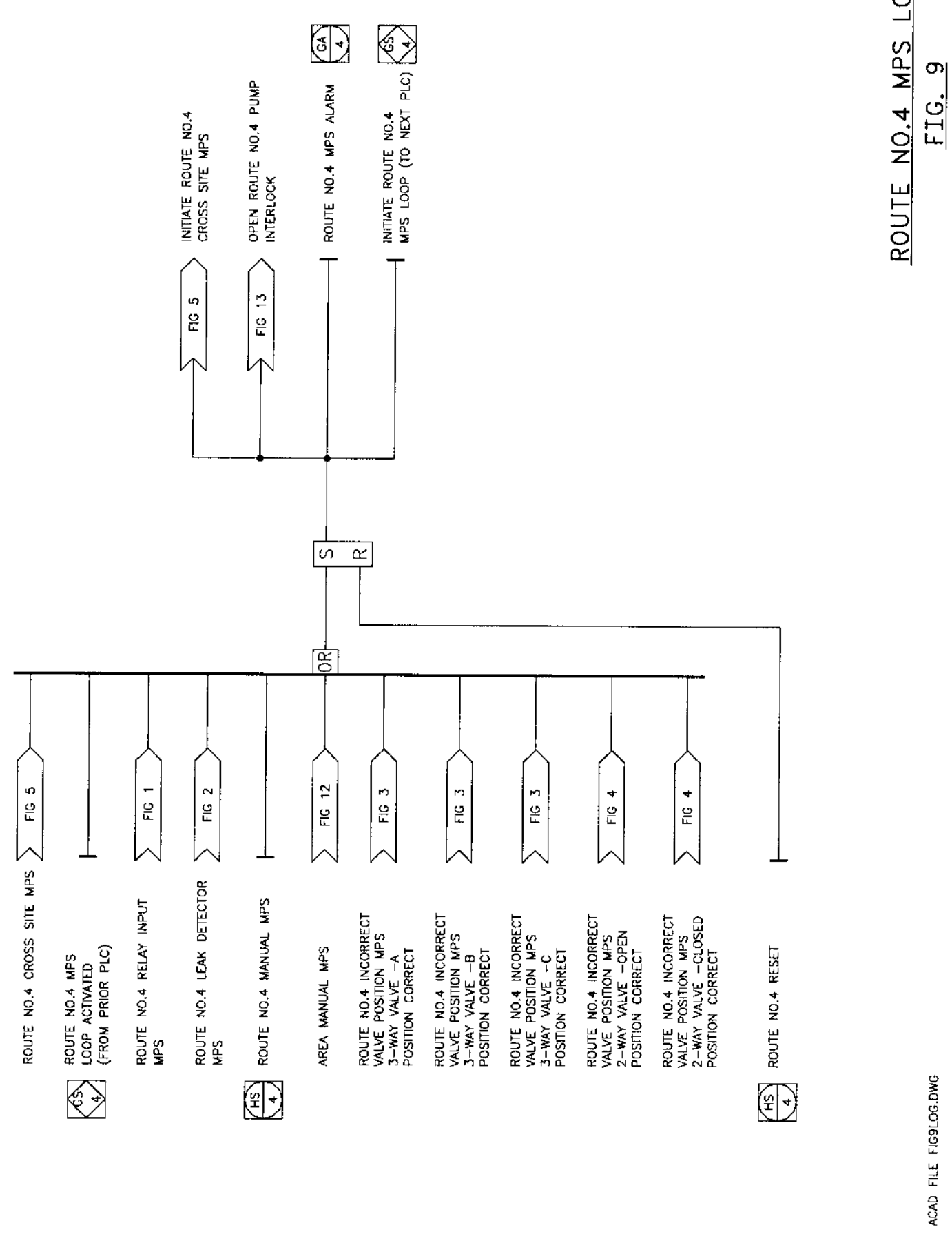

㐫 
$\begin{array}{ll}0 & 0 \\ 0 & 0 \\ 0 & 0 \\ 0 & 0\end{array}$

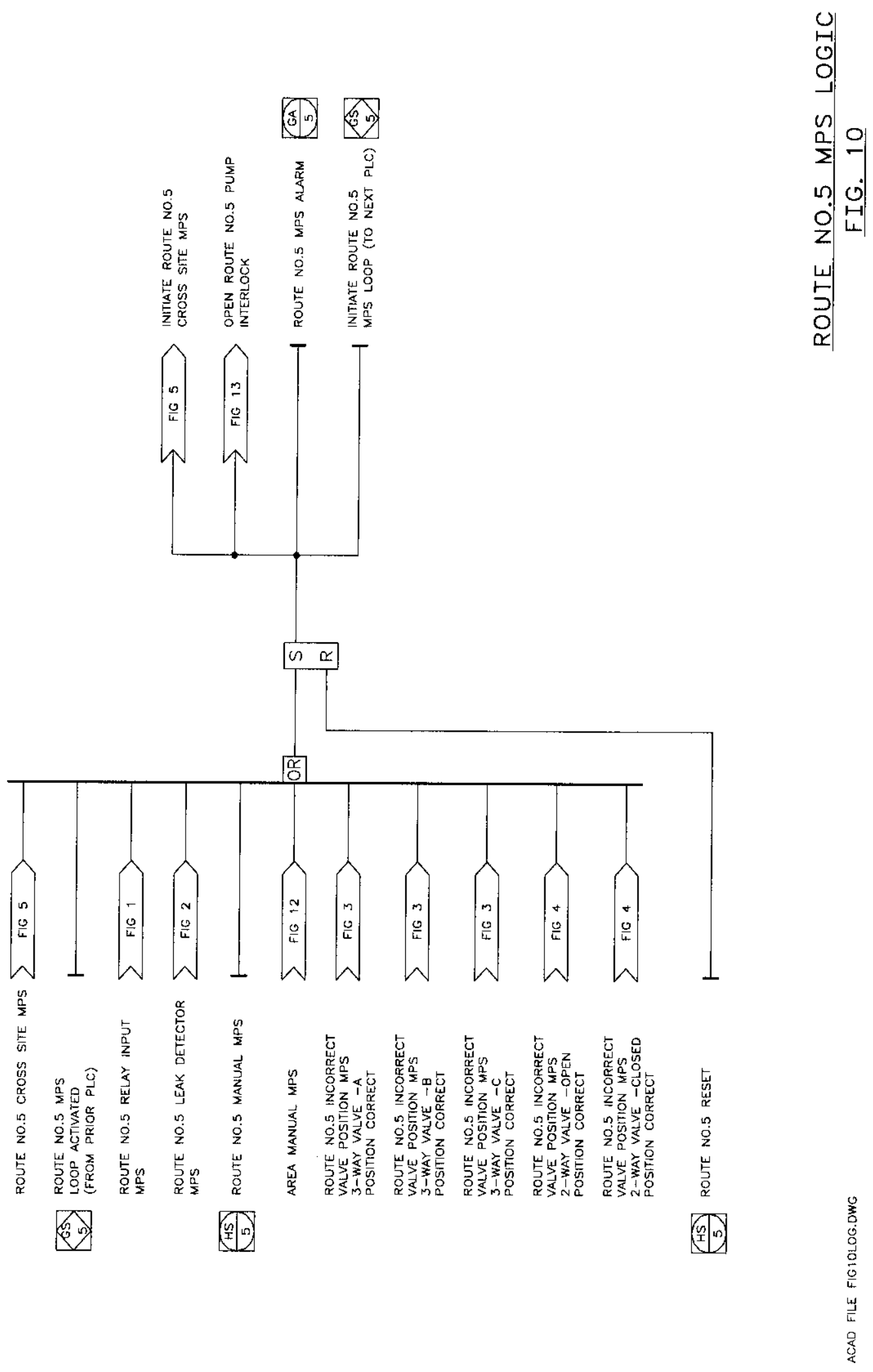



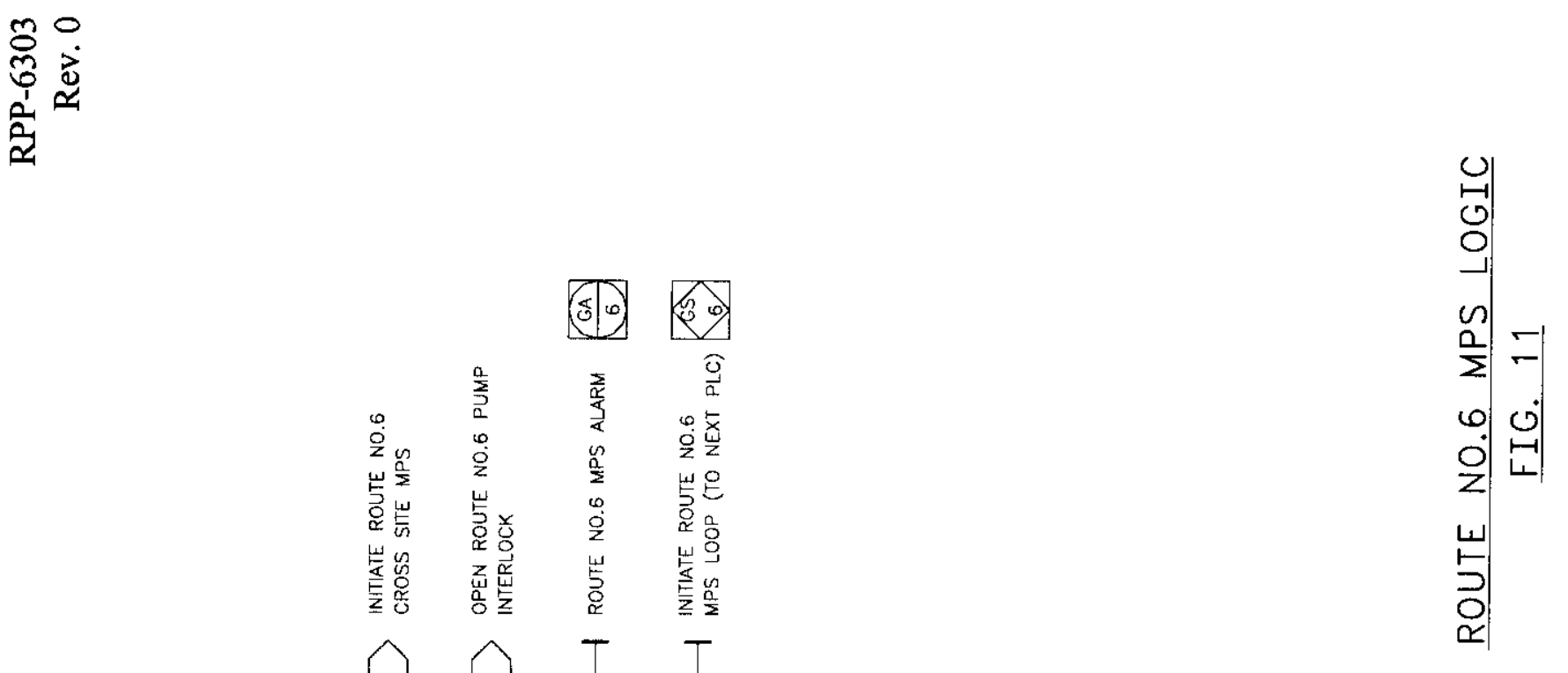

㐿

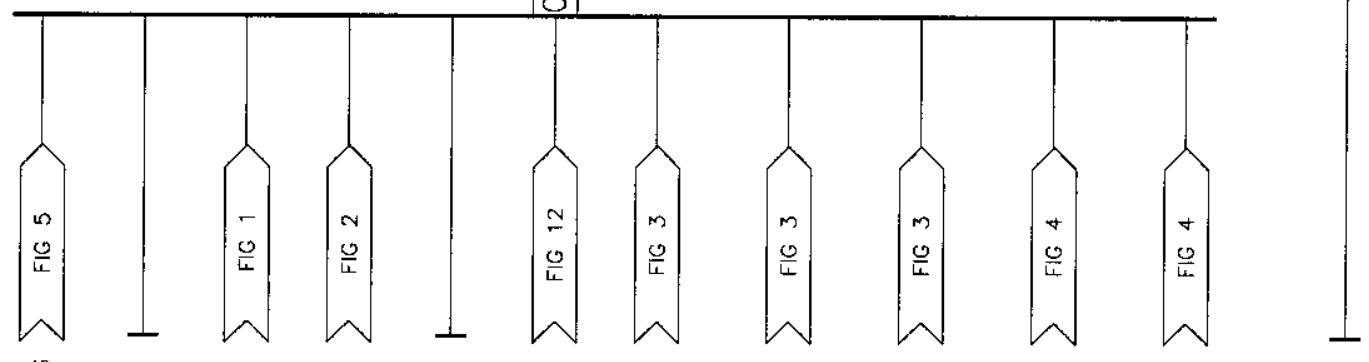

ฐั

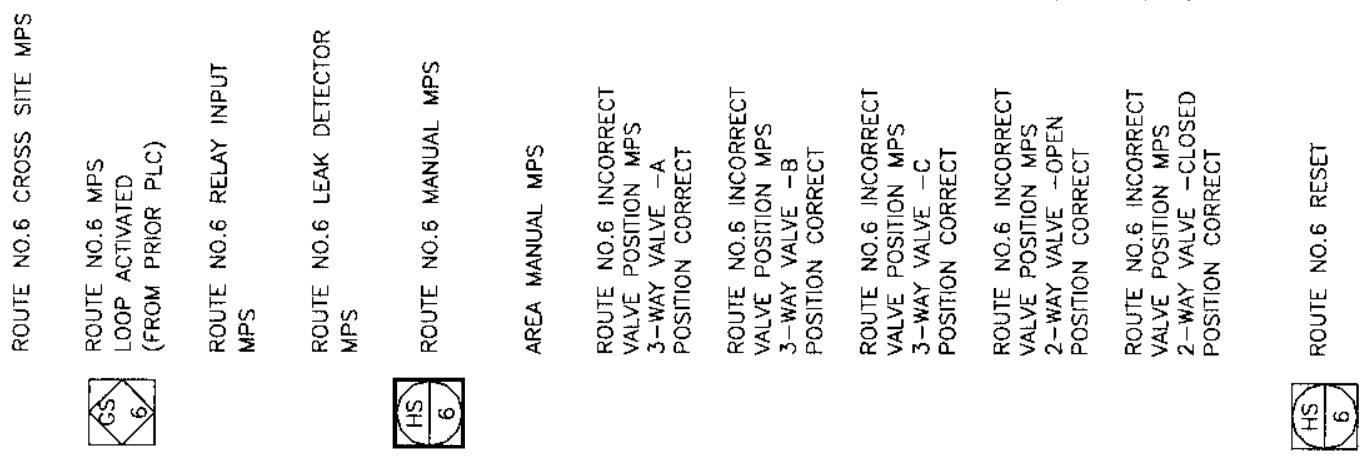




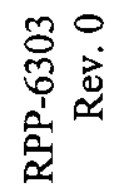

주욤

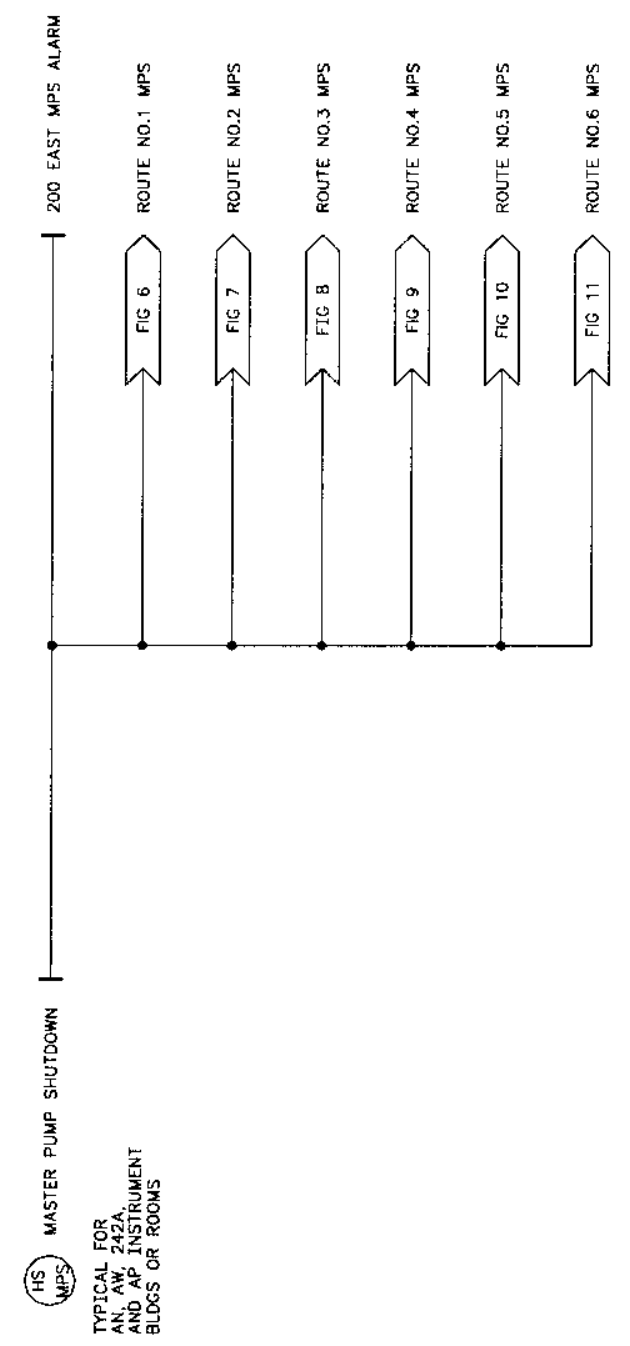

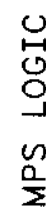

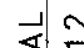

紊包

농

곤

ஸ்

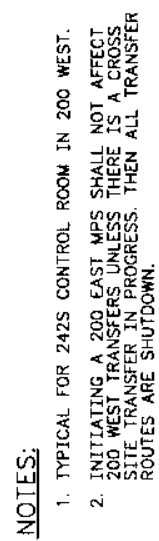




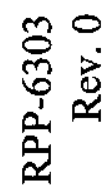

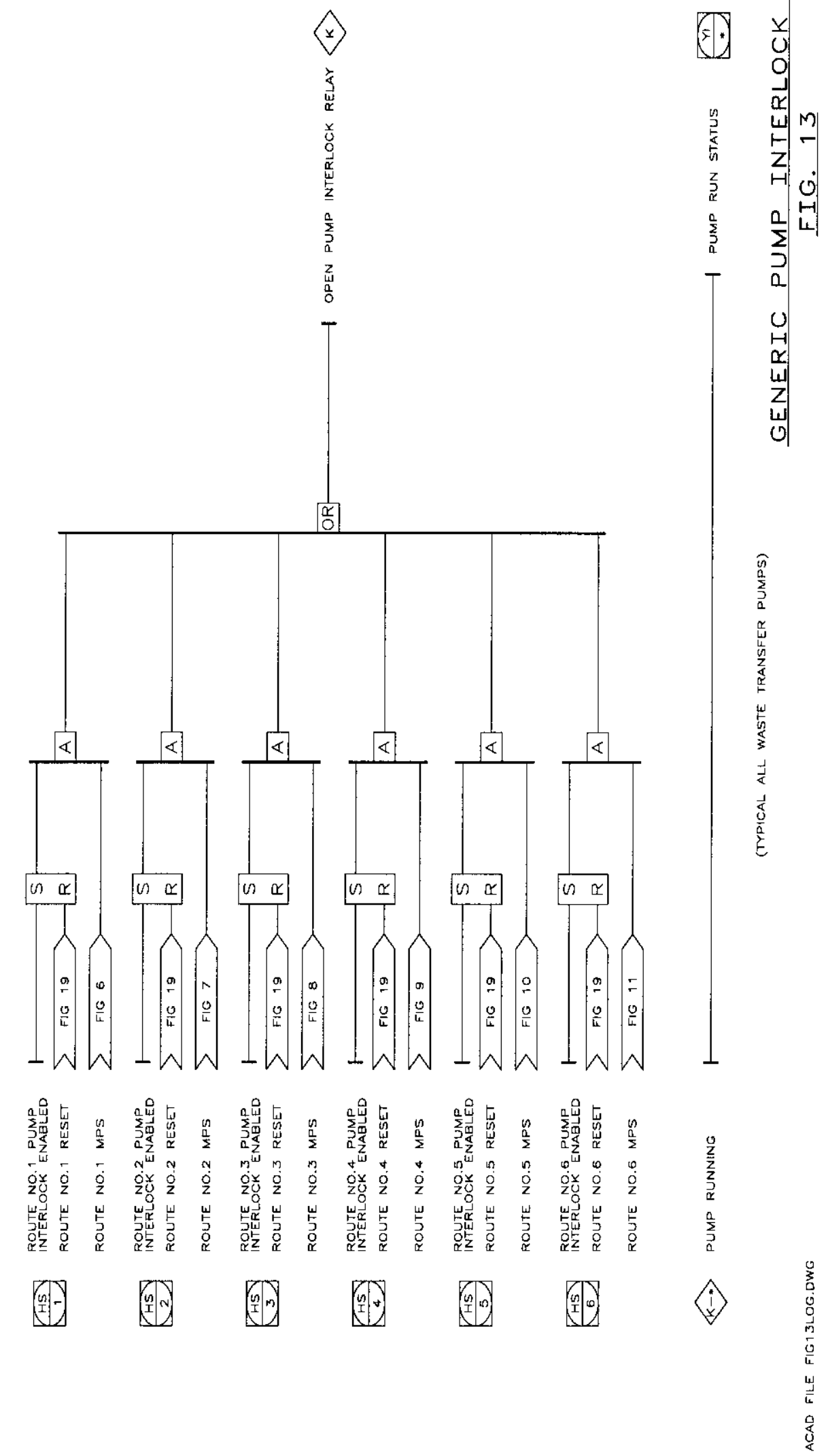




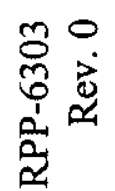

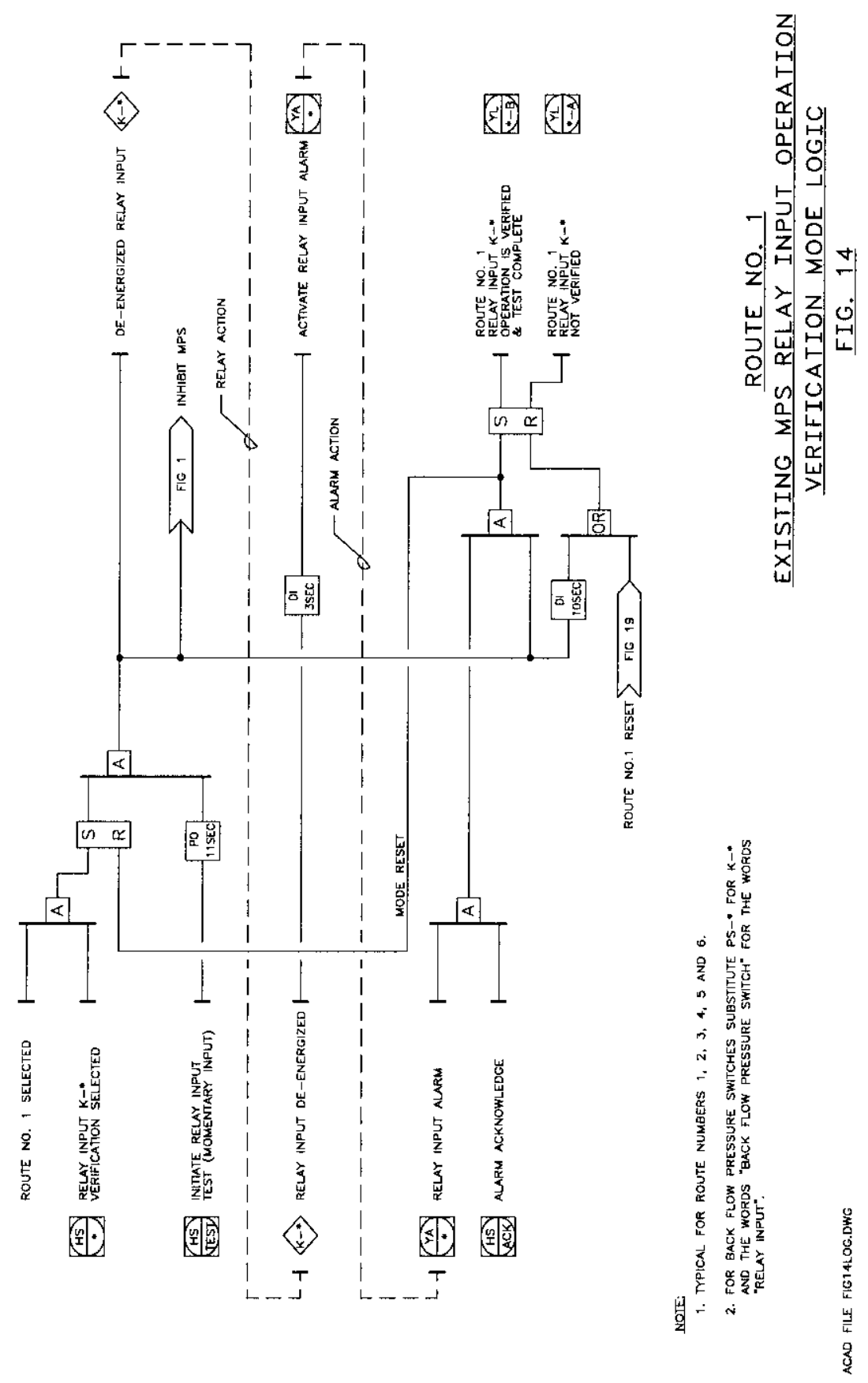

๖ั่ 


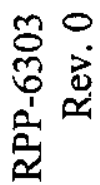

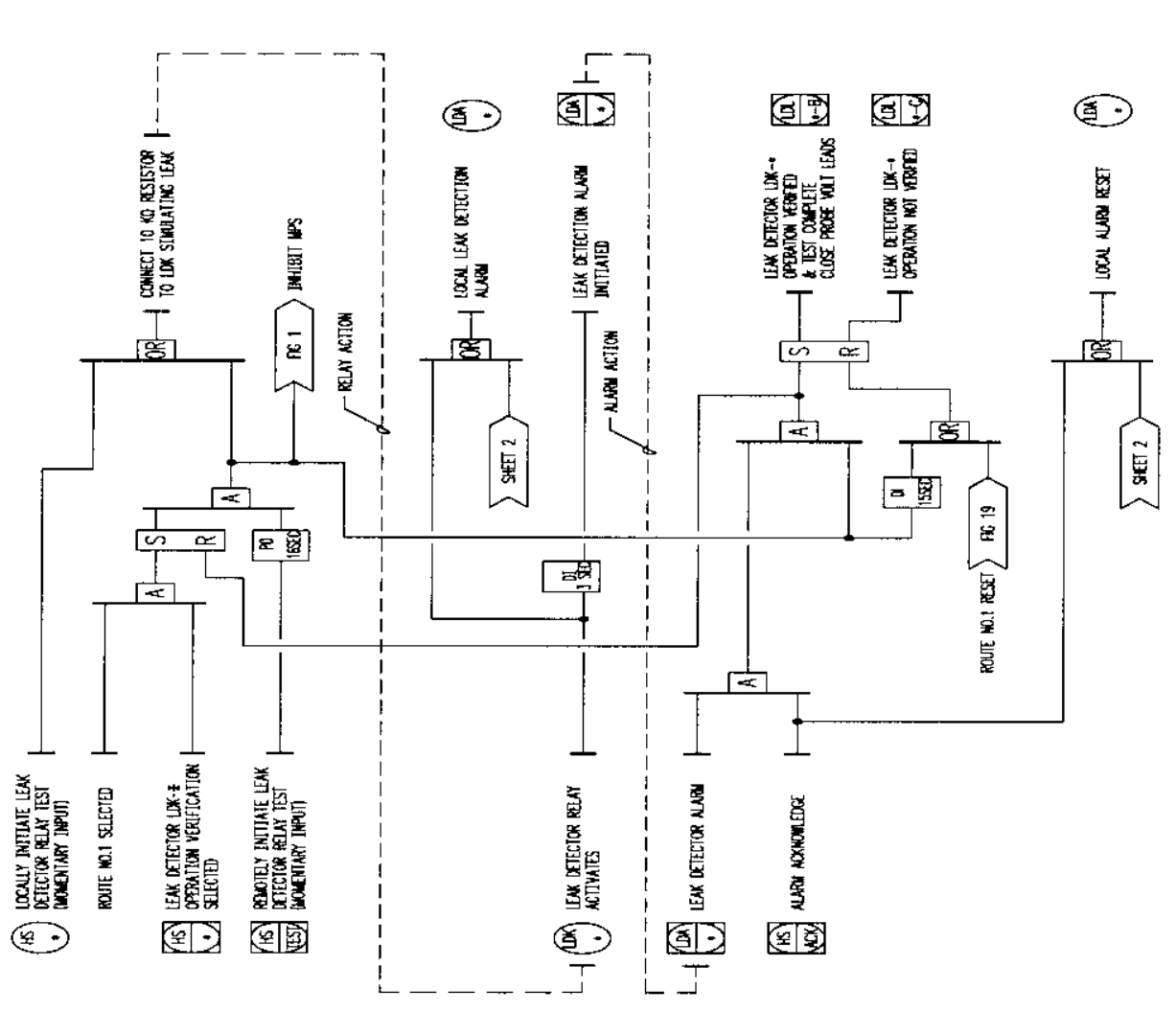



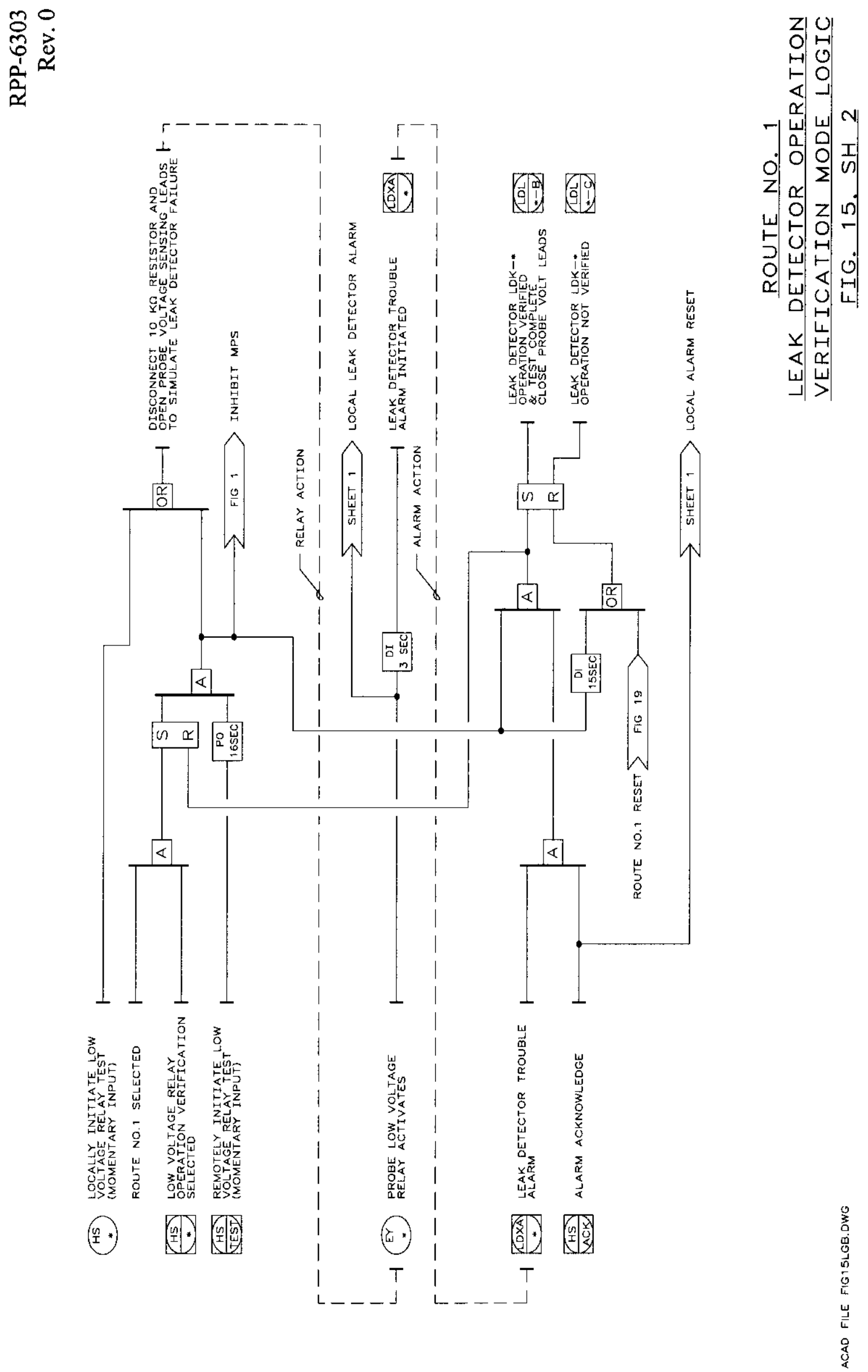

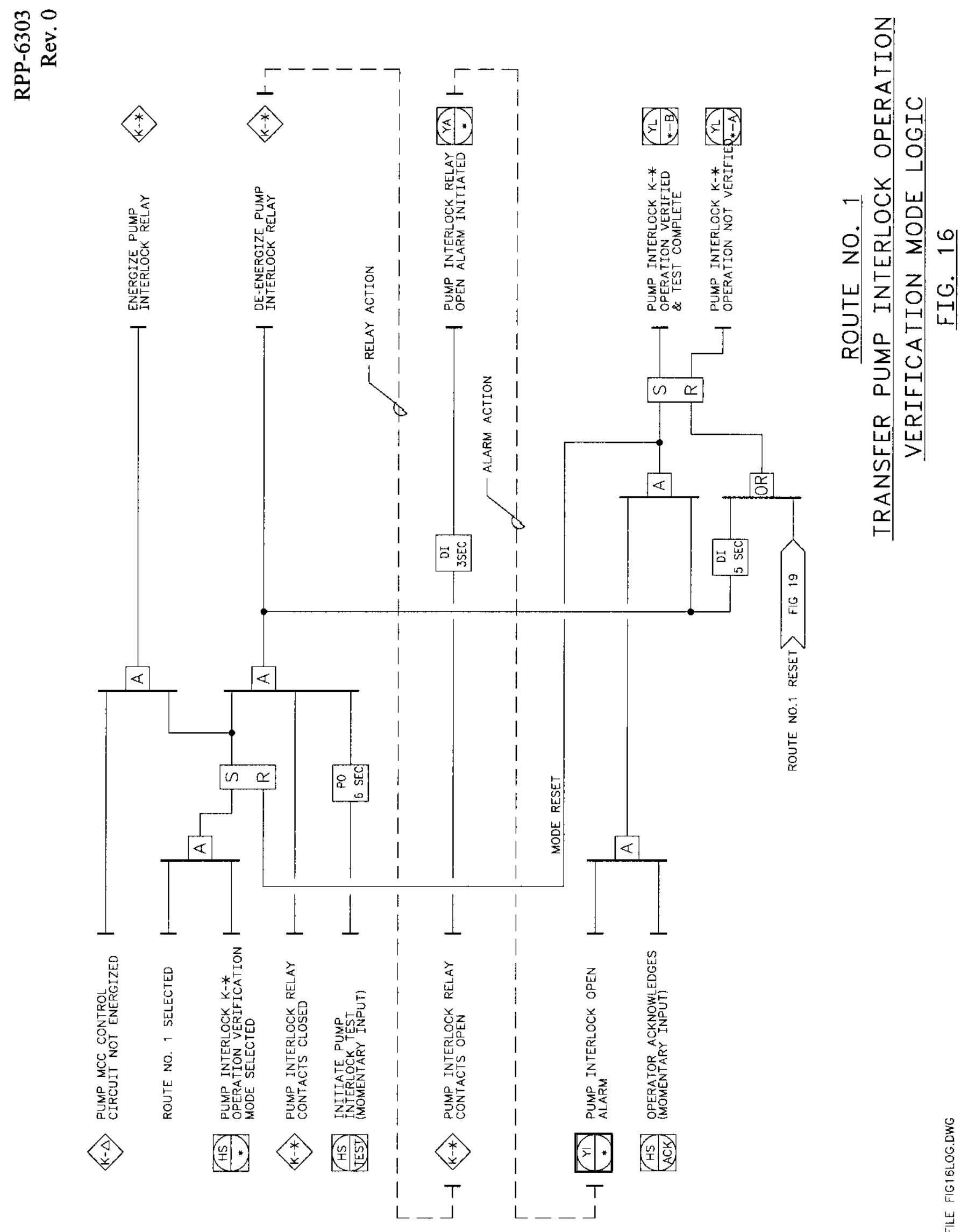

ㅁํㅁ 


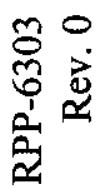

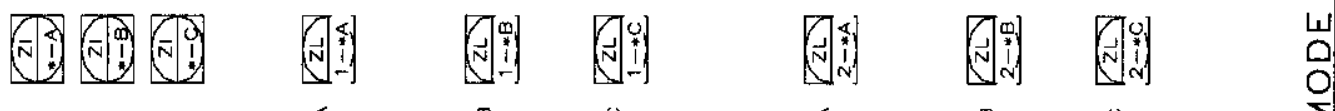
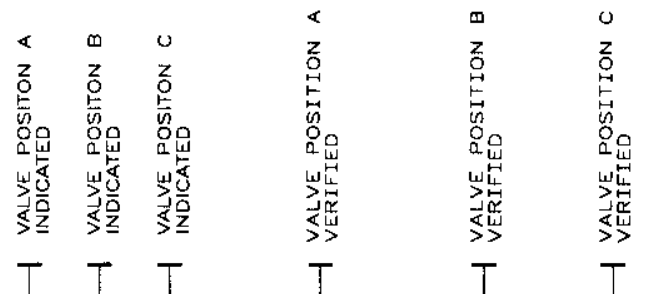

ติ

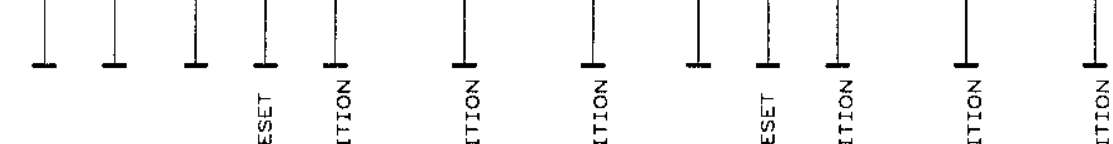

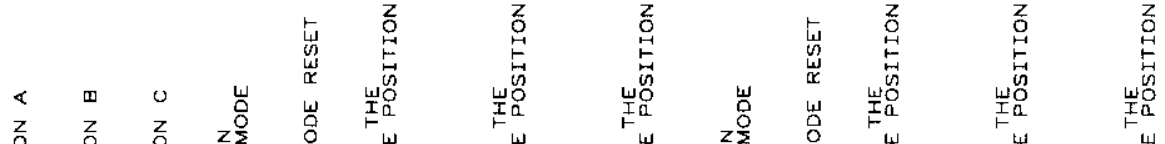

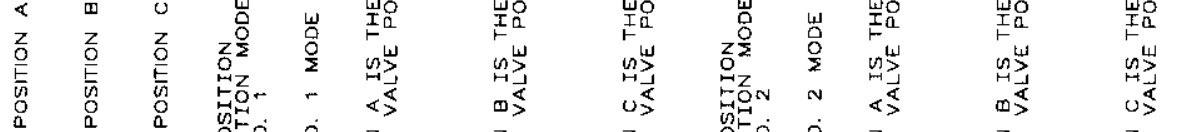

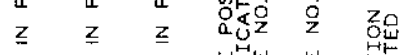

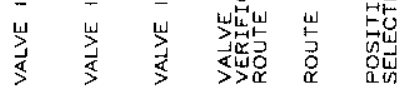

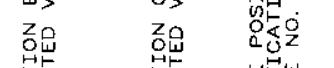

量

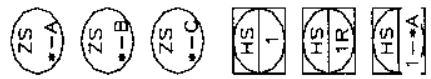

鰨?

酌

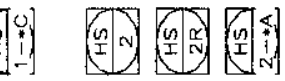

zo

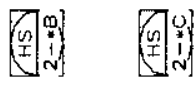




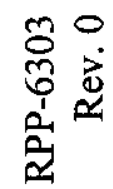

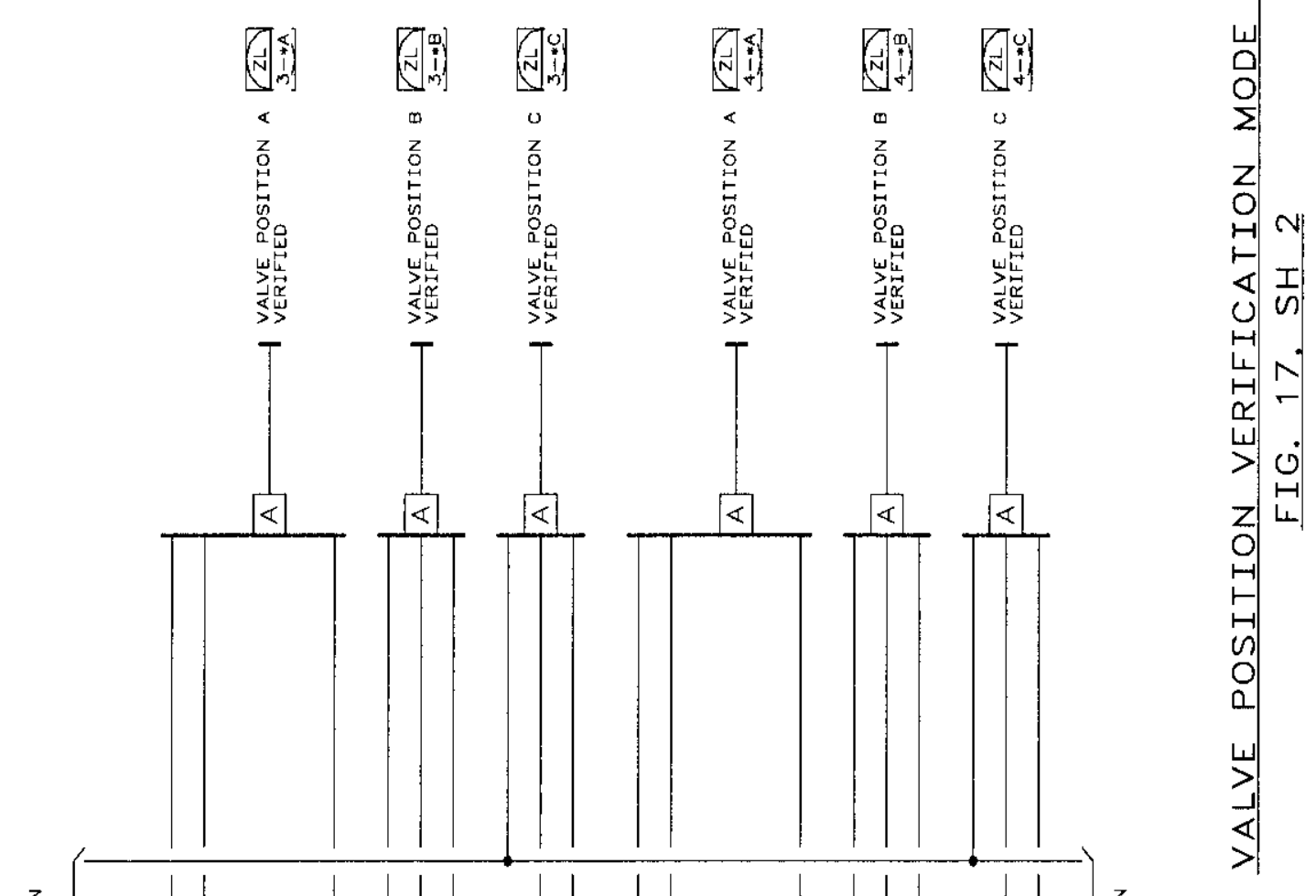




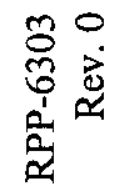

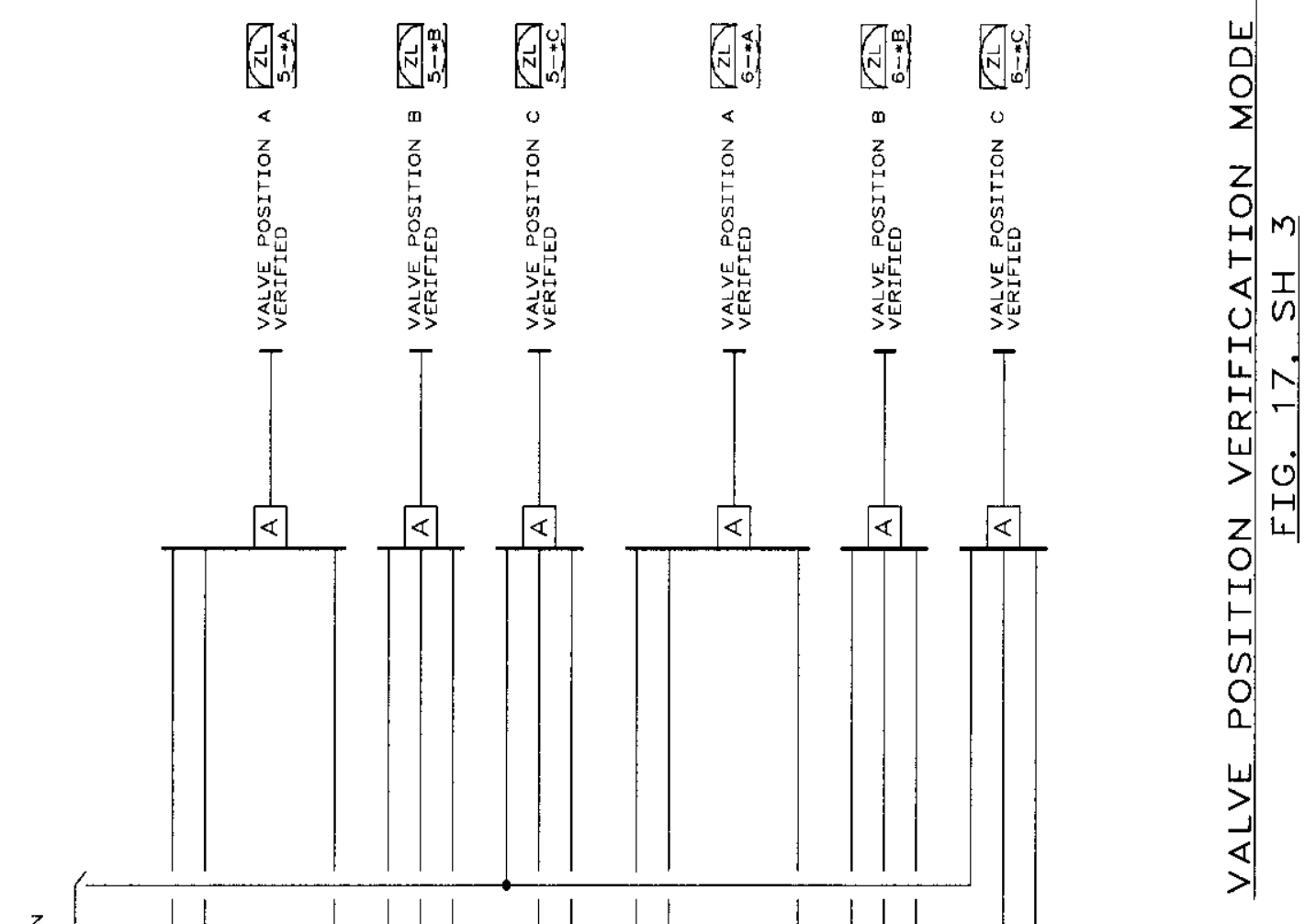

â 

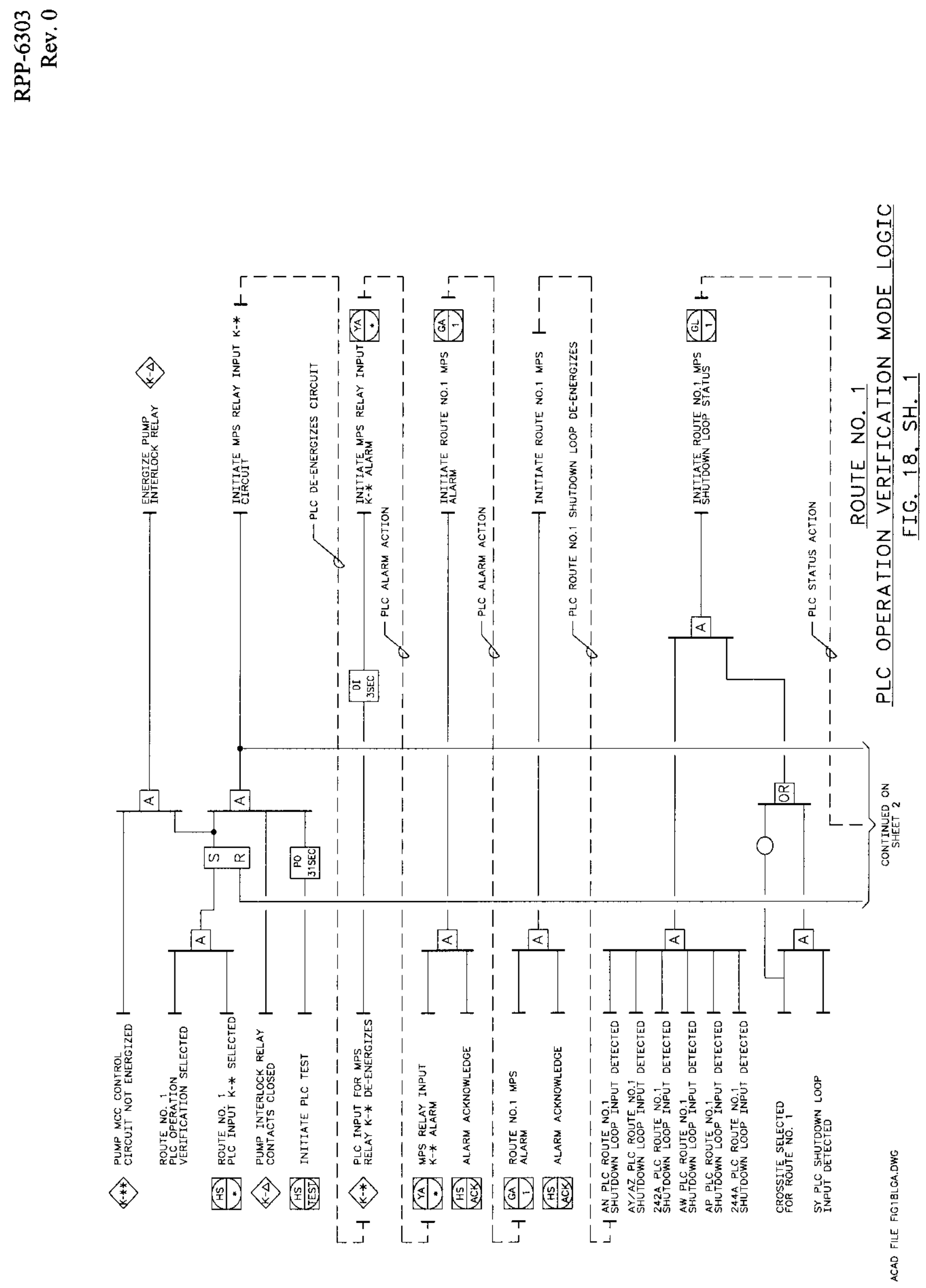


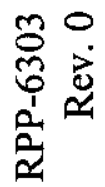
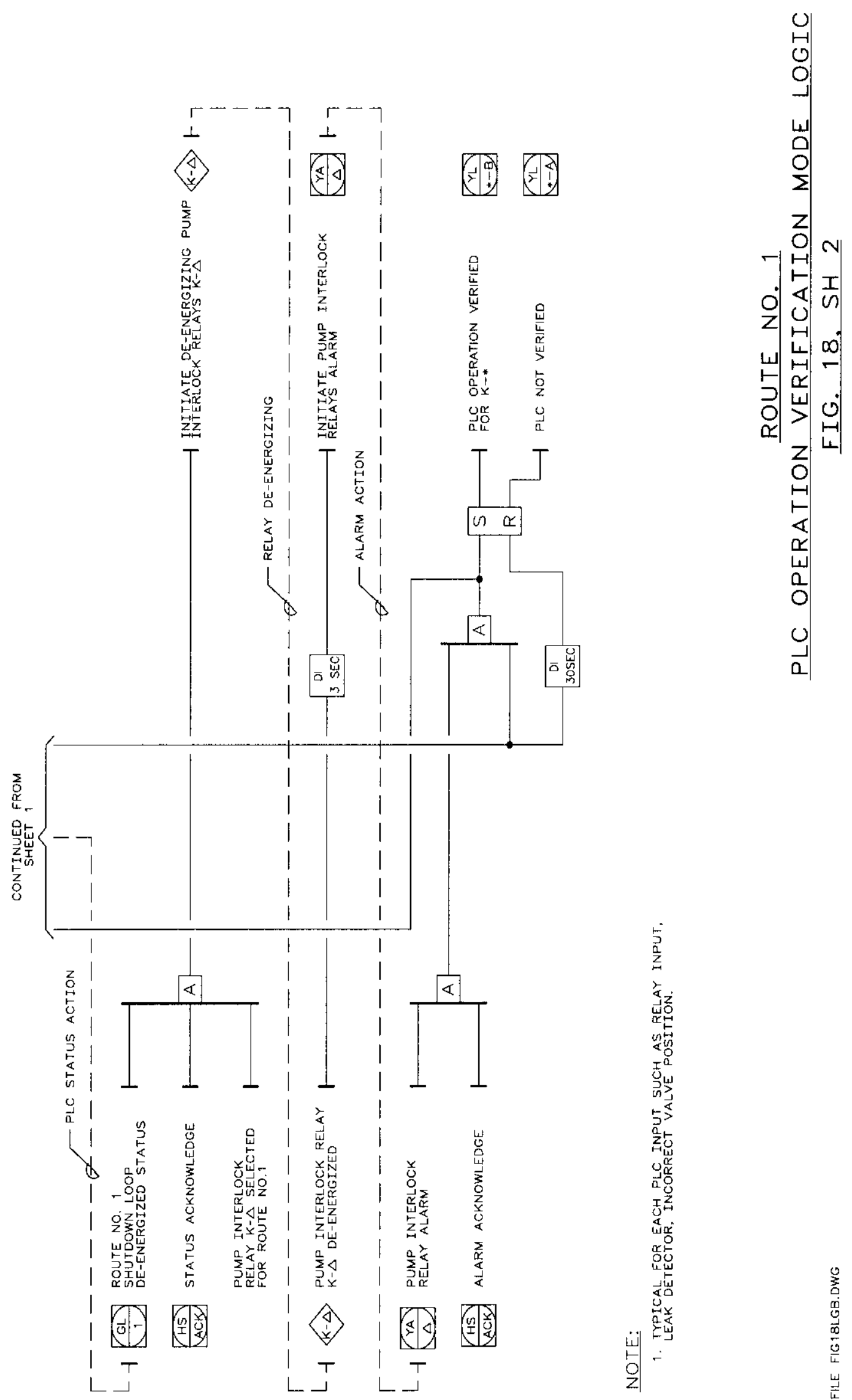

$\bar{g}$

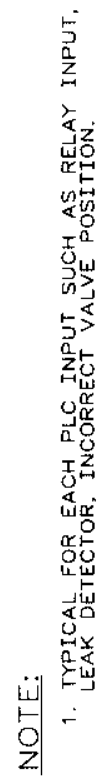




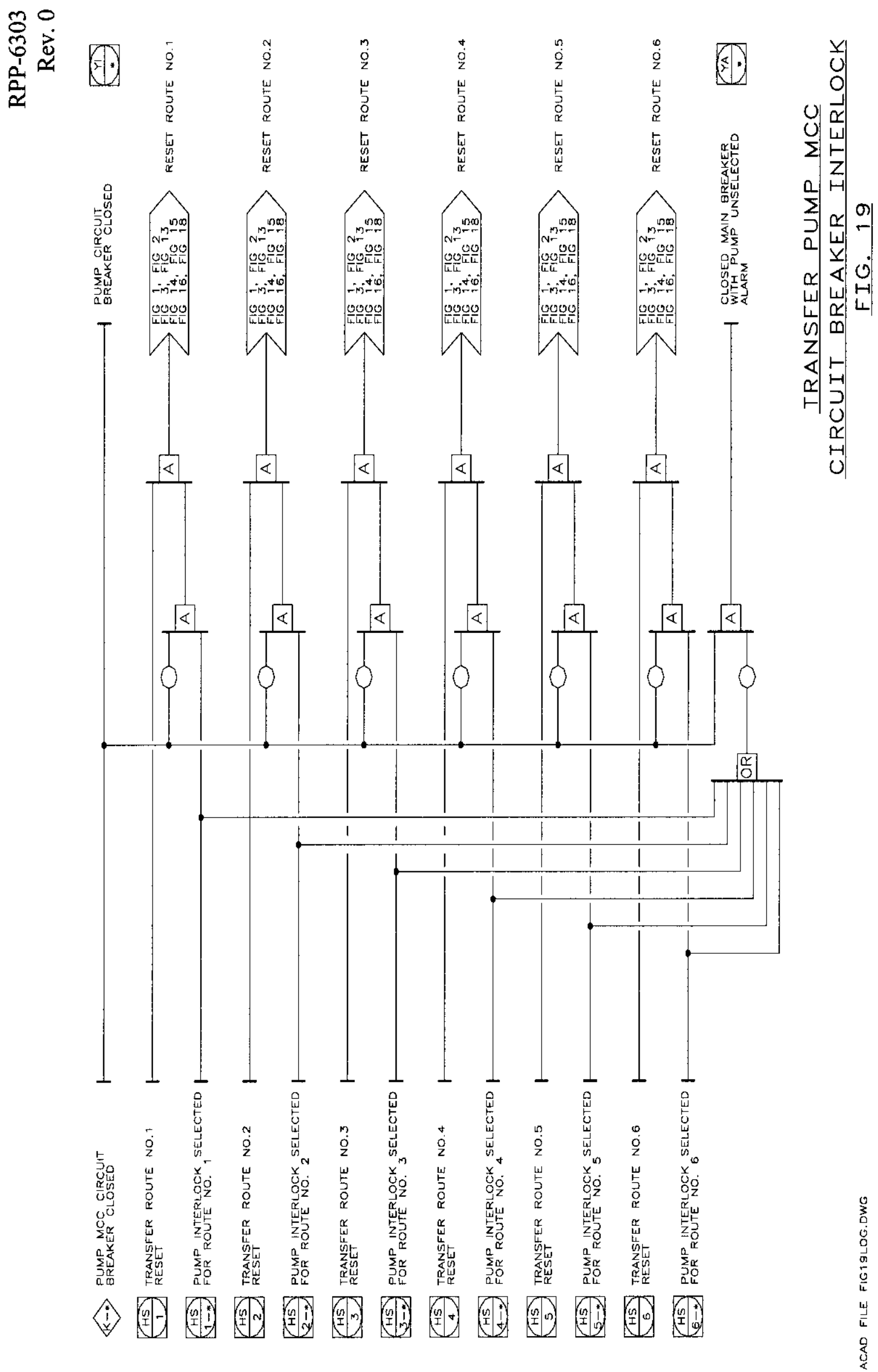


$\begin{array}{ll}3 & 0 \\ 0 & 0 \\ 0 & 0 \\ 1 & 0 \\ 2 & 1\end{array}$
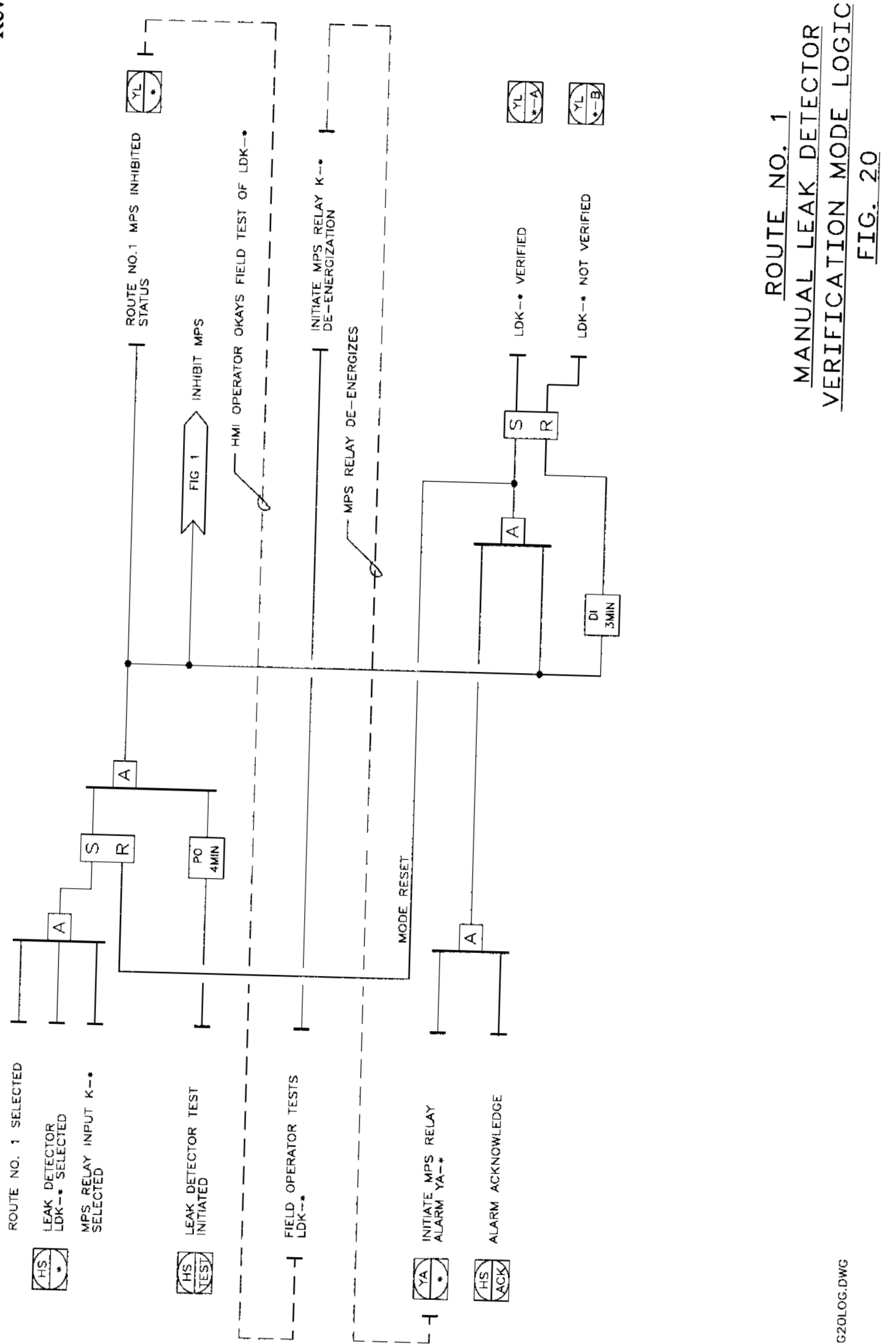


\section{APPENDIX S}

\section{Monitoring and Control}

\section{Human-Machine Interface (HMI) Screens}




\section{APPENDIX S \\ Human-Machine Interface (HMI) Screen Descriptions}

\section{OVERVIEW}

Included in this appendix is a tree showing how all of the HMI screens interrelate to one another and a table of screen descriptions for each of the HMI screens. The table is in alphabetical order by filename. The table includes the filename and a brief description of the screen contents and functions. There is also a table for the mode status color coding and highlighting of the various screen objects.

There are several modes of operation: Transfer Route Select Mode, Transfer Route Setup Mode, Transfer Route Verify Mode (includes system valve position verify, manual valve position verify, system leak detector verify, isolated and ganged manual leak detector verify and system interlock relay verify) Waste Transfer Annunciator Mode, and Transfer Route Create Mode. Along with the graphic display screens showing tanks, in-farm piping, etc., are alarm information screens, system information screens and messages screens.

Screens types are identified by a prefix: WTA (Waste Transfer Annunciator), TMS (Transfer Mode Screen), CBS (Create By Segments), etc.

The TMS screens are used to select, create, modify or delete a transfer route. The predetermined route must be selected before it can be added to the active transfer route list. A transfer route can be created by selecting mechanical elements, such as, valves, piping segments, pumps, etc., which is related to individual PLC I/O, such as, pumps, leak detectors, etc. Creating predetermined transfer routes is an off-line function performed at a shift supervisor access level or higher. Once created the transfer route is added to the predetermined route list. A predetermined transfer route can be modified by selecting mechanical elements. Lastly, a predetermined transfer route can be deleted if no longer found to be useful.

The CBS screens are used to create a route for the predetermined route list by selecting the appropriate mechanical elements. This function is only available to shift supervisors or those possessing a higher level of access. The process starts with the selection of the source tank. The user is then given a list of the valid mechanical elements to select from, including the transfer and flush lines coming into and leaving the tank. The user then follows the piping out to the next pit or tank, which when selected may yield a new display of mechanical elements.

Once the transfer route has been selected from the list of predetermined routes, it can be verified for valve positions, leak detector functions, input and interlock relay functions, etc. Once the function has been verified, its database record will reflect the new status. For any function, the status can also be changed to "bypassed", if needed.

The verify MPS relays function allows the operator to apply a test signal to a selected MPS relay and observe the result. The verify system leak detectors function allows the operator to apply a test signal to a selected leak detector and observe the result. The verify MPS interlocks function is similar to the previous two functional tests, except the pump permissive status is monitored. The manual valve verify mode screens are used to record manual verification that valves, without position sensor inputs to a MPS PLC, are in the required position. The manual leak detector verify mode screens are used to record manual verification that the leak detectors have been successfully tested. The status of the function can then be changed to "operator verified".

The Waste Transfer Annunciator Mode screens are arranged in a geographical hierarchy. These screens provide a view of the tank farms from a level of 200 East or 200 West, down to an individual tank. On these views, in the event of an MPS shutdown, the particular input that caused the shutdown can be determined. Also at the individual tank level, a "DETAILS" button will display the waste level, dome pressure, temperatures, motor status, etc.

The Alarm Information screens are used to display a list of all alarms generated by the HMI system. Information from the Alarms Information Screen can be exported to auxiliary software to be sorted/displayed based on various parameters. 
The System Information screens are used to provide information on the HMI system, PLC communications and other system information that would not be used by an operator in the normal course of events. Access to these screens is permitted only at the Supervisor or Engineer level.

The Message screens contain a brief, informative message to the operator and a "close the book" button that will remove the message from the screen. 
RPP-6303

Nevo

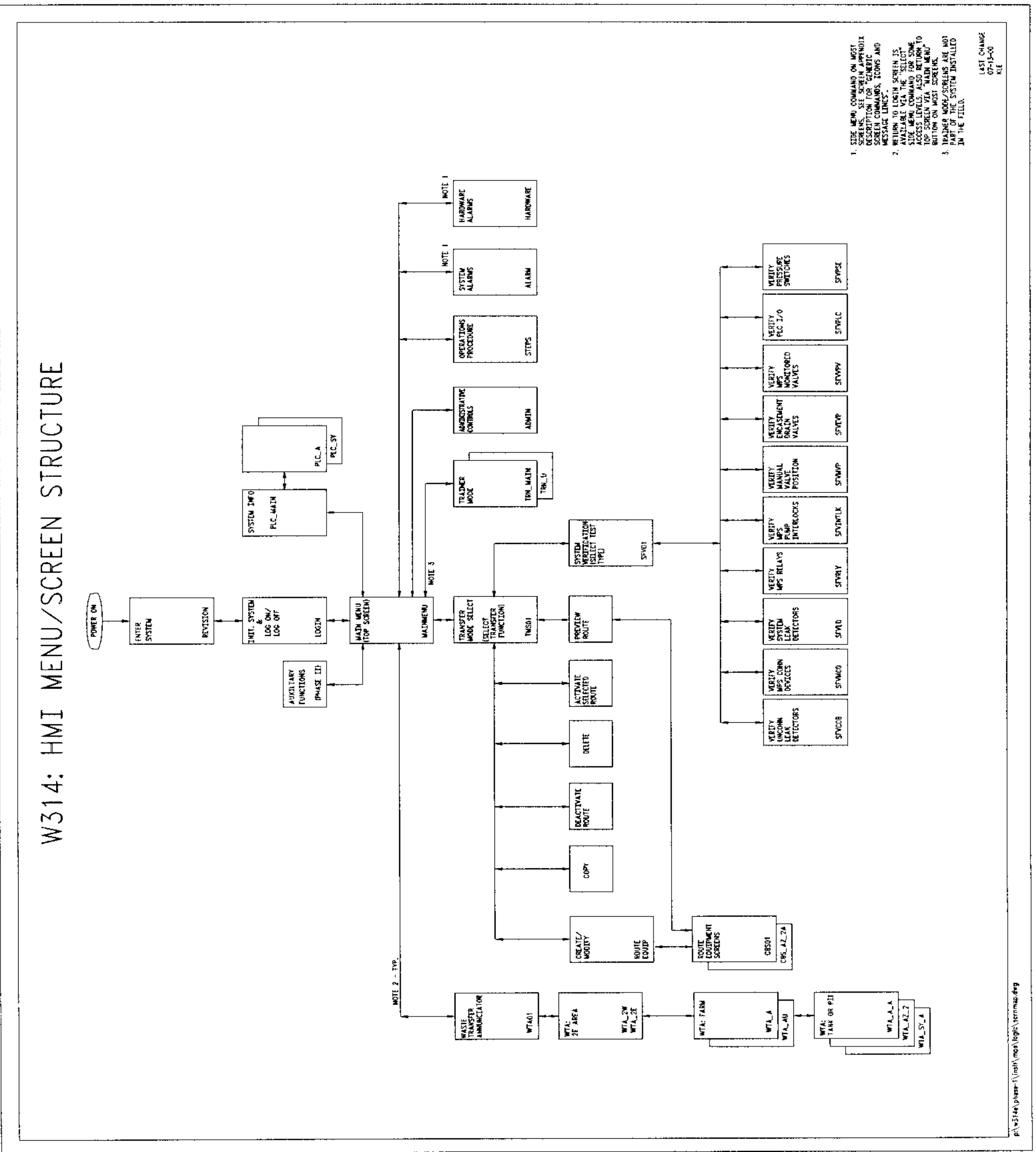




\section{SCREEN COLOR CODING}

For all equipment types, the color reflects that particular items state, depending if the HMI user is in the WTA mode or CBS mode (except PLC modules).

Leak Detectors - All leak detectors are shown as a round button with the leak detector instrument number adjacent. If it is a system leak detector (connected to PLC I/O): on (true input) = green, while off (false input) = white. If it is a manual leak detector (not connected to PLC I/O) it will be green with a black " $M$ " in the middle. Any user can right click on the leak detector symbol to find the current status including: connected to PLC I/O, manual; out-of-service; in-service, unselected, selected, unverified and verified. All leak detectors are tested periodically and the results are posted in the PMS system. A leak detector is considered verified if there is an OK status in the PMS database. When a leak detector alarm is activated LD symbol flashes red for unacknowledged and is steady red for acknowledged.

MPS Input Relays - All MPS input relays are shown on a list with the MPS input relay instrument number as the identifier. If it is a manual MPS input relay (not connected to PLC I/O) it will have an "M" in the middle. As MPS input relays also indicate leak alarms, the color coding is the same as that for leak detectors shown in Table S-1. In order to see more detailed information about the relay the user right clicks on the item. A pop up window appears which shows current status including: connected to PLC I/O, manual: out-of-service; in-service, unselected, selected, unverified and verified. All MPS input relays are tested periodically and the results are unselected, selected, unverified and verified. All MPS input relays are tested periodically and the results are posted in the PMS system. A MPS input relay is considered verified if all leak detectors and other relays connected to it are tested and actuate the MPS input relay.

Pipe -For a listing of the colors and states for pipe graphics see Table S-2. Pipe alarm is activated when associated leak detector alarm(s) is activated. When pipe alarm is activated: entire pipe segment symbol is red with flashing text for unacknowledged and is steady red for acknowledged.

Valves - For a listing of the colors and states for valve graphic see Table S-3. Color-challenged operators, or any user for that matter, can obtain the current status on any valve including: connected to PLC I/O, manual, out-of-service, in-service, unselected, selected, unverified, operator verified, QC verified and supervisor verified

Pumps -For listing of the colors and states for pump graphics see Table S-4. Pump alarm is activated if pump power breaker is on the pump has not been selected for an active transfer or if the pump stops before the transfer is complete.

PLC Modules: the status of the PLC modules is shown only on the "PLC Status screens". For a listing of the colors and states for PLC module graphics see Table S-5. The effects of the HMI user being in the WTA or CBS modes does not apply to the PLC modules as the "PLC Status" screens do not belong to either mode. 


\begin{tabular}{|l|c|c|}
\hline \multicolumn{2}{|c|}{ Table S-1: Leak Detector \& Relays/MCD Color(s) } \\
\hline State & Color & Screens \& Notes \\
\hline Out of Service & Black & WTA \\
\hline Unselected & White & CBS \\
\hline Selected & Lt. Blue & WTA \\
\hline No Alarm & Green & WTA Note 2 \\
\hline Alarm (unACK'd @ HMI) & Flash Red & WTA Note 2 \\
\hline Alarm (ACK'd @ HMI) & Solid Red & WTA \\
\hline Bypassed & Note & W \\
\hline
\end{tabular}

Note 1: When item is "BYPASSED" the border is white, the main color is based on other variables. Note 2: Either a leak detection or an instrument failure cause an alarm.

\begin{tabular}{|l|c|c|}
\hline \multicolumn{2}{|c|}{ Table S-2: Pipe Color(s) } \\
\hline State & Color & Screens \& Notes \\
\hline Unselected & White & CBS \& WTA \\
\hline Selected & Gray & CBS Note 1 \\
\hline Selected & Gray & WTA Note 1 \\
\hline "Flow" & Green & WTA Note 2 \\
\hline Alarm (unACK'd @ HMI) & Red with Flashing Text & WTA Note 3 \\
\hline Alarm (ACK'd @HMI) & Solid Red & WTA Note 3 \\
\hline
\end{tabular}

Note 1: Selection status is stored in the HMI database.

Note 2: Flashing diamonds in the pipe are also displayed, either when flow is detected by the flowmeter, or when the appropriate bit in \#_RUNSTAT_WD is on.

Note 3: Applies only to pipes that contain encasement leak detectors in the MPS System. 
Table S-3: Valve Port Color(s)

\begin{tabular}{|l|c|c|}
\hline \multicolumn{1}{|c|}{ State } & Color & Screens \& Notes \\
\hline Out of Service & Black & WTA \\
\hline Unselected & Gray & CBS \\
\hline Selected: Open port & Green & CBS \\
\hline Selected: Shut port & White & WTA \\
\hline Operate: Open port & Green & WTA \\
\hline Operate: Shut port & White & WTA Note 3 \\
\hline Operate: Transition & Yellow (all ports) & WTA \\
\hline No Alarm & Per port state & WTA Note 2,3,4 \\
\hline Alarm (unACK'd @ HMI) & Flash Red & WTA Note 2,3,4 \\
\hline Alarm (ACK'd @ HMI) & Solid Red & WTA \\
\hline Bypassed & Note 1 & CBS \\
\hline
\end{tabular}

Note 1: When item is "BYPASSED", the border is white; the main color is based on other variables.

Note 2: Two or more position sensors activated.

Note 3: No valve position sensor activated.

Note 4: Valve position different than the position that was verified.

\begin{tabular}{|l|c|c|c|}
\hline \multicolumn{1}{|c|}{ State } & Color & Notes & Text \\
\hline Out of Service & Black & WTA & \\
\hline Unselected & White & CBS \& WTA & \\
\hline Selected & Lt. Blue & CBS & Stopped \\
\hline $\begin{array}{l}\text { Selected: Pump } \\
\text { Off/Power Off }\end{array}$ & Gray & WTA & Stopped \\
\hline $\begin{array}{l}\text { Selected: Pump } \\
\text { Off/Power On }\end{array}$ & Yellow & WTA & Running \\
\hline Selected: Pump On & Green & WTA & Stopped \\
\hline $\begin{array}{l}\text { Alarm (unACK'd @ } \\
\text { HMI) }\end{array}$ & Flash Red & WTA & Stopped \\
\hline $\begin{array}{l}\text { Alarm (ACK'd @ } \\
\text { HMI) }\end{array}$ & Solid Red & WTA & PWR On \\
\hline $\begin{array}{l}\text { Power Status } \\
\text { (Note 3) }\end{array}$ & Note 1 & WTA & PWR Off \\
\cline { 2 - 4 }
\end{tabular}

Note 1: The text "PWR ON" is displayed; the main color remains unchanged.

Note 2: The text "PWR OFF" is displayed; the main color remains unchanged.

Note 3: For manual pumps only. 
Rev. 0

\begin{tabular}{|l|c|c|}
\hline \multicolumn{3}{|c|}{ Table S-5: PLC Card Color(s) } \\
\hline State & Color & Screen \\
\hline Blank & Black & PLC Status \\
\hline Running & Green & PLC Status \\
\hline Fault & Flash Red & PLC Status \\
\hline
\end{tabular}

Note: The status of PLC modules appear only on the "PLC Status" screens. 


\section{GENERIC SCREEN COMMANDS, ICONS AND MESSAGE LINES}

? (Displayed in menu bar at top of screen) -- Displays the input to the CPU, such as from the computer keyboard or an on screen slider.

! (Displayed in menu bar at top of sereen) - Displays the output from the CPU, such as alarms.

$f(x)\left(2^{\text {nd }}\right.$ menu bar at top of screen $)$ - Displays last activated alarm

Bottom left - Displays a description of the icon where the cursor is positioned.

Bottom middle right - Displays the current page title.

Alarm Summary Page - Displays a history of alarm activity, including when cach alarm was generated, acknowledged, and reset for the last 24 hour.

Help Page - Displays the help page.

Print Page - Prints the currently viewed page to the printer or a file

Select Page -- This button will provide a dropdown menu of all available sereens. Only those screens to which the user has been given aceess will be available for selection. Default is access to all screens.

Previous Page - Returns the user to the last screen viewed before the current screen.

Hardware Alarm Page - Displays the hardware alarm page. Hardware alarms are generated when faults are found in peripheral equipment, such as $\mathbf{I}$ /O Devices. It is also the catchall repository for system messages not programmed as an alarm or operator event.

Present Users - This button displays a form indicating the present users logged into the system.

Acknowledge all Alarms - This button acknowledges all unacknowledged alarms on the displayed page, Alarm, Hardware, or Summary.

Close Window/Page - This button closes the current active pop-up window or exits the Create by Segment mode. 
RPP-6303

Rev. ()

Citect Kernel - This button opens the Citect Kencl (displayed only on the admin page)

Silenee farm Horn - Silences the audible alarm in the specified farm. 


\begin{tabular}{|c|c|c|}
\hline No. & $\begin{array}{c}\text { Screen } \\
\text { Filename }\end{array}$ & HMI Screen Description \\
\hline & ADMIN & $\begin{array}{l}\text { Admin Screen shows buttons to add or edit users and change password as well as a } \\
\text { shutdown button. Additional functions TBD. }\end{array}$ \\
\hline & HARDWARE & Hardware Screen shows all active acknowledged and unacknowledged hardware alarms. \\
\hline \multirow[t]{2}{*}{2} & ALARM & $\begin{array}{l}\text { Active Alarms Screen shows the current active acknowledged and unacknowledged alarms } \\
\text { with the most recent alarms at the top of the list. }\end{array}$ \\
\hline & LOGIN & $\begin{array}{l}\text { LOGIN Screen shows the screen where system operators will log into and out of the } \\
\text { system. }\end{array}$ \\
\hline 3 & SUMMARY & $\begin{array}{l}\text { Alarm Summary Screen shows a complete history of all alarms, as well as, when they } \\
\text { occurred and when they were acknowledged. }\end{array}$ \\
\hline \multirow[t]{6}{*}{23} & CBS01 & $\begin{array}{l}\text { Create a Transfer by Segment Selection Screen shows access to tank farm mechanical } \\
\text { element (segment) lists is via TMS01. Current route being created is displayed. }\end{array}$ \\
\hline & CBS_219S & $\begin{array}{l}\text { Create By Segment 219-S Liquid Waste Drain Screen displays a graphic showing all } \\
\text { available segments for the facility. It also shows the selected waste transfer name/number, } \\
\text { pump and the } 219-S-102 \text { collection tank and the line leading to the } 244-S \text { receiver vault. } \\
\text { Screen also shows an Encasement Valve Position key and the Valve Position Key. The } \\
\text { operator can go to the next level of detail by clicking on the item of interest and the } \\
\text { appropriate screen is displayed. }\end{array}$ \\
\hline & CBS_242A & $\begin{array}{l}\text { Create By Segment 242-A Evaporator Screen displays a graphic showing all available } \\
\text { segments for the evaporator. It also shows the selected waste transfer name/number, pump } \\
\text { and a detailed evaporator graphic. The operator can go to the next level of detail by clicking } \\
\text { on the item of interest and the appropriate screen is displayed. }\end{array}$ \\
\hline & CBS_244S & $\begin{array}{l}\text { Create By Segment 244-S Catch Station Screen displays a graphic showing all available } \\
\text { segments for the catch station and the selected waste transfer name/number, pumps lines and } \\
\text { pits involved. Screen also shows an Encasement Valve Position key and the Valve Position } \\
\text { Key. The operator can go to the next level of detail by clicking on the item of interest and } \\
\text { the appropriate screen is displayed. }\end{array}$ \\
\hline & CBS6241A & $\begin{array}{l}\text { Create By Segment Diversion Box 6241-A Screen displays a graphic showing all available } \\
\text { segments for the diversion box. It also shows the selected waste transfer name/number, the } \\
\text { valve pit and which connection areas, tanks and pits are involved. Screen also shows an } \\
\text { Encasement Valve Position key and the Valve Position Key. The operator can go to the next } \\
\text { level of detail by clicking on the item of interest and the appropriate screen is displayed. }\end{array}$ \\
\hline & CBS6241V & $\begin{array}{l}\text { Create By Segment Vent Station 6241-V Screen displays a graphic showing all available } \\
\text { segments for the vent station. It also shows the selected waste transfer name/number, the } \\
\text { valve pit and which connection areas, tanks and pits are involved. Screen also shows an } \\
\text { Encasement Valve Position key and the Valve Position Key. The operator can go to the next } \\
\text { level of detail by clicking on the item of interest and the appropriate screen is displayed. }\end{array}$ \\
\hline 24 & CBS 2E & $\begin{array}{l}200 \text { East Create By Segment Screen shows the hierarchy of all } 200 \text { E elements connected } \\
\text { to MPSS. Access to tank farm mechanical element (segment) lists is via CBS01. }\end{array}$ \\
\hline 25 & CBS_2W & $\begin{array}{l}200 \text { West Create By Segment Screen shows the hierarchy of all } 200 \mathrm{~W} \text { elements connected } \\
\text { to MPSS. Access to tank farm mechanical element (segment) lists is via CBS01. }\end{array}$ \\
\hline
\end{tabular}




\begin{tabular}{|c|c|c|}
\hline No. & $\begin{array}{c}\text { Screen } \\
\text { Filename }\end{array}$ & HMI Screen Description \\
\hline \multirow[t]{2}{*}{26} & CBS_A & $\begin{array}{l}\text { Create By Segment Tank Farm A Screen displays the 204-AR Building, Valve Pits } 241 \text { - } \\
\text { A-A and } 241 \text {-A-B, new waste transfer predetermined route name/number being constructed } \\
\text { and a graphic display of the tank farm showing all available lines, valve pits, pumps etc. } \\
\text { Items are selected by the user operator clicking on a particular item, either on the listing or } \\
\text { on the graphic item. Once a particular item has been selected, it is can be added to or deleted } \\
\text { from the new predetermined transfer route. Items on the graphic that are selected for this } \\
\text { particular transfer will be displayed in an emphasized manner. Items that are available but } \\
\text { not selected are displayed in an non-emphasized manner. Screen also shows valve position } \\
\text { key. The operator can go to the next level of detail by clicking on the item of interest and } \\
\text { the appropriate screen is displayed. This screen will be deleted in Phase } 2 \text {, }\end{array}$ \\
\hline & CBS_A350 & $\begin{array}{l}\text { Create By Segment 241-A-350 Drainage Lift Station Screen displays a graphic display of } \\
\text { the lift station showing all available segments. Screen also shows the Valve Position Key. } \\
\text { The operator can go to the next level of detail by clicking on the item of interest and the } \\
\text { appropriate screen is displayed. }\end{array}$ \\
\hline 29 & CBS_AN & $\begin{array}{l}\text { Create By Segment Tank Farm AN Screen displays the selected waste transfer } \\
\text { name/number and a graphic display of the Tank farm showing all available segments. See } \\
\text { CBS A screen description for further discussion. }\end{array}$ \\
\hline 30 & CBS_AN_A & $\begin{array}{l}\text { Create By Segment Valve Pit 241-AN-A Screen displays the selected waste transfer } \\
\text { name/number and a graphic display of the valve pit showing all available segments and } \\
\text { devices. See CBS A screen description for further discussion. }\end{array}$ \\
\hline \multirow[t]{7}{*}{31} & CBS_AN_B & $\begin{array}{l}\text { Create By Segment Valve Pit 241-AN-B Screen displays the selected waste transfer } \\
\text { name/number and a graphic display of the valve pit showing all available segments and } \\
\text { devices. See CBS A screen description for further discussion. }\end{array}$ \\
\hline & CBS_AN_I & $\begin{array}{l}\text { Create By Segment Tank 241-AN-101 Screen displays a graphic showing all available } \\
\text { segments for the tank and the selected waste transfer name/number, pumps lines and pits } \\
\text { involved. Screen also shows the Valve Position Key. The operator can go to the next level } \\
\text { of detail by clicking on the item of interest and the appropriate screen is displayed. }\end{array}$ \\
\hline & CBS_AN_2 & $\begin{array}{l}\text { Create By Segment Tank 241-AN-102 Screen displays a graphic showing all available } \\
\text { segments for the tank and the selected waste transfer name/number, pumps lines and pits } \\
\text { involved. Screen also shows the Valve Position Key. The operator can go to the next level } \\
\text { of detail by clicking on the item of interest and the appropriate screen is displayed. }\end{array}$ \\
\hline & $\overline{\text { CBS_AN_3 }}$ & $\begin{array}{l}\text { Create By Segment Tank 241-AN-103 Screen displays a graphic showing all available } \\
\text { segments for the tank and the selected waste transfer name/number, pumps lines and pits } \\
\text { involved. Screen also shows the Valve Position Key. The operator can go to the next level } \\
\text { of detail by clicking on the item of interest and the appropriate screen is displayed. }\end{array}$ \\
\hline & CBS_AN_4 & $\begin{array}{l}\text { Create By Segment Tank 241-AN-104 Screen displays a graphic showing all available } \\
\text { segments for the tank and the selected waste transfer name/number, pumps lines and pits } \\
\text { involved. Screen also shows the Valve Position Key. The operator can go to the next level } \\
\text { of detail by clicking on the item of interest and the appropriate screen is displayed. }\end{array}$ \\
\hline & CBS_AN_5 & $\begin{array}{l}\text { Create By Segment Tank 241-AN-105 Screen displays a graphic showing all available } \\
\text { segments for the tank and the selected waste transfer name/number, pumps lines and pits } \\
\text { involved. Screen also shows the Valve Position Key. The operator can go to the next level } \\
\text { of detail by clicking on the item of interest and the appropriate screen is displayed. }\end{array}$ \\
\hline & CBS_AN_6 & $\begin{array}{l}\text { Create By Segment Tank 241-AN-106 Screen displays a graphic showing all available } \\
\text { segments for the tank and the selected waste transfer name/number, pumps lines and pits } \\
\text { involved. Screen also shows the Valve Position Key. The operator can go to the next level } \\
\text { of detail by clicking on the item of interest and the appropriate screen is displayed. }\end{array}$ \\
\hline
\end{tabular}




\begin{tabular}{|c|c|c|}
\hline No. & $\begin{array}{c}\text { Screen } \\
\text { Filename }\end{array}$ & HMI Screen Description \\
\hline & CBS_AN_7 & $\begin{array}{l}\text { Create By Segment Tank 241-AN-107 Screen displays a graphic showing all available } \\
\text { segments for the tank and the selected waste transfer name/number, pumps lines and pits } \\
\text { involved. Screen also shows the Valve Position Key. The operator can go to the next level } \\
\text { of detail by clicking on the item of interest and the appropriate screen is displayed. }\end{array}$ \\
\hline \multirow[t]{2}{*}{32} & CBS_AP & $\begin{array}{l}\text { Create By Segment Tank Farm AP Screen displays the selected waste transfer } \\
\text { name/number and a graphic display of the Tank farm showing all available segments. See } \\
\text { CBS A screen description for further discussion. }\end{array}$ \\
\hline & CBS-AP-VP & $\begin{array}{l}\text { Create By Segment Valve Pit 241-AP displays the selected waste transfer name/number } \\
\text { and a graphic of the valve pit showing all available segments and devices. See CBS_A } \\
\text { screen description for further discussion. }\end{array}$ \\
\hline \multirow[t]{10}{*}{33} & CBS_AP_A & $\begin{array}{l}\text { Create By Segment Valve Pit 241-AP-A Screen displays the selected waste transfer } \\
\text { name/number and a graphic display of the valve pit showing all available segments and } \\
\text { devices. See CBS A screen description for further discussion. }\end{array}$ \\
\hline & CBS_APFP & $\begin{array}{l}\text { Create By Segment Flush Pit 241-AP Screen displays a graphic of the flush pit showing } \\
\text { all available segments and devices. It also shows the selected waste transfer name/number, } \\
\text { the valve pit and which connection areas, tanks and pits are involved. Screen also shows the } \\
\text { Valve Position Key. The operator can go to the next level of detail by clicking on the item of } \\
\text { interest and the appropriate screen is displayed. }\end{array}$ \\
\hline & CBS_AP_1 & $\begin{array}{l}\text { Create By Segment Tank 241-AP-101 Screen displays a graphic showing all available } \\
\text { segments for the tank and the selected waste transfer name/number, pumps lines and pits } \\
\text { involved. Screen also shows the Valve Position Key. The operator can go to the next level } \\
\text { of detail by clicking on the item of interest and the appropriate screen is displayed. }\end{array}$ \\
\hline & CBS_AP_2 & $\begin{array}{l}\text { Create By Segment Tank 241-AP-102 Screen displays a graphic showing all available } \\
\text { segments for the tank and the selected waste transfer name/number, pumps lines and pits } \\
\text { involved. Screen also shows the Valve Position Key. The operator can go to the next level } \\
\text { of detail by clicking on the item of interest and the appropriate screen is displayed. }\end{array}$ \\
\hline & CBS_AP_3 & $\begin{array}{l}\text { Create By Segment Tank 241-AP-103 Screen displays a graphic showing all available } \\
\text { segments for the tank and the selected waste transfer name/number, pumps lines and pits } \\
\text { involved. Screen also shows the Valve Position Key. The operator can go to the next level } \\
\text { of detail by clicking on the item of interest and the appropriate screen is displayed. }\end{array}$ \\
\hline & CBS_AP_4 & $\begin{array}{l}\text { Create By Segment Tank 241-AP-104 Screen displays a graphic showing all available } \\
\text { segments for the tank and the selected waste transfer name/number, pumps lines and pits } \\
\text { involved. Screen also shows the Valve Position Key. The operator can go to the next level } \\
\text { of detail by clicking on the item of interest and the appropriate screen is displayed. }\end{array}$ \\
\hline & CBS_AP_5 & $\begin{array}{l}\text { Create By Segment Tank 241-AP-105 Screen displays a graphic showing all available } \\
\text { segments for the tank and the selected waste transfer name/number, pumps lines and pits } \\
\text { involved. Screen also shows the Valve Position Key. The operator can go to the next level } \\
\text { of detail by clicking on the item of interest and the appropriate screen is displayed. }\end{array}$ \\
\hline & CBS_AP_6 & $\begin{array}{l}\text { Create By Segment Tank 241-AP-106 Screen displays a graphic showing all available } \\
\text { segments for the tank and the selected waste transfer name/number, pumps lines and pits } \\
\text { involved. Screen also shows the Valve Position Key. The operator can go to the next level } \\
\text { of detail by clicking on the item of interest and the appropriate screen is displayed. }\end{array}$ \\
\hline & CBS_AP_7 & $\begin{array}{l}\text { Create By Segment Tank 241-AP-107 Screen displays a graphic showing all available } \\
\text { segments for the tank and the selected waste transfer name/number, pumps lines and pits } \\
\text { involved. Screen also shows the Valve Position Key. The operator can go to the next level } \\
\text { of detail by clicking on the item of interest and the appropriate screen is displayed. }\end{array}$ \\
\hline & CBS_AP_8 & $\begin{array}{l}\text { Create By Segment Tank 241-AP-108 Screen displays a graphic showing all available } \\
\text { segments for the tank and the selected waste transfer name/number, pumps lines and pits } \\
\text { involved. Screen also shows the Valve Position Key. The operator can go to the next level } \\
\text { of detail by clicking on the item of interest and the appropriate screen is displayed. }\end{array}$ \\
\hline
\end{tabular}




\begin{tabular}{|c|c|c|}
\hline No. & $\begin{array}{c}\text { Screen } \\
\text { Filename }\end{array}$ & HMI Screen Description \\
\hline 34 & CBS_AW & $\begin{array}{l}\text { Create By Segment Tank Farm AW Screen displays the selected waste transfer } \\
\text { name/number and a graphic display of the Tank farm showing all available segments. See } \\
\text { CBS A screen description for further discussion. }\end{array}$ \\
\hline 35 & CBS_AW_A & $\begin{array}{l}\text { Create By Segment Valve Pit 241-AW-A Screen displays the selected waste transfer } \\
\text { name/number and a graphic display of the valve pit showing all available segments and } \\
\text { devices. See CBS_A screen description for further discussion. }\end{array}$ \\
\hline \multirow[t]{8}{*}{36} & CBS_AW_B & $\begin{array}{l}\text { Create By Segment Valve Pit 241-AW-B Screen displays the selected waste transfer } \\
\text { name/number and a graphic display of the valve pit showing all available segments and } \\
\text { devices. See CBS_A screen description for further discussion. }\end{array}$ \\
\hline & CBS_AWFP & $\begin{array}{l}\text { Create By Segment Flush Pit 241-AW Screen displays a graphic of the flush pit showing } \\
\text { all available segments and devices. It also shows the selected waste transfer name/number, } \\
\text { the valve pit and which connection areas, tanks and pits are involved. Screen also shows the } \\
\text { Valve Position Key. The operator can go to the next level of detail by clicking on the item of } \\
\text { interest and the appropriate screen is displayed. }\end{array}$ \\
\hline & CBS_AW_1 & $\begin{array}{l}\text { Create By Segment Tank 241-AW-101 Screen displays a graphic showing all available } \\
\text { segments for the tank and the selected waste transfer name/number, pumps lines and pits } \\
\text { involved. Screen also shows the Valve Position Key. The operator can go to the next level } \\
\text { of detail by clicking on the item of interest and the appropriate screen is displayed. }\end{array}$ \\
\hline & CBS_AW_2 & $\begin{array}{l}\text { Create By Segment Tank 241-AW-102 Screen displays a graphic showing all available } \\
\text { segments for the tank and the selected waste transfer name/number, pumps lines and pits } \\
\text { involved. Screen also shows the Valve Position Key. The operator can go to the next level } \\
\text { of detail by clicking on the item of interest and the appropriate screen is displayed. }\end{array}$ \\
\hline & CBS_AW_3 & $\begin{array}{l}\text { Create By Segment Tank 241-AW-103 Screen displays a graphic showing all available } \\
\text { segments for the tank and the selected waste transfer name/number, pumps lines and pits } \\
\text { involved. Screen also shows the Valve Position Key. The operator can go to the next level } \\
\text { of detail by clicking on the item of interest and the appropriate screen is displayed. }\end{array}$ \\
\hline & $\overline{\text { CBS_AW_4 }}$ & $\begin{array}{l}\text { Create By Segment Tank 241-AW-104 Screen displays a graphic showing all available } \\
\text { segments for the tank and the selected waste transfer name/number, pumps lines and pits } \\
\text { involved. Screen also shows the Valve Position Key. The operator can go to the next level } \\
\text { of detail by clicking on the item of interest and the appropriate screen is displayed. }\end{array}$ \\
\hline & CBS_AW_5 & $\begin{array}{l}\text { Create By Segment Tank 241-AW-105 Screen displays a graphic showing all available } \\
\text { segments for the tank and the selected waste transfer name/number, pumps lines and pits } \\
\text { involved. Screen also shows the Valve Position Key. The operator can go to the next level } \\
\text { of detail by clicking on the item of interest and the appropriate screen is displayed. }\end{array}$ \\
\hline & $\overline{C B S \_A W \_6}$ & $\begin{array}{l}\text { Create By Segment Tank 241-AW-106 Screen displays a graphic showing all available } \\
\text { segments for the tank and the selected waste transfer name/number, pumps lines and pits } \\
\text { involved. Screen also shows the Valve Position Key. The operator can go to the next level } \\
\text { of detail by clicking on the item of interest and the appropriate screen is displayed. }\end{array}$ \\
\hline \multirow[t]{3}{*}{42} & $\mathrm{CBS \_ AY}$ & $\begin{array}{l}\text { Create By Segment Tank Farm AY Screen displays the selected waste transfer } \\
\text { name/number and a graphic display of the Tank farm showing all available segments. See } \\
\text { CBS A screen description for further discussion. }\end{array}$ \\
\hline & CBS_AY_l & $\begin{array}{l}\text { Create By Segment Tank 241-AY-101 Screen displays a graphic showing all available } \\
\text { segments for the tank and the selected waste transfer name/number, pumps lines and pits } \\
\text { involved. Screen also shows the Valve Position Key. The operator can go to the next level } \\
\text { of detail by clicking on the item of interest and the appropriate screen is displayed. }\end{array}$ \\
\hline & CBS_AY_2 & $\begin{array}{l}\text { Create By Segment Tank 241-AY-102 Screen displays a graphic showing all available } \\
\text { segments for the tank and the selected waste transfer name/number, pumps lines and pits } \\
\text { involved. Screen also shows the Valve Position Key. The operator can go to the next level } \\
\text { of detail by clicking on the item of interest and the appropriate screen is displayed. }\end{array}$ \\
\hline
\end{tabular}




\begin{tabular}{|c|c|c|}
\hline No. & $\begin{array}{c}\text { Screen } \\
\text { Filename }\end{array}$ & HMI Screen Description \\
\hline \multirow[t]{4}{*}{46} & CBS_AZ & $\begin{array}{l}\text { Create By Segment Tank Farm AZ Screen displays the selected waste transfer } \\
\text { name/number and a graphic display of the tank farm showing all available segments. See } \\
\text { CBS A screen description for further discussion. }\end{array}$ \\
\hline & CBS_AZ_A & $\begin{array}{l}\text { Create By Segment Valve Pit 241-AZ-A Screen displays a graphic showing all available } \\
\text { segments for the valve pit. It also shows the selected waste transfer name/number, the valve } \\
\text { pit and which connection areas, tanks and pits are involved. Screen also shows an } \\
\text { Encasement Valve Position key and the Valve Position Key. The operator can go to the next } \\
\text { level of detail by clicking on the item of interest and the appropriate screen is displayed. }\end{array}$ \\
\hline & CBS_AZ_1 & $\begin{array}{l}\text { Create By Segment Tank 241-AZ-101 Screen displays a graphic showing all available } \\
\text { segments for the tank and the selected waste transfer name/number, pumps lines and pits } \\
\text { involved. Screen also shows the Valve Position Key. The operator can go to the next level } \\
\text { of detail by clicking on the item of interest and the appropriate screen is displayed. }\end{array}$ \\
\hline & CBS_AZ_2 & $\begin{array}{l}\text { Create By Segment Tank 241-AZ-102 Screen displays a graphic showing all available } \\
\text { segments for the tank and the selected waste transfer name/number, pumps lines and pits } \\
\text { involved. Screen also shows the Valve Position Key. The operator can go to the next level } \\
\text { of detail by clicking on the item of interest and the appropriate screen is displayed. }\end{array}$ \\
\hline \multirow[t]{7}{*}{49} & CBS_SY & $\begin{array}{l}\text { Create By Segment Tank Farm SY Screen displays the selected waste transfer } \\
\text { name/number and a graphic display of the tank farm showing all available segments. See } \\
\text { CBS A screen description for further discussion. }\end{array}$ \\
\hline & CBS_SY_1 & $\begin{array}{l}\text { Create By Segment Tank 241-SY-101 Screen displays a graphic showing all available } \\
\text { segments for the tank and the selected waste transfer name/number, pumps lines and pits } \\
\text { involved. Screen also shows the Valve Position Key. The operator can go to the next level } \\
\text { of detail by clicking on the item of interest and the appropriate screen is displayed. }\end{array}$ \\
\hline & CBS_SY_2 & $\begin{array}{l}\text { Create By Segment Tank 241-SY-102 Screen displays a graphic showing all available } \\
\text { segments for the tank and the selected waste transfer name/number, pumps lines and pits } \\
\text { involved. Screen also shows the Valve Position Key. The operator can go to the next level } \\
\text { of detail by clicking on the item of interest and the appropriate screen is displayed. }\end{array}$ \\
\hline & CBS_SY_3 & $\begin{array}{l}\text { Create By Segment Tank 241-SY-103 Screen displays a graphic showing all available } \\
\text { segments for the tank and the selected waste transfer name/number, pumps lines and pits } \\
\text { involved. Screen also shows the Valve Position Key. The operator can go to the next level } \\
\text { of detail by clicking on the item of interest and the appropriate screen is displayed. }\end{array}$ \\
\hline & CBS_SY_A & $\begin{array}{l}\text { Create By Segment Valve Pit 241-SY-A Screen displays a graphic showing all available } \\
\text { segments for the valve pit. It also shows the selected waste transfer name/number, the valve } \\
\text { pit and which connection areas, tanks and pits are involved. Screen also shows an } \\
\text { Encasement Valve Position key and the Valve Position Key. The operator can go to the next } \\
\text { level of detail by clicking on the item of interest and the appropriate screen is displayed. }\end{array}$ \\
\hline & CBS_SY_B & $\begin{array}{l}\text { Create By Segment Valve Pit 241-SY-B Screen displays a graphic showing all available } \\
\text { segments for the valve pit. It also shows the selected waste transfer name/number, the valve } \\
\text { pit and which connection areas, tanks and pits are involved. Screen also shows an } \\
\text { Encasement Valve Position key and the Valve Position Key. The operator can go to the next } \\
\text { level of detail by clicking on the item of interest and the appropriate screen is displayed. }\end{array}$ \\
\hline & CBS_SYFA & $\begin{array}{l}\text { Create By Segment Flush Pit 241-SY-A Screen displays a graphic showing all available } \\
\text { segments for the flush pit as well as the selected waste transfer name/number, the valve pit } \\
\text { and which connection areas, tanks and pits are involved. Screen also shows an Encasement } \\
\text { Valve Position key and the Valve Position Key. The operator can go to the next level of } \\
\text { detail by clicking on the item of interest and the appropriate screen is displayed. }\end{array}$ \\
\hline
\end{tabular}




\begin{tabular}{|c|c|c|}
\hline No. & $\begin{array}{c}\text { Screen } \\
\text { Filename }\end{array}$ & HMI Screen Description \\
\hline & CBS_SYFB & $\begin{array}{l}\text { Create By Segment Flush Pit 241-SY-B Screen displays a graphic showing all available } \\
\text { segments as well as the selected waste transfer name/number, the valve pit and which } \\
\text { connection areas, tanks and pits are involved. Screen also shows an Encasement Valve } \\
\text { Position key and the Valve Position Key. The operator can go to the next level of detail by } \\
\text { clicking on the item of interest and the appropriate screen is displayed. }\end{array}$ \\
\hline 50 & $\overline{C S D} 01$ & $\begin{array}{l}\text { Compare Source/Destination Screen displays the following: } \\
\text { Waste flow rate from Source tank } \\
\text { Running total of flow from Source tank (based on calculations for Phase 1) } \\
\text { Source tank transfer pump speed (if pump powered by variable speed drive) } \\
\text { Source tank dome pressure } \\
\text { Destination tank dome pressure (Phase 2) } \\
\text { Total Flow Setpoint for Selected Transfer } \\
\text { Total difference in flow (Source - Destination) } \\
\text { Selected waste transfer name/number. } \\
\text { The following buttons are available: } \\
\text { RESET Total (3) allows the user with the appropriate access level to reset the totalized } \\
\text { flow to zero. }\end{array}$ \\
\hline 79 & PLC-242A & $\begin{array}{l}\text { A Farm PLC Screen displays the status of the PLC racks and modules, as well as, the } \\
\text { HMI's. Buttons are shown for accessing other PLC screens. }\end{array}$ \\
\hline 80 & PLC_AN & $\begin{array}{l}\text { AN Farm PLC Screen displays the status of the PLC racks and modules, as well as, the } \\
\text { HMI's. Buttons are shown for accessing other PLC screens. }\end{array}$ \\
\hline 81 & PLC_AP & $\begin{array}{l}\text { AP Farm PLC Screen displays the status of the PLC racks and modules, as well as, the } \\
\text { HMI's. Buttons are shown for accessing other PLC screens. }\end{array}$ \\
\hline 82 & PLC_AW & $\begin{array}{l}\text { AW Farm PLC Screen displays the status of the PLC racks and modules, as well as, the } \\
\text { HMI's. Buttons are shown for accessing other PLC screens. }\end{array}$ \\
\hline 83 & PLC_AYAZ & $\begin{array}{l}\text { AY and AZ Farms PLC Screen displays the status of the PLC racks and modules, as well } \\
\text { as, the HMI's. Buttons are shown for accessing other PLC screens. }\end{array}$ \\
\hline & PLC_OT & $\begin{array}{l}\text { Operator/Trainer PLC Screen displays the status of the PLC racks and modules, as well } \\
\text { as, the HMI's for the operator/trainer. }\end{array}$ \\
\hline 84 & PLC_2W & $\begin{array}{l}200 \text { West PLC Screen displays the status of the PLC racks and modules, as well as, the } \\
\text { HMI's. Buttons are shown for accessing other PLC screens. }\end{array}$ \\
\hline
\end{tabular}




\begin{tabular}{|c|c|c|}
\hline No. & $\begin{array}{c}\text { Screen } \\
\text { Filename }\end{array}$ & HMI Screen Description \\
\hline \multirow[t]{10}{*}{86} & SFV01 & $\begin{array}{l}\text { System Function Verify Screen displays the selected waste transfer name and number, and } \\
\text { the current summary status of the system leak detectors, the MPS Relays and MPS } \\
\text { Interlocks. The following buttons allow selecting a screen to perform these functions: } \\
\text { MPS Relays Inputs takes the user to the MPS Relays Screen (SFVRLY). } \\
\text { MPS Connected Devices takes the user to the System Connected Devices Screen } \\
\text { (SFVMCD). } \\
\text { MPS Monitored Valves takes the user to the System Monitored Valves Screen (SFVVPV). } \\
\text { MPS Manual COBs takes the user to the System Manual COBs Screen (SFVCOB). } \\
\text { MPS Leak Detectors takes the user to the System Leak Detectors Screen (SFVLD). } \\
\text { Manual Valves takes the user to the System Manual Valves Screen (SFVMVP). } \\
\text { Encasement Valves takes the user to the System Encasement Valves Screen (SFVEVP). } \\
\text { Pump Interlock Relays takes the user to the System Pump Interlock Relays Screen } \\
\text { (SFVINTLK). } \\
\text { PLC Input/Output Test takes the user to the System PLC Input/Output Test Screen } \\
\text { (SFVPC). } \\
\text { There are also "indicator lights" for the summary status of the System Leak Detectors, the } \\
\text { MPS Relays and the MPS Interlocks. Green indicates verified, Red indicates unverified and } \\
\text { Gray indicates not in route. }\end{array}$ \\
\hline & SFVCOB & $\begin{array}{l}\text { System Function Verify Manual Leak Detector Screen displays the selected waste } \\
\text { transfer name and number, current summary status of the system Manual leak detectors. } \\
\text { Screen also shows buttons to verify Manual Leak Detectors. }\end{array}$ \\
\hline & SFVEVP & $\begin{array}{l}\text { System Function Verify Encasement Valves Screen displays the selected waste transfer } \\
\text { name and number, the name and number of the Encasement Valve and the current summary } \\
\text { status of the Encasement valves. Screen also shows buttons to verify Encasement Valves }\end{array}$ \\
\hline & SFVINTLK & $\begin{array}{l}\text { System Function Verify Interlock Relays Screen displays the selected waste transfer name } \\
\text { and number, the name and number of the Interlock Relay and the current summary status of } \\
\text { the Interlock Relays. Screen also shows buttons to verify the Interlock Relays. }\end{array}$ \\
\hline & SFVLD & $\begin{array}{l}\text { System Function Verify MPS Leak Detectors Screen displays the selected waste transfer } \\
\text { name and number, the name and number of the MPS Leak Detectors and the current } \\
\text { summary status of the system leak detectors. Screen also shows buttons to verify the MPS } \\
\text { Leak Detectors. }\end{array}$ \\
\hline & SFVMCD & $\begin{array}{l}\text { System Function Verify MCD Relays Screen displays the selected waste transfer name } \\
\text { and number, the name and number of the MCD Relay and the current summary status of the } \\
\text { MCD Relay. Screen also shows buttons to verify the MCD Relays. }\end{array}$ \\
\hline & SFVMVP & $\begin{array}{l}\text { System Function Verify Manual Valve Screen displays the selected waste transfer name } \\
\text { and number, the name and number of the manual Valve and the current summary status of } \\
\text { the Manual Valves. Screen also shows buttons to verify the Manual Valves. }\end{array}$ \\
\hline & SFVPLC & $\begin{array}{l}\text { System Function Verify PLC Input/Output Screen displays the selected waste transfer } \\
\text { name and number, and the current summary status of the PLC Input/Output Test screen. } \\
\text { Screen also shows buttons to verify the PLC Input/Output Test. }\end{array}$ \\
\hline & SFVRLY & $\begin{array}{l}\text { System Function Verify MPS Relay Screen displays the selected waste transfer name and } \\
\text { number, the name and number of the MPS Relay and the current summary status of the MPS } \\
\text { Relay Verification. Screen also shows buttons to verify the MPS Relays. }\end{array}$ \\
\hline & SFVVPV & $\begin{array}{l}\text { System Function Verify MPS Monitored Valves Screen displays the selected waste } \\
\text { transfer name and number, the name and number of the MPS Monitored Valves and the } \\
\text { current summary status of the MPS Monitored Valves. Screen also shows buttons to verify } \\
\text { the MPS Relays. }\end{array}$ \\
\hline 95 & STEPS_1 & Page 1 of example of overall checklist for setting up a transfer route. \\
\hline
\end{tabular}




\begin{tabular}{|c|c|c|}
\hline No. & $\begin{array}{c}\text { Screen } \\
\text { Filename }\end{array}$ & HMI Screen Description \\
\hline & STEPS_2 & Page 2 of checklist for setting up a transfer route. \\
\hline \multirow[t]{2}{*}{96} & PLC MAIN & $\begin{array}{l}\text { System Information Screen displays the status of various portions of the system and allows } \\
\text { the user to make system wide changes. This screen and other system screens accessed } \\
\text { through this screen are available only to selected groups of users, based on access level. } \\
\text { The following buttons are available: } \\
\text { PLC accesses various screens related to PLC status (PLC_242A, PLC_AN, PLC_AP, } \\
\text { PLC_AW, PLC-2W, PLC_SY and Operator Trainer PLC). } \\
\text { Main Menu returns to the top screen (Mainmenu). }\end{array}$ \\
\hline & & $\begin{array}{l}\text { Transfer Route Mode Screen allows the selection, verification, creation, deletion and/or } \\
\text { modification of waste transfer routes. This screen displays the selected waste transfer name } \\
\text { and number as well as the current displayed route. If a name not yet assigned, the name } \\
\text { shown is "Available". There are the following buttons: } \\
\text { Select Predetermined Route button allows the user to select from the Predetermined } \\
\text { Transfer Routes list. This is the only way to select a route. } \\
\text { Create New Transfer Route button takes the user to the Create By Segment Screen } \\
\text { (CBS01). }\end{array}$ \\
\hline \multirow[t]{4}{*}{99} & TMS01 & $\begin{array}{l}\text { Activate Selected Route button adds the selected Predetermined Route to the Active Waste } \\
\text { Transfer Routes list, provided there is an "Available" slot. } \\
\text { Verify Current Active Route button is enabled only when a predetermined transfer route } \\
\text { has been selected and activated by the operator. When this function is selected, the } \\
\text { appropriate active transfer route screen (1-6) appears, allowing the operator to verify all of } \\
\text { the mechanical elements: leak detectors, valves, MPS relays, etc. } \\
\text { Modify Selected Route button is enabled only when a predetermined transfer route has been } \\
\text { selected but not activated by the operator. This function allows the user to modify the } \\
\text { selected predetermined transfer route by adding or deleting mechanical elements (including } \\
\text { route segments) or PLC I/O elements. The user is taken to the Create By Segment Screen } \\
\text { (CBS01). } \\
\text { Delete Route button is enabled only when a predetermined transfer route has been selected } \\
\text { but not activated by the operator. When this function is selected, the selected predetermined } \\
\text { transfer route may be deleted by the user with the appropriate access level. The user is } \\
\text { asked to confirm the deletion. } \\
\text { Return to Main Menu takes the user to the top screen (MainMenu). } \\
\text { Deactivate route deactivates an active route from the current active route list. } \\
\text { Disable Route disables selection of a predetermined waste transfer route. } \\
\text { Enable Route enables a predetermined waste transfer route that had been previously } \\
\text { disabled. }\end{array}$ \\
\hline & TRN_AN_A & $\begin{array}{l}\text { Valve Pit 241-AN-A Trainer Screen. This screen displays the AN-A Valve Pit for the } \\
\text { Trainer/Instructor. This screen also displays all active waste transfers (1-6) and valve } \\
\text { position keys. }\end{array}$ \\
\hline & TRN_AN_B & $\begin{array}{l}\text { Valve Pit 241-AN-B Trainer Screen. This screen displays the AN-B Valve Pit for the } \\
\text { Trainer/Instructor. This screen also displays all active waste transfers (1-6) and valve } \\
\text { position keys. }\end{array}$ \\
\hline & TRN_MAIN & MAIN Trainer Screen. This screen displays the Main screen for the Trainer/Instructor. \\
\hline
\end{tabular}




\begin{tabular}{|c|c|c|}
\hline No. & $\begin{array}{c}\text { Screen } \\
\text { Filename }\end{array}$ & HMI Screen Description \\
\hline \multirow[t]{7}{*}{108} & Mainmenu & $\begin{array}{l}\text { Top Screen. At this screen the operator can select from several different modes. } \\
\text { The System Info Screen (PLC Main) is available only if the user has an appropriate access } \\
\text { level. } \\
\text { All alarms are always active and can be viewed on the alarm summary screen. } \\
\text { The following mode selections are available: } \\
\text { Waste Transfer Annunciator button displays the Waste Transfer Annunciator Site Screen } \\
\text { (WTA01) } \\
\text { Transfer Mode Select button displays the Transfer Mode Screen (TMS01). } \\
\text { Compare Source/Dest Flow button displays the Compare Source and Destination Flow } \\
\text { Mode Screen (CSD01) } \\
\text { Auxiliary Functions button displays auxiliary functions which can be selected such as turn } \\
\text { the printer on or off, etc. (TBD) } \\
\text { System Info Screen button displays the System Information Screen (PLC-Main). } \\
\text { Exit to Login Screen takes the user to the login screen (). }\end{array}$ \\
\hline & TRN-219S & $\begin{array}{l}\text { 219-S Liquid Waste Drain Trainer Screen displays the selected waste transfer } \\
\text { name/number, pump and the } 219-\mathrm{S}-102 \text { collection tank and the line leading to the } 244-\mathrm{S} \\
\text { receiver vault. Screen also shows an Encasement Valve Position key and the Valve Position } \\
\text { Key. The operator can go to the next level of detail by clicking on the item of interest and } \\
\text { the appropriate screen is displayed. }\end{array}$ \\
\hline & TRN-242A & $\begin{array}{l}\text { 242-A Evaporator Trainer Screen displays the selected waste transfer name/number, } \\
\text { pump and a detailed evaporator/crystallizer graphic. The operator can go to the next level of } \\
\text { detail by clicking on the item of interest and the appropriate screen is displayed. }\end{array}$ \\
\hline & TRN-244S & $\begin{array}{l}\text { 244-S Catch Station Trainer Screen displays the selected waste transfer name/number, } \\
\text { pump lines and pits involved. Screen also shows an Encasement Valve Position key and the } \\
\text { Valve Position Key. The operator can go to the next level of detail by clicking on the item of } \\
\text { interest and the appropriate screen is displayed. }\end{array}$ \\
\hline & TRN_6241A & $\begin{array}{l}\text { Diversion Box 6241-A Trainer Screen displays the selected waste transfer name/number, } \\
\text { the Diversion Box and which connection areas, tanks and pits are involved. Screen also } \\
\text { shows the Valve Position Key. The operator can go to the next level of detail by clicking on } \\
\text { the item of interest and the appropriate screen is displayed. }\end{array}$ \\
\hline & TRN_624lV & $\begin{array}{l}\text { Vent Station 6241-V Trainer Screen displays the selected waste transfer name/number, the } \\
\text { vent pit and which connection areas, tanks and pits are involved. Screen also shows the } \\
\text { Valve Position Key. The operator can go to the next level of detail by clicking on the item of } \\
\text { interest and the appropriate screen is displayed. }\end{array}$ \\
\hline & TRN_2E & $\begin{array}{l}200 \text { East Tank Farms Trainer Screen displays the selected waste transfer name/number } \\
\text { and indicates which Tank Farm(s) are involved. The operator can go to the next level of } \\
\text { detail by clicking on the area of interest and the appropriate screen is displayed. } \\
\text { TR_A has details of A farm valve pits. } \\
\text { TR_AN has details of AN farm and valve pits. } \\
\text { TR_AP has details of AP farm and valve pits. } \\
\text { TR_AW has details of AW farm and valve pits. } \\
\text { TR_AY has details of AY farm and pits. } \\
\text { TR_AZ has details of AZ farm and pits. } \\
\text { TR_242A has details of 242-A building. } \\
\text { TR_204AR has details of 204-AR Building. } \\
\text { TR_6241A has details of Diversion Box 6241-A. } \\
\text { TR_6241V has details of Vent Station 6241-V. }\end{array}$ \\
\hline
\end{tabular}




\begin{tabular}{|c|c|c|}
\hline No. & $\begin{array}{c}\text { Screen } \\
\text { Filename }\end{array}$ & HMI Screen Description \\
\hline & TRN_2W & $\begin{array}{l}200 \text { West Tank Farms Trainer Screen displays the selected waste transfer name/number } \\
\text { and indicates which Tank Farm(s) are involved. The operator can go to the next level of } \\
\text { detail by clicking on the area of interest and the appropriate screen is displayed. } \\
\text { TR_244S has details of } 244-S \text { catch station. } \\
\text { TR SY has details of SY farm and pits. }\end{array}$ \\
\hline & TRN_A & $\begin{array}{l}\text { 241-A Tank Farm Trainer Screen displays the 204-AR Building, Valve Pits } 241-\mathrm{A}-\mathrm{A} \text { and } \\
\text { 241-A-B, selected waste transfer name/number and indicates which connecting areas, tanks } \\
\text { and pits are involved. The operator can go to the next level of detail by clicking on the item } \\
\text { of interest and the appropriate screen is displayed. Screen also shows valve position key. } \\
\text { This screen will be removed during Phase } 2 \text {. }\end{array}$ \\
\hline & TRN_A350 & $\begin{array}{l}\text { 241-A-350 Drainage Lift Station Trainer Screen displays the selected waste transfer } \\
\text { name/number, pump lines and pits involved. Screen also shows the Valve Position Key. The } \\
\text { operator can go to the next level of detail by clicking on the item of interest and the } \\
\text { appropriate screen is displayed. }\end{array}$ \\
\hline & TRN_AN & $\begin{array}{l}\text { 241-AN Tank Farm Trainer Screen displays the selected waste transfer name/number and } \\
\text { indicates which connecting areas, tanks and pits are involved. The operator can go to the } \\
\text { next level of detail by clicking on the item of interest and the appropriate screen is displayed. }\end{array}$ \\
\hline & TRN_AN_1 & $\begin{array}{l}\text { Tank 241-AN-101 Trainer Screen displays the selected waste transfer name/number, the } \\
\text { tank and which connecting areas, tanks and pits are involved. The operator can go to the } \\
\text { next level of detail by clicking on the item of interest and the appropriate screen is displayed. }\end{array}$ \\
\hline & TRN_AN_2 & $\begin{array}{l}\text { Tank 241-AN-102 Trainer Screen displays the selected waste transfer name/number, the } \\
\text { tank and which connecting areas, tanks and pits are involved. The operator can go to the } \\
\text { next level of detail by clicking on the item of interest and the appropriate screen is displayed. }\end{array}$ \\
\hline & TRN_AN_3 & $\begin{array}{l}\text { Tank 241-AN-103 Trainer Screen displays the selected waste transfer name/number, the } \\
\text { tank and which connecting areas, tanks and pits are involved. The operator can go to the } \\
\text { next level of detail by clicking on the item of interest and the appropriate screen is displayed. }\end{array}$ \\
\hline & TRN_AN_4 & $\begin{array}{l}\text { Tank 241-AN-104 Trainer Screen displays the selected waste transfer name/number, the } \\
\text { tank and which connecting areas, tanks and pits are involved. The operator can go to the } \\
\text { next level of detail by clicking on the item of interest and the appropriate screen is displayed. }\end{array}$ \\
\hline & TRN_AN_5 & $\begin{array}{l}\text { Tank 241-AN-105 Trainer Screen displays the selected waste transfer name/number, the } \\
\text { tank and which connecting areas, tanks and pits are involved. The operator can go to the } \\
\text { next level of detail by clicking on the item of interest and the appropriate screen is displayed. }\end{array}$ \\
\hline & TRN_AN_6 & $\begin{array}{l}\text { Tank 241-AN-106 Trainer Screen displays the selected waste transfer name/number, the } \\
\text { tank and which connecting areas, tanks and pits are involved. The operator can go to the } \\
\text { next level of detail by clicking on the item of interest and the appropriate screen is displayed. }\end{array}$ \\
\hline & TRN_AN_7 & $\begin{array}{l}\text { Tank 241-AN-107 Trainer Screen displays the selected waste transfer name/number, the } \\
\text { tank and which connecting areas, tanks and pits are involved. The operator can go to the } \\
\text { next level of detail by clicking on the item of interest and the appropriate screen is displayed. }\end{array}$ \\
\hline & TRN_AP & $\begin{array}{l}\text { 241-AP Tank Farm Trainer Screen displays the selected waste transfer name/number and } \\
\text { indicates which connecting areas, lines, leak detectors, tanks and pits are involved. The } \\
\text { operator can go to the next level of detail by clicking on the item of interest and the } \\
\text { appropriate screen is displayed. }\end{array}$ \\
\hline & TRN-APVP & $\begin{array}{l}\text { Valve Pit 241-APVP Trainer Screen displays the selected waste transfer name/number, a } \\
\text { detailed valve pit graphic and which connecting areas, tanks and pits are involved. The } \\
\text { operator can go to the next level of detail by clicking on the item of interest and the } \\
\text { appropriate screen is displayed. }\end{array}$ \\
\hline & TRN_AP_A & $\begin{array}{l}\text { Valve Pit 241-AP-A Trainer Screen displays the selected waste transfer name/number, a } \\
\text { detailed valve pit graphic and which connecting areas, tanks and pits are involved. The } \\
\text { operator can go to the next level of detail by clicking on the item of interest and the } \\
\text { appropriate screen is displayed. }\end{array}$ \\
\hline
\end{tabular}




\begin{tabular}{|c|c|c|}
\hline No. & $\begin{array}{c}\text { Screen } \\
\text { Filename }\end{array}$ & HMI Screen Description \\
\hline & TRN_APFP & $\begin{array}{l}\text { AP Flush Pit Trainer Screen displays the selected waste transfer name/number, a detailed } \\
\text { flush pit graphic and which connecting areas, tanks and pits are involved. The operator can } \\
\text { go to the next level of detail by clicking on the item of interest and the appropriate screen is } \\
\text { displayed. }\end{array}$ \\
\hline & TRN_AP_1 & $\begin{array}{l}\text { Tank 241-AP-101 Trainer Screen displays the selected waste transfer name/number, the } \\
\text { tank and which connecting areas, tanks and pits are involved. The operator can go to the } \\
\text { next level of detail by clicking on the item of interest and the appropriate screen is displayed. }\end{array}$ \\
\hline & TRN_AP_2 & $\begin{array}{l}\text { Tank 241-AP-102 Trainer Screen displays the selected waste transfer name/number, the } \\
\text { tank and which connecting areas, tanks and pits are involved. The operator can go to the } \\
\text { next level of detail by clicking on the item of interest and the appropriate screen is displayed. }\end{array}$ \\
\hline & TRN_AP_3 & $\begin{array}{l}\text { Tank 241-AP-103 Trainer Screen displays the selected waste transfer name/number, the } \\
\text { tank and which connecting areas, tanks and pits are involved. The operator can go to the } \\
\text { next level of detail by clicking on the item of interest and the appropriate screen is displayed. }\end{array}$ \\
\hline & TRN_AP_4 & $\begin{array}{l}\text { Tank 241-AP-104 Trainer Screen displays the selected waste transfer name/number, the } \\
\text { tank and which connecting areas, tanks and pits are involved. The operator can go to the } \\
\text { next level of detail by clicking on the item of interest and the appropriate screen is displayed. }\end{array}$ \\
\hline & TRN_AP_5 & $\begin{array}{l}\text { Tank 241-AP-105 Trainer Screen displays the selected waste transfer name/number, the } \\
\text { tank and which connecting areas, tanks and pits are involved. The operator can go to the } \\
\text { next level of detail by clicking on the item of interest and the appropriate screen is displayed. }\end{array}$ \\
\hline & TRN_AP_6 & $\begin{array}{l}\text { Tank 241-AP-106 Trainer Screen displays the selected waste transfer name/number, the } \\
\text { tank and which connecting areas, tanks and pits are involved. The operator can go to the } \\
\text { next level of detail by clicking on the item of interest and the appropriate screen is displayed. }\end{array}$ \\
\hline & TRN_AP_7 & $\begin{array}{l}\text { Tank 241-AP-107 Trainer Screen displays the selected waste transfer name/number, the } \\
\text { tank and which connecting areas, tanks and pits are involved. The operator can go to the } \\
\text { next level of detail by clicking on the item of interest and the appropriate screen is displayed. }\end{array}$ \\
\hline & TRN_AP_8 & $\begin{array}{l}\text { Tank 241-AP-108 Trainer Screen displays the selected waste transfer name/number, the } \\
\text { tank and which connecting areas, tanks and pits are involved. The operator can go to the } \\
\text { next level of detail by clicking on the item of interest and the appropriate screen is displayed. }\end{array}$ \\
\hline & TRN_AW & $\begin{array}{l}\text { 241-AW Tank Farm Trainer Screen displays the selected waste transfer name/number and } \\
\text { indicates which connecting areas, tanks, lines, leak detectors and pits are involved. The } \\
\text { operator can go to the next level of detail by clicking on the item of interest and the } \\
\text { appropriate screen is displayed. }\end{array}$ \\
\hline \multirow[t]{5}{*}{$\square$} & TRN_AWFP & $\begin{array}{l}\text { Flush Pit 241-AW Trainer Screen displays the selected waste transfer name/number, the } \\
\text { flush pit and which connection areas, tanks and pits are involved. Screen also shows an } \\
\text { Encasement Valve Position key and the Valve Position Key. The operator can go to the next } \\
\text { level of detail by clicking on the item of interest and the appropriate screen is displayed. }\end{array}$ \\
\hline & TRN_AW_A & $\begin{array}{l}\text { Valve Pit 241-AW-A Trainer Screen displays the selected waste transfer name/number, a } \\
\text { detailed valve pit graphic and which connecting areas, tanks and pits are involved. The } \\
\text { operator can go to the next level of detail by clicking on the item of interest and the } \\
\text { appropriate screen is displayed. }\end{array}$ \\
\hline & TRN_AW_B & $\begin{array}{l}\text { Valve Pit 241-AW-B Trainer Screen displays the selected waste transfer name/number, a } \\
\text { detailed valve pit graphic and which connecting areas, tanks and pits are involved. The } \\
\text { operator can go to the next level of detail by clicking on the item of interest and the } \\
\text { appropriate screen is displayed. }\end{array}$ \\
\hline & TRN_AW_1 & $\begin{array}{l}\text { Tank 241-AW-101 Trainer Screen displays the selected waste transfer name/number, the } \\
\text { tank and which connecting areas, tanks and pits are involved. The operator can go to the } \\
\text { next level of detail by clicking on the item of interest and the appropriate screen is displayed. }\end{array}$ \\
\hline & TRN_AW_2 & $\begin{array}{l}\text { Tank 241-AW-102 Trainer Screen displays the selected waste transfer name/number, the } \\
\text { tank and which connecting areas, tanks and pits are involved. The operator can go to the } \\
\text { next level of detail by clicking on the item of interest and the appropriate screen is displayed. }\end{array}$ \\
\hline
\end{tabular}




\begin{tabular}{|c|c|c|}
\hline No. & $\begin{array}{c}\text { Screen } \\
\text { Filename }\end{array}$ & HMI Screen Description \\
\hline & TRN_AW_3 & $\begin{array}{l}\text { Tank 241-AW-103 Trainer Screen displays the selected waste transfer name/number, the } \\
\text { tank and which connecting areas, tanks and pits are involved. The operator can go to the } \\
\text { next level of detail by clicking on the item of interest and the appropriate screen is displayed. }\end{array}$ \\
\hline & TRN_AW_4 & $\begin{array}{l}\text { Tank 241-AW-104 Trainer Screen displays the selected waste transfer name/number, the } \\
\text { tank and which connecting areas, tanks and pits are involved. The operator can go to the } \\
\text { next level of detail by clicking on the item of interest and the appropriate screen is displayed. }\end{array}$ \\
\hline & TRN_AW_5 & $\begin{array}{l}\text { Tank 241-AW-105 Trainer Screen displays the selected waste transfer name/number, the } \\
\text { tank and which connecting areas, tanks and pits are involved. The operator can go to the } \\
\text { next level of detail by clicking on the item of interest and the appropriate screen is displayed. }\end{array}$ \\
\hline & TRN_AW_6 & $\begin{array}{l}\text { Tank 241-AW-106 Trainer Screen displays the selected waste transfer name/number, the } \\
\text { tank and which connecting areas, tanks and pits are involved. The operator can go to the } \\
\text { next level of detail by clicking on the item of interest and the appropriate screen is displayed. }\end{array}$ \\
\hline & TRN_AY & $\begin{array}{l}\text { 241-AY Tank Farm Trainer Screen displays the selected waste transfer name/number and } \\
\text { indicates which connecting areas, tanks and pits are involved. The operator can go to the } \\
\text { next level of detail by clicking on the item of interest and the appropriate screen is displayed. }\end{array}$ \\
\hline & TRN_AY_l & $\begin{array}{l}\text { Tank 241-AY-101 Trainer Screen displays the selected waste transfer name/number, the } \\
\text { tank and which connecting areas, tanks and pits are involved. The operator can go to the } \\
\text { next level of detail by clicking on the item of interest and the appropriate screen is displayed. }\end{array}$ \\
\hline & TRN_AY_2 & $\begin{array}{l}\text { Tank 241-AY-102 Trainer Screen displays the selected waste transfer name/number, the } \\
\text { tank and which connecting areas, tanks and pits are involved. The operator can go to the } \\
\text { next level of detail by clicking on the item of interest and the appropriate screen is displayed. }\end{array}$ \\
\hline & TRN_AZ & $\begin{array}{l}\text { 241-AZ Tank Farm Trainer Screen displays the selected waste transfer name/number and } \\
\text { indicates which connecting areas, tanks and pits are involved. The operator can go to the } \\
\text { next level of detail by clicking on the item of interest and the appropriate screen is displayed. }\end{array}$ \\
\hline & $\overline{T R N \_A Z \_A}$ & $\begin{array}{l}\text { Valve Pit 241-AZ Trainer Screen displays the selected waste transfer name/number, the } \\
\text { valve pit and which connection areas, tanks and pits are involved. Screen also shows an } \\
\text { Encasement Valve Position key and the Valve Position Key. The operator can go to the next } \\
\text { level of detail by clicking on the item of interest and the appropriate screen is displayed. }\end{array}$ \\
\hline & TRN_AZ_l & $\begin{array}{l}\text { Tank 241-AZ-101 Trainer Screen displays the selected waste transfer name/number, the } \\
\text { tank and which connecting areas, tanks and pits are involved. The operator can go to the } \\
\text { next level of detail by clicking on the item of interest and the appropriate screen is displayed. }\end{array}$ \\
\hline & TRN_AZ_2 & $\begin{array}{l}\text { Tank 241-AZ-102 Trainer Screen displays the selected waste transfer name/number, the } \\
\text { tank and which connecting areas, tanks and pits are involved. The operator can go to the } \\
\text { next level of detail by clicking on the item of interest and the appropriate screen is displayed. }\end{array}$ \\
\hline & TRN_SY & $\begin{array}{l}\text { 241-SY Tank Farm Trainer Screen displays the selected waste transfer name/number and } \\
\text { indicates which connecting areas, tanks and pits are involved. The operator can go to the } \\
\text { next level of detail by clicking on the item of interest and the appropriate screen is displayed. }\end{array}$ \\
\hline & TRN_SY_A & $\begin{array}{l}\text { Valve Pit 241-SY-A Trainer Screen displays the selected waste transfer name/number, the } \\
\text { valve pit and which connection areas, tanks and pits are involved. Screen also shows an } \\
\text { Encasement Valve Position key and the Valve Position Key. The operator can go to the next } \\
\text { level of detail by clicking on the item of interest and the appropriate screen is displayed. }\end{array}$ \\
\hline & TRN_SY_B & $\begin{array}{l}\text { Valve Pit 241-SY-B Trainer Screen displays the selected waste transfer name/number, the } \\
\text { valve pit and which connection areas, tanks and pits are involved. Screen also shows an } \\
\text { Encasement Valve Position key and the Valve Position Key. The operator can go to the next } \\
\text { level of detail by clicking on the item of interest and the appropriate screen is displayed. }\end{array}$ \\
\hline & TRN_SYFA & $\begin{array}{l}\text { Flush Pit 241-SY-A Trainer Screen displays the selected waste transfer name/number, the } \\
\text { flush pit and which connection areas, tanks and pits are involved. Screen also shows an } \\
\text { Encasement Valve Position key and the Valve Position Key. The operator can go to the next } \\
\text { level of detail by clicking on the item of interest and the appropriate screen is displayed. }\end{array}$ \\
\hline
\end{tabular}




\begin{tabular}{|c|c|c|}
\hline No. & $\begin{array}{c}\text { Screen } \\
\text { Filename }\end{array}$ & HMI Screen Description \\
\hline & TRN_SYFB & $\begin{array}{l}\text { Flush Pit 241-SY-B Trainer Screen displays the selected waste transfer name/number, the } \\
\text { valve pit and which connection areas, tanks and pits are involved. Screen also shows an } \\
\text { Encasement Valve Position key and the Valve Position Key. The operator can go to the next } \\
\text { level of detail by clicking on the item of interest and the appropriate screen is displayed. }\end{array}$ \\
\hline & TRN_SY_1 & $\begin{array}{l}\text { Tank 241-SY-101 Trainer Screen displays the selected waste transfer name/number, the } \\
\text { tank and which connecting areas, tanks and pits are involved. The operator can go to the } \\
\text { next level of detail by clicking on the item of interest and the appropriate screen is displayed. }\end{array}$ \\
\hline & TRN_SY_2 & $\begin{array}{l}\text { Tank 241-SY-102 Trainer Screen displays the selected waste transfer name/number, the } \\
\text { tank and which connecting areas, tanks and pits are involved. The operator can go to the } \\
\text { next level of detail by clicking on the item of interest and the appropriate screen is displayed. }\end{array}$ \\
\hline & TRN_SY_3 & $\begin{array}{l}\text { Tank 241-SY-103 Trainer Screen displays the selected waste transfer name/number, the } \\
\text { tank and which connecting areas, tanks and pits are involved. The operator can go to the } \\
\text { next level of detail by clicking on the item of interest and the appropriate screen is displayed. }\end{array}$ \\
\hline \multirow[t]{6}{*}{117} & WTA01 & $\begin{array}{l}\text { Waste Transfer Annunciator Screen displays the overall Tank Farm functions which are } \\
\text { basically system ready functions. Displayed is a graphic of the } 200 \text { East and West areas with } \\
\text { cross-site transfer line in between. Additionally, a listing of all active transfer routes is } \\
\text { shown. The operator can go to the next level of detail by selecting the area of interest and } \\
\text { the desired screen will be displayed. WTA_2E has details of } 200 \text { East area and WTA_2W } \\
\text { has details of } 200 \text { West area. } \\
\text { The following buttons are displayed: } \\
\text { Main menu button takes the user to the top screen (main menu) } \\
\text { Reset Loop Button: Resets loop/route after shutdown on that loop occurs. } \\
\text { Shutdown Transfer button: Allows Operations to stop the transfer pump remotely from the } \\
\text { HMI. }\end{array}$ \\
\hline & WTA-219S & $\begin{array}{l}\text { 219-S Liquid Waste Drain WTA Screen displays the selected waste transfer } \\
\text { name/number, pump and the } 219-\mathrm{S}-102 \text { collection tank and the line leading to the 244-S } \\
\text { receiver vault. Screen also shows an Encasement Valve Position key and the Valve Position } \\
\text { Key. The operator can go to the next level of detail by clicking on the item of interest and } \\
\text { the appropriate screen is displayed. }\end{array}$ \\
\hline & WTA-242A & $\begin{array}{l}\text { 242-A Evaporator WTA Screen displays the selected waste transfer name/number, pump } \\
\text { and a detailed evaporator/crystallizer graphic. The operator can go to the next level of detail } \\
\text { by clicking on the item of interest and the appropriate screen is displayed. }\end{array}$ \\
\hline & WTA-244S & $\begin{array}{l}\text { 244-S Catch Station WTA Screen displays the selected waste transfer name/number, pump } \\
\text { lines and pits involved. Screen also shows an Encasement Valve Position key and the } \\
\text { Valve Position Key. The operator can go to the next level of detail by clicking on the item of } \\
\text { interest and the appropriate screen is displayed. }\end{array}$ \\
\hline & WTA6241A & $\begin{array}{l}\text { Diversion Box 6241-A WTA Screen displays the selected waste transfer name/number, the } \\
\text { Diversion Box and which connection areas, tanks and pits are involved. Screen also shows } \\
\text { the Valve Position Key. The operator can go to the next level of detail by clicking on the } \\
\text { item of interest and the appropriate screen is displayed. }\end{array}$ \\
\hline & WTA6241V & $\begin{array}{l}\text { Vent Station 6241-V WTA Screen displays the selected waste transfer name/number, the } \\
\text { vent pit and which connection areas, tanks and pits are involved. Screen also shows the } \\
\text { Valve Position Key. The operator can go to the next level of detail by clicking on the item of } \\
\text { interest and the appropriate screen is displayed. }\end{array}$ \\
\hline
\end{tabular}




\begin{tabular}{|c|c|c|}
\hline No. & $\begin{array}{c}\text { Screen } \\
\text { Filename }\end{array}$ & HMI Screen Description \\
\hline 118 & WTA_2E & $\begin{array}{l}\text { 200E WTA Screen displays the selected waste transfer name/number and indicates which } \\
\text { Tank Farm(s) are involved. The operator can go to the next level of detail by clicking on the } \\
\text { area of interest and the appropriate screen is displayed. } \\
\text { WTA_A has details of A farm valve pits, 204-AR Building and 241-A-A Valve Pit. } \\
\text { WTA_AN has details of AN farm and valve pits. } \\
\text { WTA_AP has details of AP farm and valve pits. } \\
\text { WTA_AW has details of AW farm and valve pits. } \\
\text { WTA_AY has details of AY farm and pits. } \\
\text { WTA_AZ has details of AZ farm and pits. } \\
\text { WTA_242A has details of 242-A building. } \\
\text { WTA6241A has details of Diversion Box 6241-A. } \\
\text { WTA6241V has details of Vent Station 6241-V. }\end{array}$ \\
\hline 119 & WTA_2W & $\begin{array}{l}\text { 200W WTA Screen displays the selected waste transfer name/number and indicates which } \\
\text { Tank Farm(s) are involved. The operator can go to the next level of detail by clicking on the } \\
\text { area of interest and the appropriate screen is displayed. } \\
\text { WTA_244S has details of } 244-S \text { catch station. } \\
\text { WTA_SY has details of SY farm and pits. }\end{array}$ \\
\hline \multirow[t]{2}{*}{120} & WTA_A & $\begin{array}{l}\text { 200E A Farm WTA Screen displays the 204-AR Building, Valve Pits } 241-\mathrm{A}-\mathrm{A} \text {, and 24lA- } \\
\text { B displays the selected waste transfer name/number and indicates which connecting areas, } \\
\text { tanks, pumps lines and pits are involved. The operator can go to the next level of detail by } \\
\text { clicking on the item of interest and the appropriate screen is displayed. The CBS_A screen } \\
\text { has a similar background and in the final implementation will be combined with this screen. } \\
\text { Screen also shows valve position key. This screen will be removed during Phase } 2 \text {. }\end{array}$ \\
\hline & WTA_A350 & $\begin{array}{l}\text { 241-A-350 Drainage Lift Station WTA Screen displays the selected waste transfer } \\
\text { name/number, pump lines and pits involved. Screen also shows the Valve Position Key. The } \\
\text { operator can go to the next level of detail by clicking on the item of interest and the } \\
\text { appropriate screen is displayed. }\end{array}$ \\
\hline \multicolumn{3}{|l|}{121} \\
\hline 123 & WTA_AN & $\begin{array}{l}\text { 200E AN Farm WTA Screen displays the selected waste transfer name/number and } \\
\text { indicates which connecting areas, tanks and pits are involved. The operator can go to the } \\
\text { next level of detail by clicking on the item of interest and the appropriate screen is displayed. }\end{array}$ \\
\hline 124 & WTA_AN_A & $\begin{array}{l}\text { Valve Pit 241-AN-A WTA Screen displays the selected waste transfer name/number, a } \\
\text { detailed valve pit graphic and which connecting areas, tanks and pits are involved. The } \\
\text { operator can go to the next level of detail by clicking on the item of interest and the } \\
\text { appropriate screen is displayed. }\end{array}$ \\
\hline 125 & WTA_AN_B & $\begin{array}{l}\text { Valve Pit 241-AN-B WTA Screen displays the selected waste transfer name/number, a } \\
\text { detailed valve pit graphic and which connecting areas, tanks and pits are involved. The } \\
\text { operator can go to the next level of detail by clicking on the item of interest and the } \\
\text { appropriate screen is displayed. }\end{array}$ \\
\hline 126 & WTA_AN_1 & $\begin{array}{l}\text { Tank 241-AN-101 WTA Screen displays the selected waste transfer name/number, the tank } \\
\text { and which connecting areas, tanks and pits are involved. The operator can go to the next } \\
\text { level of detail by clicking on the item of interest and the appropriate screen is displayed. }\end{array}$ \\
\hline 127 & WTA_AN_2 & $\begin{array}{l}\text { Tank 241-AN-102 WTA Screen displays the selected waste transfer name/number, the tank } \\
\text { and which connecting areas, tanks and pits are involved. The operator can go to the next } \\
\text { level of detail by clicking on the item of interest and the appropriate screen is displayed. }\end{array}$ \\
\hline 128 & WTA_AN_3 & $\begin{array}{l}\text { Tank 241-AN-103 WTA Screen displays the selected waste transfer name/number, the tank } \\
\text { and which connecting areas, tanks and pits are involved. The operator can go to the next } \\
\text { level of detail by clicking on the item of interest and the appropriate screen is displayed. }\end{array}$ \\
\hline
\end{tabular}




\begin{tabular}{|c|c|c|}
\hline No. & $\begin{array}{c}\text { Screen } \\
\text { Filename }\end{array}$ & HMI Screen Description \\
\hline 129 & WTA_AN_4 & $\begin{array}{l}\text { Tank 241-AN-104 WTA Screen displays the selected waste transfer name/number, the tank } \\
\text { and which connecting areas, tanks and pits are involved. The operator can go to the next } \\
\text { level of detail by clicking on the item of interest and the appropriate screen is displayed. }\end{array}$ \\
\hline 130 & WTA_AN_5 & $\begin{array}{l}\text { Tank 241-AN-105 WTA Screen displays the selected waste transfer name/number, the tank } \\
\text { and which connecting areas, tanks and pits are involved. The operator can go to the next } \\
\text { level of detail by clicking on the item of interest and the appropriate screen is displayed. }\end{array}$ \\
\hline 131 & WTA_AN_6 & $\begin{array}{l}\text { Tank 241-AN-106 Tank WTA Screen displays the selected waste transfer name/number, } \\
\text { the tank and which connecting areas, tanks and pits are involved. The operator can go to the } \\
\text { next level of detail by clicking on the item of interest and the appropriate screen is displayed. }\end{array}$ \\
\hline 132 & WTA_AN_7 & $\begin{array}{l}\text { Tank 241-AN-107 WTA Screen displays the selected waste transfer name/number, the tank } \\
\text { and which connecting areas, tanks and pits are involved. The operator can go to the next } \\
\text { level of detail by clicking on the item of interest and the appropriate screen is displayed. }\end{array}$ \\
\hline \multirow[t]{2}{*}{133} & WTA_AP & $\begin{array}{l}\text { 241-AP Tank Farm WTA Screen displays the selected waste transfer name/number and } \\
\text { indicates which connecting areas, lines, leak detectors, tanks and pits are involved. The } \\
\text { operator can go to the next level of detail by clicking on the item of interest and the } \\
\text { appropriate screen is displayed. }\end{array}$ \\
\hline & WTA-APVP & $\begin{array}{l}\text { Valve Pit 241-APVP WTA screen displays the selected waste transfer name/number, a } \\
\text { detailed valve pit graphic and which connecting areas, tanks and pits are involved. The } \\
\text { operator can go to the next level of detail by clicking on the item of interest and the } \\
\text { appropriate screen is displayed. }\end{array}$ \\
\hline \multirow[t]{2}{*}{134} & WTA_AP_A & $\begin{array}{l}\text { Valve Pit 241-AP-A Screen displays the selected waste transfer name/number, a detailed } \\
\text { valve pit graphic and which connecting areas, tanks and pits are involved. The operator can } \\
\text { go to the next level of detail by clicking on the item of interest and the appropriate screen is } \\
\text { displayed. }\end{array}$ \\
\hline & WTA_APFP & $\begin{array}{l}\text { 241-AP Flush Pit WTA Screen displays the selected waste transfer name/number, a } \\
\text { detailed flush pit graphic and which connecting areas, tanks and pits are involved. The } \\
\text { operator can go to the next level of detail by clicking on the item of interest and the } \\
\text { appropriate screen is displayed. }\end{array}$ \\
\hline 136 & WTA_AP_1 & $\begin{array}{l}\text { Tank 241-AP-101 WTA Screen displays the selected waste transfer name/number, the tank } \\
\text { and which connecting areas, tanks and pits are involved. The operator can go to the next } \\
\text { level of detail by clicking on the item of interest and the appropriate screen is displayed. }\end{array}$ \\
\hline 137 & WTA_AP_2 & $\begin{array}{l}\text { Tank 241-AP-102 WTA Screen displays the selected waste transfer name/number, the tank } \\
\text { and which connecting areas, tanks and pits are involved. The operator can go to the next } \\
\text { level of detail by clicking on the item of interest and the appropriate screen is displayed. }\end{array}$ \\
\hline 138 & WTA_AP_3 & $\begin{array}{l}\text { Tank 241-AP-103 WTA Screen displays the selected waste transfer name/number, the tank } \\
\text { and which connecting areas, tanks and pits are involved. The operator can go to the next } \\
\text { level of detail by clicking on the item of interest and the appropriate screen is displayed. }\end{array}$ \\
\hline 139 & WTA_AP_4 & $\begin{array}{l}\text { Tank 241-AP-104 WTA Screen displays the selected waste transfer name/number, the tank } \\
\text { and which connecting areas, tanks and pits are involved. The operator can go to the next } \\
\text { level of detail by clicking on the item of interest and the appropriate screen is displayed. }\end{array}$ \\
\hline 140 & WTA_AP_5 & $\begin{array}{l}\text { Tank 241-AP-105 WTA Screen displays the selected waste transfer name/number, the tank } \\
\text { and which connecting areas, tanks and pits are involved. The operator can go to the next } \\
\text { level of detail by clicking on the item of interest and the appropriate screen is displayed. }\end{array}$ \\
\hline 141 & WTA_AP_6 & $\begin{array}{l}\text { Tank 241-AP-106 WTA Screen displays the selected waste transfer name/number, the tank } \\
\text { and which connecting areas, tanks and pits are involved. The operator can go to the next } \\
\text { level of detail by clicking on the item of interest and the appropriate screen is displayed. }\end{array}$ \\
\hline 142 & WTA_AP_7 & $\begin{array}{l}\text { Tank 241-AP-107 WTA Screen displays the selected waste transfer name/number, the tank } \\
\text { and which connecting areas, tanks and pits are involved. The operator can go to the next } \\
\text { level of detail by clicking on the item of interest and the appropriate screen is displayed. }\end{array}$ \\
\hline
\end{tabular}




\begin{tabular}{|c|c|c|}
\hline No. & $\begin{array}{c}\text { Screen } \\
\text { Filename }\end{array}$ & HMI Screen Description \\
\hline 143 & WTA_AP_8 & $\begin{array}{l}\text { Tank 241-AP-108 WTA Screen displays the selected waste transfer name/number, the tank } \\
\text { and which connecting areas, tanks and pits are involved. The operator can go to the next } \\
\text { level of detail by clicking on the item of interest and the appropriate screen is displayed. }\end{array}$ \\
\hline 145 & WTA_AW & $\begin{array}{l}\text { 241-AW Tank Farm WTA Screen displays the selected waste transfer name/number and } \\
\text { indicates which connecting areas, tanks, lines, leak detectors and pits are involved. The } \\
\text { operator can go to the next level of detail by clicking on the item of interest and the } \\
\text { appropriate screen is displayed. }\end{array}$ \\
\hline & WTA AWFP & $\begin{array}{l}\text { 241-AW Flush Pit WTA Screen displays the selected waste transfer name/number, the } \\
\text { flush pit and which connection areas, tanks and pits are involved. Screen also shows an } \\
\text { Encasement Valve Position key and the Valve Position Key. The operator can go to the next } \\
\text { level of detail by clicking on the item of interest and the appropriate screen is displayed. }\end{array}$ \\
\hline 146 & WTA_AW_A & $\begin{array}{l}\text { Valve Pit 241-AW-A WTA Screen displays the selected waste transfer name/number, a } \\
\text { detailed valve pit graphic and which connecting areas, tanks and pits are involved. The } \\
\text { operator can go to the next level of detail by clicking on the item of interest and the } \\
\text { appropriate screen is displayed. }\end{array}$ \\
\hline 147 & WTA_AW_B & $\begin{array}{l}\text { Valve Pit 241-AW-B WTA Screen displays the selected waste transfer name/number, a } \\
\text { detailed valve pit graphic and which connecting areas, tanks and pits are involved. The } \\
\text { operator can go to the next level of detail by clicking on the item of interest and the } \\
\text { appropriate screen is displayed. }\end{array}$ \\
\hline 148 & WTA_AW_1 & $\begin{array}{l}\text { Tank 241-AW-101 WTA Screen displays the selected waste transfer name/number, the } \\
\text { tank and which connecting areas, tanks and pits are involved. The operator can go to the } \\
\text { next level of detail by clicking on the item of interest and the appropriate screen is displayed. }\end{array}$ \\
\hline 149 & WTA_AW_2 & $\begin{array}{l}\text { Tank 241-AW-102 WTA Screen displays the selected waste transfer name/number, the } \\
\text { tank and which connecting areas, tanks and pits are involved. The operator can go to the } \\
\text { next level of detail by clicking on the item of interest and the appropriate screen is displayed. }\end{array}$ \\
\hline 150 & WTA_AW_3 & $\begin{array}{l}\text { Tank 241-AW-103 WTA Screen displays the selected waste transfer name/number, the } \\
\text { tank and which connecting areas, tanks and pits are involved. The operator can go to the } \\
\text { next level of detail by clicking on the item of interest and the appropriate screen is displayed. }\end{array}$ \\
\hline 151 & WTA_AW 4 & $\begin{array}{l}\text { Tank 241-AW-104 WTA Screen displays the selected waste transfer name/number, the } \\
\text { tank and which connecting areas, tanks and pits are involved. The operator can go to the } \\
\text { next level of detail by clicking on the item of interest and the appropriate screen is displayed. }\end{array}$ \\
\hline 152 & WTA_AW_5 & $\begin{array}{l}\text { Tank 241-AW-105 WTA Screen displays the selected waste transfer name/number, the } \\
\text { tank and which connecting areas, tanks and pits are involved. The operator can go to the } \\
\text { next level of detail by clicking on the item of interest and the appropriate screen is displayed. }\end{array}$ \\
\hline 153 & WTA_AW_6 & $\begin{array}{l}\text { Tank 241-AW-106 WTA Screen displays the selected waste transfer name/number, the } \\
\text { tank and which connecting areas, tanks and pits are involved. The operator can go to the } \\
\text { next level of detail by clicking on the item of interest and the appropriate screen is displayed. }\end{array}$ \\
\hline 160 & WTA_AY & $\begin{array}{l}\text { 241-AY Tank Farm WTA Screen displays the selected waste transfer name/number and } \\
\text { indicates which connecting areas, tanks and pits are involved. The operator can go to the } \\
\text { next level of detail by clicking on the item of interest and the appropriate screen is displayed. }\end{array}$ \\
\hline 161 & WTA_AY_1 & $\begin{array}{l}\text { Tank 241-AY-101 WTA Screen displays the selected waste transfer name/number, the tank } \\
\text { and which connecting areas, tanks and pits are involved. The operator can go to the next } \\
\text { level of detail by clicking on the item of interest and the appropriate screen is displayed. }\end{array}$ \\
\hline 162 & WTA_AY_2 & $\begin{array}{l}\text { Tank 241-AY-102 WTA Screen displays the selected waste transfer name/number, the tank } \\
\text { and which connecting areas, tanks and pits are involved. The operator can go to the next } \\
\text { level of detail by clicking on the item of interest and the appropriate screen is displayed. }\end{array}$ \\
\hline 166 & WTA_AZ & $\begin{array}{l}\text { 241-AZ Tank Farm WTA Screen displays the selected waste transfer name/number and } \\
\text { indicates which connecting areas, tanks and pits are involved. The operator can go to the } \\
\text { next level of detail by clicking on the item of interest and the appropriate screen is displayed. }\end{array}$ \\
\hline
\end{tabular}




\begin{tabular}{|c|c|c|}
\hline No. & $\begin{array}{c}\text { Screen } \\
\text { Filename } \\
\end{array}$ & HMI Screen Description \\
\hline & WTA_AZ_A & $\begin{array}{l}\text { Valve Pit 241-AZ WTA Screen displays the selected waste transfer name/number, the } \\
\text { valve pit and which connection areas, tanks and pits are involved. Screen also shows an } \\
\text { Encasement Valve Position key and the Valve Position Key. The operator can go to the next } \\
\text { level of detail by clicking on the item of interest and the appropriate screen is displayed }\end{array}$ \\
\hline 168 & WTA_AZ_1 & $\begin{array}{l}\text { Tank 241-AZ-101 WTA Screen displays the selected waste transfer name/number, the tank } \\
\text { and which connecting areas, tanks and pits are involved. The operator can go to the next } \\
\text { level of detail by clicking on the item of interest and the appropriate screen is displayed. }\end{array}$ \\
\hline 169 & WTA_AZ_2 & $\begin{array}{l}\text { Tank 241-AZ-102 WTA Screen displays the selected waste transfer name/number, the tank } \\
\text { and which connecting areas, tanks and pits are involved. The operator can go to the next } \\
\text { level of detail by clicking on the item of interest and the appropriate screen is displayed. }\end{array}$ \\
\hline \multirow[t]{5}{*}{170} & WTA_SY & $\begin{array}{l}\text { 241-SY Tank Farm WTA Screen displays the selected waste transfer name/number and } \\
\text { indicates which connecting areas, tanks and pits are involved. The operator can go to the } \\
\text { next level of detail by clicking on the item of interest and the appropriate screen is displayed. }\end{array}$ \\
\hline & WTA_SY_A & $\begin{array}{l}\text { Valve Pit 241-SY-A WTA Screen displays the selected waste transfer name/number, the } \\
\text { valve pit and which connection areas, tanks and pits are involved. Screen also shows an } \\
\text { Encasement Valve Position key and the Valve Position Key. The operator can go to the next } \\
\text { level of detail by clicking on the item of interest and the appropriate screen is displayed. }\end{array}$ \\
\hline & WTA_SY_B & $\begin{array}{l}\text { Valve Pit 241-SY-B WTA Screen displays the selected waste transfer name/number, the } \\
\text { valve pit and which connection areas, tanks and pits are involved. Screen also shows an } \\
\text { Encasement Valve Position key and the Valve Position Key. The operator can go to the next } \\
\text { level of detail by clicking on the item of interest and the appropriate screen is displayed. }\end{array}$ \\
\hline & WTA_SYFA & $\begin{array}{l}\text { Flush Pit 241-SY-A WTA Screen displays the selected waste transfer name/number, the } \\
\text { flush pit and which connection areas, tanks and pits are involved. Screen also shows an } \\
\text { Encasement Valve Position key and the Valve Position Key. The operator can go to the next } \\
\text { level of detail by clicking on the item of interest and the appropriate screen is displayed. }\end{array}$ \\
\hline & WTA_SYFB & $\begin{array}{l}\text { Flush Pit 241-SY-B WTA Screen displays the selected waste transfer name/number, the } \\
\text { valve pit and which connection areas, tanks and pits are involved. Screen also shows an } \\
\text { Encasement Valve Position key and the Valve Position Key. The operator can go to the next } \\
\text { level of detail by clicking on the item of interest and the appropriate screen is displayed. }\end{array}$ \\
\hline 171 & WTA_SY_1 & $\begin{array}{l}\text { Tank 241-SY-101 WTA Screen displays the selected waste transfer name/number, the tank } \\
\text { and which connecting areas, tanks and pits are involved. The operator can go to the next } \\
\text { level of detail by clicking on the item of interest and the appropriate screen is displayed. }\end{array}$ \\
\hline 172 & WTA_SY_2 & $\begin{array}{l}\text { Tank 241-SY-102 WTA Screen displays the selected waste transfer name/number, the tank } \\
\text { and which connecting areas, tanks and pits are involved. The operator can go to the next } \\
\text { level of detail by clicking on the item of interest and the appropriate screen is displayed. }\end{array}$ \\
\hline 173 & WTA_SY_3 & $\begin{array}{l}\text { Tank 241-SY-103 WTA Screen displays the selected waste transfer name/number, the tank } \\
\text { and which connecting areas, tanks and pits are involved. The operator can go to the next } \\
\text { level of detail by clicking on the item of interest and the appropriate screen is displayed. }\end{array}$ \\
\hline
\end{tabular}

